PNL-6099

UC-810

\title{
Preliminary Characterization of Risks in the Nuclear Waste Management System Based on Information in the Literature
}
P. M. Daling
D. H. Hill
R. E. Rhoads
S. A. Nilson
A. E. Van Luick
M. Rowe
G. R. Armstrong
N. L. Sevigny
B. A. Fecht
E. Stern

January 1992

Prepared for

the Office of Civilian Radioactive Waste Management under a Related Services Agreement with the U.S. Department of Energy

Contract DE-AC06-76RLO 1830

Pacific Northwest Laboratory

Operated for the U.S. Department of Energy

by Battelle Memorial Institute 


\title{
DISCLAIMER
}

This report was prepared as an account of work sponsored by an agency of the United States Government. Neither the United States Government nor any agency thereof, nor Battelle Memorial Institute, nor any of their employees, makes any warranty, expressed or implied, or assumes any legal liability or responsibility for the accuracy, completeness, or usefulness of any information, apparatus, product, or process disclosed, or represents that its use would not infringe privately owned rights. Reference herein to any specific commercial product, process, or service by trade name, trademark, manufacturer, or otherwise does not necessarily constitute or imply its endorsement, recommendation, or favoring by the United States Government or any agency thereof, or Battelle Memorial Institute. The views and opinions of authors expressed herein do not necessarily state or reflect those of the United States Government or any agency thereof.

\author{
PACIFIC NORTHWEST LABORATORY \\ operated by \\ BATTELLE MEMORIAL INSTITUTE \\ for the \\ UNITED STATES DEPARTMENT OF ENERGY \\ linder Contract DE-ACO6-76RLO 1830
}

Printed in the United States of America

Available to DOE and DOE contractors from the

Office of Scientific and Technical Information, P.O. Box 62, Oak Ridge, IN 37831; prices available from (615) 576-8401. FTS 626-8401.

Available in the public from the National Technical Information Service, U.S. Department of Commerce, 5285 Port Royal Rd., Springfield, VA 22161. 

P. M. Daling
D. H. $\mathrm{Hill}$ (b)
R. E. Rhoads
A. E. Van Luick
S. A. Nilson
G. R. Armstrong (a)
M. Rowe (b)
B. A. Fecht
N. L. Seyigny
E. Stern (b)

January 1992

Prepared for

the Office of Civilian Radioactive

Waste Management

U.S. Department of Energy

under Contract DE-AC06-76RLO 1830

Pacific Northwest Laboratory

Operated for the U.S. Department of Energy

by Battelle Memorial Institute

\footnotetext{
(a) Westinghouse Hanford $\mathrm{CO}$., Richland, Washington.

(b) Brookhaven National Laboratory Upton, New York.
} 


\section{PREFACE}

This report presents the results of a study to 1) review the technical literature containing information on the risks in the civilian high-level nuclear waste management system and 2) use this information to develop pre1 iminary estimates of a potential magnitude of these risks. The scope of the study includes a potential integral Monitored Retrievable Storage (MRS) facility, the potential repository, and the transportation system that supports the repository and MRS facilities. The waste management system used as the basis for this study is that described in the Mission Plan for the Civilian Radioactive Waste Management Program (DOE 1985) and does not reflect the current configuration of the system. This document is being issued in order to disseminate summary safety-related information from a broad variety of past studies and to aid in future planning efforts. 


\section{ABSTRACT}

This document presents preliminary information on the radiological and nonradiological risks in the nuclear waste management system. The objective of the study was to 1) review the literature containing information on risks in the nuclear waste management system and 2) use this information to develop preliminary estimates of the potential magnitude of these risks. Information was collected on a broad range of risk categories to assist the U.S. Department of Energy (DOE) in communicating information about the risks in the waste management system. The study examined all of the portions of the nuclear waste management system currently expected to be developed by the DOE. The scope of this document includes the potential repository, the integral MRS facility, and the transportation system that supports the potential repository and the MRS facility. Relevant 1 iterature was reviewed for several potential repository sites and geologic media. However, only the potential tuff repository site was considered when developing estimates of the annual and total life-cycle risks in the waste management system.

A wide range of "risk categories" are addressed in this report: 1) public and occupational risks from accidents that could release radiological materials, 2) public and occupational radiation exposure resulting from routine operations, 3) public and occupational risks from accidents involving hazards other than radioactive materials, and 4) public and occupational .risks from exposure to nonradioactive hazardous materials during routine operations. Although "risk" is traditionally defined as the product of the probability of an event (usually an accident) and its consequences, it is al so used in this report to describe "consequences" of normal or routine operations, such as occupational and public radiation doses from routine effluents. The phases of the facility life cycles addressed in the study include construction, operations, decommissioning, repository retrieval, and repositor' postclosure performance. The report is intended to provide a broad spectrum of risk-related information about the waste management system. This information is intended to be helpful for planning future studies.

The risk estimates in this report were derived from the available 1iterature. Because the waste management system is in it.s developmental phase, 
comprehensive studies of the risks in the system have not yet been performed. Relevant information was found in the literature that can provide insights into the risks in the system. This report collects the information in a convenient form and derives order-of-magnitude estimates of annual and total system life-cycle risks. The uncertainties in the derived risk estimates are relatively large because of variations in the bases, assumptions, and intended uses of the past studies that were used to derive the risk estimates. In some cases, the results from one study were not comparable with results from another study. It was necessary to use some results in spite of this comparability problem. Adjustments were made, where possible, to normalize the results from different studies to common bases. The technical bases for the risk values contained in this report are appropriate for developing insights and indicating general trends about the risks in the waste management system but lack the accuracy necessary for evaluation of the incremental risks associated with alternative facility sites and design concepts.

Recognizing the above uncertainties, some preliminary conclusions from the study include:

- Risks in the waste management system are sma11. Radiological risks are much less than the risks from natural background radiation.

- Radiological risks in the waste management system are much less than nonradiological risks.

- Risks to the public are much less than risks to the workers in waste management facilities. 


\section{SUMMARY}

This report presents the results of a study to develop preliminary estimates of the risks in the nuclear waste management system using information available in the literature. Because the system is in its developmental stage, comprehensive studies of the risks in the system have not yet been performed. More detailed risk studies that will provide more accurate information are planned at later stages in the development of the system when site-specific data have been collected and more complete information is available on the system configuration and facility designs. Relevant information was found that can provide an overall perspective and insights into the risks from the waste management system. This report collects the available information in a convenient form and evaluates the applicability of this information for the system designs being planned by the DOE. It is intended that the information provided in this report will be used to communicate risk-related information about the waste system to interested groups outside the DOE and to guide the direction of future risk studies.

\section{SCOPE OF WORK}

Because the configuration of the waste management system has not yet been finalized, this study examined risks for two system configurations. The first system includes a geologic repository and the transportation operations necessary to move wastes to the repository. The second system incorporates an MRS facility as an integral part of the waste management system. This study was based on the waste management system described in DOE (1985) and as such it may contain statements that are not consistent with current DOE policy, particularly in regard to the MRS facility. Risk information was collected for potential repositories in three geologic media: tuff, salt, and basalt. However, annual total system life-cycle risk estimates were developed for systems with a potential repository in tuff. Brief descriptions of the potential repository, the MRS facility, and the waste transportation system are provided in Chapter 3.0 of this document. The study scope was 1 imited to the federally-owned portions of the waste management system. Waste handling and storage operations at reactors and other 
commercial sites were not included. All potentially significant risks in the federal waste management system were examined in this siudy. Risk categories examined included:

- risks to the public and workers

- risks from accidents and routine operations

- radiological and nonradiological risks

- health and economic risks.

A11 meaningful combinations of these risk categories were examined for each of the waste management system components. The phases of facility operation investigated included construction, operations, decommissioning, possible retrieval of waste from a repository, and repository postclosure performance. However, because potential repository retrieval operations are not well known at this time, no risk estimates are developed for this facility phase.

\section{LITERATURE REVIEW}

The preliminary estimates of risks in the waste management system presented in this report were based on a comprehensive review of the literature. Documents that contained potentially applicable information were reviewed in detail and the results summarized. The document reviews are presented in chapter 4.0. The available information was evaluated for its technical basis and applicability to this study. As a result of this screening, the best sources of risk information were selected for use in deriving preliminary estimates of the risks in the waste management system. Criteria used in this selection process included:

- technical accuracy and reproducibility of results

- degree of realism in the assumptions

- appropriateness of models used

- consistency of bases, assumptions, and system parameters with the office of Civilian Radioactive Waste Management (OCRWM) plans

- comprehensiveness of the analysis. 
The results of the literature reviow and evaluation are summarized in Table S.1. This table presents a qualitative evaluation of the information available to estimate risks in each of the risk categories included in this siudy. The literature review indicated that previous work focused on assessment of radiological risks primarily because these risks are important considerations in licensing activities and in environmental assessments. Risks to the public from routine emissions and accidental releases of radioactive materials have been addressed in a number of previous studies. Routine radiation doses to workers have also been studied extensively. Many other risk categories have been analyzed only superficially or not at all.

A number of conclusions were drawn from the literature review:

TABLE S.1. Qualitative Evaluation of Literature by Risk Category

\begin{tabular}{|c|c|c|c|c|c|c|c|c|c|}
\hline & \multicolumn{5}{|c|}{ Accidents } & \multicolumn{4}{|c|}{$\begin{array}{r}\text { Rout ine } \\
\end{array}$} \\
\hline & \multicolumn{2}{|c|}{ Radiological } & \multicolumn{2}{|c|}{ Nonradiological } & \multirow[b]{2}{*}{ Economic $^{(a)}$} & \multicolumn{2}{|c|}{ Radiological } & \multicolumn{2}{|c|}{ Nonradiologica } \\
\hline & Public & Worker & public & Worker & & Public & Worker & public & Worken \\
\hline \multicolumn{10}{|l|}{ Repository } \\
\hline Construction & - & $\cdot$ & S & $R$ & - & $R$ & $F$ & $\mathrm{~F}$ & N \\
\hline Operations & $F$ & $\mathrm{~F}$ & N & $\mathrm{F}$ & N & $R$ & $R$ & $\mathrm{~F}$ & N \\
\hline Decormissioning & $\mathrm{F}$ & $F$ & N & N & N & $F$ & $F$ & $F$ & N \\
\hline Retrieval & $\mathrm{N}$ & N & N & N & N & $\mathrm{N}$ & $F$ & N & N \\
\hline Postclosure & $\mathrm{F}$ & - & $\cdot$ & - & $N$ & $F$ & - & - & $\cdot$ \\
\hline \multicolumn{10}{|l|}{ MRS } \\
\hline Construction & - & $\cdot$ & N & N & - & - & - & $F$ & N \\
\hline Operations & R & $s$ & N & N & N & $\mathrm{R}$ & $\mathrm{R}$ & $F$ & N \\
\hline Decormissioning & N & N & N & N & N & $\mathrm{F}$ & $F$ & $\mathrm{~F}$ & N \\
\hline \multicolumn{10}{|l|}{ Iransportation } \\
\hline Operations & G & s & G & $\mathrm{R}$ & S & $G$ & G & $\mathrm{R}$ & $\mathrm{N}$ \\
\hline
\end{tabular}

(a) The economic risks considered in this study are those resulting from accidental release of radioactive material

$\underline{K E Y}$

- = No risks in this category.

$N=$ No information available.

$S=$ Some related information available, but risk category not directly addressed in the literature.

$F=$ Few references address this risk category. Major difference between study scope or bases and OCRWM needs.

$R=$ Reasonable information available. Several studies address this category.

$G=$ cood information available. This category addressed directly in literature using bases consistent with OCRWM needs. 
- Risk estimates developed in previous studies were based on a wide variety of methods, data, assumptions, and system designs. The available information can be used to develop crude and conservative estimates that can lend perspective to the consideration of waste management system risks. The available information is not adequate to develop a technically consistent risk estimate for most of the risk categories of interest in this study.

- The available literature provides a better documented technical basis for estimating transportation risks than for estimating the risks in other elements of the waste management system.

- Reasonable information is available on routine radiological risks to the public and facility workers. Estimates of these risks may need to be refined to reflect final system designs, but the currently available methods and data can provide credible estimates.

- Public and occupational risks associated with maintenance and repair activities at the repository and the MRS facility have not been addressed.

- Several risk categories have not been addressed in previous work. These include risks from repository retrieval, economic risks from accidents, and risks from potential repository and MRS facility decommissioning.

- Most available estimates of radiological risks to the public from accidents at the MRS facility and the repository and nonradiological risks to workers from repository accidents are not based on current facility designs.

- Substantial work has been done on repository postclosure risks. However, the extremely long time periods involved and the extremely complex problems of projecting risk parameters (e.g., population distributions, land uses, disruptive event probabiTities) and integrating risks over geologic time scales result in inherent uncertainties in tho available risk estimates.

\section{RISK ESTIMATES}

The most applicable information from the literature was used to develop preliminary estimates of the risks in the waste management system. Straightforward adjustments were made to the risk estimates obtained from the literature to make them as consistent as possible with the system configurations described in the OCRWM Mission PIan (DOE 1985) and in Waste Management Descriptions (DOE 1986a). These adjustments were typically limited to scaling-type normalizations to major system parameters such as throughput 
rates or inventories. It is emphasized that all of the risk estimates in this report are preliminary values with substantial uncertainty. They are based on published information from a variety of previous studies that were done for many purposes. Some were comprehensive and detailed while others represented preliminary approximations based on simple methods and limited data. In a study based solely on available information, it is necessary to utilize all applicable studies to develop as complete a picture as possible; however, great care and technical judgment must be exercised when using the information presented. Because of differences in scope, objectives, methods, and key assumptions among available studies, there are many cases in which estimates from one source are not directly comparable with results from another study. It was necessary to select some results and adjust them accordingly in spite of the inherent inconsistencies in details.

The preliminary annual and total life-cycle risk estimates developed in $"$ this study are summarized in Table S.2. Because of the uncertainty in the system configuration that will be implemented, the risk estimates reported are averaged over both configurations. The risks associated with fuel handling and storage operations at reactor sites are not included. Some risks due to increased spent fuel storage requirements at reactor sites may be avoided if the MRS facility becomes operational before the repository. The predicted health effects from natural background radiation in the population potentially affected by waste management system operations are also included in the table. These estimates can help to place the risks associated with the waste management system in perspective. Figure S.1 presents a pictorial summary of the public and occupational radiological and nonradiological risks for the life cycle of the waste management system from facility construction through decommissioning. In this rigure, the expected value for each majnr risk category has been represented by the volume of a cube.

The system life-cycle risk estimates were developed from estimates for the annual risks for each operating phase of each system component. Annual risks were integrated over the expected lifetime of each system component and phase as indicated in the OCRWM Mission Plan (DOE 1985) to develop the system life-cycle risk estimates. Radiological risks from accidents, radiological risks from routine operations, and nonradiological risks are each presented 
TABLE S.2. Summary of Annual and Total Life-Cycle Risk Estimates for the Waste Management System(a)

Risk Category

Public Risks

- Radiological Accidents(e)

- Radiological Routine(e)

- Nonradiviogical(f)

- Postclosure Radiological(g)

Occupational Risks

- Radiological Accidents(e)

- Radiological Routine(e)

- Nonradiological(f)

Risk Perspective

\begin{tabular}{c} 
Operating Phase(b,c) Total Life-(c,d) \\
Annual Risks \\
\hline
\end{tabular}

$0.001 \quad 0.04$

0.062

$0.4 \quad 10$

$0.001 \quad-$ Not calculated--

$0.0001 \quad 0.004$

$0.06 \quad 3$

$0.4 \quad 100$

60

2000

(a) Average for waste management system configurations with and without an MRS facility.

(b) Annual risks from facility operating phases only. Does not include construction, decommissioning, and potential repository retrieval risks.

(c) Based on $30 \%$ truck $/ 70 \%$ rail shipments from reactors, $100 \%$ rail from the MRS facility (where applicable), and 100\% rail shipments from high-level waste (HLW) generators.

(d) Risks associated with spent fuel storage at reactor and other commercial sites are not included on the total life-cycle risk estimates.

(e) Annual radiological risks are given in units of latent health effects per year (LHE/yr); total life-cycle risks are given in units of LHEs.

(f) Annual nonradiological risks are given in units of fatalities/yr; total life-cycle nonradiological risks are given in units of fatalities.

(g) Peak annual radiological health effects from routine releases and selected disruptive events.

(h) Based on the estimated latent health effects from the population dose from natural background radiation within $80 \mathrm{~km}$ of the potential repository and MRS sites and within $0.5 \mathrm{~km}$ of a highway or railroad.

in Figure S.1. Radiological risks are expressed as latent health effects. (Latent health effects are increased incidences of fatal cancers and genetic effects that current radiation health effects models predict will occur in the exposed populations.) Nonradiological risks are expressed in expected fatalities. 

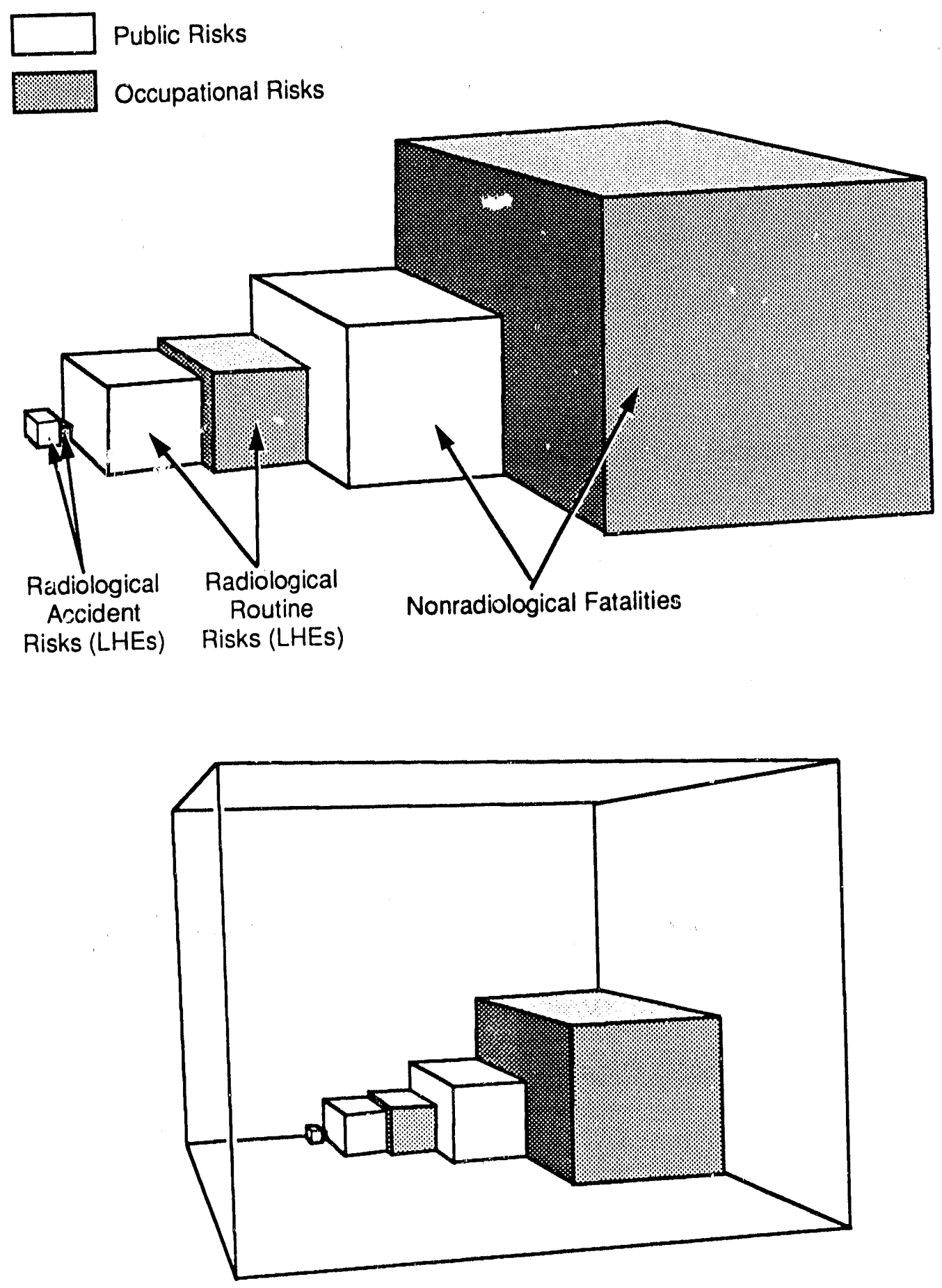

Comparison with Natural Background Radiation Doses

FIGURE S.1. Illustration of Total Life-Cycle Risks for the Waste Management System 
A11 risk estimates presented in the Table S.2 and Figure S.1 were developed by multiplying potential consequences by the frequency with which these consequences are estimated to occur in the waste management system. Transportation risk estimates were based on the assumption that $70 \%$ of the waste (on a MTU basis) will be shipped from the reactors by rail and $30 \%$ wi11 be shipped by truck. It was assumed that all shipments from the MRS facility and all HLW shipments will be $b_{s}^{\prime}$ rail. There was not sufficient information in the literature to estimate risks from retrieval activities at the repositories. These risks are not included in the results presented. These risks are dependent upon the reason(s) why retrieval is implemented (such as discovery of a new fault or unacceptable performance of an engineered barrier); the magnitude of the retrieval operati; that is deemed necessary; the degree of degradation of the waste forms and warte packages; and the retrieval schedule and timing. Postclosure risks are also not included in the system life-cycle risk estimates. There is not sufficient information available to estimate the postclosure risks for all of the postclosure period. Information is available to develop a preliminary estimate of the peak annual public risks during postclosure. This estimate is presented in Table S.2.

There were a number of risk categories for which no estimates were found in the literature. These categories are simply omitted from the summary results presented. Therefore, the risk estimates presented here represent only a partial evaluation of the total risk of the waste management system. The information can, however, be used to develop general insights about some of the significant risks in the waste management system. These estimates are not int.ended to accurately reflect differences among system components, facilit designs, or system configurations.

Sound technical judgment and consistency needs to be exercised in developing conclusions based on the preliminary waste system risk estimates presented here because uncertainties can, in many cases, make comparisons inconclusive. Conclusions that the authors of this report have nade include:

- The radiological risks in the waste management system are small. Radiological risks are much less than the predicted radiological consequences of natural background radiation. 
- Nonradiological risks to the public over the life cycle of the waste management system are smaller than nonradiological risks to workers. The risks to workers result primariiy from nonradiological industrial-type accidents during construction, operations, and decommissioning of the waste management facilities.

- Risks resulting from the radiological hazards in the waste management system are estimated to be about one-tenth as large as risks resulting from the nonradiological hazards in the system.

- Occupational and public radiological risks from accidents are about one-hundredth as large as the risks from hazards resulting from routine operations, based on the available information.

- Risks to the public during the postclosure phase of the repository have not yet been definitively analyzed. Results of preliminary, highly-conservative calculations indicate that these risks are small.

Radiological risks are clearly small, as evidenced by the comparisoris with natural background radiation. Nonradiological risks are typical of similar activities encountered by individuals in everyday 1/fe (e.g., highway and rail transport, mining, operating heavy machinery, etc.). There is no reason to believe that the nonradiological risks created by the waste management system would be any different than the nonra:iological risks created by construction of any underground facility.

\section{RECOMMENDATIONS}

Based on the work in this study, the authors made several recommendations for future risk assessment work. These recommendations are intended to provide input to the risk assessment planning process within OCRWM. They are focused on work that should be started soon to provide useful information until more detailed studies are completed or to provide methods and data that will support other planned future work. Major recommendations include the following:

- A study should be initiated to davelop technically consistent estimates for all of the risk cat?gories in the waste management system. This study should use the hest available methods and data to develop these estimates. 
- A study should be initiated to collect the data needed to develop more realistic and technically defensible estimates of the amount and the physical and chemical characteristics of radioactive material released from spent nuclear fuel in accident conditions. 


\section{ACKNOWLEDGMENTS}

The authors would like to express their appreciation to the following individuals for their assistance and guidance during the preparation of this document; Dr. Norman Eisenberg, formerly of the Department of Energy, for guidance and encouragement; Mr. P. J. Pelto for numerous reviews of prepublication drafts of this report; Mr. C. A. Counts for his patience and skill during a difficult technical editing assignment; and Rose Moreno, Margot White, and the Sigma IV Text Processing group for their support in preparing this manuscript. 


\section{CONTENTS}

PREFACE ........................... . . $i i_{i}$ ABSTRACT . . . . . . . . . . . . . . . . . . v v SUMMARY ........................... vii

ACKNOWLEDGMENTS . . . . . . . . . . . . . . . . . . xVii

1.0 INTRODUCTION . . . . . . . . . . . . . . . . . . 1.1

2.0 ELEMENTS OF RISK ANALYSIS . . . . . . . . . . . . . . . . 2.1

2.1 RISK CONCEPTS AND TERMINOLOGY . . . . . . . . . . . . 2.1

2.1.1 Types of Risks . . . . . . . . . . . . . 2.2

2.1.2 Uses of Risk Information . . . . . . . . . . 2.2

2.1.3 Presentation of Results . . . . . . . . . 2.4

2.2 RISK METHODS . . . . . . . . . . . . . . . . 2.7

2.3 LIMITATIONS AND UNCERTAINTIES IN RISK ANALYSIS . . . . . . . 2.11

2.4 OVERVIEW OF RISKS IN THE WASTE MANAGEMENT SYSTEM . . . . . . 2.14

2.4.1 Repository ................. 2. 2.15

2.4.2 MRS Facility . . . . . . . . . . . . . . 2.19

2.4.3 Transportation ............... 2. . . . . . .

2.5 SPECIAL FEATURES AND GENERIC DIFFICULTIES IN ASSESSING

2.5.1 Repository Preclosure . . . . . . . . . . . 2.21

2.5.2 Repository Postclosure . . . . . . . . . . 2.22

2.5.3 Monitored Retrievable Storage . . . . . . . . 2.27

2.5.4 Transportation ............... . 2.27

3.0 WASTE MANAGEMENT SYSTEM DESCRIPTION . . . . . . . . . . . . . . 3.1

3.1 GENERAL DESCRIPTION OF A REPOSITORY . . . . . . . . . . . 3.5

3.2 DESCRIPTION OF THE INTEGRAL MRS FACILITY . . . . . . . . 3.16 
3.3 DESCRIPTION OF THE TRANSPORTATION SYSTEM . . . . . . . . 3.22

4.0 LITERATURE REVIEW . . . . . . . . . . . . . . . . . . . . . . 4.1

4.1 REPOSITORY PRECLOSURE . . . . . . . . . . . . . . . . . 4.4

4.1.1 Review of the Repository Preclosure Risk

Literature................ . 4.4

4.1.1.1 Generic Environmental Impact Statement . . 4.4

4.1.1.2 Spent Fuel Disposal Options Study . . . . 4.9

4.1.1.3 Risk Analysis Methodology for a Spent

Fuel Repository in Bedded Salt... . . 4.13

4.1.1.4 Occupational Exposures at a Spent Fue1

Repository............. 4.15

4.1.1.5 EPRI Fuel Cycle Accident Risk Assessment . . 4.17

4.1.1.6 HLW Preclosure Systems Safety Analysis . . 4.20

4.1.1.7 Deaf Smith Environmental Assessment . . . 4.21

4.1.1.8 Hanford Environmental Assessment . . . . . 4.24

4.1.1.9 Yucca Mountain Environmental Assessment . . 4.26

4.1.1.10 Occupational Exposures for a Potential
Repository in Tuff. . . . . . . . . 4.29

4.1.1.11 Safety Assessment for a Potential

Repository in Tuff......... . 4.31

4.1.1.12 First Repository Site-Selection

Methodology Document. . . . . . . . 4.35

4.1.1.13 Section 175 Report........... . 4.38

4.1.1.14 Site Characterization P1an - Conceptual

Design Report ........... 4.40

4.1.1.15 Preliminary Analysis of Routine Doses at

Yucca Mountain.......... . 4.43

4.1.2 Reports Selected for Use in This Study . . . . . . . 4.44

4.2 REPOSITORY POSTCLOSURE . . . . . . . . . . . . . . . . . . 4.51 
4.2.1 Review of Repository Postclosure Risk Literature . . 4.52

4.2.1.1 The Postclosure Risk Assessment Supporting the DOE's Final Environmental Impact

Statement ............ 4.53

4.2.1.2 Risk Assessments Supporting the EPA

Standard ............. 4.56

4.2.1.3 Risk Assessment Supporting the Selection of

the Reference Defense Waste Form . . . . 4.60

4.2.1.4 Waste Isolation Systems Panel Assessments

of Hypothetical Repository Risks at OGR

Candidate Repository Locations . . . . 4.61

4.2.1.5 Repository Environmental Assessments . . . 4.70

4.2.1.6 A Bounding Analysis for the Yucca Mountain

Hypothetical Repository....... 4.73

4.2.1.7 Studies Supporting NRC Activities . . . . 4.77

4.2.1.8 International Repository Performance/Risk
Assessments................... 4.83

4.2.2 Reports Selected for Use in This Study . . . . . . 4.96

4.2.2.1 Basalt . . . . . . . . . . . 4.98

4.2.2.2 Salt ................ 4.99

4.2.2.3 Tuff ................. 4.100

4.3 MONITORED RETRIEVABLE STORAGE . . . . . . . . . . . . 4.100

4.3.1 Review of MRS Risk Literature. . . . . . . . . . 4.101

4.3.1.1 MRS Facility Environmental Assessment . . 4.101

4.3.1.2 Safety Evaluation of MRS Storage Concepts . 4.106

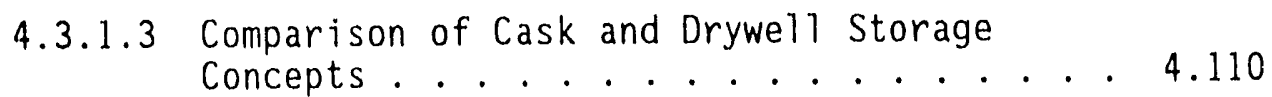

4.3.1.4 Review of Dry Storage Concepts . . . . . . 4.110

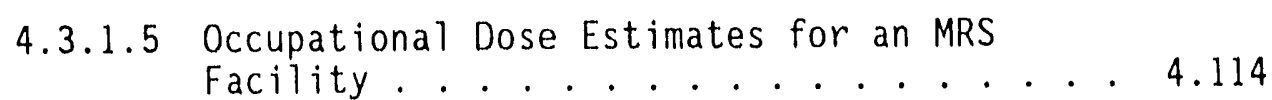


4.3.1.6 Radiological Doses in Alternative Waste

Management Systems ........ 4.116

4.3.1.7 Generic Environmental Impact Statement . . 4.117

4.3.1.8 Decommissioning Spent Fuel Storage Installations .......... 4.119

4.3.2 Reports Selected for Use in This Study . . . . . . 4.120

4.4 TRANSPORTATION . . . . . . . . . . . . . . . . 4.125

4.4.1 Review of Transportation Risk Literature . . . . 4 4.126

4.4.1.1 Final Environmental Statement on the

Transportation of Radioactive Material by

Air and Other Modes ......... 4.126

4.4.1.2 Transportation of Radionuclides in Urban

Environs: Draft Environmental Assessment . . 4.128

4.4.1.3 An Analysis of the Risk of Transporting

Spent Nuclear Fuel by Train ...... 4.133

4.4.1.4 An Assessment of the Safety of Spent Fuel Transportation in Urban Environs . .. . . 4.137

4.4.1.5 Transportation Impacts of the Commercial Radioactive Waste Management Program . . . 4.139

4.4.1.6 Exposures and Health Effects from Spent Fuel Transportation .......... 4.141

4.4.1.7 Nonradiological Impacts of Transporting Radioactive Material . . . . . . 4 4.150

4.4.1.8 OCRWM Transportation ALARA Study . . . . 4.152

4.4.2 Reports Selected for Use in This Study . . . . . . . 4.154

5.0 ASSESSMENT OF WASTE MANAGEMENT SYSTEM RISKS . . . . . . . . . . . 5.1

5.1 REPOSITORY PRECLOSURE RISKS . . . . . . . . . . . . . 5.1

5.1.1 Repository Preclosure Risk Values . . . . . . . . . 5.2

5.1.1.1 Radiological Health Risks . . . . . 5.2

5.1.1.2 Nonradiological Health Risks... . . . 5.7

5.1.2 Discussion of Uncertainties in the Risk Estimates . . 5.10 
5.2 REPOSITORY POSTCLOSURE RISKS . . . . . . . . 5.15

5.2 .1 Postclosure Risk Values . . . . . . . . 5.15

5.2.1.1 Risks for a Hypothetical Repository
in Tuff . . . . . . . . . 5.16

5.2.2 Discussion of Uncertainties in the Risk Estimates . 5.18

5.3 MRS FACILITY RISKS . . . . . . . . . . . . . 5.21

5.3 .1 MRS Facility Risk Values . . . . . . . . 5.21

5.3.1.1 Radiological Health Risks ...... 5. 5.21

5.3.1.2 Nonradiological Health Risks . . . . . 5.28

5.3.2 Discussion of Uncertainties in the Risk Estimates . 5.30

5.4 TRANSPORTATION SYSTEM RISKS ............. 5.32

5.4 .1 Transportation Risk Values ........ 5.33

5.4.1.1 Radiological Health Risks ....... 5. 53

5.4.1.2 Nonradiological Health Risks ...... 5. 5.33

5.4 .2 Discussion of Uncertainties . . . . . . . 5.35

5.5 ECONOMIC RISKS . . . . . . . . . . . . . 5.38

5.6 AgGREGATED RISKS OF THE WASTE MANAGEMENT SYSTEM ..... 5.40

5.6.1 Aggregated Annual Risks for the System Without
an MRS Facility. . . . . . . . . . . 5.41

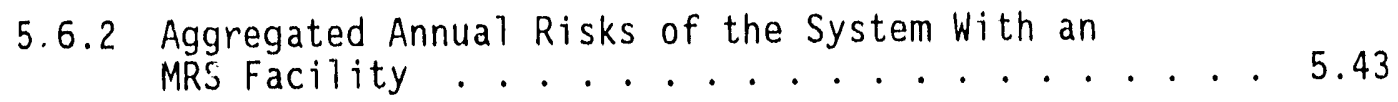

5.6.3 Total System Life-Cycle Risks . . . . . . . 5.46

6.0 CONCLUSIONS AND RECOMMENDATIONS ................... 6.1

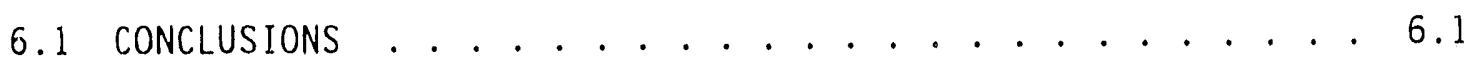

6.1 .1 Risk Literature . . . . . . . . . . . 6.2

6.1 .2 Risk Estimates ........... . . . 6.8

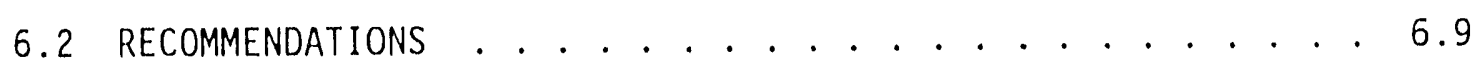


6.2.1 Waste Management Risk Study . . . . . . . . 6.10

6.2.2 Spent Fuel Source Terms ............. . 6.11

6.2.3 Postclosure Risk Assessment . . . . . . . . . 6.11

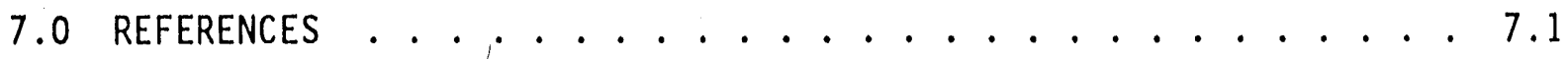




\section{FIGURES}

S.1 Illustration of Total Life-Cycle Risks for the Waste

Management System................... xiti

2.1 Sample Risk Curves . . . . . . . . . . . . . . 2.5

2.2 Major Steps in an Accident Risk Analysis . . . . . . . . 2.9

2.3 Components of a Strategy for Assessing the Postclosure
Performance of the Mined Geologic Repository System . . . . . . 2.23

3.1 General Configuration of the System Without an MRS Facility . . 3.2

3.2 General Configuration of the system With an MRS Facility . . . 3.3

3.3 Block Diagram for Repositories in the System Without an MRS

Facility..................... 3.6

3.4 Simplified Block Diagram for Repositories in the System

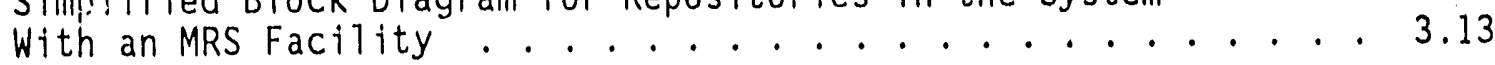

3.5 Artist's Rendition of the Potential Tuff Repository . . . . . . 3.15

3.6 Simplified Block Diagram for an Integral MRS Facility . . . . . 3.17

3.7 Monitored Retrievable Storage Facility R\&H Building . . . . . 3.18

3.8 Concrete Storage Cask. . . . . . . . . . . . . . 3.20

3.9 Field Drywell . . . . . . . . . . . . . . . 3.21

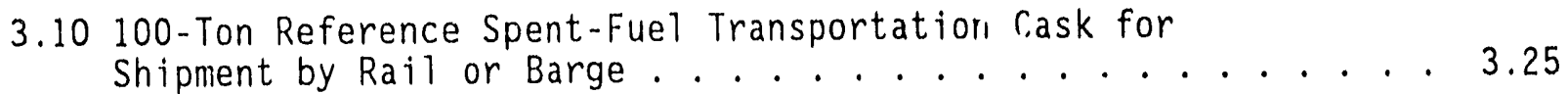

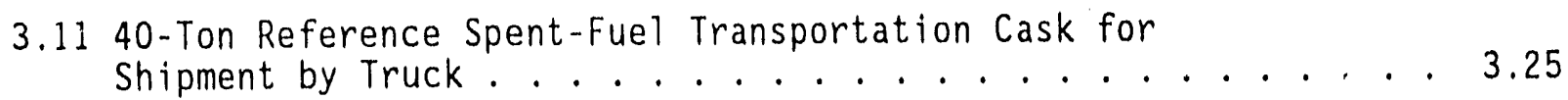

4.1 MRS Dry Well Risk Curve................ . . . 4.110

4.2 Risk Spectra for Spent Fuel Shipments by Train for $100 \mathrm{GW}$
Nuclear Capacities and for Other Events in the United States . . 4.136

5.1 Overview of Sources of Uncertainty . . . . . . . . . . . 5.13

5.2 Comparison of Spent-Fuel Transportation Risk Estimates . . . . 5.36

5.3 Illustration of the Total Life-Cycle Risks for Construction,
Operation, and Decommissioning of the Waste Management System . 5.48 


\section{TABLES}

S.1 Qualitative Evaluation of Literature by Risk Category . . . . . ix

S.2 Summary of Annual and Total Life-Cycle Risk Estimates for the Waste Management System ............... xit

2.1 Risk Categories Considered in This Study . . . . . . . . 2.15

2.? Waste Management Risk Matrix . . . . . . . . . . . . 2.16

3.1 Potential Repository Waste Package Characteristics for Intact Spent Fuel Assemblies . . . . . . . . . . . 3.7

3.2 Potcntial Repository Waste Package Characteristics for Consolidated Spent Fllel Assemblies . . . . . . . . . 3.8

3.3 Repository Radiation Inventories for 10-Year-01a Spent Pressurized Water Reactor Fuel (Ci) System Without an MRS Facility . . . . . . . . . . . . . . . 3.10

3.4 Airborne Emissions During Construction and Operation of a Potential Repository ................ 3.11

3.5 Repository Radiation Inventories for 10-year 01d Spent PWR Fuel - System With an MRS Facility . . . . . . . . . . 3.14

3.6 Concrete Cask Contents . . . . . . . . . . . . . . 3.20

3.7 Drywe11 Dimensions and Contents............ 3.22

3.8 MRS Facility Radiation Inventories for 10-Year-01d Spent PWR Fuel $(\mathrm{C} i) . . . . . . . . . . .3 .23$

3.9 Routine Radiological and Nonradiological Emissions from the MRS Facility................. 3.24

3.10 Nominal Shipping Cask Characteristics . . . . . . . . . 3.26

3.11 Radionuclide Inventories in Truck and Rail Shipping Casks . . . . 3.27

3.12 Transportation Cask Capacities in the System With an MRS Facility................. 3.28

4.1 Criteria Used to Select References Used to Develop Risk Estimates.................. 4.3

4.2 Estimated 70-Year Population and Worker Exposures for Potential Repository Construction 
4.3 Estimated Routine Doses to Work Force During Repository

Operation ................... 4 48

4.4 Nonradiological Disabling Injuries and Fatalities During

Repository Construction.............. . . 4.9

4.5 Occupational Dose During Normal Operation and from a

Shaft Drop Accident .................. 4.11

4.6 Public Dose During Normal Operation and from a Shaft

Drop Accident ... . . . . . . . . . . . . . 4.11

4.7 Occupational Dose During Normal Operation and from Accidents

During Decommissioning and Retrieval Phases of a Repository . . 4 4.12

4.8 Accident Release Fractions for a Cask Breach With and

Without Fire ................... 4.14

4.9 Dose and Health Effects Estimates for a Transfer Cask

Breach with Fire.................. 4.15

4.10 Summary of Occupational Doses Estimated for Spent Fuel Handling and Disposal Activities ............ . 4.17

4.11 Summary of Repository Accident Releases, Frequencies, Consequences, and Risk Values............... . 4.19

4.12 Nonradiological Injury Rates for Miners per 200,000 Work-Hours Per Year................ 4.21

4.13 Radiation Exposure from Normal Construction and Operation . . . 4.23

4.14 Radiation Exposure from Accidents . . . . . . . . . . . . . 4.24

4.15 Occupational Dose During Potential Tuff Repository Operation . . 4.28

4.16 Summary of Annual Occupational Exposures for Spent-Fuel and HLW Operations at a Potential Tuff Repository . . . . . . . 4.31

4.17 Estimated 50-Year Whole-Body Dose Commitment to tile Public, Maximally Exposed Individual, and Workers fron Accidents . . . . 4.33

4.18 Preliminary Risk Estimates for Postulated Accidents at a Potential kepository in Tuff ............. . 4.34

4.19 Average Staffing Levels for the Repositories . . . . . . . . . 4.36

4.20 Total Radiological Worker Fatalities from Construction and Emplacement Periods of Three Alternative Potential Repository Sites 
4.21 Total Nonradiological Worker Fatalities from Construction and Operation of Repositories in Three Geologic Media . . . . . 4.37

4.22 Projectç Accidents Involving Repository-Generated Traffic and Comparisolls with Baseline Projections......... 4.39

4.23 Frequercies and Consequences of Accident Scenarios Projected to Result in Offsite Doses Greater than 0.05 Rem . . . . . . 4.42

4.24 General Overview of Repository Preclosure Risk Data in Reviewed Documents ............. 4.45

4.25 Repository Preclosure Radiological Risk Values as Reported in the Literature .............. 4.47

4.26 Comparison of Unit Occupational Dose Estimates from the Literature

4.27 Comparison of Normalized Public Accident Risk Values from Various Studies............... 4.50

4.28 Expected Health Effects Over 10,000 Years for Hypothetical 100,000 MTHM Repositories in Basalt, Bedded Salt, Shale and Granite .................... . 4.58

4.291985 Revised EPA Estimates of 10,000-Year Health Effects for 100,000 MTHM Repositories in Basalt, Bedded Salt, Tuff, and Granite . . . . . . . . . . . . . . 4.59

4.30 Maximum Individual Dose Rates Estimated for a Hypothetical Repository in Basalt ............. 4.65

4.31 Maximaliy Exposed Individual Dose Rates Estimated for a Hypothetical Repository for HLW in Salt . . . . . . . 4.66

4.32 Maximum Individual Dose Rates Estimated for a Hypothetical Repository for HLW in Tuff . . . . . . . . . . 4.67

4.33 Summary of Maximum Irdividual Dose Rates for Hypothetical Repositories in Basalt, Salt, and Tuff ........ 4.68

4.34 Expected Case Releases, Normalized to the EFA 10,000-Year Cumulative Release Standard, for Hypothetical Repositories in

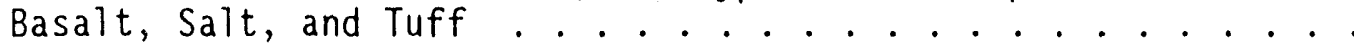

4.35 Seventy-Year Cumulative Maximally Exposed Individual and Regional Population Doses for the Two Peak Dose Periods for a Potential Tuff Repository . . . . . . . . . . . . .

4.36 Radionuclide Solubility Ranges in Brine as Used by Pepping et a 7 . 
4.37 Distribution Coefficients for Radionuclides in Brines Used by Pepping et a1. Compared with WISP Values . . . . . . . . 4.80

4.38 Peak Conditional Cancer Risks Due to Ingestion for the 100,000 Year Postclosure Period for a 90,000 MTU Spent Fuel Repository in Bedded Salt ................. . 4.81

4.39 Peak Dose Values for a Nuclear Waste Repository in Crystalline Rock for the Fennoscandian Shield . . . . . . . . 4.86

4.40 Preliminary Peak Individual Doses for a Mixed Nuclear Waste Repository in a Salt Dome . . . . . . . . . . . 4 4.88

4.41 Overview of Repository Postclosure Risk Literature . . . . . . 4.97

4.42 Radiation Exposures from Routine Operations at the MRS Facility .................... 4.103

4.43 Radiological Impacts of Potential MRS Facility Accidents for Sealed Storage Cask at the Clinch River Site . . . . . . . . 4.104

4.44 Occupational Dose from MRS Facility Operations . . . . . . . 4.105

4.45 Release Categories .................. . 4.108

4.46 Summary of MRS Drywell Risk Analysis . . . . . . . . . . . . 4.109

4.47 Spent Fuel Release Fractions . . . . . . . . . . . . . . 4.112

4.48 Summary of Results .................... . 4.113

4.49 Summary of Occupational Doses from MRS Facility Operations . . . 4.116

4.50 Occupational Dose Estimates for Selected MRS Operations . . . . 4.117

4.51 Summary of Accident Scenarios in GEIS . . . . . . . . . . . 4.118

4.52 Overview of MRS Facility Risk Data in Reviewed Documents . . . 4.122

4.53 MRS Facility Radiological Risk Values as Reported in the
l.iterature . . . . . . . . . . . . . . . . . . . . 23

4.54 Summary of Results from the NRC for Spent Fuel Shipments . . . . 4.127

4.55 Summary of Radiological Impacts from Routine Transport by Dose Group . . . . . . . . . . . . . . . . . . . . . 4 4.130

4.56 Expected Radiological Risk Values from Vehicular Accidents per Year of Shipping Activity . . . . . . . . . . . . . 4.131

4.57 Expected Economic Risk Values from Vehicular Accidents . . . . . 4.132 
4.58 Summary of Spent Fuel Truck and Rail Transportation Risks . . . 4.136

4.59 Surnmary of the Total Transportation Risks for the System Without an MRS Facility............... . 4.142

4.60 Summary of the Total Transportation Risks for the System With an MRS Facility................. 4.143

4.61 Projected Maximum Individual Exposures from Normal Spent Fuel Transport by Truck Cask . . . . . . . . . . . . . 4.145

4.62 Projected Maximum Individual Exposures from Normal Spent Fuel Transport by Rail Cask ............... 4. . . . . . 466

4.63 Maximum Individual Radiation Dose Estimates for Rail Cask Accidents................... 4.147

4.64 50-Year Population Dose Estimates for Spent Fuel Rail Cask Accidents . . . . . . . . . . . . . . . . 4.148

4.65 Population Radiation Exposure from Water Ingestion for Severe but Credible Spent Fuel Rail Cask Accidents . . . . . . . 4.149

4.66 Summary of Collective Radiation Doses from Postulated Reference Transportation System Activities . . . . . . . . 4.153

4.67 General Overview of Transportation Operations Risk Data in Reviewed Documents ................. 4.15.4

5.1 Annual Construction Worker Risks . . . . . . . . . . . 5.3

5.2 Estimated Annual Radiological Risks from the Preclosure Phases of the Potential Tuff Repository . . . . . . . . . . . 5.8

5.3 Annual and Total Nonradiological Fatalities for Each Phase of the Life Cycle of a Potential Repository . . . . . . . . . . 5.9

5.4 Population Health-Effects for a Hypothetical Repository in Unsaturated Tuff . . . . . . . . . . . . . . . 5.18

5.5 Annual Radiological Risk from Routine Emissions from the MRS Facility . . . . . . . . . . . . . . . . 5.23

5.6 Estimated Annual Radiological Risks from the MRS Facility . . . 5.28

5.7 Annual Nonradiological Accident Risks for the MRS Facility by Phase

5.8 Estimated Emissions from Construction and Operation and EPA'S "Significant" Levels for Emission. . . . . . . . . . . . . 5.30 
5.9 Annual Radiological Transportation Risks ......... 5.34

5.10 Annual Nonradiological Transportation Risks . . . . . . . 5.34

5.11 Aggregated Public Risks for the Preclosure Phases of the System Without an MRS Facility ........... 5.42

5.12 Aggregated Occupational Risks for the Preclosure Phases of the System Without an MRS Facility .......... 5.43

5.13 Aggregated Public Risks for the Preclosure Phases of the System With an MRS Facility............ 5.44

5.14 Aggregated Occupational Risks for the Preclosure Phases of the System With an MRS Facility. . . . . . . . . . . 5.45

5.15 Total Preclosure Life-Cycle Risk Estimates for the Waste Management System .............. 5.47

5.16 Projected Health Effects from Natural Background Radiation . . 5.49

6.1 Summary of Literature by Rish Category . . . . . . . . . 6.2

6.2 Qualitative Evaluation of Literature by Risk Category . . . . . 6.3 


\subsection{INTRODUCTION}

The Nuclear Waste Policy Act of 1982 (NWPA) and the Nuclear Waste Policy Amendments Act of 1987 (Amendments Act) established the legal and institutional mechanisms necessary to accomplish the ultimate disposal of commercially generated radioactive wastes in deep geologic repositories. The U.S. Department of Energy (DOE) Office of Civilian Radioactive Waste Management (OCRWM) is proceeding to implement the provisions of these acts. Activities are underway that will lead to the siting, design, licensing, construction, and operation of the first potential repository; acquisition and operation of the transportation system; and possibly deployment of an integral Monitored Retrievable storage (MRS) facility. The primary objective of the waste management program established by the NWPA is to safely dispose of spent fuel and other high-level radioactive wastes (HLW). Because safe disposal is the principal function of the waste management system, information on the risks associated with waste management operations provides useful input for decisions on siting, designing, and operating the system.

Risk, or more broadly "safety," is one major attribute of the waste management system. Two other major attributes are costs and benefits. Costs for development and deployment of the waste management system are on the order of $\$ 20$ billion. These costs for disposal of HLW are being paid by nuclear utilities, at the rate of $1 \mathrm{mil} / \mathrm{kWh}$ of nuclear generated electricity, and by the U.S. Department of Defense. The benefits of the waste management system are primarily linked to the long-term isolation of spent fuel and HLW from people and the environment. This isolation period will allow the highly-radioactive radionuclides to decay to safe levels. A related benefit is that deployment of the waste management system will allow utilities to remove their spent fuel from above-ground storage facilities. Most of the spent fuel is currently in storage pools that are cooled by circulating water systems and contained within forced-ventilation containment systems. Transferring fuel into the waste management system, which is predominantly protected by passive cooling and containment systems, should provide more reliable protection of the public from radiological hazards. Transferring fuel to the waste management system also allows utilities to proceed with 
decommissioning of their reactors on a timely basis after their operating licenses expire. The costs and benefits of the waste management system are addressed in detail elsewhere. The scope of this document is limited to the risks of the waste management system.

The objective of this report is to document the available information on the risks in the waste management system. Because the system is in its developmental stage, comprehensive studies of the risks in the system have not yet been performed. More detailed risk studies are contemplated in later stages of system development when site-specific data has been collected and more complete information is available on system configuration and facility designs. Relevant information is available, however, from many sources that can provide insights into the risks from the waste management system. The purpose of this report is to collect the available information in a convenient form. This information can be used to help guide the direction of future risk studies and to facilitate DOE's dissemination of safety-related information about the waste system to interested groups outside the DOE.

Because the configuration of the waste management system has not yet been finalized, this study examined risks for systems with and without an MRS facility. Risk information was collected for each of the three potential repository sites (i.e., repositories in tuff, salt, and basalt geologic media). However, because the Amendments Act specified that site characterization activities would be performed at the tuff site, risk estimates are developed only for the potential tuff repository. For simpiicity, this study considered only the first potential repusitory and the first 70,000 MTU of spent fuel and HLW, although the NWPA and the Amendments Act provide for a second potential repository. This decision to focus on the first repository only was made because little facility design information and site data are available for the second repositosy. Some differences in total 1 ife-cycle risks can be expected for a second repository because of different fuel characteristics, demographics, and transportation distances, but insufficient information is available to characterize the risks from the second repository. Spent fuel management operations at reactor sites and other commercial sites were not included in the study scope. 
The study documented in this report examined potentially significant risks in the federal waste management system. Risk is characterized in terms of:

- risks to the public and workers

- risks from accidents and routine operations

- radiological and nonradiological risks

- health and economic risks.

The phases of facility operation investigated included construction, operations, decommissioning, possible retrieval of waste from a repository, and repository postclosure. All meaningful combinations of these risk categories and operating phases were examined for each of the waste management system components.

A literature review was performed to identify potential sources of waste management facility risk estimates. In some cases, the risk values derived in the literature were not equal for similar facilities. Some of the reasons for these differences include the assumptions about population densities and weather distributions around a particular site, the scope and objectives of the analysis, and different system parameters such as waste characteristics, throughput rate, and capacity. In these cases, the best available risk estimates were incorporated into this document. The best information was selected based on its applicability to the current waste management system configurations and facility designs, technical consistency, reproducibility of results, and comprehensiveness. In many cases, the estimates available in the literature were for systems that differ from the waste system evaluated in this study. Straightforward corrections were made to the risk values obtained from the literature to make them as consistent as possible with the system configurations described in the OCRWM Mission Plan (DOE 1985) and in Waste Management Systems Requirements and Descriptions (DOE 1986a). These corrections were typicaliy limited to scaling-type adjustments to major system parameters such as throughput rates or inventories. In this report, results are given in terms of annual risks for a fully functioning waste management system operating at a throughput rate of 3,000 MTU/yr. Total risks 
for each phase of operation of each of the system components are also estimated. To the extent that information is available, the range of potential consequences from radiological releases are also estimated for each system component.

It is emphasized that all of the risk estimates in this report are preliminary. They are based on published information from a variety of previous studies that have been done for many purposes. Some of these reports have been comprehensive and detailed while others represent preliminary approximations based on simple methods and limited data. In a study based solely on available information, it is necessary to utilize all applicable studies to develop as complete a picture as possible, but great care and proper technical judgment must be exercised in developing conclusions from the information presented. Because of differences in scope, objectives, methods, and key assumptions among available studies, the risk estimates can only be used to develop general insights about the risks in the waste management system. These estimates may not accurately reflect differences between system components, facility designs, or potential facility sites. It is suggested that the reader carefully review the source documents before using information presented here for purposes other than gaining general insights into the magnitude of the risks in the waste system and the status of risk work in this area.

The remainder of this report is divided into five chapters. Chapter 2.0 provides a general discussion of risk analysis methods and concepts, defines the categories of risk that are included in this report, and presents a discussion of special features of risk assessment methods for each facility in the system. Chapter 3.0 presents overview descriptions of the waste system facilities. The results of the literature review and evaluation are presented in Chapter 4.0. Chapter 5.0 presents the risk estimates for each of the waste system components and aggregated risk estimates for the total system. A general discussion of the uncertainties in these estimates is also provided. The conclusions and recommendations from the study are presented in Chapter 6.0. 


\subsection{ELEMENTS OF RISK ANALYSIS}

This chapter of the report provides a general discussion of risk analysis concepts and methods to familiarize the reader with the terms that will be used in the remainder of the document. Risk concepts and terminology are introduced and general limitations and sources of uncertainties in risk assessments are described. A brief overview of the risks in the waste management system is presented to provide a general context for the more detailed discussions that follow. Special features and general difficulties associated with performing risk analyses for each of the facilities in the waste management system are discussed at the end of this chapter.

\subsection{RISK CONCEPTS AND TERMINOLOGY}

The concept of risk is complicated because the term is used in many different ways. A very general definition of risk is the possibility of loss or injury. Virtually every human activity involves some risk and each person makes risk-based decisions, either explicitly or implicitly, many times each day. Activities such as managing the wastes from nuclear power plants require decisions that affect risks and benefits to segments of the population. Various federal laws require government agencies to conduct their decision-making activities in open forums and to document the decision process for public review. Many of these decisions are important and complex enough that they require formal quantification of the risks considered in the decision process. Risk analysis methods have been developed to perform quantitative assessments of the risks associated with various types of activities and technological systems such as nuclear power plants and waste management facilities.

Risk analysis simultaneously considers the magnitude of the potential losses or injuries associated with an activity and the probability that the loss or injury will be produced. To produce a loss or injury, a hazardous condition must be present and people must be exposed to the hazardous condition. Typically a wide variety of potential hazards can be produced by a given system and a given hazardous condition can result in a range of poten tial injuries. There is a probability distribution associated with each of 
the factors that affect the level of hazard and the number of people exposed to the hazard. A comprehensive risk study uses engineering analys is of the system together with information on the probability distributions to develop comprehensive lists of potential consequences and the probability that each level of consequence will occur.

\section{1 .1 Types of Risks}

Many kinds of consequences are possible from operation of complex systems such as the nuclear waste management system. Routine events and accidents can result in exposure to radiation and hazardous chemicals; can produce injuries or fatalities from exposure to mechanical, electrical, or other hazards; or can produce environmental damage. Both workers and members of the public can be affected. There are economic as well as health and environmental effects associated with many of these consequence categories. Risk analysis can be used to address all of these consequences. Many decision-making processes may involve complex tradeoffs between types of risks in the system. There are risk implications associated with decisions that primarily effect other system parameters such as cost, schedule, throughput rate, or public acceptability. Risk analysis provides a means for quantifying all of the types of risk in a system so the safety implications of decision alternatives can be understood.

\section{1 .2 Uses of Risk Informition}

Risk analysis is essentially a method used to quantify the safety performance of a system. Because this quantification considers both the probability and the consequences of potential exposures to hazardous conditions or substances, it provides the basis for comparing the safety performance of very different activities. Early applications of risk analysis methods focused on providing a consistent basis for comparing the hazards from different activities in society. Many more uses for risk information have been identified as the analytical methods have matured and more experience has been gained with estimating risks and understanding the information contained in the risk analysis. Uses of risk information can be divided into the four general categories described below. 
1. Policy Considerations. Risk information can be considered along with other information on the costs and benefits associated with a technology to make policy decisions about the development, use, and siting of that technology. This may be done through formalized decision-making processes in which most of the important policy factors are quantified through less-formal processes in which the factors are considered more intultively, or through political processes. In all cases, risk analysis provides information on the potential safety impacts associated with the technology. Risk associated with a given technology can be compared with risks and benefits from other technologies to help in making risk acceptability decisions. Risk analysis can also describe the range of potential consequences that could be produced.

2. Cublic Information. Risk analysis provides a quantitative measure of system safety. In the process of performing the analysis and evaluating the results, many insights are gained about the safety of the system, the parameters that affect the safety, and measures that could be taken to improve safety. The numerical results of the analysis as well as the insights gained can be used to develop information that can be used to inform the public about the potential safety impacts of a system. This can help the public to more effectively participate in regulatory, policymaking, and publicdecision-making processes.

3. System Design Improvement.s. Comprehensive risk analyses require detailed modeling of the performance of many of the important sys tems in a facility. This modeling may identify areas in which cost effective design changes may be made to improve the safety and/or the reliability, operability, or functional performance of the system. The quantitative nature of the risk analys is results allows the safety performance of alternative system designs or configurations to be readily compared.

4. Requlatory Analysis. Risk information is being used extensively in regulatory processes. A central mission of most regulatory 
agencies is protection of the health and welfare of the public and facility workers. Risk information provides a quantitative measure of the potential safety impacts on these people. Risk information can be used to help guide regulatory improvements, to evaluate new systems, and in some cases, to show compliance with regulatory requirements. The U.S. Environmental Protection Agency (EPA) guidelines for the postclosure containment requirements of a waste repository (40 CFR 191, subpart B) are written in risk terms. Risk analysis information will be needed to demonstrate compliance with these requirements.

The results of a single comprehensive analysis could be used in a11 of these ways. Other studies could be aimed at one or two of these potential uses. The uses of the results will have a strong influence on the scope and level of detail of the analysis.

\subsubsection{Presentation of Results}

The results of a risk analysis can be presented in many ways, depending on the information needed. In their most basic form, the results are a series of number-pairs. Each pair of numbers includes a potential magnitude of consequence that could occur and the estimated frequency of occurrence of that level of consequence. These numbers can be combined mathematically in several ways to display the results to best meet the needs of the assessment. Two of the traditional methods of displaying these results are the risk curve (or complementary cumulative distribution function) and the risk number. The risk number is also commonly referred to as the "expected risk", the "total risk" or simply the "risk." These terms are used interchangeably in this document .

The risk curve is a plot of consequences and frequencies. Frequencies are usually plotted cumulatively. The curve is constructed by arranging the consequences and associated frequencies in descending order based on the magnitude of the consequences. The frequencies are then summed sequentialiy and the resulting consequence/cumulative frequency pairs are plotted. The frequency that appears on the plot is then the frequency of a given level of 
consequences or greater. This kind of curve contains substantial information, but usually requires extensive experience to interpret. The curve shows the full range of potential consequences that can be produced and shows how the frequency changes with consequence level. In yeneral it is desirable for the frequency to decrease rapidly as the consequence level increases.

Two sample risk curves are shown in Figure 2.1. Curve $A$ shows that, for this hypothetical system, the maximum consequence event would result in about 30 fatalities and is predicted to occur about once every 1,000 years of operation of the system. An event that results in one or more fatalities is predicted to occur about once every 10 years. For Curve $B$, the maximum consequence event produces 10 fataltities and occurs with the same frequency as the maximum consequence event for the systems in curve $A$. The frequency

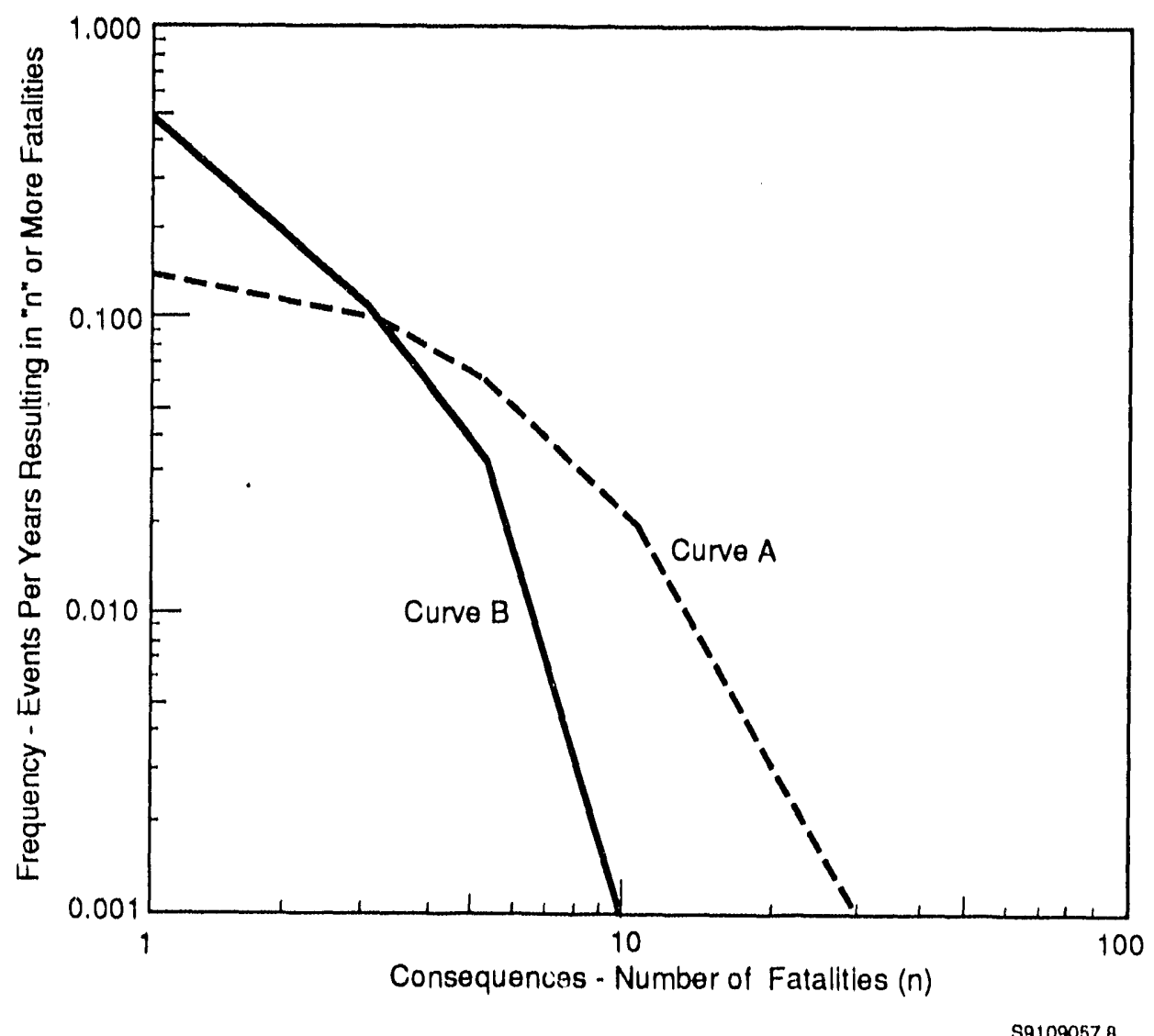

EIGURE 2.1. Sample Risk Curves 
of events resulting in one or more fatalities on Curve $B$ is about 0.2 per year or one event every 5 years of system operation.

The risk number is obtained by multiplying each consequence level by its estimated frequency of occurrence and summing the resultant products. This number gives the expected value or "average" level of consequences from the facility or activity. Typical units for the risk number are fatalities per year. This means that averaged over a long period of operation, the facility would be expected to produce the indicated number of fatalities in a typical year. The utility of the risk number lies in its simplicity. It provides a single number that represents the safety performance of the system. The sample risk curves in Figure 2.1 illustrate the limitations in the risk numbers. The risk number for the two systems represented by Curves $A$ and $B$ can be calculated by decomposing the cumulative risk curves into their basic consequence-frequency pairs, multiplying each consequence by its associated frequency, and then summing the resultant products. The result for the two curves in the figure is the same - about 0.3 fatalities per year. Based solely on the risk number, one would say that the two systems produce equivalent risks. The risk curves demonstrate that higher consequence events can occur with the system represented by Curve $A$, while the system in Curve $B$ has a higher likelihood of events that result in just one or two fatalities. This type of tradeoff can only be understood if the risk curves are available. Both the risk curve and the risk number can be compared with similar results for other systems or activities to help make judgments about the acceptability of the risks from the system being analyzed.

The consequence analysis for a risk study can be performed in a variety of ways, depending on the use of the results of the risk analysis. For facility design studies, it is often sufficient to express the consequences in terms of the quantity of radioactive or other hazardous material released from the facility. This approach will adequately distinguish between the safety performance of alternative designs and will simplify the analysis because environmental transport and health effects calculations are not needed. Many licensing standards, such as the EPA repository performance standard, are written in terms of releases to the accessible environment. For policy or regulatory decision processes, however, it is usually necessary 
to perform a complete consequence analysis. If the decision-making process is focused on the radiological safety aspects of the system, consequences may be expressed in terms of the radiation dose to the potentially exposed population. If risk acceptability is being addressed, additional calculations are usually performed to estimate the health effects (usually latent cancer fatalities or genetic effects) that might result from these exposures.

Industrial accidents or transportation accidents can occur in the waste management systems that do not result in exposure to radioactive materials, but still may harm workers or members of the public. The consequences of these accidents are most easily expressed as fatalities or injuries. Radiological concequences are often expressed as estimated latent cancer fatalities so that they can be compared with nonradiological consequences from the same system.

Accidents in the waste management system can also produce economic consequences. These consequences are associated with onsite and offsite cleanup costs, facility downtime, and repair costs. The same risk analysis methods can be used to address economic risks, although different consequence models will be needed to calculate the economic effects produced.

\subsection{RISK METHODS}

There are two basic categories of risks being considered in this study: 1) risks from routine events and 2) risks from accidents. The analytical methods used to assess the risks in these two categories are generally quite different. For assessments of routine radiation doses to the pubiic, the following analytical activities are carried out:

- Define the sources and magnitude of potential hazards. For example, this might require characterization of the radiation fields in a facility to estimate the routine doses to people working in the facility or calculation of the amount of effluents released from the facility to estimate consequences to the public from routine emissions.

- Estimate the consequences produced by the hazards. This usually involves estimating the number of people potentially exposed to the hazard, analyzing the pathway from the source of the hazard to 
people, and estimating the magnitude and potential health effects of the exposures. There is usually some variability in the corisequences from routine events. For example, if routine doses to workers are being estimated, the radiation fields may vary at a particular location depending on the type of operation being carried out at the facility at a particular time. The number of people at the location may also vary depending on the operation, the shift being worked, and other factors. For routine effluents, the consequences depend not only on the magnitude of the release, which will vary with facility operations, but also on weather parameters that control the transport of the material from the source to the environment and 1 and use. For example, the number of people exposed to a routine release of materials will be affected by the wind direction, since the materials are dispersed by the wind and the population distribution around a facility is not constant. Land-use data are needed to estimate the consequences of ingesting contaminated food or food that is grown in areas with trace amounts of residual contamination.

Routine doses to workers are evaluated using different methods than those used to estimate routine public doses. The most widely used occupational dose assessment method consists of performing detailed timeand-motion studies of worker activities to estimate the amounts of time and number of workers that occupy specific areas of the facilities (e.g., shipping cask handling areas, hot cell operating galleries). The next step is to estimate the external radiation dose rates in these areas. In most previous studies, dose rates were based on the maximum allowable dose rates specified in regulations. A few studies used dose rates that were based on shielding analyses. After the worker occupancy and dose rate data were established, they were combined to develop estimates of occupational doses.

For risks that result from accidents, a more detailed assessment of the events that could produce hazardous conditions is usually required. Industrial, mining, or transportation accidents that do not involve the external release of radioactive materials can generally be analyzed using historical data. Assessment of risks from accidents that could release significant amounts of radioactive materials to the environment usually require predictive methods. A general description of the activities in a predictive risk analysis is provided below. A comprehensive assessment that examines all of the potencial contributors to accident risks is described. The level of detail irdicated in the discussion will not be needed for all assessments. 
The discussion is based on analysis of accident risks from a fixed operating facility such as an MRS facility or a repository. Some variations in the methods are required to analyze transportation risks or postclosure repository risks. The special features of these methods are discussed in Section 2.5.

The basic steps in a predictive risk analysis for a waste management facility include: 1) description of the facility and site; 2) identification of potential accident scenarios, estimation of the scenario probability, and estimation of the amount of hazardous material release by each scenario; 3 ) analysis of the consequences of the hazardous material released; and 4) estimation of the system risk.

Figure 2.2 shows how these elements are typically organized to perform a comprehensive risk analysis. A risk analysis begins with a detailed description of the safety-related portions of the facility including the process steps, operating procedures, and engineered safety features. Site-specific data on weather, population distribution, land use, and surface-water and groundwater systems that are needed to calculate accident consequences are also collected.

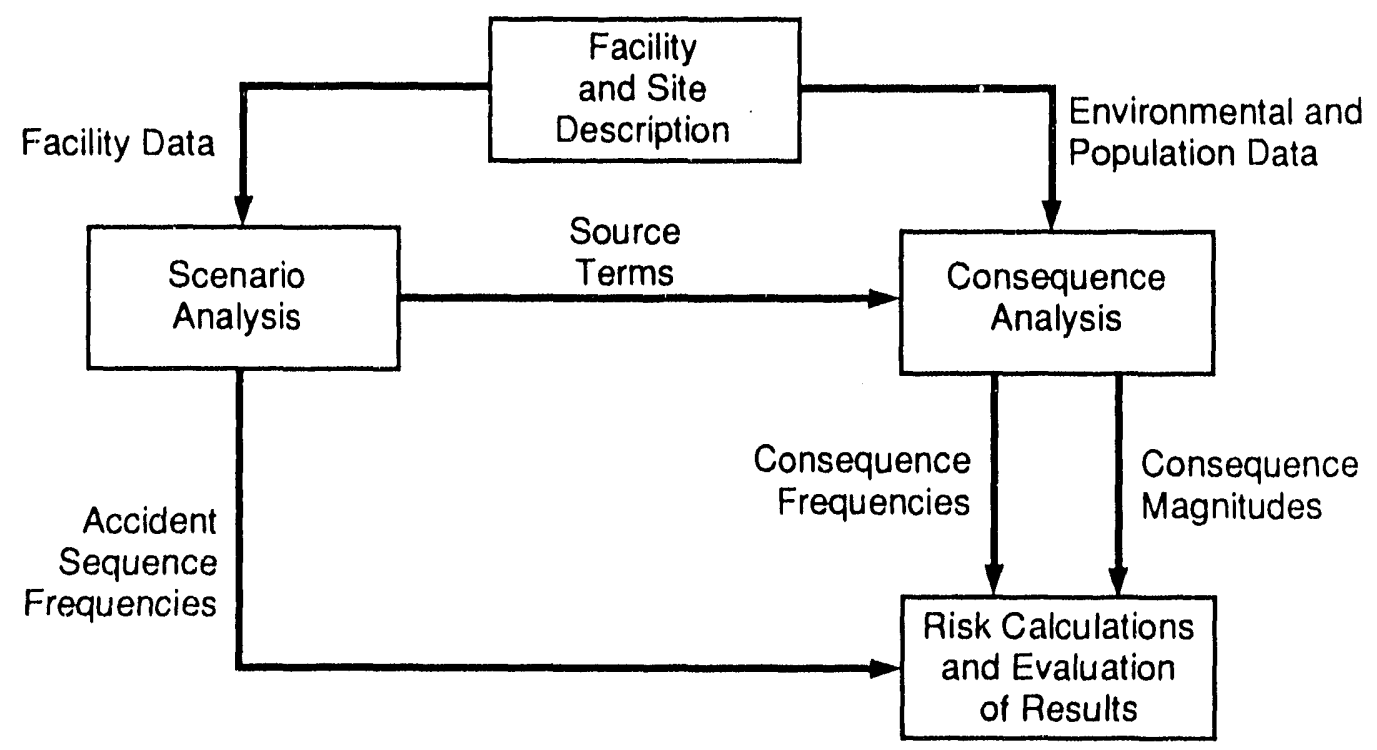

S9109057.1

FIGURE 2.2. Major Steps in an Accident Risk Analys is 
Scenario analysis methods are then applied to determine the important accident sequences for the facility. Historical data on accidents or unusual events in similar facilities can be a valuable source of information to help define accident scenarios. Detailed modeling of plant systems and processes during normal operations and process upsets may be required to determine the sequences of events that would lead to a release. External events such as earthquakes, fires, or tornados that could initiate accidents and/or cause multiple equipment failures may be considered in this portion of the analysis. The effects of plant operators in initiating accidents or in mitigating or exacerbating an accident in progress can also be an important consideration.

Once the important accident sequences have been identified, they are analyzed and used to estimate the amount of material released in the accident and the probability that the accident will occur. Probabilistic modeling methods generaliy use data from similar systems, components, or human actions to estimate the frequency of each event in an accident sequence. Caution must be exercised to ensure the data is applicable to the system or facility being analyzed. The event frequencies are then combined to calculate the accident sequence frequencies.

Source terms are characierized by estimating the amount of material released from process vessels, piping, and cells in an accident; determining the physical and chemical charicteristics of this material; and characterizing the material that escapes the confinement boundaries and beccmes available for offsite release. This information is used to estimate the consequences of the accident to workers inside the plant and as the source term for calculation of consequences outside the plant.

Calculation of offsite consequences requires a detailed description of the plant site because the consequences depend on the gengraphical, meteorological, and demographic characteristics of the site. Because these factors are variable at a given site, each accidental release can result in a range of potential consequences. Typically, all potential consequences are calculated for each release and the frequency of each consequence is estimated 
using data on the frequency of the meteorological and population distributions associated with each potential consequence level. Postclosure release consequences must also consider aquatic transport of the radionuclides. This is combined with the probability information for the accident sequences leading to the release to obtain the overall probabilities for the analysis.

In the risk calculation step, the probability and consequence informa tion are combined to produce the study results in a way that best addresses the original objectives of the assessment. The results are then interpreted to extract the conclusions and insights from the analysis, and the work in the assessment is documented. A risk analysis is a systematic, often detailed, examination of the safety-related components of a system. Often the insights gained in this systematic analysis are at least as important as the numerical results of the risk calculations. These insights can include information on which portions of the system are most important to protecting the public or workers from the hazards present; what types of system improvements would have the greatest impact on the safety performance of the system; and where better methods or data could substantially reduce uncertainties in the results. Analysis techniques such as sensitivity studies are used to help develop these insighcs and to quantify the importance of key factors. Study insights are usually documented along with the risk results. The analysis can also provide the basic information needed to quickly assess safety-related issues about the system that arise in the future.

\subsection{LIMITATIONS AND UNCERTAINTIES IN RISK ANALYSIS}

Risk analysis has inherent limitations because the analysis attempts to make predictive projections from historical data and engineering analys is to the consequences and probabilities of future events. A comprehensive analysis will not necessarily identify all possible undesirable events. The methods are structured to identify all important categories of events, but limitations in knowledge, data, or available resources can result in incomplete coverage of potential events. Risk analyses also typically use mathematical models of hardware and physical and biological systems to develop event sequences and estimate consequences and probabilities. This use of models is necessary so the analysis can be performed with a reasonable 
expenditure of resources and because of limited data on the behavior of these kinds of systems. Use of these models requires simplifying assumptions to account for data limitations and to keep the analysis tractable. The traditional practice is to make assumptions that tend to overestimate the risks from the system being analyzed. (This is commonly referred to as the "conservative" analysis approach.) Most risk assessments will therefore tend to describe an upper bound or a conservative best estimate of the system risks. This approach is taken to provide some assurance that events that are not analyzed are covered by the conservatism. Because of variations in the degree of conservatism assumed and the objectives of different studies, the data used, and the resources expended, variations in the results resulting from different studies can be considerable.

Where possible, risk analy'sis relies on historical data to identify hazardous events and to estimate the consequences and frequencies of these events. For example, the insurance iridustry operates almost totally with historical data. Where there is substantial previous experience, this is usually the most accurate and cost effective way to analyze risks, although even good historical data may not identify high-consequence, low-probability events. In the waste management system, there is little directly applicable historical information available. In this case, predictive risk analysis techniques need to be applied. These techniques require that the systems be analyzed to a level of detail that perinits available data to be used. For example, an MRS facility has never beer built and operated, so there is no direct experience that can be used to estimate the risks to the public from potential accidents at a facility. However, most of the equipment planned for use in the MRS facility has been used in the nuclear industry and in other industries for many years, and information is available on the reliability and failure modes of this equipment. Analytical methods can be applied to identify the combinations of component failures that could result in a release of materials from the MRS facility, and historical data can be used to estimate the frequency with which these component failures and human errors will occur. In this way, an estimate of accident frequencies can be developed for a system for which there is no previous operating experience. 
Risk analysis is applicable to consequences that might result from routine or planned releases of hazardous materials as well as to accidental releases. Analysis of the consequences and associated frequencies from routine releases can help to set standards for routine releases or demonstrate compliance with standards as well as provide perspective on the consequences from accidents. Although the maximum allowable routine releases are usually set by regulatory standards, the actual releases can vary with operating conditions. The consequence of a particular release will also change depending on the location of the facility that is the source of the release and the weather and other conditions at the time of the release.

A risk analysis for routine releases or events therefore has probabilistic elements that need to be considered in the analysis, just as in a risk analysis for accidents. The results are expressed in the same terms as the results of an accident risk analysis. There is a subtle difference between risks from routine events and risks from accidents that needs to be considered when comparing the results from analyses of these two risk categories. A risk analysis for routine events really describes the possible range of consequences from events that are anticipated to occur. An accident risk analysis describes the potential consequences from events that might occur. At a given facility consequences from the routine events will occur within the predicted range with a relatively high degree of certainty, while a severe accident that resulted in offsite consequences may be highly unlikely. The accident could occur, but the probability of occurrence is typically very small for severe accidents because the facility is designed to prevent them. Each of these analyses provides useful information for decision-making processes, and the results can be expressed in similar ways and compared. However, care must be exercised in making these comparisons. Similar difficulties can arise in comparing consequences from accidents, such as a mining cave-in that result in immediate effects, with accidents, such as radioactive material releases, that result in an increased chance of cancer at a later time in the exposed population. Even though the end result of each of these consequences is increased fatalities, the nature of the consequence mechanism is sufficiently different to require care when comparing the results. 
There are a number of sources of uncertainty in the results of a risk analysis. Limitations in data, knowledge of the system, capabilities of mathematical models used, and the level of detail applied all contribute to uncertainties. It is important that the limitations of the analysis be well understood so that the results can be used appropriately in decision making processes. For example, it may not be reasonable to use a particutar study as the basis for making a design change that would lower the system risk by $10 \%$ if the study has only been able to estimate the risks within an accuracy of a factor of 2. A variety of techniques can be applied to define the sources of these uncertainties and the affect of the uncertainties on the results. Sensitivity studies are often used to identify important analysis parameters and to demonstrate the impact of key assumptions on the study results. Techniques are also available for use in estimating uncertainties in mathematical models and computer codes and in combining estimates of uncertainties in various portions of the analysis into an overall uncertainty estimate. Often uncertainty estimates are made qualitatively rather than quantitatively. These estimates are based on the judgment of the analysts that contributed to the work.

\subsection{OVERVIEW OF RISKS IN THE WASTE MANAGEMENT SYSTEM}

In this study, the most applicable available published information is used to develop estimates of the risks associated with the nuclear waste management system. A broad range of risk categories in the system are included in the scope of the study. Effects from both accidents and routine operations to both the public anci workers in the waste management facilities are included. All phases of development and operation of the waste management system are being considered in the study including construction, operations, and decommissioning. Both the preclosure and postclosure phases of the potential repository are included. Operations that would be required if it were necessary to retrieve wastes from a repository are also included. Consequence categories of interest include radiological and nonradiological health effects and economic consequences. Economic consequences include cleanup costs, costs of removing resources from use for some period of time 
following an accident, and facility downtime and repair costs. Only fatal health effects are being considered.

The risk categories of interest are summarized in Table 2.1. Only fatal latent health effects are included under radiological consequences. Immediate health effects can be produced from very large radiation exposures, but events that could produce exposures of this magnitude in the waste management system have not been identified. Theoretically, all of the possible combinations of these categories would be addressed in this study. However, a number of the combinations are not meaningful. For example, there are no significant quantities of radioactive materials at the MRS facility site during construction. Radiological consequences are not expected from either accidents or routine events during MRS facility construction. Table 2.2 provides a summary of the potentially important risk categories in the waste management system. Categories in which risks are potentially produced are indicated by an " $x$ " in the table. Nonmeaningful categories are either deleted from the table or indicated with a "-". The discussion below provides a brief description of the risks in the meaningful categories and the rationale for eliminating the nonmeaningful categories. The risks in many of the meaningful categories may be very sma11, but the magnitude of all these risks must be characterized to develop a comprehensive picture of the risks in the waste management system.

\subsubsection{Repository}

Construction-Accidents. Because there are no significant quantities of radioactive materials present at the site during construction, there are no

TABLE 2.1. Risk Categories Considered in This Study

\begin{tabular}{|c|c|c|c|c|}
\hline $\begin{array}{c}\text { System } \\
\text { Components }\end{array}$ & Operating Phase & $\begin{array}{l}\text { Consequence } \\
\text { Categories }\end{array}$ & $\begin{array}{c}\text { Exposed } \\
\text { Population, } \\
\end{array}$ & $\begin{array}{l}\text { Exposure } \\
\text { Mechanism }\end{array}$ \\
\hline $\begin{array}{l}\text { Repository } \\
\text { MRS Facility } \\
\text { Transportation }\end{array}$ & $\begin{array}{l}\text { Construction } \\
\text { Operations } \\
\text { Decommissioning } \\
\text { Retrieval } \\
\text { Postclosure }\end{array}$ & $\begin{array}{l}\text { Radiological } \\
\text { - Latent cancer } \\
\text { - Genetic effects } \\
\text { Nonradiological } \\
\text { - Fatalities } \\
\text { Economic Consequences } \\
\text { of Accidents }\end{array}$ & $\begin{array}{l}\text { Workers } \\
\text { Publ ic }\end{array}$ & $\begin{array}{l}\text { Accident } \\
\text { Routine }\end{array}$ \\
\hline
\end{tabular}


TABLE 2.2. Waste Management Risk Matrix

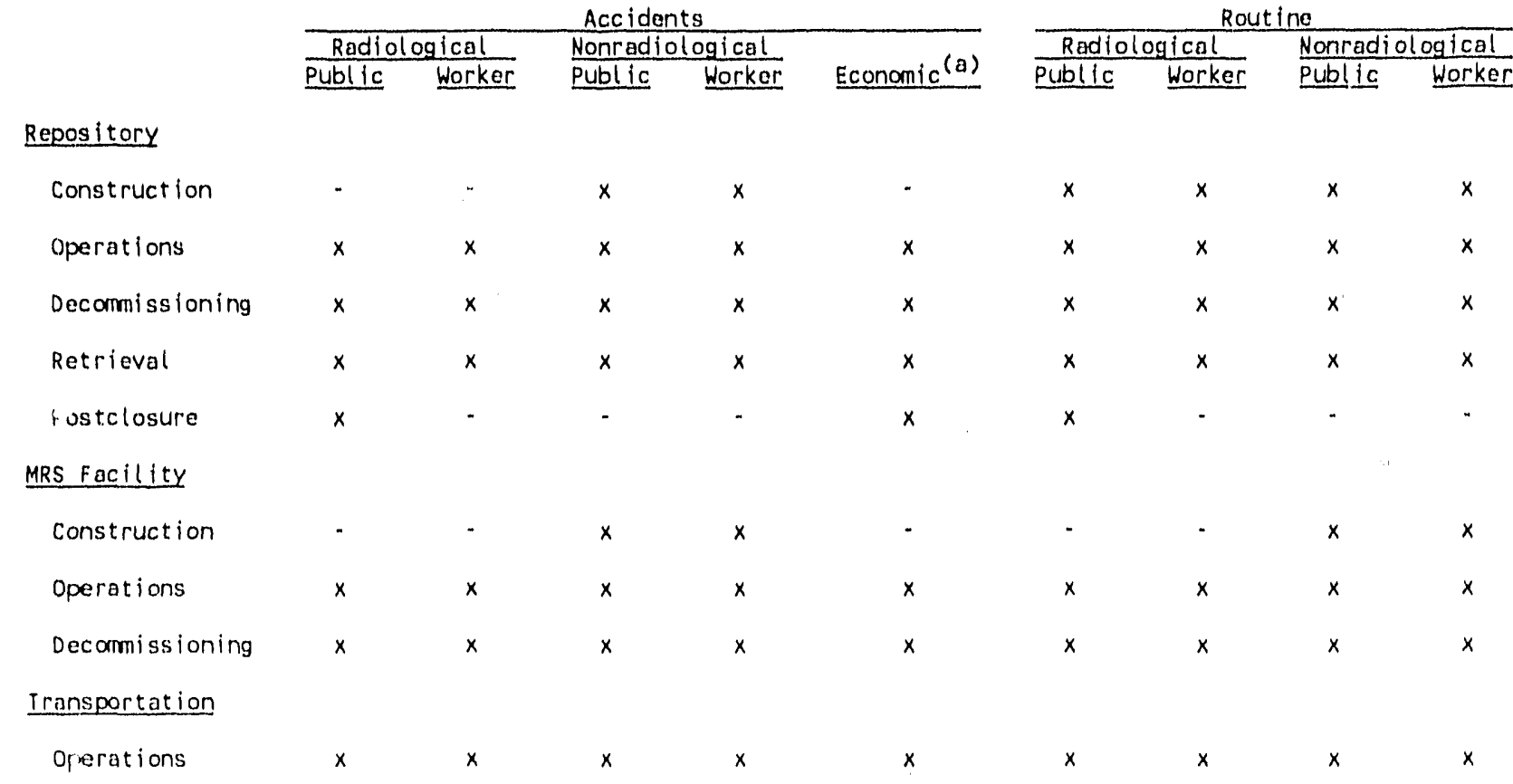

(a) The econonic risks considered in this study are those resulting from accidental release of radioactive material.

$x=$ Meaningful risk categories.

- = No risks in this category.

radiological effects from accidents during this time period. Accidents during construction of the surface facilities should be typical of any large construction project. These accidents will primarily affect the workers. Some public effects are possible from construction accidents, but these would principally be associated with the transportation of construction materials to the site. Construction of the mined portion of the repository could be a significant source of risk to workers. Significant data exist on the risks from mining operations, and preliminary work has been done to apply these data to the mining operations associated with a geologic repository.

Construction-Routine. Routine nonradiological risks associated with construction of the surface portions of the repository are relatively modest and typically characterized as part of an environmental assessment. There may be radiological risks to both the public and workers during routine construction of the mined portion of the repository. These mining operations will result in releases into the atmosphere of some natural radioactive 
matertals that are present in the source rock as in most mining operations. Some data exist on the amount of radioactive material present in the air in underground mines. This data has been used to make preliminary estimates of the radioactive material that would be present in the mine and, therefore, would be available for the miners to breathe and the amount of material that may be released from the mine to the atmosphere. The repository mining operation will also require storage of large amounts of the host rock material on the surface during the construction and operational phases of the repository. It is possible that this practice will result in release of constituents of the host rock to either the atmosphere by wind action or to the groundwater by leaching, although methods are available for controlling or reducing these releases. Nonradiological effects may also be observed in the workers during the underground construction operations. Dust generated in the mining uperations could produce health effects in the miners $(\mathrm{e} . \mathrm{g}$, silicosis).

Operations-Accidents, Radiological risks to the public from accidents during plant operations are the category of risks that are traditionally addressed in risk assessment studies. These accidents can effect both workers and the public. Small "industrial" type accidents could expose workers to both radiological and nonradiological hazards. Some accidents could cause significant damage to the facility and exposure of workers, but not result in significant offsite releases. Most previous risk studies have not addressed these types of accidents in a comprehensive way.

Because of the hazards associated with the underground portions of the repository, there may be significant nonradiological risks to the workers from accidents during operation of the repository. There are no large quantities of nonradioactive hazardous materials associated with emplacement operations at the repository; although, some nonradiological hazardous inaterials, such as diesel fuel and explosives, will be present at the sites. Nonradiological accident risks to the public should be small. Accidents that result in offsite release of radioactive materials will have economic consequences associated with cleanup and removal of resources from use. 
Operations-Routine. Workers wi11 receive routine radiological doses from handling the radioact tve wastes that are received at the facility and placed in the underground facility. Small amounts of radioactive material may be released as routine effluents from the factlity. The only potentially significant source of routine nonradiological effluents is the mined material stored at the surface, which was discussed above under construction.

Decommissioning-Accidents. Decommisstoning involves firial closure of the subsurface facilities and removal of any restdual radioactivity from the surface factlities. Nonradioactive surface facilities may also be removed and permanent markers erected at the site. Radiological risks from accidents during decommissioning will be small because there are expected to be only small amounts of residual radioactive material in the surface facilities. Nonradiological accident risks during decommissioning should be similar to nonradiological risks from accidents during construction. Economic risks during decommissioning should be small because the chance of a significant offsite release of radioactive materials during this phase is smal1.

Decommissioning-Routine. Workers will be exposed to low levels of radiation routinely during the decommissioning operations and could be exposed to dust and other potential nonradiological hazards. These risks are expected to be sma11. No significant routine offsite effluents are expected.

Retrieval. Retrieval can be thought of as another operational phase of the potential repository. Risks during retrieval would be characterized using similar methods to those applied to estimate risk during operations.

Postclosure. Normal physical and geological processes or disruptive events may result in releases of radioactive materials to the environment after the repository is closed. These releases would typically involve very small amounts of material entering the biosphere over very long periods of time. Economic consequences are possible from these releases if the releases are large enough to require protective actions for potentially exposed individuals or contaminated property. 


\section{4 .2 MRS Factlity}

Construction. Activities during construction of an MRS facility will be typical of any large construction project, similar to construction of the surface factlities at a potential repository. Workers may be involved in construction accidents. The public will be affected during construction primarily by accidents during transportation of construction materials to the site. The consequences of other construction accidents should be confined to the site. There will be minor routine nonradiological effluents from the construction operation. Because there are no significant quantities of radioactive materials on site during construction, there is no potential for radiological consequences during this phase.

Operations. Accidents are possible at the MRS facility that could result in exposure of workers or the public to radioactive materials. Economic consequences are also possible from these releases. Workers will be routinely exposed to small levels of radiation during MRS facility operations. Very low levels of radioactive materials may be routinely released to the environment. There are no significant sources of nonradiological effluents from the MRS facility. The MRS facility also does not contain any significant quantities of nonradioactive hazardous materials that could affect the public if accideritally reieased.

Decommissioning. Risks from decommissioning the MRS facility will be similar to those from decommissioning the surface facilities at the potential repository. Public risks will be small, because very little radioactive or other hazardous materials will remain in the facility when decommissioning takes place. Workers will be exposed to low levels of radiation and to industrial hazards associated with the decommissioning operations.

\subsubsection{Transportation}

Construction. Construction of transportation casks and vehicles is a straightforward industrial activity that involves no unusual hazards. The scale of these activities is much smaller than the construction of the potential MRS facility or repository. Transportation construction activities will not contribute measurably to the risks in the waste management system and will not be addressed in detail in this study. 
Operations. Accidents can occur during transportation. Most of these accidents will not result in the release of radtoactive materials, but trans portation workers or members of the public could be injured in the accident, just as in any other transportation accident. Only very severe accidents could result in release of radioactive materials and exposure of the public to these materials. Economic consequences would result from accidents that release significant quantities of radioactive material. Transportation also results in the routine exposure of transportation workers, such as truck drivers and train crewmembers, and members of the public along the transport route, to low levels of radiation. Transportation operations also release nonradioactive effluents from the burning of transportation fuels. These effluents are routinely characterized in environmental assessments, and always found to be of 1 ittle concern because the amount of fuel that is consumed in the waste transportation system is very small compared with that consumed by all transportation operations in the country. These effects will not be quantified in this study.

Decommissioning. Transportation casks will be removed from service when they reach the end of their serviceable life or are no longer needed. Some relatively routine decontamination operations will probably be performed as part of this operation, and portions of the cask may be disposed of as radioactive waste. Transportation decommissioning operations are very smal1 in scale compared with decommissioning of a major facility. They will not contribute significantly to the risks in the waste management system and will not be characterized in this study.

\subsection{SPECIAL FEATURES AND GENERIC DIFFICULTIES IN ASSESSING RISKS IN THE WASTE MANAGEMENT SYSTEM}

Assessing the risks in the waste management system has some inherent difficulties that arise from the nature of the facilities and the types of risks that must be addressed. These difficulties are discussed in this section. The speciai features that are incorporated into risk assessment methods for waste management facilities to deal with these difficulties are also described. The discussion is organized by major facility in the waste management system. The discussion of repository risk assessment is divided into 
the preclosure and postclosure phases because of the unique risk assessment challenges associated with each of these phases.

\subsubsection{Repository Preclosure}

The receiving, handing, and packaging operations at the potential repository are similar co operations that have been conducted in the nuclear industry for many years. Risk studies of these types of operations have been performed and the risk methods to analyze these operation: are available. There are some unique features of the potential repository operations that provide special challenges from a risk assessment perspective, however. Preliminary data indicates that nonradiological risks associated with underground construction and operations at the repository will be an important contributor to the overall risks from the waste management system. It will be important to develop reasonable estimates of these risks. Underground construction and operations have not been dealt with in any detailed way in past risk assessments. There is data available from mining operations that can be used to help evaluate these risks, but there are significant differences between the potential repository underground operations and conventional mining operations. Because of these differences, the mining data has to be used very carefully. The data will probab?: have to be corrected for the specific differences that exist between the construction and operating conditions in the repository and the mining conditions under which the data was collected. The repository will also utilize special equipment that has not been used in underground operations before. The effects of underground conditions on this equipment will need to be analyzed to estimate the failure rates and predict the failure modes for use in accident risk studies.

It will be difficult to develop accurate estimates of the risks from retrieval operations at a potential repository. The operations that would be required to retrieve the fuel have not yet been characterized in detail for any of the potential repository designs. Even after these studies have been completed, there will still be substantial uncertainty about the operations. This uncertainty occurs because it is impossible to predict the conditions that would make retrieval operations necessary. Available information indicates that the repositories will perform as designed and retrieval will 
not be required. The retrievability requirement has been developed to deal with unforseen problems. Actually, the retrieval operations, condition of the fuel when it is retrieved, and condition of the potential repository at the time of retrieval will not be known until the time that retrieval becomes necessary. Many assumptions will therefore be required to develop risk estimates for this phase of the repository operations. The risk assessment methods used for the analys is are generally available, and will be very similar to those used for the regular operating phase. The inherent lack of information about the retrieval operations will result in larger uncertainties for risk estimates that are developed for this phase than the risk estimates for the emplacement phase.

Most previous risk studies for facilities of all types have focused on accidents that lead to offsite consequences. These studies have identified the frequency and potential consequences of very severe accidents that could result in significant releases of hazardous materials. Another category of accident has been largely ignored--accidents that may result in significant damage to the facility and injury to the workers in the facility, but in which the facility's containment systems are not breached. The protective systems built into the facility may prevent a release, but significant consequences could occur inside the facility. The probability of these types of accidents will likely be higher than the probability of accidents that produce offsite consequences. Because these accidents can injure facility workers, the actual risk from this category of accidents could be higher than the risk from accidents that produce offsite consequences. Extensions to existing methods may be required to develop reasonable estimates of the risks that are produced.

\subsubsection{Repository Postclosure}

The assessment of postclosure repository performance is a complicated, multifaceted undertaking. Figure 2.3 (Van Luik et a?. 1986) shows the components of a strategy for assessing the postclosure performance of the geologic repository system. This strategy is directed towards the goals of showing compliance with the EPA standard (EPA 1985a) and the NRC performance requirements (NRC 1983a). The EPA standard (EPA 1985a) specifies probabilistic 


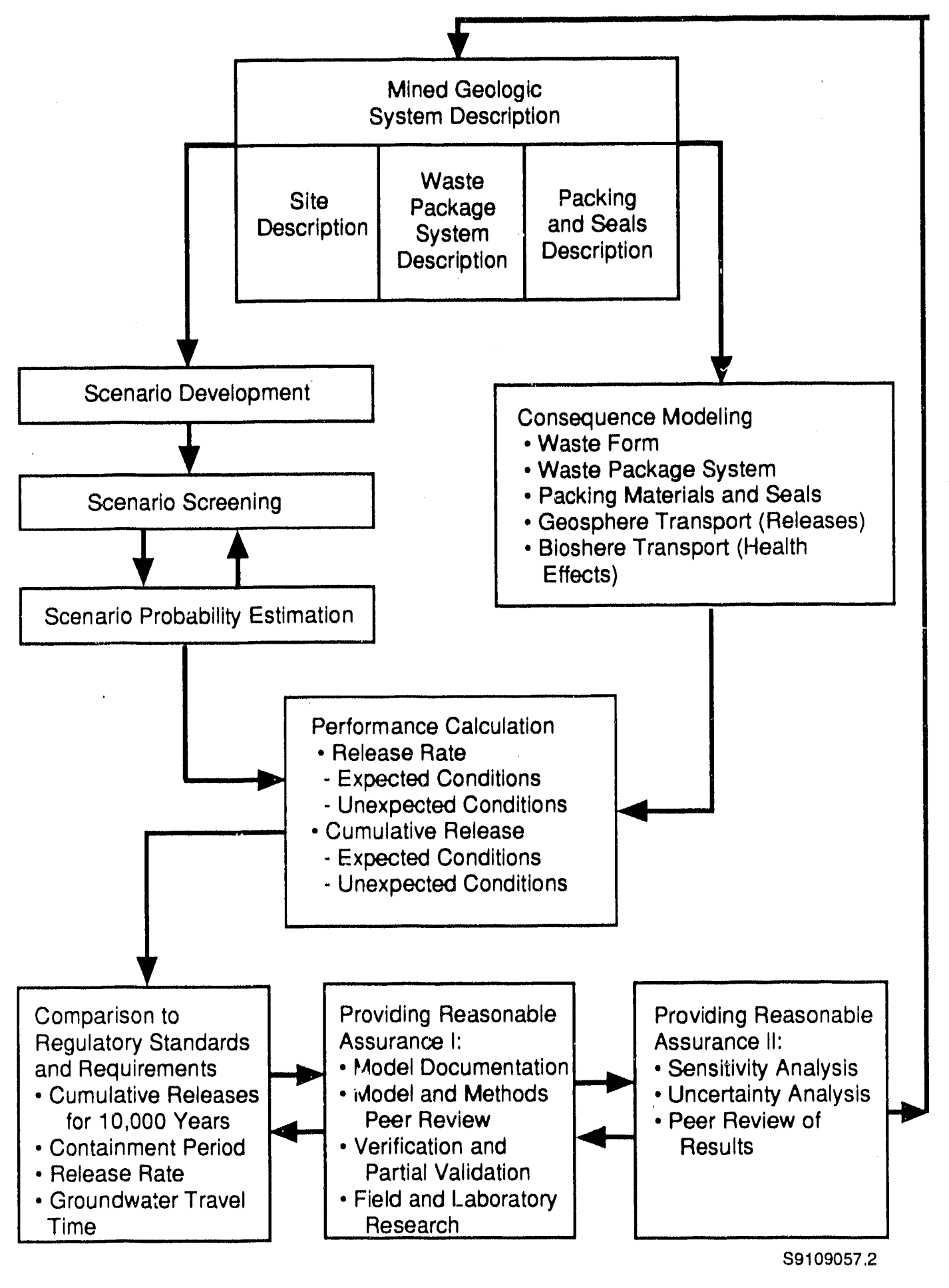

FIGURE 2.3. Components of a Strategy for Assessing the Postclosure Performance of the Mined Geologic Repository System 
quantitative cumulative release limits to a boundary within the geosphere called the accessible environment. Since these radionuclide-specific release limits are based on population risk estimates, the DOE does not have to address population risks in showing regulatory compliance.

The NRC (NRC 1983a) specifies a minimum time period during which the waste packages must provide substantially complete containment, and prescribes maximum allowable rates of radionuclide releases from the engineered barrier system after containment failure. In addition, the NRC specifies a minimum groundwater travel time from the disturbed rock zone to the accessible environment. The NRC performance requirements are deterministic in nature, and calculations addressing these requirements will consider only expected conditions.

The EPA standard requires the use of probabilistic evaluations to show compliance. This requirement is reflected in the parallel structure of performance assessment with respect to scenario development and consequence modeling (see Figure 2.3). This parallel structure suggests that defining processes or events, either natural or anthropogenic, that could result in radionuclide releases to the accessible environment is as important as being able to model the consequences of those events. Scenario identification and screening, and the estimating of scenario and consequence probabilities is not easily done. Recent efforts in this area by the DOE are reported in the document that supports the selection of three potential repository sites for characterization (DOE 1986f), and in section 8.3.5.13 of the Site Characterization Plan (DOE 1988). For licensing purposes, both the scenario work and the calculational work that makes up the performance assessment must provide a basis for finding that a repository can comply with tiie EPA standard. In addition, risk estimates are needed to confirm safety and to satisfy the public decision-making process required by the National Environmental Policy Act (NEPA). This need for the communication of risk information is being addressed in part by this report.

The remaining two boxes in Figure 2.3 illustrate the need for documenting and evaluating the performance calculations and their results. A 
consensus must be built regarding the adequacy of the performance assessment and its results across a wide spectrum of interested parties.

A significant difficulty facing the analyst required to do a probabilistic postclosure risk assessment lies in the fact that consensus has not been achieved on a comprehensive set of intrusive and disruptive scenarios that could result in enhanced releases of materials beyond the repository site. The problem of assigning probabilities to release scenarios remains the subjert of current research. Recent DOE effort in this area (DOE 1986f) may be useful as a start for developing consensus regarding the probabilities of some scenarios and consequences. Likewise, the discussion of credible scenario classes in the Site Characterization P1an (DOE 1988) may aid the development of a consensus regarding an approach to the selection of credible scenarios for the Yucca Mountain site in Nevada.

There are a number of published preliminary performance analyses that have included disruptive and intrusive event release scenarios. One of the more recent is the EPA's background information document supporting the final EPA standard (EPA 1985b). These studies have addressed the issue of the probabilities of scenarios and their consequences in a variety of ways. Hunter et a1. (1985) cited a number of publications as including examples of unstated, assumed probabilities; stated, assumed probabilities; probabilities calculated using sophisticated mathematics and uncertain data; probabilities based on geologic considerations and arguments; and probabilities based on combinations of these approaches. The purpose of the review was to make the point that no consensus exists on how to go about assigning probabilities to events with a low likelihood of occurring.

The work in risk/performance assessment methods being done on behalf of the NRC has included evaluations of the EPA standard (Ortiz et a1. 1984). In the Sandia National Laboratory application of its risk assessment methodology to hypothetical systems in basalt, bedded salt, and tuff, a number of findings were made with regard to the then proposed EPA standard. Of greater interest to the present subject, however, is the conclusion of these authors that they have demonstrated a method of assessing compliance with the EPA standard ". . Which can take into account the uncertainty of scenario 
frequencies. The more difficult problem of assigning realistic ranges and distributions to the scenario frequencies remains to be addressed. . . ." Although these authors (Ortiz et a1. 1984) agreed that this problem ". . . is one of the most difficult areas in assessing compliance with the EPA standard. . .," they are nevertheless confident that reasonable approaches are either developed or under development.

Internationally, the prospects for the formulation of a defensible methodology for assigning probability distributions to release scenarios have fared similarly. Despite a 1980 NEA workshop on the subject (NEA 1981), in 1985 the recommendation was again made to the NEA to have a workshop or form an expert group to address methodology development for radionuclide release scenario identification and screening, and the assignment of probabilities and probability distributions to release scenarios (NEA 1986). The subject continues to challenge the repository risk/performance assessment community, and some experts are pessimistic about the prospects of doing credible, technically defensible work in this area of assigning probability distributions to release scenarios, as required to show compliance with the EPA standard (Kocher et al. 1985).

The NRC recently published its proposed amendments (NRC 1986) to its final rule on the disposal of HLW and spent nuclear fuel (NRC 1983a). In these proposed amendments, which conform the NRC rule with the final F.PA standard, there is a discussion of the NRC's intent concerning the assignment of probabilities to scenarios (processes and events) resulting in releases to the accessible environment:

"The Commission [NRC] will require an extensive and thorough inves: tigation of relevant processes and events, but will require analyses of the probability and/or consequence of each only to the extent necessary to determine its contribution to the overall probability distribution. ... Generally, categories of processes and events which can be shown to have a likelihood less than one chance in 10,000 over 10,000 years, along with categories of processes and events which otherwise can be shown not to change the remaining probability distribution of cumulative release significantly, need not receive further analysis."

The likelihood of the occurrence of a process or event that could result in a significant release needs to be described in terms of a probability 
distribution. If there is no consensus on the bounds of this probability distribution, uncertainty exists. This type of uncertainty may be treated by making conservative bounding calculations according to the NRC (1986), which may mean assigning a probability at or near unity and including the process or event in the consequence probability distribution. This approach of assigning a unit probability to a scenario has been used in some of the preliminary risk assessments done to date.

\subsubsection{Monitored Retrievable Storage}

The receiving, handling, and packaging operations at the MRS facility will be very similar to the comparable operations at the potential repository. Special risk assessment features associated with these types of operations were discussed in the section on repository preclosure risk analysis and will not be repeated here. The storage phase of the MRS facility operations is the only portion that may present unique risk assessment challenges. The MRS facility will contain spent fuel in passively cooled storage containers such as drywells or casks. Analysis of the risks from the MRS facility requires consideration of events such as earthquakes that might damage the containment boundaries for a number of the storage containers at one time. Previous studies that have considered these types of accidents have made pessimistic assumptions about the damage caused by earthquakes. It is also possible that some long term degradation mechanisms may affect the fuel and the storage casks or drywells during the storage period. The storage systems are designed to prevent or inhibit known or suspected degradation mechanisms. The fuel will also be monitored to detect the onset of degradation, but the possibility that degradation might occur and initiate accident scenarios or affect the releases from accidents initiated by other sources may warrant consideration.

\subsubsection{Transportation}

The principal difficulties in transportation risk analysis arise from the fact that transportation occurs in the public domain where risk assessment variables such as population and climate, are not fixed (i.e., they vary with location). Shipping casks are loaded and unloaded at a fixed facility 
with known site parameters. However, as the cask moves along the trarisportation route, the variables that affect the frequency and consequences of transportation risks change continuously. The cask may not follow the same route each time, even between the same origin and destination. Shipments from reactors to the potential repository or MRS facility will originate from about 75 different sites. Although the routes will tend to converge in "transportation corridors" such as major interstate highways, substantial portions of each route will be unique (e.g., the routes from the reactor sites to the interstates). As the transport vehicle moves along the route, population densities, 1 and use patterns, weather parameters, traffic densities, accident frequencies, and the likelihood of encountering severe accident conditions all change. There is not sufficient data available to treat each of these variables in detail for all of the potential transportation routes. If the data were available, the calculations would be very complex and require substantial resources to perform. Analytical techniques have been developed to deal efficiently with the wide range of variables that must be treated in transportation risk studies. Detailed treatment of all the variables is generally not needed.

The large variabilities in important risk parameters and unavailability of detailed data for some of these parameters is typically dealt with by constructing average data sets. These average data sets reasonably represent the more detailed data in a form that can be readily collected and used in the analysis. This process can still produce credible results, because most risk methods use "averaging" processes in which the frequency of a given condition is used to weight it for combination with other similar conditions. However, using the "averaged" data set tends to neglect areas where important parameters that lead to higher than average risks coincide (e.g., areas where high population densities coincide with high accident rates). The DOE is currently developing the capability to perform route-specific transportation risk analyses that will account for such conditions.

Average data sets are created in a number of ways. Typically, the data needs and the available data source that most closely approximates the needed data are identified and the data that will be used to develop the data set are analyzed. These data sets usually take the form of a distribution over 
the possible range of the needed variable. The range is often divided into segments and the probability of the variable being in each segment is estimated. These probability distributions can then be used in the risk analysis to represent the variable of interest.

Population densities can be used to illustrate this process. As the transport vehicle moves along the transportation route, it passes through areas with a wide variety of population densities. One portion of the route may pass through densely populated urban areas, another portion through less densely populated suburban areas, and a large portion through sparsely populated rural areas. A transportation accident could occur at any point along the route, but the consequences would be vastly different because of the differences in the number of people exposed to a release, if one should occur. The risk analysis needs to deal with each of these potential population densities to adequataly describe the potential range of consequences from the accident. The probability of the accident occurring in each of the population zones needs to be determined also so that a probability can be associated with each of the consequence levels. There are essentially an infinite number of locations along a transportation route where an accident could take place. It is clearly not feasible to try to estimate the consequences of an accident at al1 potential accident sites. This problem can be made tractable by developing a set of poputation zones and using them to represent the actual population distribution along the route. The actual population data can be used to develop these data. The data can be divided into several representative densities and the portion of the route that passes through zones of each density category can be determined. If data is not available to estimate the frequency of accidents in each zone, accidents can be assumed to be equally likely in each zone. The consequences of an accident in each population zone can then be estimated and the fraction of the route through each zone can be used as an estimate of the probability that the accident will occur in that zone. Similar averaging processes have been used for weather conditions, accident rates, traffic densities, and 1 and use patterns. 
Another difficulty in transportation risk assessment is predicting the conditions that will be required to damage the shipping cask sufficiently to allow a release. The casks are designed to withstand very severe mechanical and thermal stresses, and thus, the probability of a release is extremely sma11. Most of the analysis that is available has been done to demonstrate that the cask will not fail in the test conditions that are required for the cask to be licensed. Little analysis or experimental data is avallable upon which to base estimates of the failure threshold of the cask in severe accident environments. Most of the accident risk assessments performed to date use simple but conservative analytical methods to estimate these thresholds. More sophisticated analytical tools are available, but they are expensive to use. Most previous studies have not had the resources available to apply these methods.

Difficulties have also been encountered in estimating the amount of spent fuel material that would be released from a cask in a severe accident. It is difficult analytically to estimate the stresses that the fuel would experience inside the cask. Little data is available to estimate the behavior of the fuel in the environments that could be experienced in a transportation accident. Some effort has been expended to develop a consensus of the technical community on spent fuel transportation accident source terms (Wilmot et a1. 1981), but most studies have used conservative estimates because of the lack of good data.

Predicting the accident forces that will be experienced by a transportation cask in an accident is also difficult. A cask will only be damaged in a very severe accident. These accidents are a very small fraction of the accidents that occur. The factors that influence the accident severity are very complex. No analytical models are available to predict when very severe accidents will take place. The only work available that describes accident environments in the engineering terms needed to predict the frequency of accidents severe enough to fail the cask is based on nationally averaged accident data and has substantial uncertainties associated with it (Dennis et al. 1978). This information does not make it possible to predict how the frequency of severe accidents will vary along a particular transportation 
C route, although it probably provides a reasonable basis for estimating risks from a large transportation fleet that includes shipments through much of the country. 


\subsection{WASTE MANAGEMENT SYSTEM DESCRIPTION}

This chapter presents a description of the waste management system that was used as the basis for this study. The description focuses on the design features of the facilities in the system that are important to safety, such as throughput rate, capacity, untt operations, and inventories of radioactive materials. The OCRWM Misston Plan (DOE 1985) and conceptual design studies form the bases for much of the information presented.

The DOE is currently considering two major potential configurations for the waste management system: systems with and without an MRS factlity. The specific capabilities of the MRS factlity are also uncertain at this time. The MRS facility options currently under consideration include a storage-only configuration, storage plus fuel consolidation, and storage plus consolidation and repository disposal packaging. Furthermore, the specific capabilities of the potential repository are also uncertain regarding whether or not to consolidate fuel at the repository. This study was completed prior to passage of the Amendments Act and also prior to completion of detalled repository design studies. The reader is therefore cautioned that the design descriptions in this section and the analyses in later chapters of this report may be inconsistent with current DOE policy regarding the MRS facility or the most recent design of the repository. However, the impacts of these uncertainties on the results and conclusions of this study will be considered in Chapters 5.0 and 6.0 .

Illustrations of the two general configurations of the commercial waste management system envisioned by the DOE are shown in Figures 3.1 and 3.2 (DOE 198 $8^{\circ}$. As shown, the system is comprised of one or more repositories (both configurations), an integral MRS facility (system with an MRS facility), and the transportation system that supports both system configurations. Although a second repository is shown on the figures, for simplicity this report focuses on the risks associated with the first repository. Material flows between the waste sources [commercial power reactors and commercial and defense high-level waste (DHLW) generators] and the DOE waste management facilities are also shown in the figures. Commercial high-level wastes (CHLW) are those that will be solldified during the West Valley 


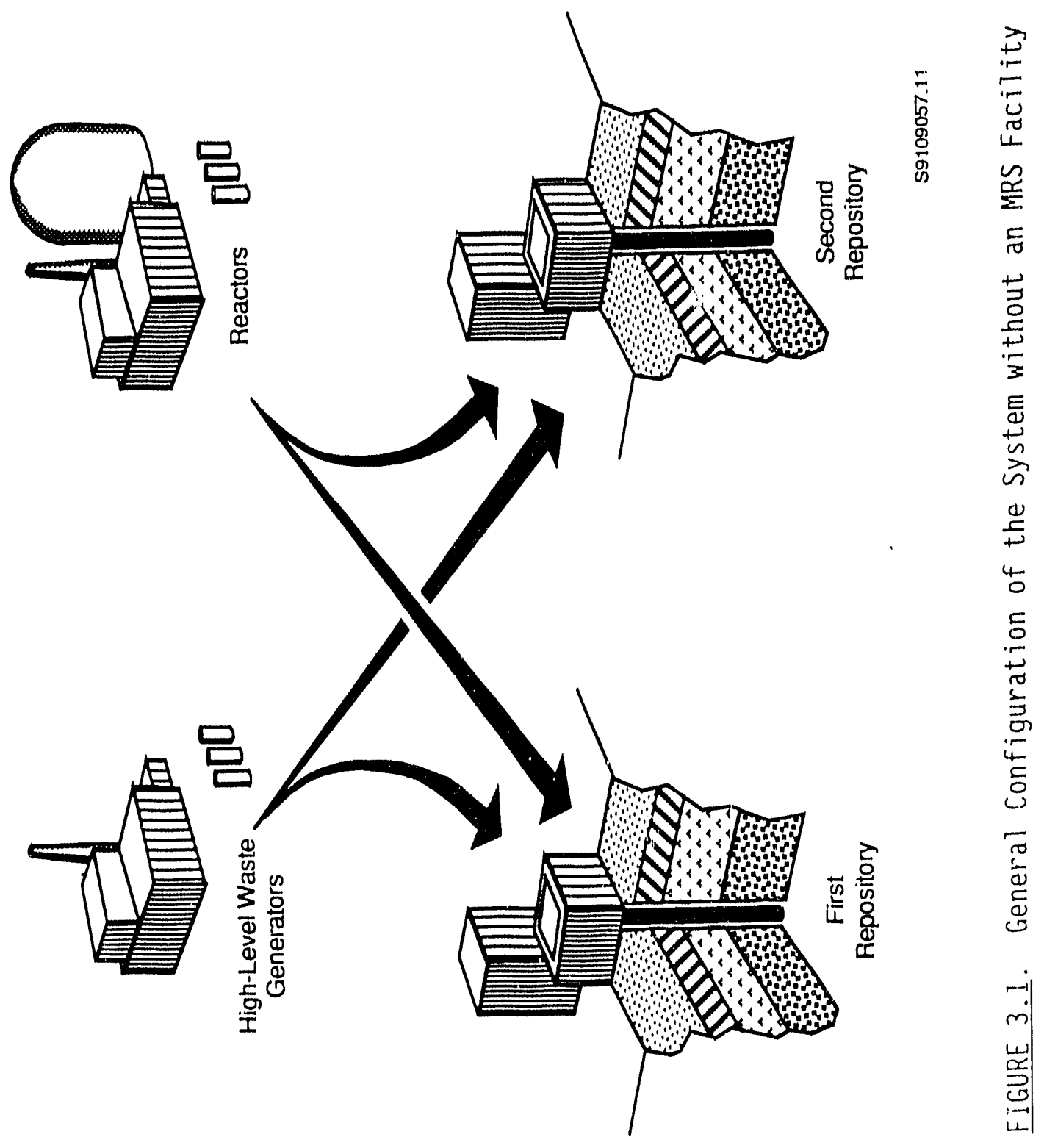




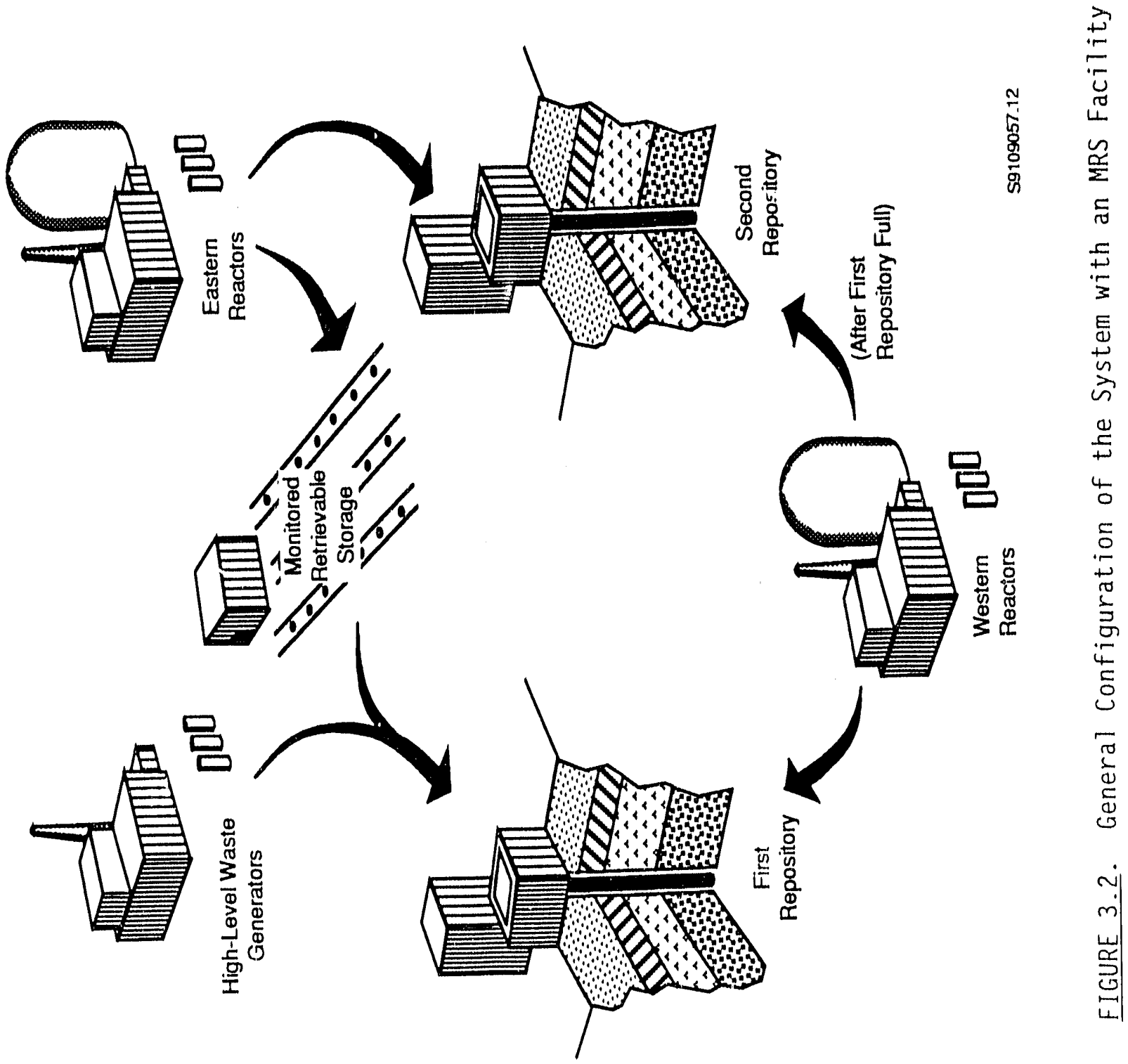


Demonstration Project. Defense high-level waste generators include the Savannah River Plant, the Idaho National Engineering Laboratory, and the Hanford Site.

The two elements that make up the system without an MRS facility are the potential repository and the transportation system. The OCRWM will take title to the waste prior to departing the gates of the generating facilities. The waste will be transported to the repository by rail or truck using specially designed, shielded transportation casks. The repository consists of a waste disposal preclosure subsystem and a waste disposal postclosure subsystem. The preclosure subsystem will prepare the waste for emplacement by consolidating the spent fuel as needed; packaging the spent fuel, DHLW, and CHLW for final disposal; and emplacing the wastes in underground rooms for permanent isolation. The postclosure system includes the engineered and geologic barriers that isolate the waste from the accessible environment for 1,000 years or more.

In the system with an MRS facility, the waste will be transported to the MRS facility and the potential repository. The majority of the spent fuel destined for the repository will be transported from the reactors to the MRS facility and then from the MRS facility to the repository. Current plans call for shipping spent fuel from nearby western reactors directly to the first repository.

At the MRS facility, spent fuel will be disassembled, and the rods will be consolidated into canisters and stored. The canistered fuel will be shipped to the repository for disposal.

This section is organized into three main sections. Section 3.1 describes the important safety-related data for the potential tuff repository. The information provided in this section includes process flows, routine emissions, throughput rate, waste disposal package characteristics, and inventories of radioactive materials at various locations within the potential tuff repository. Section 3.2 presents the same types of information for the MRS facility. The transportation system is described in 
Section 3.3. The sections on the repositories and the transportation system include discussions of differences that arise from inclusion of an MRS facility in the system.

\subsection{GENERAL DESCRIPTION OF A REPOSITORY}

The repository will have both surface and underground facilities. The surface facilities will consist of waste-handling systems and other repository support facilities. A general process flow diagram for a repository in the system without an MRS facility is shown in Figure 3.3. The wastehandling system will include facilities for receiving, packaging, storing, and transporting the waste. The waste will be received at the repository gate in rail or truck transportation casks and, after inspection and washdowns, will be moved into the hot-cell area of the waste-handling building.

In the system without an MRS facility, spent fuel will be disassembled and consolidated at the repositories prior to disposal. Fuel assemblies will be consolidated in a device that clamps the spent-fuel assemblies in position, cuts off the top and bottom fittings, rotates the assemblies to the horizontal position, grips the exposed fuel rods, and pulls them from the structural hardware. The consolidated fuel rods will then be loaded into a canister in the encapsulation (or packaging) hot cell. It is assumed that the structural hardware from the consolidation operation will be compacted and loaded into drums. These drums will be loaded into disposal canisters similar to those used for spent fuel. Some fuel assemblies will not be consolidated because of cladding or structural defects. These assemblies will be transferred to a canister in the encapsulation hot cell.

The spent fuel and HLW operations will result in production of secondary waste streams. Examples of secondary wastes include used ventilation filters, ion exchange resins from the liquid waste treatment system, contaminated failed equipment, and laboratory wastes. Other secondary wastes that would be classified as low-level wastes (LLW) will be packaged and transported offsite to a LIW disposal facility. The LLW may also be treated in some manner (e.g., compaction, incineration, etc.) prior to packaging them for transport. These wastes could also be disposed of in the underground 


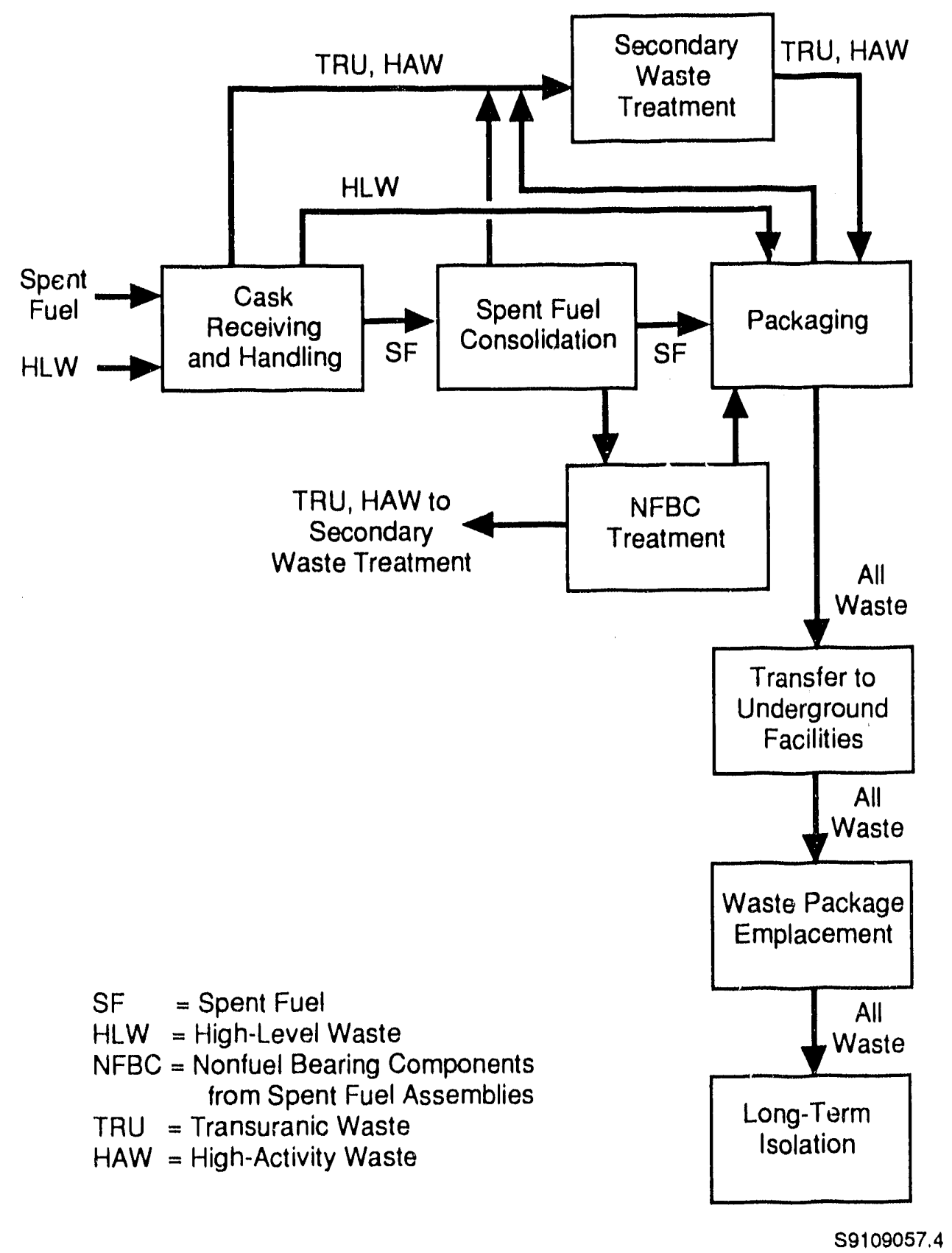

FIGURE 3.3. Block Diagram for Repositories in the System Without an MRS Facility

portion of the repository. It is presently anticipated that the highactivity wastes (HAW) that cannot be classified as LLW will be packaged and disposed of in the repository. These HAW may also be treated in some manner to reduce their volume and enhance their stability. 
It is currently planned that DHLW and CHLW will be placed in stainlesssteel canisters prior to shipment to the repository. At the potential tuff repository, the canisters will be sealed inside a thin-wall, stainless-steel container prior to emplacement. A summary of the waste package characteristics for the repository is provided in Table 3.1 for intact spent fuel (DOE 1986e) and Table 3.2 for consolidated spent fuel (DOE 1986b).

TABLE 3.1. Potential Repository Waste Package Characteristics for Intact Spent Fuel Assemblies (DOE 1986e)

\section{Waste Form}

Number of Assemblies

Thermal Output (watts) (a)

Length $(\mathrm{cm})(\mathrm{b})$

Weight $(\mathrm{kg})(\mathrm{b})$

\section{Canister}

Type

Diameter $(\mathrm{cm})$

Weight $(\mathrm{kg})(\mathrm{b})$

\section{Disposal Container}

Material

Outside Diameter (cm)

Wall Thickness (cm)

Length $(\mathrm{cm})(\mathrm{b})$

Weight Empty $(\mathrm{kg})(\mathrm{b})$

Weight Full $(\mathrm{kg})(\mathrm{b})$

\section{Packing}

Type

Min. Thickness $(\mathrm{cm})$

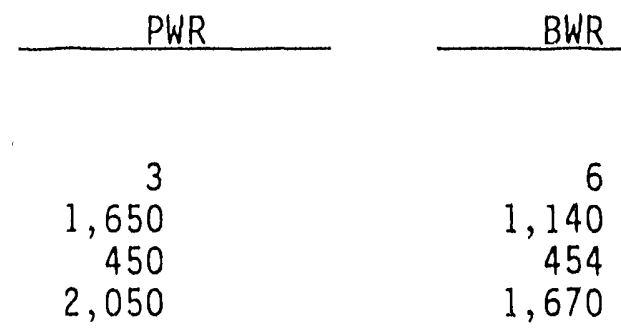

Space Frame
NS (C)
NS
NS

Space Frame

NA

NS

330

$\begin{array}{cc}\text { Stainless Steel } & \text { Stainless Stee } \\ 66.0 & 66.0 \\ 1.0 & 1.0 \\ 470.0 & 470.0 \\ 930 & 930 \\ 3,190 & 2,930\end{array}$

None

None

(a) Based on 10-year-old PWR fuel with 33,000 MWD/MTU burnup, and 10-year-old BWR fuel with 27,500 MWD/MTU burnup.

(b) Representative values only for this study. This value depends on fuel rod dimensions.

(c) NS: Not specified.

NA: Not applicable. 
TABLE 3.2. Potential Repository Waste Package Characteristics for Consolidated Spent Fuel Assemblies (DOE 1986e)

\section{Waste Form}

Number of Assemblies

Thermal Oytput

(watts) (a)

Length $(\mathrm{cm})$ (b)

Weight $(\mathrm{kg})(\mathrm{b})$

\section{Canister}

Type

Diameter $(\mathrm{cm})$

Length $(\mathrm{cm})(\mathrm{b})$
Weight $(\mathrm{kg})(\mathrm{b})$

\section{Disposal Container}

\section{Material}

Outside Diameter $(\mathrm{cm})$

Wall Thickness $(\mathrm{cm})$

Length $(\mathrm{cm})(\mathrm{b})$

Weight Empty $(\mathrm{kg})(\mathrm{b})$

Weight Full $(\mathrm{kg})(\mathrm{b})$

\section{Packing}

Type

Min. Thickness $(\mathrm{cm})$

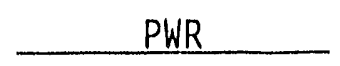

3300

385

3960

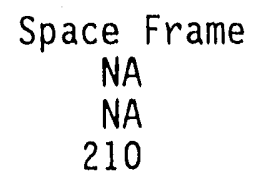
Stainless Steel
66.0
1.0
405
820
4,990

None

None

\section{BWR}

14

2660

385

3820

Space Frame

NA

NA

330

(a) Based on 10-year-old PWR fuel with 33,000 MTD/MTU burnup, and 10-year-01d BWR fuel with 27,500 MWD/MTU burnup.

(b) Representative values only for this study. This value depends on fuel rod dimensions.

Sufficient lag storage capacity will be available at the repository to accommodate peak receipt rates and potential delays in underground operations. Support facilities will include maintenance, utilities, warehousing, storage, administration, security, visitors center, personnel, training and other miscellaneous buildings. Emergency power generators, shaft-headframe structures, ventilation fans, and hoisting facilities will be provided. Access to the surface facilities will be restricted and monitoring facilities 
will be provided. Facilities for the handling and storage of mined rock and for the processing and decontamination of site-generated radioactive wastes and effluents will also be provided.

Multiple independent barriers, both natural and engineered, will be used to isolate the wastes from the environment. The three types of barriers used are classified as the natural system, the repository, and the waste package.

The natural system will consist of the geologic media that limits radionuclide transport through the geohydrologic environment to the biosphere and minimizes the potential for human interference in the future. The repository portion will consist of the underground structures and components, including engineered barriers not associated with the waste package (i.e., shaft seals, the backfill of tunnels and disposal rooms, and the host rock that supports them). The repository will be designed to mitigate the chemical and physical interactions of the waste and the geologic media.

The waste package includes the waste form and any containers, shielding, packing barriers, and other absorbent materials that separate the waste from the host rock. The waste package will be designed to provide substantially complete containment of the waste for 300 to 1,000 years. The waste package will also protect the waste from groundwater intrusion and control the release and migration of radionuclides into the host rock.

Inventories of radioactive materials at selected facility locations are presented in Table 3.3. The data presented in the table represents the maximum inventory of radionuclides that may be present at a given time. These inventories were developed from the conceptual design of the basalt repository and are representative of the potential tuff repository design. The actual inventories at plant locations for the potential tuff repository design is slightly different but are not expected to result in major differences in public and occupational risks.

Emissions of radioactive and nonradioactive effluents will occur as a result of repository operation and construction. Nonradiological effluents will include dust and pollutants generated from operation of machinery during facility construction and mining operations. Radiological effluents will consist primarily of releases of radon and its decay products (naturally 


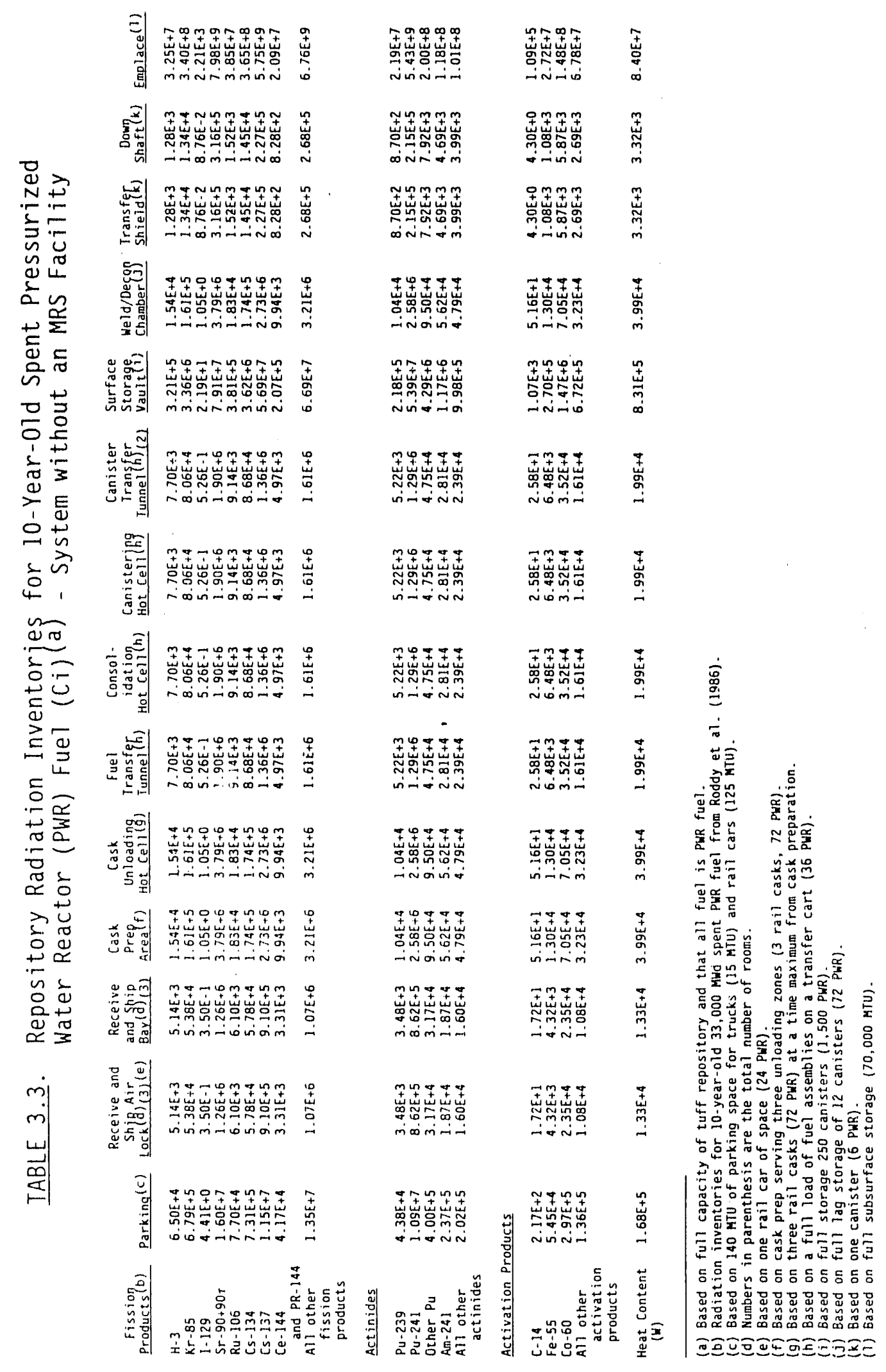


occurring in rocks) during mining operations and releases from the ventilation systems at the surface factlities during normal operations. These emissions are summarized in Table 3.4 .

Special waste handling operations will be of two types: 1) rework of waste containers and 2) performance confirmation testing. Repairs wi11 be needed for the spent fuel disposal containers of HLW overpacks that do not pass final inspection. The repair procedures will vary with the container design. TABLE 3.4. Airborne Emissions During Construction and Operation of a
Potential Repository (system without an MRS facility) (a)

Emissions

\section{Operating Phase/Material}

Construction

Carbon monoxide
Sulfur dioxide
Nitrogen oxides
Total suspended
particulates
Hydrocarbons

$\mathrm{Pb}-210$

$\mathrm{Pb}-212$

$\mathrm{Pb}-214$

Bi- 210

$\mathrm{Rn}-220$

$\mathrm{Rn}-222$

Operations

Carbon monoxide

Sulfur dioxide

Nitrogen oxides

Total suspended particulates Hydrocarbons

$H \cdot 3$

C. 14

Kr-85

$1-129$
Nonradiological Pollutants (kg/yr)

$4.4 E+3$
$1.2 E+3$
$2.3 E+4$
$1.4 E+3$
$1.6 E+3$

Radionuclide Emissions ( $\mathrm{Ci} / \mathrm{Yr}$ )

4. $T E-4$

$8.8 E-3$

5.6

5.6

5.9

5.6

Nonradiological Pollutants $(\mathrm{kg} / \mathrm{yr})$

$7.4 E+3$

$2.4 E+3$

$3.8 \mathrm{E}+4$

$3.6 E+3$

2. $7 E+3$

Radionuclide Emissions (Ci/Yr)

$2.8 E+2^{(b)}$

$1.1 E+0(b)$

$1.4 E+4(b)$

$2.8 \mathrm{E}-2$

(a) Sources: DOE 1986b, DOE 1980, and DOE 1979a.

(b) It was assumed by DOE (1986C) that virtually all of the H-3, $\mathrm{C}-14, \mathrm{Kr}-85$, and $1-129$ that will be released into the building ventilation system will be released into the surrounding environnent . 
To meet NRC regulatory requirements (NRC 1983a) the potential repository will be designed to maintain the capability to retrieve wastes for 50 years after the first waste has been emplaced. A performance confirmation program will be conducted beginning at the site characterization phase and continuing throughout the operating life of the repository and the retrievability period.

With an integral MRS facllity in the waste management system, the surface facilities of the repository will have a reduced number of functions to perform since the MRS facility will provide many of the waste handling and waste preparation functions. The principal functional difference between first potential repository designs in the systems with and without an MRS facility is in the exclusion of consolidation facilities at the potential repository in the system with an MRS facility. That function is allocated to the MRS facility. Figure 3.4 presents a block diagram for repositories in the system with an MRS facility.

The reduced functional requirements of the potential repository in the system with an MRS facility will result in reductions in the need for waste handling and support facilities. The repository, however, will maintain the capability for remedial operations on damaged waste containers and for performance confirmation testing as required to meet 1 icensing and quality assurance requirements. The principal change from the system without an MRS facility will be the enlargement of the waste handling building to accommodate receipts of spent fuel as well as nonfuel bearing hardware and other secondary wastes produced at the MRS facility. Inventories of radioactive materials at various locations in the potential tuff repository for the system with an MRS facility are presented in Table 3.5.

The waste emplacement area for the potential tuff repository (DOE 1986e) will be only 800 feet lower in elevation than the waste handling facilities on the surface. For this reason, at the tuff site a ramp rather than a vertical shaft will be used for transporting the waste underground. An artist's rendition of the surface facilities is shown in Figure 3.5 . 


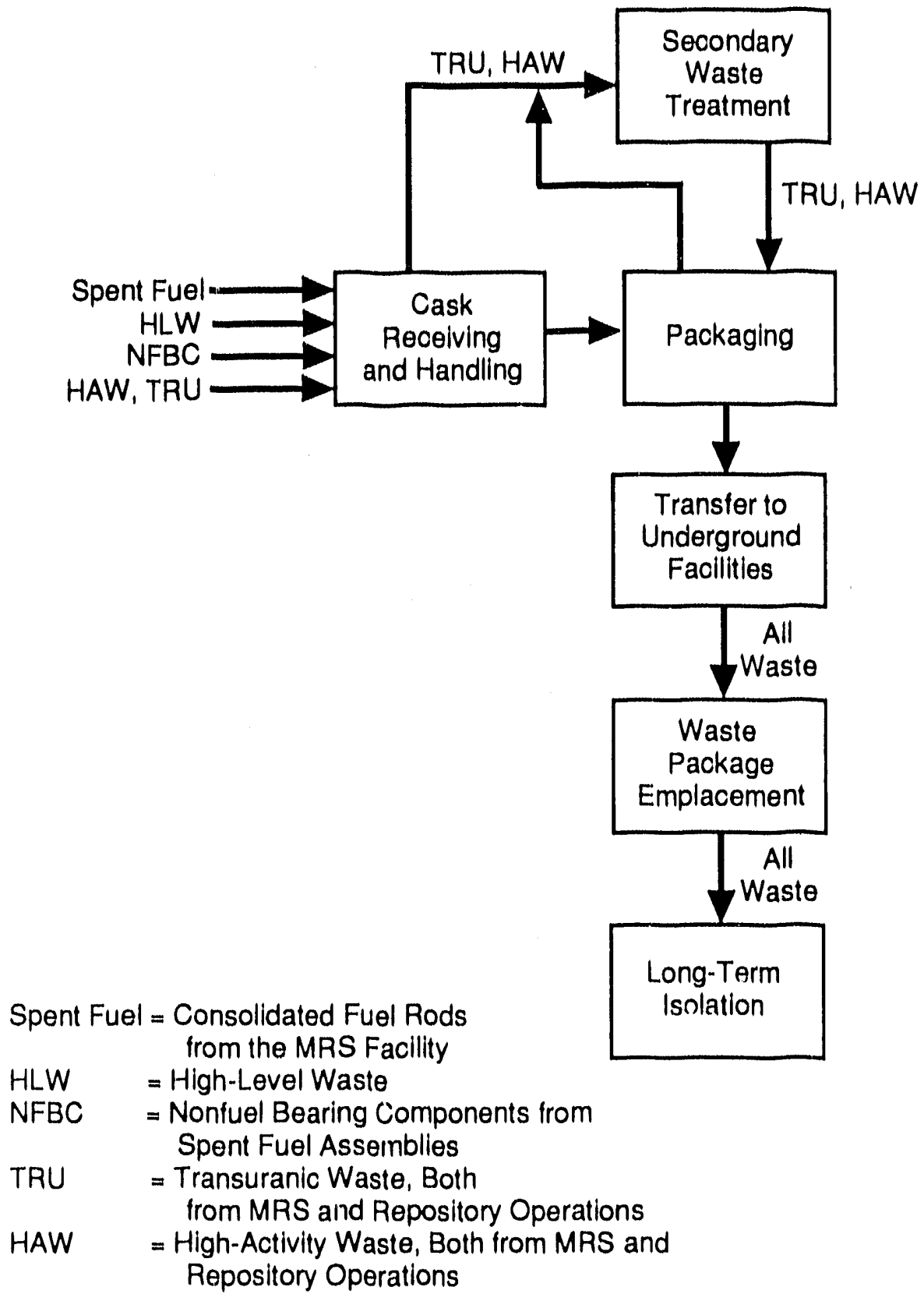

S9109057.5

FIGURE 3.4. Simplified Block Diagram for Repositories in the System with an MRS Facility 


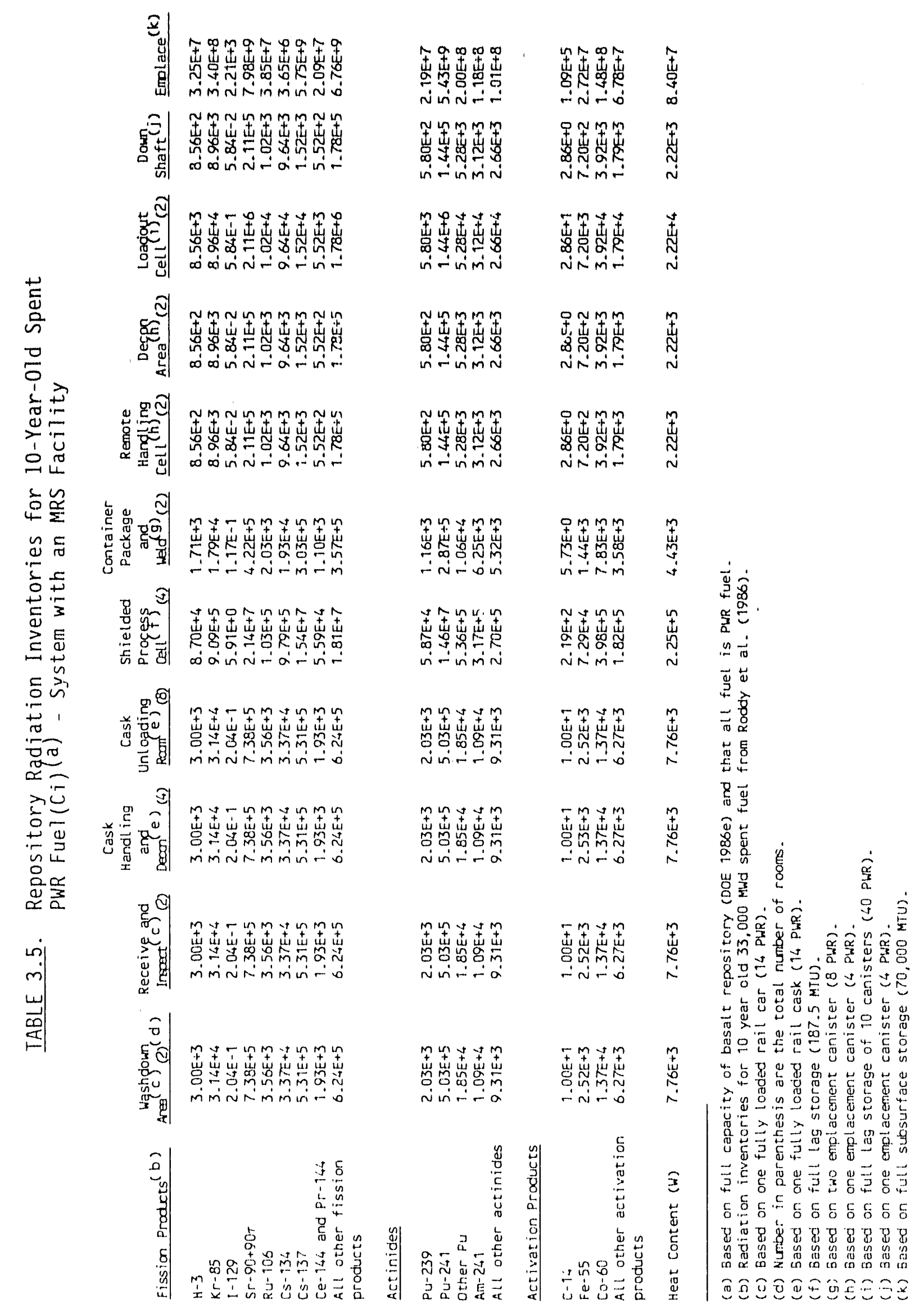

3.14 


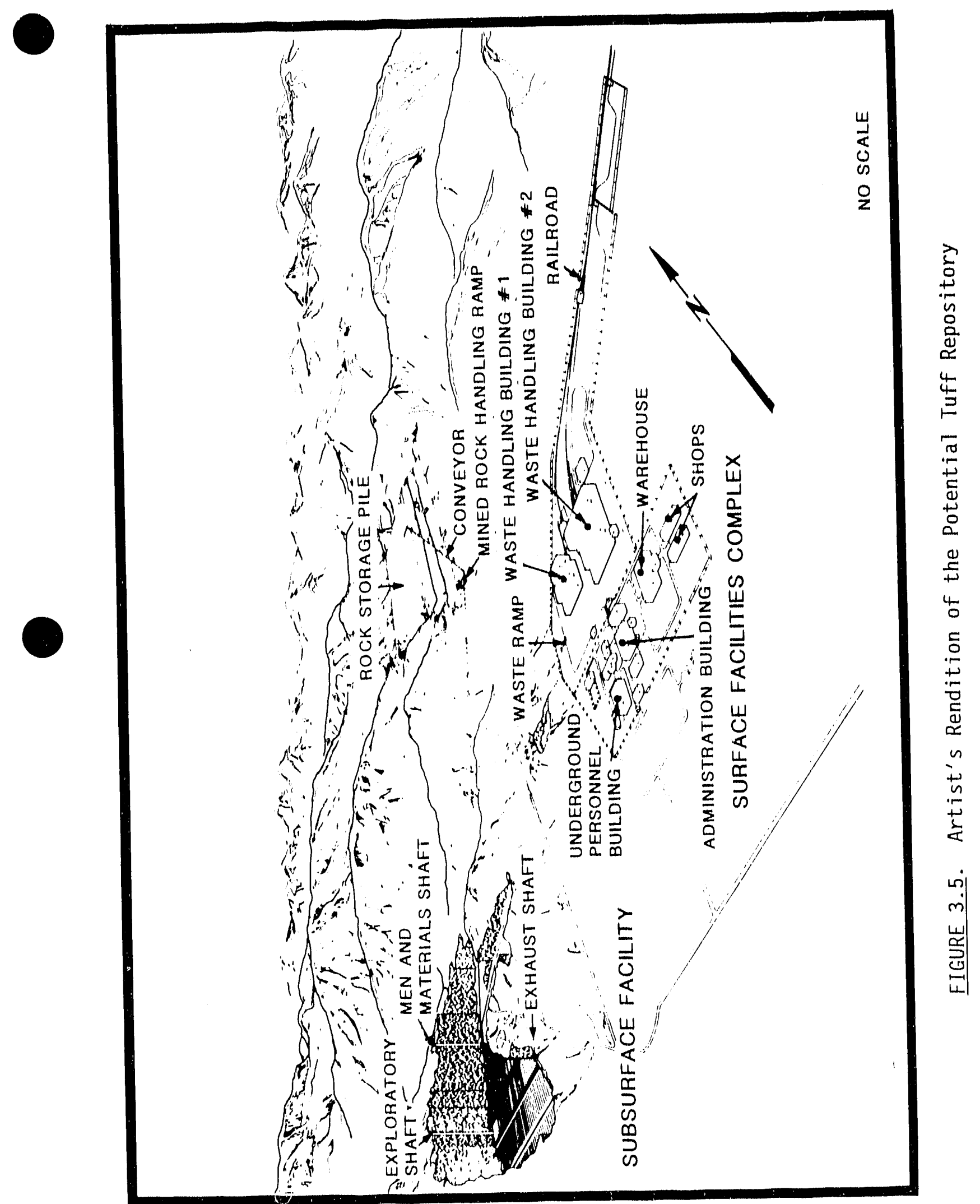


The tuff waste package will be composed of a thin-wa11, stainless-steel container with an internal spaceframe for holding spent fuel pins or assemblies and HLW containers.

Access for waste packages to the underground factlities at the potential tuff repository will be via a ramp rather than a shaft that is used at the basalt and salt repositories. A transfer cask, simflar to those used in the salt and basalt repositorles, will be driven down the ramp rather than lowered down a shaft. Emplacement activities will also be similar. At this time, both vertical and horizontal emplacement configurations are being carried along in sign process. A concrete shield plug and cover plate will be installed in each borehole.

\subsection{DESCRIPTION OF THE INTEGRAL MRS FACILITY}

The second major configuration of the waste management system wil1 include an integral MRS facility. The wastes for eventual placement in the repository will be prepared and stored at the MRS factlity until the repository is ready to receive them. The MRS facility would consist of factitities for waste receipt and storage, temporary storage of the waste and various support facilities. A simplified block diagram for the MRS facility is illustrated in Figure 3.6 .

The operational sequence for the MRS facility will begin with the arrival of waste by truck or rail in heavily shielded transportation casks. The waste will be received into the receiving-and-handling (R\&H) building, which is illustrated in Figure 3.7. Here the waste will be prepared for temporary storage at the MRS facility. Operations in the R\&H building will be performed by remote control inside "hot cells" to protect the workers from direct contact with, or exposure to, the highly radioactive materials.

Consolidation of the spent fuel rods, if consolidation is to be performed at the MRS facility, will occur while in the R\&H building. Consolidation will decrease the number of waste packages, thus increasing the efficiency of waste transportation to a repository and decreasing the amount of handling required at the repository. During consolidation, the spent fuel assemblies will first be disassembled by removing the upper and lower tie 


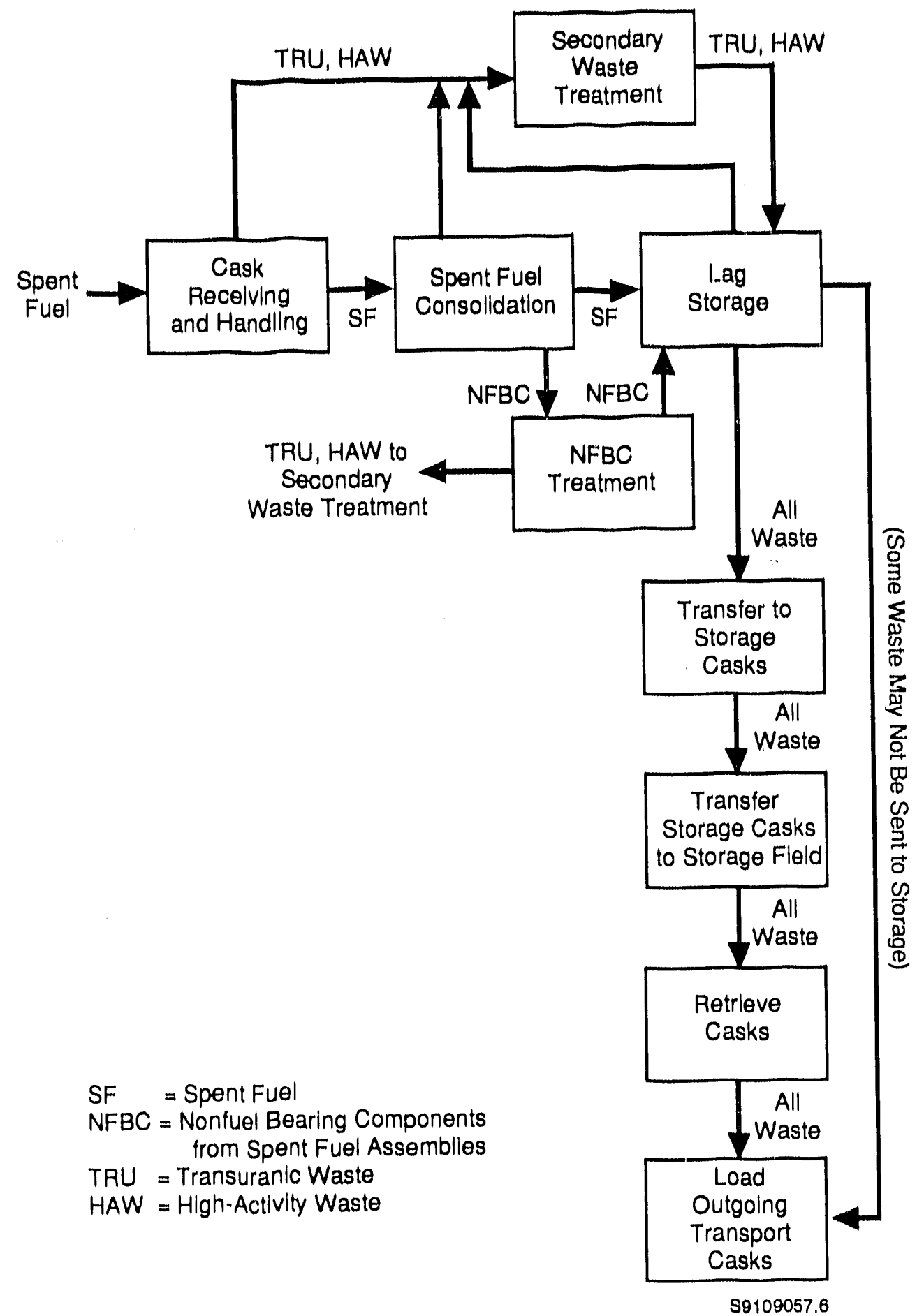

FIGURE 3.6. Simplified Block Diagram for an Integral MRS Facility 


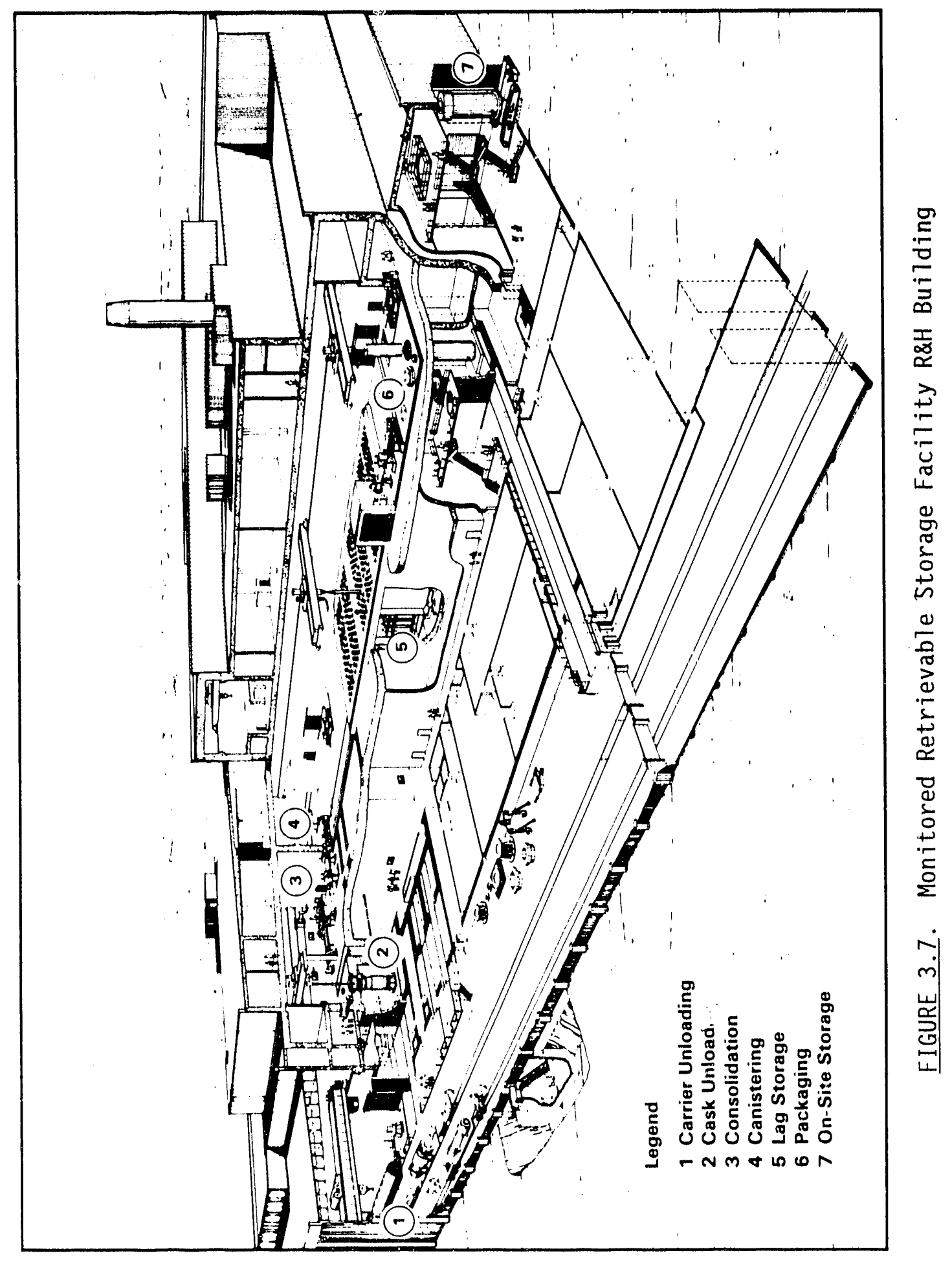

3.18 
plates, the spacer grids that separate the fuel rods, and any other structural members. The fuel rods will then be formed into a ciosely packed bundle for insertion into a canister. The nonfuel bearing scrap of the fuel assemblies will be compacted and loaded into containers for eventual shipment to a repository. Defective assemblies will not be consolidated. They will be loaded directly into canisters. Canisters used at the MRS facility are expected to be designed for efficient handling and use at the repository.

After the spent fuel rods are loaded into the canisters, the canisters will be purged of air; filled with an inert gas such as argon, helium, or nitrogen; and welded shut. The canisters would be tested for leaks and inspected for weld quality. If necessary, the exterior surfaces would be cleaned to remove any radioactive surface contamination. Loaded canisters will be placed in storage at the MRS facility or shipped directly to the repository.

Sealed concrete storage casks have been selected as the preferred method for storage of the canistered waste at an integral MRS facility. Field drywells are being considered as a design alternative. A sealed storage cask is a large steel-lined, reinforced-concrete cylinder that holds welded stainless-steel canisters of spent fuel. The cask is closed with a thick concrete shield plug and a welded steel lid. The capacity of each cask for different types of waste is provided in Table 3.6. The concrete storage cask concept is illustrated in Figure 3.8 .

Canisters or other containers of waste will be loaded into the casks inside the R\&H building, and the cask will be moved to the storage area and placed upright on a concrete pad. The heat emitted by the waste will be conducted through the walls of the cask to the surrounding atmosphere. Temperature within the cask will remain below levels that could result in damage to either the cask or the sealed canisters stored inside it. The thick walls of the cask will keep the radiation levels at the cask surfaces within safe limits.

Each storage module will be capable of being routinely monitored to detect any loss of canister integrity. In addition, the environment of the 
TABLE 3.6. Concrete Cask Contents (Parsons 1985)

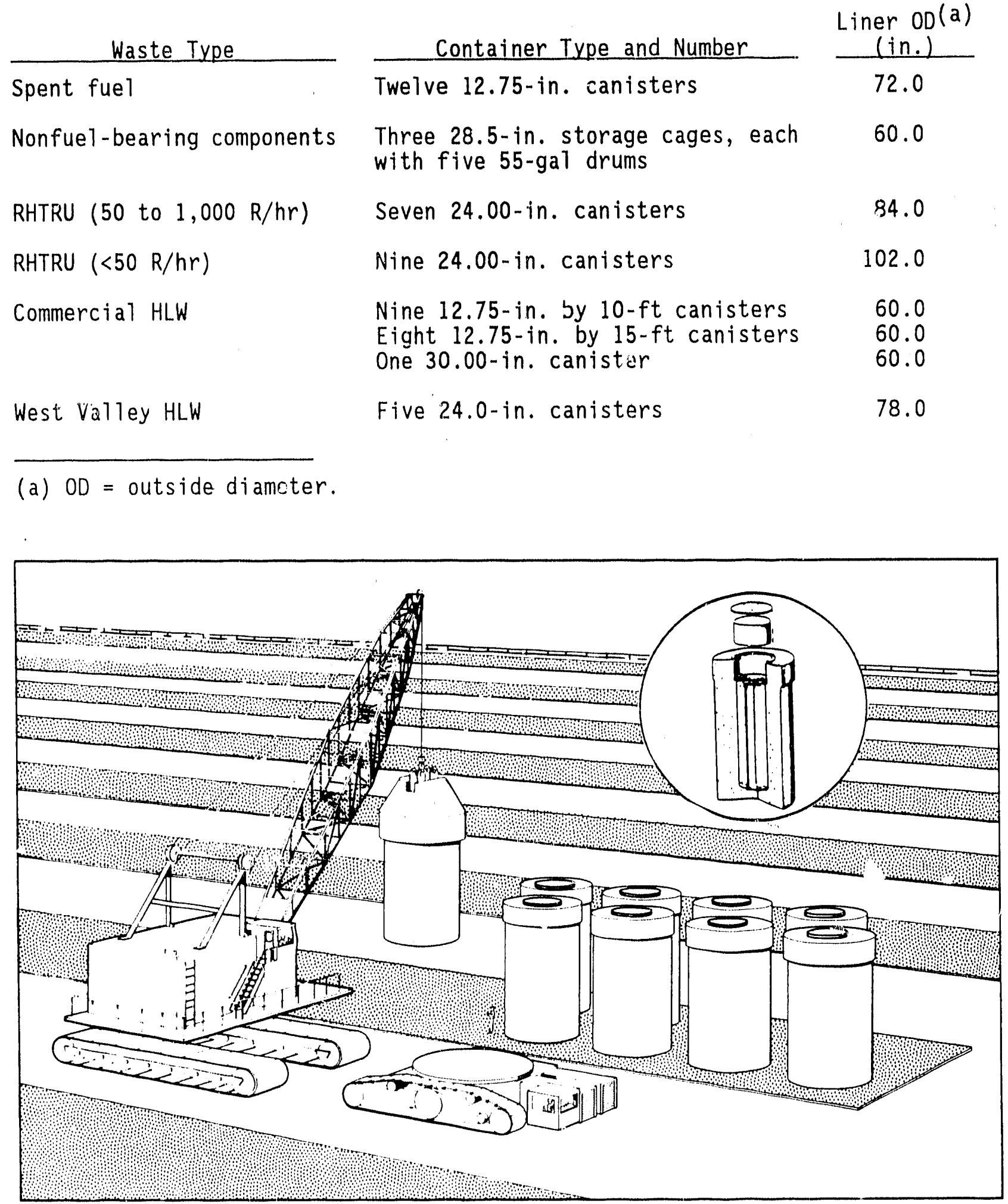

FIGURE 3.8. Concrete Storage Cask 
storage area will be continuously monitored to detect any failures in the containment of the radioaciive waste materials.

The field drywell (see rigure 3.9) will be in an inground sealed metal el.closure for storing canisters of waste. The drywells can be bored to different sizes as required to accept different sizes of canisters. The capacities of field drywells for different types of wastes are shown in Table 3.7. Nominal radionuclide inventories in a spent fuel storage cask can be found in Table 3.8 .

To load the field drywells, waste canisters would be loaded into a shielded transporter vehicle while inside the R\&H building. The transporter

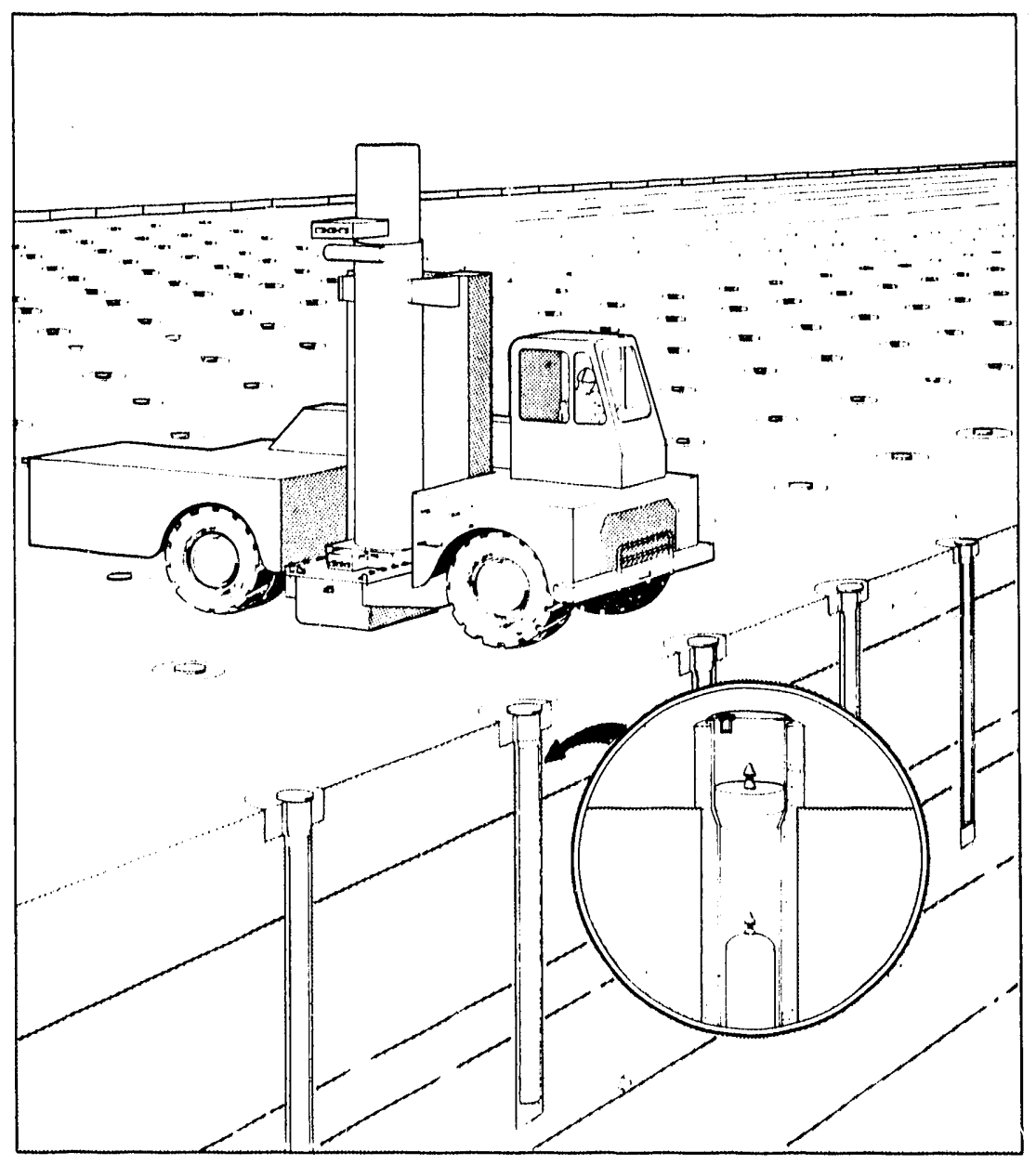

FIGURE 3.9. Field Drywell 
TABLE 3.7. Drywel1 Dimensions and Contents (Parsons 1985)

\begin{tabular}{|c|c|c|c|c|}
\hline $\begin{array}{l}\text { Liner } \\
\text { Diameter } \\
\text { (in.) }\end{array}$ & $\begin{array}{l}\text { Liner } \\
\text { Length } \\
\text { (in.) }\end{array}$ & Contents & $\begin{array}{l}\text { Container } \\
\text { OD(in.) }\end{array}$ & $\begin{array}{l}\text { Container } \\
\text { Length } \\
\text { (in.) } \\
\end{array}$ \\
\hline 16.0 & 247.0 & Spent fuel canister & 12.75 & 192.0 \\
\hline 18.0 & $\begin{array}{l}235.88 \\
181.88\end{array}$ & $\begin{array}{l}\text { Commercial HLW canister } \\
\text { Commercial HLW canister }\end{array}$ & $\begin{array}{l}12.75 \\
12.75\end{array}$ & $\begin{array}{l}180.0 \\
120.0\end{array}$ \\
\hline 30.0 & 247.0 & $\begin{array}{l}\text { Nonfuel-bearing components } \\
\text { Drum (five per package) } \\
\text { West Valley HLW canister } \\
\text { RHTRU canister or drum }\end{array}$ & $\begin{array}{l}28.50 \\
28.50\end{array}$ & 186.5 \\
\hline 36.0 & 247.0 & $\begin{array}{l}\text { Commercial HLW canister } \\
\text { Overpacked } 55 \text { gal drum } \\
\text { (five per package) }\end{array}$ & $\begin{array}{l}30.00 \\
31.50\end{array}$ & 202.5 \\
\hline
\end{tabular}

would then carry the canister/cask configuration outside the building to the drywe11, lower the canister into the drywe11, and cover it with the top shield plug. The drywell closure plate would then be welded onto the liner of the cavity. The drywell's metal cavity and the surrounding soil would provide both a radiation shield and a medium for conducting heat away from the stored materials.

Like the sealed storage cask, each drywell will be routinely monitored to detect any leakage from the stored containers. The environment of the storage area will also be monitored continuously.

Nominal inventories of radionuclides at various locations within the MRS facility are presented in Table 3.8. Radiological and nonradiological emissions are shown in Table 3.9 .

\subsection{DESCRIPTION OF THE TRANSPORTATION SYSTEM}

The waste transportation system will include the casks, transportation vehicles, and ancillary equipment that will be used to transport waste to the repository and the MRS facility.

In the system without an MRS facility, the transportation of spent fuel and solidified HLW to the repository is expected to be accomplished with 


TABLE 3.9. Routine Radiologjcal and Nonradiological Emissions from the MRS Facility (a)

\section{Material}

Nonradiological Pollutants (kg/yr)

Carbon monoxide

Sulfur oxides

Nitrogen oxides

Total suspended

Radiological Emissions ( $\mathrm{Ci} / \mathrm{yr}$ )

$\mathrm{H}-3$

$\mathrm{Kr}-85$

I- 129
Annual Release

Construction Operation

Not given (b)

Not given

Not given

$4.5 E+4$

$4.5 E+3$

$2.5 \mathrm{E}+4$

$1.6 \mathrm{E}+4$

$4.5 \mathrm{E}+3$

(a) Source: DOE 1985b.

(b) These pollutants were not considered in the MRS environmental assessment (DOE 1985b) because mobile sources are not considered in 40 CFR 51 .

legal-weight truck (LWT) and rail casks depending on the cask handling capabilities at the reactor sites.

Shipping casks for transporting spent fuel and solidified HLW are massive, heavily-shielded, thick-walled containers. A "new generation" of shipping casks will be designed and constructed over the next several years to transport fuel that has been discharged from reactors for at least 5 years (i.e., 5 -to-10-year-old fuel), compared with the much more thermally and radiologically "hot" 120-day-old fuel that the existing shipping casks are designed to transport. Conceptual designi of future rail and truck versions of spent fuel shipping casks are illustrated in Figures 3.10 and 3.11, respectively. The nominal characteristics of these casks are presented in Table 3.10. Inventories of the principal radionuclides in truck and rail shipping casks that are shown in Table 3.11. More specific cask design information will evolve during the ongoing cask procurement process.

The primary transportation links in the system with an MRS facility will be those associated with: 1) the movement of spent fuel from reactor 


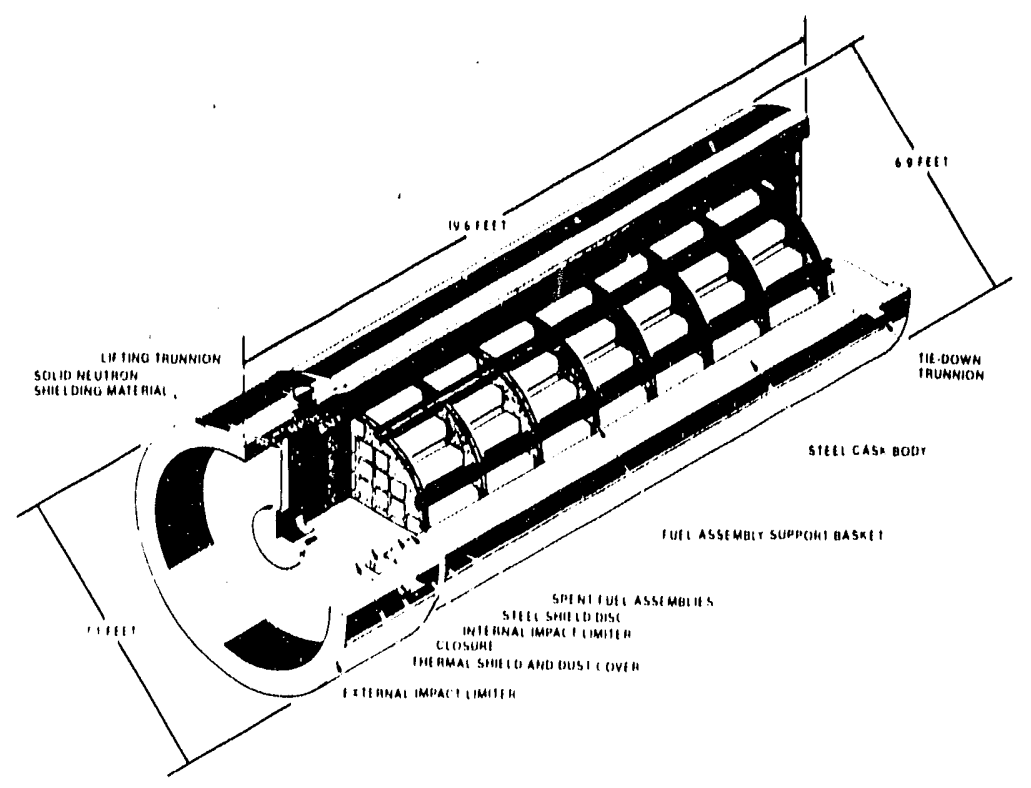

FIGURE 3,10. 100-Ton Reference Spent Fuel Transportation Cask for Shipment by Rail or Barge

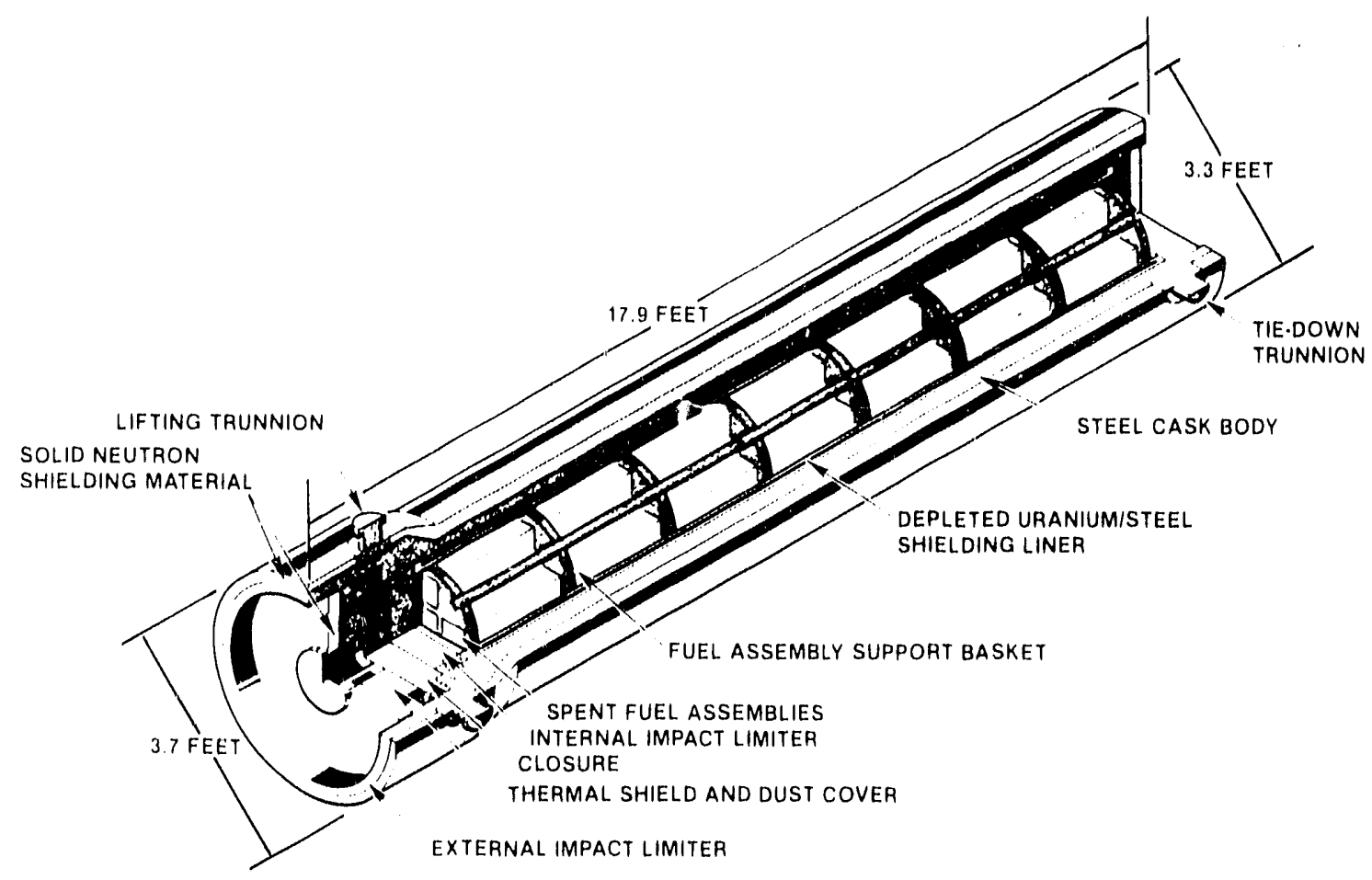

EIGURE 3.11. 40-Ton Reference Spent Fuel Transportation Cask for Shipment by Truck 
TABLE 3.10. Nominal Shipping Cask r: raiierlstics (DOE 1986a)

Legal-Weight Truck Cask Characteristics

Top OD $(\mathrm{cm})$

Overal1 Length $(\mathrm{cm})$

Empty Weight $(\mathrm{kg})$

Loaded Weight $(\mathrm{kg})$

Type of Closure

Cavity Atmosphere

Maximum Thermal Output (kW)

Outer Surface

Capacities:

Intact spent fue 1 assemblies

Consolidated fuel assemblies

Defense HLW canisters (b)
112

546

22,000

24,000

Double

Dry Gas

2.8

Smooth Steel

2 PWR or 5 BWR

4 PWR or $8 B W R(a)$

Not shipped by truck
Rail

Cask Characteristtcs

216

597

74,000

86,000

Double

Dry Gas

13

Smooth Steel

14 PWR or 36 BWR

20 PWR or 50 BWR

5

(a) Consolidated fuel rods are assumed to be packaged in square canisters.

(b) Each canister of DHLW is assumed to be the equivalent of 0.5 MTU of spent fuel. The DHLW shipping cask is 1ikely to be of a different design. The cask characteristics listed in the table approximate the design parameters of a DHLW shipping cask.

sites to the MRS facility and 2) the shipment of consolidated fuel rods and associated waste products from the MRS facility to a repository. Shipments of spent fuel from the reactors to the MRS facility will be made by both rail and truck. Spent fuel shipments between the MRS facility and the first repository will be made using multiple rail-car dedicated trains. Dedicated trains are assumed to consist of five cask cars. The dedicated train will carry no other freight. Commercial high-level waste will be transported by rail and truck. A common transportation system has been assumed for DHLW. It is assumed that DHLW will be transported by rail to both repositories. Defense Waste Processing Facility (DWPF) DHLW may be added to trains carrying spent fuel leaving from the MRS facility to the first repository. However, the DHLW would not go to the MRS facility fur storage or preparation. All of the shipping casks will be similar to those illustrated previously in 
TABLE 3.11. Radionuclide Inventories in Truck and Rait Shipping Casks (a)

\section{Fisston Products}

$\mathrm{H}-3$

$\mathrm{Kr}-85$

I -129

Sr-90+Y-90

Ru- 106

Cs -134

Cs -137

Ce-144+Pr-144

A11 other FPs

\section{Actinides}

$4.3 E+2$

$4.4 E+3$

$2.9 E-2$

$1.1 E+5$

$5.1 E+2$

$4.9 E+3$

$7.6 \mathrm{E}+4$

$2.7 E+2$

$8.9 E+4$
Rat1 Cask (Ci) (b)

$3.0 E+3$

$3.1 \mathrm{E}+4$

2. $0 E-1$

$7.4 E+5$

$3.6 \mathrm{E}+3$

$3.4 E+4$

$5.3 E+5$

$1.9 \mathrm{E}+3$

$6.2 E+5$

$\begin{array}{llr}\text { Pu-239 } & 2.9 E+2 & 2.0 E+3 \\ \text { Pu-241 } & 7.1 E+4 & 5.0 E+5 \\ \text { Other Pu } & 2.7 E+3 & 1.9 E+4 \\ \text { AM-241 } & 1.6 E+3 & 1.1 E+4 \\ \text { A11 other Actinides } & 1.3 E+3 & 9.3 E+3\end{array}$

Activation Products (AP)

$\begin{array}{lll}C-14 & 1.4 & 1.0 \mathrm{E}+1 \\ \mathrm{Fe}-55 & 3.6 \mathrm{E}+3 & 2.5 \mathrm{E}+3 \\ \text { Co-60 } & 2.0 \mathrm{E}+3 & 1.4 \mathrm{E}+4 \\ \text { A11 other APs } & 9.0 \mathrm{E}+2 & 6.3 \mathrm{E}+3 \\ \text { Heat Output (W) } & 1.1 \mathrm{E}+3 & 7.8 \mathrm{E}+3\end{array}$

(a) Inventories assume 10-year-01d fue1, 33,000 MWd/MTU exposure, (Roddy et al. 1986).

(b) Assumes shipment from reactors of intact fuel. To estimate inventories assuming fue 1 is consolidated at reactors, multiply inventories by ratios of cask capacities given in Table 3.10.

Figures 3.10 and 3.11 . The nominal characteristics of the shipping casks presented in Table 3.5 are also generally applicable to the transportation system in the MRS system configuration, with the exception of the capacities of the MRS-to-repository shipping casks. The capacities of the casks used in the system with an MRS facility are presented in Table 3.12. Radionuclide 
inventortes for these casks can be estimated by multiplying the inventories given in Table 3.11 by the ratio of the cask capacities given in Table 3.12 to those in Table 3.10.

TABLE 3.12. Transportation Cask Capacities in the System with an MRS Facility (DOE 1986a)

Truck (from reactors)

Rail (from reactors)

Rail (spent fuel from MRS facility)

- To Potential Basalt Repository

- To Potential Salt Repository

- To Potential Tuff Repository

Rail (from MRS facility)

Hardware and High Activity Waste

Contact-Handled Transuranic Waste

Rai1 (DHLW)
Number of

Assemblies

PWR BWR

25

$14 \quad 36$

$48 \quad 99 \quad \ldots$

$36 \quad 90 \quad \ldots$

$24 \quad 56$

20 drums

72 drums

5 canisters 


\subsection{LITERATURE REVIEW}

This chapter provides a review and evaluation of selected 1tterature (e.g., speeches, articles, reports, books, etc.) that address the risks in the vartous portions of the waste management system. The documents reviewed were selected from a comprehensive, relevant 1ist of 1 tterature developed in two related programs at Brookhaven National Laboratory (BNL) and Paciffc Northwest Laboratory (PNL). The following criteria were used to select the documents that were reviewed in detail in this study:

- The publication contained results that could be used to develop the waste system risk estimates presented in Chapter 5.0.

- The work represented a substantial contribution to the waste management risk 1tterature.

- The publication was the principal reference for the work. Papers or other documents based on a major work were not reviewed.

- The work represented the current state of the art. For example, earlier work by the same authors was not included, nor was earlier work by other authors that led to the most recent methods or applications.

The discussion in this chapter provides a brief overview of the documents that were selected for review and an evaluation of the applicability of the work in the document to meet the needs of the OCRWM. Risk information is useful for a number of potential applications. These applications include addressing safety concerns of the states, affected Indian tribes, the Congress, and the public; program management decisions on allocation of resources; development of designs for the facilities and the transportation system; and interactions with regulatory agencies. The review focused on the methods and data that were used. Areas in which the methods would not be expected to provide useful information for OCRWM are identified, and areas in which better data are needed are pointed out. Major results potentially applicable to the development of the risk estimates in Chapter 5.0 are also summarized. It should be noted that this evaluation is not intended to reflect on the technical quality of the work reviewed. In all cases, the publications did a credible job of addressing the objectives identified for the studies. None of the available studies was aimed at the broad range of 
OCRWM uses for risk assessment information. Evaluation of these studies relative to OCRWM uses was intended to provide some basic information to help plan future risk assessment work.

The 1iterature review is arranged by major factilty in the waste management system. A separate section is provided for literature on the risks assoctated with the preclosure and postclosure phases of the potential repository, the MRS facility, and the transportation system. The risk estimates provided in the reviewed documents were the basis for the waste management system risk estimates presented in Chapter 5.0. In many cases, there were a number of estimates avallable in the literature for a given risk category. Reported risk estimates may differ widely because of differences in methods, assumptions, reference factlities, or data. In those cases, it was necessary to select the estimate or estimates that most closely met the objectives of this study. The rationale for selecting the sources that form the basis for the risk estimates provided in chapter 5.0 is presented. This discussion follows the section that provides the literature review and evaluation for each of the facilities in the waste management system.

A set of qualitative criteria were developed to assist in the selection of the documents that would be used as the basis for the estimates presented in chapter 5.0. These criteria are summarized in Table 4.1. The criteria were used as a guide in selecting the most appropriate references for use in the remainder of the study. The criteria are listed in their approximate order of importance. Because each of the studies presented in the reference documents was performed for a specific purpose that is different from the objectives established for this study, none of the references met all of the criteria. Selection of the most appropriate reference was, therefore, not always straightforward. Documents dealing with the same risk category often exnibited mixed performance against the criteria, with one document receiving a high rating based on some of the criteria and another document receiving a high rating based on other criteria. For example, one document might contain risk results for a system that is very similar to the system configuration being used as the basis for this study, but might use worst-case assumptions and only deal with some of the applicable accident scenarios. Another document might perform a comprehensive assessment of the applicable 
TABLE 4.1. Criterta Used to Select References Used to Develop Risk Estimates

\section{Criteria}

1. Present risk or dose results

2. Credibility

2a. Technical Accuracy

2b. Realism

2c. Modeling Sufficiency

3. Applicability

4. Comprehensiveness
Definition

1. Documents are preferred that present estimates of health effects or radiation doses and assoctated probabil. ittes. If this information is avallable, this criterta eliminates other documents that are 1 imited to source-term estimates, accident scenarto definitions, and methodology development activities.

2a. Documentation of calculations and assumptions was clear and thorough.

- Document was internally consistent.

- Document was consistent with references.

- Computation results were consistent with methods and data.

2b. - Degree to which assumptions are based on actual data, experimental results, and historical experience

- Degree of realism in assumptions

2c. - The models used match the physical system, data, assumptions, and desired types of output.

3. Degree to which the bases/assumptions match the OCRWM system; examples include through-put rate, capacity, fuel age and burnup assumptions

4. Degree to which important risk parameters were addressed (e.g., worse-case accident analysis versus thorough identification and evaluation of accident scenarios; generic versus site-specific consequence analyses). 
scenarios, but be based on a very different configuration of the waste system. In those cases, the judgment of the project staff was used to select the reference that most closely met the study objectives. When there was no clear "best" reference, a range of values was selected.

\subsection{REPOSITORY PRECLOSURE}

This section discusses the literature that contains information on the potential risks that would result from the preclosure phases of the repository. Preclosure includes construction, operation, decommissioning, and retrieval activities at a potential repository. Posiclosure risk literature is discussed in Section 4.2. Where possible, risk and safaty information are discussed separately for repositories in the three geologic media that were considered for the first repository. Most of the information on the safety and risk of the geologic repositories has been developed over the last 10 to 15 years.

\subsubsection{Review of the Repository Preclosure Risk Literature}

A brief overview of the objective, scope, bases, and results is presented in this section for each document reviewed. A brief evaluation of each document is also provided. The evaluation basically describes the applicability of each document to OCRWM's needs for risk information on the preclosure phases of repositories, and its development was guided by the qualitative criteria shown previously in Table 4.1. The results available from different sources are compared in Section 4.1.2. The rationale is also presented for selecting the documents that ars used in Section 5.2 to develop estimates of potential repository preclosure risks.

\subsubsection{Generic Environmental Impact Statement}

The Generic Er.vironmental Impact Statement, Management of Commercially Generated Radioactive Waste (DOE 1980), known as as the GEIS, was issued as a basis for a reexamination of the strategy for disposing of HLW in a mined geologic repository. The GEIS depended in large measure on two supporting documents: Technology for Commercial Radioactive Waste Management (DCIE 1979a) and Environmental Aspects of Commercial Radioactive Waste Management 
(DOE 1979b). This section summarizes those parts of the GEIS and supporting documents that address repository preclosure risks.

The GEIS presented estimates of radiological and nonradiological exposures from routine emissions and accidents for managing radioactive wastes from several alternative configurations of the nuclear fuel cycle. The discussion here will address only the once-through fuel cycle option in which spent fuel is disposed of as waste. Construction (mining), transportation, operations, and decommissioning of conceptual facilities are included. The risk categories analyzed in the GEIS included:

- nonradiological accidents to the work force

- routine and accidentat radiation exposure to the work force

- annual and 70-year radiation dose commitments to the maximally exposed individual in the general public from potential worst-case accidents

- 70-year regional and world-wide population radiation dose commitments from routine emissions.

Example repositories located in salt. granite, shale, and basalt were analyzed at a "reference" location in a midwestern state. A potential repository in tuff was not analyzed. Accident scenarios and routine emissions were described by DOE (1979b); analyses of accidents and dose calculations were also provided by DOE (1979a).

The example repositories in the GEIS had the following capacities (in cnousands of canisters):

\begin{tabular}{|c|c|c|c|c|c|}
\hline $\begin{array}{l}\text { Geologic } \\
\text { Medium }\end{array}$ & $\begin{array}{l}\text { PWR Spent } \\
\text { Canisters } \\
\end{array}$ & $\begin{array}{l}\text { Fuel } \\
\text { MTU }\end{array}$ & $\begin{array}{l}\text { BWR Spent } \\
\text { Canisters }\end{array}$ & $\begin{array}{l}\text { Fue } 1 \\
\text { MTU }\end{array}$ & $\begin{array}{l}\text { Total } \\
\text { MTU } \\
\end{array}$ \\
\hline Salt & 68.2 & 31.5 & 104.0 & 19.6 & 51.1 \\
\hline Granite & 162.7 & 75.1 & 246.3 & 46.5 & 121.6 \\
\hline Shale & 86.3 & 39.8 & 131.0 & 24.7 & 64.5 \\
\hline Basalt & 162.7 & 75.1 & 246.3 & 46.5 & 121.6 \\
\hline
\end{tabular}

Radiation doses to the refional population from chronic radiological releases to the atmosphere were estimated using a Gaussian dispersion model 
(S1ade et a1. 1968). For accidental releases, external radiation doses were calculated using SUBDOSA (Strenge at a1. 1975) and the spatial distribution determined by methods of Slade et a1. (1968) using the code XOQDOQ (Sagendorff and Goll 1977) for a semi-infinite cloud. The annual meteorological conditions assumed were for a reference location in a midwestern state, including joint frequency of occurrence of wind speed, wind direction, and atmospheric stability.

The regional area was assumed to be mainly rural with 1 and used for farming. Population within 1-kilometer radius was assumed to be about 12,000 persons and within an 80 -kilometer radius about 2 milition persons, of which about $93 \%$ resided in a metropolitan area located 50 -kilometers from the site. Worldwide population was assumed to be $6.3 E+9$ persons in the year 2000 with an annual growth rate of $1.9 \%$. These assumptions are not applicable to Yucca Mountain.

To convert radiation doses to this population to health effects, it was assumed that 1.0 million person-rem of external whole body radiation exposure resulted in 50 to 500 fatal cancers and 50 to 300 serious genetic effects for a total of 100 to 800 latent health effects (LHE) per million person-rem. This assumption was based on a review of The Effects on Populations of Exposure to Low Levels of Ionizing Radiation (the BEIR report; NAS-NRC 1972), the Reactor Safety Study: An Assessment of Accident Risks in the U.S. Commercial Nuclear Power Plants (NRC 1975), and other reports.

Routine radiological releases during construction consist of naturally occurring radon and radon decay products from mining spoils. Table 4.2 shows the exposures estimated for repositories in four media.

A total of 207 possible types of accidents were identified, of which 116 had the potential for offsite releases of radioactive material. Forty-six releases were analyzed for environmental effects. For once-through-fuel-cycle repositories, 3 minor, 3 moderate, and 8 nondesign basis accidents were postulated, for which 7 had "umbrella source terms." An expected frequency was presented for these source terms, but there were no detailed probabilistic analyses. Not all accident assessments were carried out to calculation of human exposures. 
TABLE 4.2. Estimated 70-Year Population and Worker Exposures for Potential Repository Construction

\begin{tabular}{|c|c|c|c|}
\hline $\begin{array}{l}\text { Geologic } \\
\text { Medium }\end{array}$ & $\begin{array}{c}\text { Worker } \\
\text { Exposures } \\
\text { (person-rem) }\end{array}$ & $\begin{array}{c}\text { Maximum } \\
\text { Individual } \\
\text { Exposures } \\
\text { (rem) }\end{array}$ & $\begin{array}{l}80-\mathrm{km} \\
\text { Population } \\
\text { Exposures } \\
\text { (person-rem) }\end{array}$ \\
\hline Salt & $1.8 \mathrm{E}-1$ & $2.8 E-8$ & $6.8 E-3$ \\
\hline Granite & $5.0 E+3$ & $4.1 E-4$ & $1.0 E+2$ \\
\hline Basalt & $6.2 E+3$ & $5.9 E-5$ & $1.5 \mathrm{E}+1$ \\
\hline Shale & $1.9 E+3$ & $1.5 E-4$ & $3.8 E+1$ \\
\hline
\end{tabular}

Where possible, accident frequency estimates were based on previous experience with similar equipment. Engineering judgment based on review of conceptual designs was used in the remaining estimates. Frequency values were order-of-magnitude estimates believed to be an upper limit. They were acknowledged to have "substantial" uncertainty since accident frequencies are sensitive to the type, manufacture, installation, and operation of equipment.

Dropping a spent fuel canister down the repository mine shaft was identified as the most serious "moderate" radiological accident. This accident has been considered in several subsequent risk analyses. In this case, the radionuclide release source term was estimated to be as follows:

\begin{tabular}{|c|c|c|c|}
\hline Radionuclide & Curies Released & Radionuclide & Curies Released \\
\hline$H-3$ & $1.7 \mathrm{E}+2$ & $P u-238$ & $3.9 E-6$ \\
\hline$C-14$ & $2.0 \mathrm{E}-1$ & Pu-239 & $5.2 E-7$ \\
\hline $\mathrm{Kr}-85$ & $3.6 E+3$ & $\mathrm{Pu}-240$ & $8.4 E-7$ \\
\hline Sr-90 & $1.1 E-4$ & $P u-241$ & $1.6 E-4$ \\
\hline$Y-90$ & $1.1 E-4$ & $A m-241$ & $2.0 E-6$ \\
\hline$I-129$ & $1.8 E-2$ & $\mathrm{Cm}-241$ & $1.8 E-6$ \\
\hline Cs -1.37 & $1.5 E-4$ & & \\
\hline
\end{tabular}

Material released in the mine shaft was assumed to pass through a roughing filter and two high-efficiency-particulate-air (HEPA) filters before venting to the atmosphere through a 110-meter stack; the total decontamination factor 
for particulates was $1.0 E+7$. The estimated frequency of this accident was $1.0 \mathrm{E}-5 / \mathrm{yr}$, and the maximum individual dose expected was $1.1 \mathrm{E}-4$ rem.

Routine radiological releases from preclosure repository operations were assumed to consist of additional releases of natural radon and radon decay products plus a small quantity of radionuclides released from canister failures (minor canister failures were considered to be routine events). The total 80-kilometer population dose was considered negligible. Estimated routine doses to the work force during operation are shown in Table 4.3.

The study concluded that radiological aspects of repository construction, operations, and decommissioning, including reasonably foreseeable accidents, would not constitute a significant impact on public health and safety.

Nonradiological accidents were estimated based on an injury rate of 13.6 disabling injuries and 0.17 fatalities per million hours of construction on surface facilities and 25 disabling injuries and 0.53 fatalities per million hours of subsurface construction. Estimated nonradiological injuries and fatalities for construction of the example repositories are presented in Table 4.4 .

\section{Evaluation}

The exposure assessments in the GEIS and its supporting documents represented the state of the art when the report was written. The evaluation of accident and routine release scenarios remained important inputs to more

TABLE 4.3. Estimated Routine Doses to Work Force During Repository Operation (DOE 1979b)

$\begin{array}{lr}\begin{array}{l}\text { Geologic } \\ \text { Medium }\end{array} & \begin{array}{r}\text { 70-Year Tot } \\ \text { Dose (perso }\end{array} \\ \text { Salt } & 4.3 E+3 \\ \text { Granite } & 1.1 E+4 \\ \text { Basalt } & 5.6 E+3 \\ \text { Shale } & 1.1 E+4\end{array}$


IABLE 4.4. Nonradiological Disabling Injuries and Fatalities During Repository Construction (DOE 1979b)

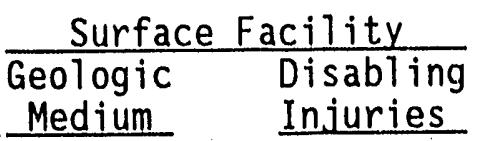

Salt

Granite

Basalt

Shale
70

70

70

70
Fatalities

1

1

1

1
Undergr Injuries

370

1400

1700

580
8

30

37

12

recent assessments throughout the radioactive waste disposal system. Public, maximally exposed individual, and worker exposures were estimated for releases from normal operations, but only maximally exposed individual exposures are estimated for preclosure accidents. No regional population doses were estimated from preclosure accidents. Thus, the accident results are not useful for this study. There is much useful information, however, such as radioactive emissions from construction, release source terms for accidents, ventilation system efficiency, and nonradiological fatalities and injuries. This information is useful to the present study, even though the facility designs and the configuration of the waste management system have changed significantly since the GEIS was prepared.

\subsubsection{Spent Fuel Disposal Options Study}

This report (Bechtel 1979) was the final product of a Spent Fuel Disposal Options Study that was conducted by the DOE National Haste Terminal Storage Program. It was part of the background documentation for the section of the GEIS that dealt with predisposal systems. The report considered three cases (options) for predisposal treatment of spent fue1:

- Case 1. Simple encapsulation and disposal of spent fuel after storage at an away-from reactor storage facility (AFR) for 9 years.

- Case 2. Encapsulation of fuel, end fittings, and secondary wastes after chopping the fuel bundle and removal of volatile materials. 
- Case 3. Encapsulation of fuel, end fittings, and secondary wastes after chopping, removal of volatile materials, calcination, and vitrification.

The scenarios assumed a spent fuel throughput of 5,000 MTU/year. Spent fuel that had cooled for 1 year was shipped to an AFR storage facility and stored for about 9 years. It was then transported to a processing and encapsulation facility, where one of the three options was exercised. Uranium hexafluoride and plutonium oxides were recycled, LLW was buried, and the encapsulated processed fuel was placed in a 2,000-acre, 2,000-foot-deep salt repository. A reference case involving storage of 10-year-old vitrified HLW was used for comparison. Variations in canister and repository design were considered, and several facility collocation options were discussed. No probabilistic assessments were made for the preclosure stage.

Repository operations were assessed for both immediate and long-term technology and hazards. Only the assessments of immediate hazards are discussed here.

Estimates of public and occupational doses from normal operations and accidents (Tables 4.5 and 4.6) were developed from preliminary safety studies of the Waste Isolation Pilot Plant (WIPP; Duncan 1979) and the Exxon Nuclear Fuel Recovery and Recycling Center Preliminary Safety Analys is Report (Exxon 1977), respectively. Some proportioning and engineering judgement were applied to normalize the estimates to a common basis. An accident consequence assessment was presented for a canister drop down the repository shaft for each case. Estimated frequencies and source terms were not specified.

Estimates of occupational doses from routine operations and accidents during repository decommissioning and retrieval operations were also presented by Bechtel (1979). Again, these estimates were based entirely on other studies, with some proportioning and engineering judgement applied to normalize the estimates to a common basis. The occupational exposures reported by Bechtel (1979) for a 5,000 MTU/yr repository facility are shown in Table 4.7 . 
TABLE 4.5. Occupational Dose During Normal Operation and from a Shaft Drop Accident (Bechtel 1979)

\begin{tabular}{|c|c|c|c|}
\hline Scenario & $\begin{array}{l}\text { Number of } \\
\text { Persons } \\
\text { Involved } \\
\end{array}$ & $\begin{array}{l}\text { Average Annual } \\
\text { Dose (rem/yr) }\end{array}$ & $\begin{array}{c}\text { Total Dose } \\
\text { (person-rem/yr) }\end{array}$ \\
\hline $\begin{array}{l}\text { Reference Case } \\
\text { - Normal Operation } \\
\text { - Accident }\end{array}$ & $\begin{array}{r}1,000 \\
300\end{array}$ & $\begin{array}{l}0.9 \\
1.5\end{array}$ & $\begin{array}{l}902 \\
454\end{array}$ \\
\hline $\begin{array}{c}\text { Case } 1 \\
- \text { Normal Operation } \\
\text { Accident }\end{array}$ & $\begin{array}{r}1,068 \\
352\end{array}$ & $\begin{array}{l}1.2 \\
1.6\end{array}$ & $\begin{array}{r}1,295 \\
569\end{array}$ \\
\hline $\begin{array}{l}\text { Case } 2 \\
\text { - Normal Operation } \\
\text { - Accident }\end{array}$ & $\begin{array}{c}1,045 \\
332\end{array}$ & $\begin{array}{l}1.1 \\
1.6\end{array}$ & $\begin{array}{r}1,188 \\
532\end{array}$ \\
\hline $\begin{aligned} \text { Case } & 3 \\
- & \text { Normal Operation } \\
- & \text { Accident }\end{aligned}$ & $\begin{array}{r}1,985 \\
603\end{array}$ & $\begin{array}{l}1.2 \\
1.6\end{array}$ & $\begin{array}{r}2,301 \\
978\end{array}$ \\
\hline
\end{tabular}

TABLE 4.6. Public Dose During Normal Operation and from a Shaft Drop Accident (Bechtel 1979)

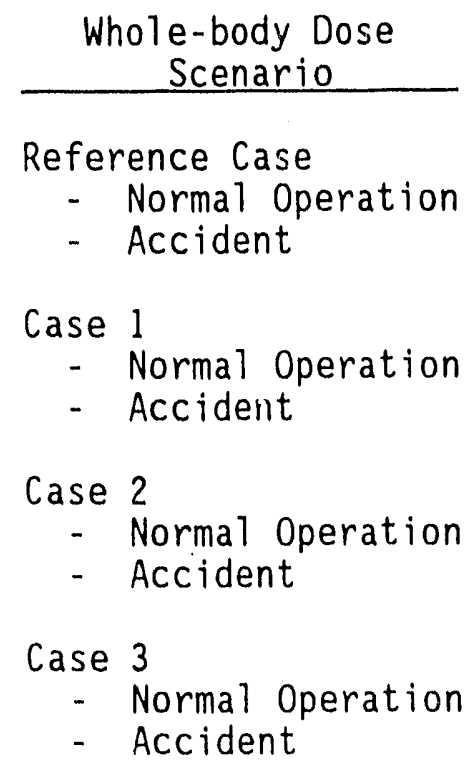

Public Dose (person-rem/yr)

1.5E-5

$6.5 \mathrm{E}-2$

$5.0 \mathrm{E}-6$

$5.6 \mathrm{E}-2$

$7.7 E-6$

$5.6 E-2$

1.1E-5

$5.6 E-2$ 
TABLE 4.7. Occupational Dose During Normal Operation and from Accidents During Decommissioning and Retrieval Phases of a Repository (Bechtel 1979)

\section{Scenario \\ Reference Case \\ - Normal Operation \\ - Accident}

Case 1

- Normal Operation

- Accident

Case 2

- Normal Operation

- Accident

Case 3

- Normal Operation

- Accident
Annual Dose (person-rem/yr)

Decommissioning Retrieval (a)

6

5

163

89

23

16

588

254

22

487

15

215

40

28
1,116

491

(a) Represents sum of doses from waste removal, offgas recovery and release, and mining and drilling activities.

\section{Evaluation}

The Spent Fuel Disposal Options Study utilized the results of previous studies and did not attempt to perform new analyses, except for limited amounts of normalization to a common basis. The study was not intended to be a detailed and comprehensive analysis. Rather, it was intended to provide a sufficient basis for performing comparative evaluations of alternative spent fuel and waste disposal options. The study addressed some repository operating phases that had not been addressed extensively, including decommissioning and retrieval phases. However, it was indicated that the estimated radiation doses for these phases were based on analyses performed for a conceptual spent fuel reprocessing $\mathrm{plant}$. Since a reprocessing $\mathrm{plant}$ is not similar to a repository, the results must be used with caution. There are also major differences between the reference system used by Bechtel (1979) and the current configuration of the waste management system (e.g., the potential repository throughput rate and capacity). In summary, most of the 
information presented by Bechtel (1979) is not applicable to this study of the risks associated with the OCRWM system.

\subsubsection{Risk Analys is Methodology For a Spent Fuel Repository in Bedded Salt}

This report (Pepping 1981) described a method for assessing the risks of radionuclide releases from the operational period of a spent-fuel repository in bedded salt. The primary purpose of the report was to present the method; risk values were estimated only as illustrations of its application.

A hypothetical reference salt repository and a reference site were described for disposal of 10-year-old spent light water reactor (LWR) fuel and LLW generated by spent fuel handling activities. Repository design capacity was 203,944 spent fuel canisters [57\% PWR, 43\% boiling water reactor (BWR)] and 64,132 LLW drums received over an operating period of 22 years. Maximum receipt rate was 8,583 PWR canisters each containing 0.461 MTU, and 6,417 BWR canisters each containing 0.367 MTU (total 6,312 MTU/yr) in the eighteenth year of operation, and 3,367 LLW drums of unspecified radionuclide content in each of the final 6 years of operation. Spent fuel radionuclide inventories were calculated using the ORIGEN code; burnup rates were not specified.

Seven risk dominating initiating events were identified, and three of these were quantified with respect to frequencies of event sequences, quantities of radionuclide releases, and their uncertainties. The events that were quantified were:

- releases from normal operations

- drop of transfer cask 2,000 feet down shaft

- airplane crash into the hoist house containing a transfer cask, followed by a fire.

The method included a probabilistic assessment that was compatible with the probabilistic risk assessment (PRA) method being developed for the postclosure period. Only the airplane crash with fire was pursued as far as estimates of population exposures. 
Normal operations were assumed to produce on $1 \mathrm{y} \mathrm{Kr}-85$ emissions from damaged fuel pins and leaking canisters. It was assumed that $0.1 \%$ of the fuel pins received at the repository were damaged in transport and that $4 \%$ of the $\mathrm{kr}-85$ in the damaged pins was available for release. The release was vented from the shipping casks into the building off-gas system.

The two acciderit scenarios for which population health effects were estimated were a cask breach with and without fire. Assumed release fractions are shown in Table 4.8.

The dose and health effects estimated by Pepping (1981) for these accidents are given in Table 4.9. These estimates assumed a uniform population density of 50 persons $/ \mathrm{mi}^{2}$ outside a 1 -mile exclusion zone. Radionuclide releases were claimed to be upper-bound estimates. Dose conversion factors were taken from the CRAC code (Wall et a1. 1977) but are not specified. The results were referred to in the document as "preliminary".

\section{Evaluation}

This was a pioneering effort to apply PRA to radioactive waste disposal, but it stopped short of useful risk results. No attempt was made to identify or evaluate all possible accident sequences. The illustrations of the probability and release calculations are useful and informative. They serve to indicate that preclosure repository risk assessment will be a different problem than a reactor PRA, but that the general methodologies are applicable to both systems. The methods used for exposure and health consequence

TABLE 4.8. Accident Release Fractions for a Cask Breach With and Without Fire (Pepping 1981)

\begin{tabular}{lcc}
\multicolumn{2}{c}{ Radionuclide } & \multicolumn{2}{c}{$\begin{array}{c}\text { Welease Fraction (\%) } \\
\text { Without Fire }\end{array}$} & $\begin{array}{l}\text { With Fire } \\
\text { Fuei dust }\end{array}$ & 1 & 2 \\
Gases & 4 & 14 \\
Volatiles & & \\
$\quad-$ Cs & 1 & 2 \\
$\quad$ - Ru & 1 & 6 \\
Activation Products & 0 & 1
\end{tabular}


TABLE 4.9. Dose and Health Effects Estimates for a Transfer Cask Breach with Fire (Pepping 1981).

Individual Worker Risk of Early Latent Cancer Fatality
$\begin{array}{cc}\text { Distance From } & \text { Stack (mi) } \\ 0.25 & \frac{\text { Lifetime Risk }}{0.75}\end{array}$
$\begin{gathered}0.1 E-4 \\ 0\end{gathered}$

Offsite Doses

Distance From
stack (mi)

1

5

10

20

30

50

Mean Latent Cancers

Peak Latent Cancers
Mean Bone Marrow Dose (rem)
$4.9 \mathrm{E}-1$
$2.5 \mathrm{E}-2$
$8.8 \mathrm{E}-3$
$2.5 E-3$
1.1E-3
$3.7 E-4$
5
7

assessment are outdated and simplified so the 1 imited health risk results presented are not useful for this study. As stated by the authors, the health effects results were never intended to be more than illustrations.

\subsubsection{Occupational Exposures at a Spent Fuel Repository}

This study (Isakari et al. 1980) estimated the routine occupational exposures associated with spent fuel receiving, handling, and emplacement for a repository in bedded salt. The analysis assumed receipt of canistered fuel assemblies at a maximum rate of 12,360 canisters/yr (about 5,700 MTU/yr). The minimum fuel age was 3 years out-of-reactor, with an average age of 10 years. The spent fuel operations analyzed included:

- inspect the shipping cask upon arrival

- prepare, wash, and sample the cask

- attach cask to hot cell 
- move canisters into unloading hot cell

- load canisters into transfer cask; move transfer cask to shaft station

- load and unload transfer cask from waste cage

- move transfer cask to storage area; load canister into borehole.

Some of the important parameter assumptions used to estimate the occupational exposures were as follows:

- Shipping casks were assumed to reduce the dose rate at their external surface to $25 \mathrm{mrem} / \mathrm{hr}$ and to less than $10 \mathrm{mrem} / \mathrm{hr}$ at 1 meter from the surface. The dose rate in the hot-cell operating gallery kias assumed to be $0.25 \mathrm{mrem} / \mathrm{hr}$.

- The dose rate at the external surface of the transfer cask was assumed to be $25 \mathrm{mrem} / \mathrm{hr}$. The dose rate at 1 meter was $5 \mathrm{mrem} / \mathrm{hr}$.

- The dose rate in the cab of the underground transporter was assumed to be $2 \mathrm{mrem} / \mathrm{hr}$.

Integrated occupational doses were estimated based on personnel locations, average occupancy time, expected maximum dose rate, and the number of persons involved in each operation.

The results presented by Isakari et a1. (1980) are summarized in Table 4.10. As shown, abrut $68 \%$ of the dose per canister will be received during shipping cask unloading operations. Underground emplacement will account for about $17 \%$ of the total per-canister dose and the remainder will be received during surface facility hot cell operations.

\section{Evaluation}

The analysis developed some preliminary estimates of occupational doses for spent fuel handling operations. The bases for the study were somewhat different than for the current system, but the approach used to estimate the occupational doses was consistent with the approaclias used in more recent studies. The assumed dose rate field around the transportation casks was somewhat optimistic and tended to underestimate the exposures (casks will probably be designed to meet the regulatory criteria of $200 \mathrm{mrem} / \mathrm{hr}$ at the surface and $10 \mathrm{mrem} / \mathrm{hr}$ at 2 meters from the transport vehicle, but not much lower). The time-and-motion studies in this report were not as comprehensive 
TABLE 4.10. Summary of Occupational Doses Estimated for Spent Fuel Handling and Disposal Activities (Isakari et al. 1980)

\begin{tabular}{|c|c|c|c|c|}
\hline Operation & $\begin{array}{c}\text { Average } \\
\text { Time(min) }\end{array}$ & $\begin{array}{l}\text { Maximum } \\
\text { Dose Rate } \\
\text { (mrem/hr) }\end{array}$ & $\begin{array}{l}\text { Number of } \\
\text { Personnel }\end{array}$ & $\begin{array}{l}\text { Integrated Dose } \\
\text { (mrem/canister) }(a)\end{array}$ \\
\hline $\begin{array}{l}\text { Shipping cask } \\
\text { inspection }\end{array}$ & $6 /$ cask & 10 & 3 & 0.42 \\
\hline $\begin{array}{l}\text { Cask washdown, } \\
\text { sampling, prep- } \\
\text { aration }\end{array}$ & $40 /$ cask & 10 & 2 & 1.91 \\
\hline $\begin{array}{l}\text { Connect cask to } \\
\text { hot cell }\end{array}$ & $20 /$ cask & 20 & 3 & 2.85 \\
\hline Unload canisters & $3 /$ canister & 0.25 & 1 & 0.01 \\
\hline Load transfer cask & 4/canister & 2 & 1 & 0.97 \\
\hline $\begin{array}{l}\text { Load/unload cask } \\
\text { from waste cage }\end{array}$ & 2.5/canister & 2 & 2 & 0.17 \\
\hline $\begin{array}{l}\text { Move transfer cask } \\
\text { to room; load } \\
\text { canister into } \\
\text { borehole }\end{array}$ & $20 /$ canister & 2 & 2 & 1.33 \\
\hline TOTAL & & & & 7.66 \\
\hline
\end{tabular}

(a) Each canister holds 1 PWR or 2 BWR spent fuel assemblies.

and detailed as in more recent studies. Consequently, the results are less credible than the results of studies that are based on detailed time-andmotion studies. Overall, it is judged that the results of this study provide order-of-magnitude estimates of occupational doses.

\subsubsection{EPRI Fuel Cycle Accident Risk Assessment}

This study (Erdmann et a7. 1979) was conducted to develop estinates of the radiological risks associated with nonreactor fuel cycle facilities. The report analyzed the doses from routine emissions from uranium mines and mills, and the accident risks associated with fuel reprocessing, mixed-oxide (MOX) fuel fabrication, transportation, and underground repository 
facilities. The discussion in this section is limited to the accident risks for the potential repository facility. The study was based on a fuel cycle with spent fuel reprocessing and recycle of recovered plutonium. As a result, the repository risks values were based on handling and disposal of solidified HLW and transuranic (TRU) wastes from reprocessing and MOX fabrication plants (i.e., spent fuel disposal was not assumed). A potential repository in salt with a total capacity of 35,000 canisters (114,000 MTUequivalent of spent fuel) was used as the basis for this study.

A Preliminary Hazards Analysis (PHA) was performed to identify potential accident sequences at the potential repository and was used as the basis for identifying the risk-dominant accident sequences. Fault trees were drawn and evaluated to estimate the frequencies of the dominant accident sequences. Release source terms were estimated based on material mobility and the accident driving forces. The efficiency of HEPA filters and their probability of failure were considered in the analysis. The CRAC computer code (Wall et a1. 1977) was used to estimate the public doses resulting from the release and dispersal of radioactive material.

The repository preclosure ascidents for which risk values were estimated are shown in Table 4.11. Also shown are the release quantities, estimated frequency, consequences, and risk value for each accident. The first three accidents involve a crash of a diesel fuel truck into the receiving area of the surface facilities followed by a fire. Risk values were estimated for canisters of cladding wastes, and drums of non-HLW TRU wastes. The aircraft crash into the receiving area was much more severa than the fuel truck crash and was assumed to affect the receiving areas for all three waste types. The elevator drop was assumed to involve $9 \mathrm{HLW}$ canisters. The non-HLW pallet drop accident was assumed to involve breakage of a single waste container. The final accident represented the airborne releases that might occur if the final HEPA filter stage of the building ventilation system failed.

\section{Evaluation}

This report represented an initial attemp to evaluate the risks of nonreactor fuel cycle facilities. Since this was a status report, the results should be considered to be preliminary. The document references unpublished 
TABLE 4.11. Summary of Repository Accident Releases, Frequencies Consequences, and Risk Values (Erdmann et a1. 1979)

\begin{tabular}{|c|c|c|c|c|}
\hline $\begin{array}{l}\text { Accident } \\
\text { Description }\end{array}$ & $\begin{array}{c}\text { Release } \\
\text { Quantity (Ci) } \\
\end{array}$ & $\begin{array}{l}\text { Frequency } \\
\text { (per yr) }\end{array}$ & $\begin{array}{l}\text { Consequences (a) } \\
\text { (person-rem) }\end{array}$ & $\begin{array}{c}\begin{array}{c}\text { Risk Value } \\
\text { (person-rem/yr) }\end{array}\end{array}$ \\
\hline $\begin{array}{l}\text { Fuel truck } \\
\text { crash into } \\
\text { HLW area }\end{array}$ & $\begin{array}{l}\mathrm{H}-3 ; 3 \\
\mathrm{Cs}-134 ; 300 \\
\mathrm{Cs}-137 ; 70\end{array}$ & $2.0 E-6$ & $2.0 E+3$ & 4.0E-3 \\
\hline $\begin{array}{l}\text { Fuel truck } \\
\text { crash into } \\
\text { cladding } \\
\text { waste area }\end{array}$ & $\begin{array}{l}\mathrm{FP}(\mathrm{b}) ; 400 \\
\text { Actinides;0.1 }\end{array}$ & $2.0 E-6$ & $2.0 \mathrm{E} 00$ & $4.0 E-6$ \\
\hline $\begin{array}{l}\text { Fuel truck } \\
\text { crash into } \\
\text { NHLW area }\end{array}$ & Actinides; 100 & $2.0 \mathrm{E}-6$ & $4.0 E+1$ & $8.0 E-5$ \\
\hline $\begin{array}{l}\text { Aircrash into } \\
\text { receiving } \\
\text { area }\end{array}$ & $\begin{array}{l}\mathrm{H}-3 ; 3 \\
\mathrm{Cs}-134 ; 300 \\
\mathrm{Cs}-137 ; 70 \\
\text { FP; } 400 \\
\text { Actinides; } 100\end{array}$ & $1.0 \mathrm{E}-7$ & $4.0 E+3$ & $4.0 E-4$ \\
\hline Elevator drop & $\begin{array}{l}\mathrm{H}-3 ; 4 \mathrm{E}-3 \\
\text { FP; } 1 \mathrm{E}-2 \\
\text { Actinides; } 4 \mathrm{E}-3\end{array}$ & $4.0 E-8$ & $5.0 E-2$ & $2.0 E-9$ \\
\hline $\begin{array}{l}\text { Non-HLW } \\
\text { pallet drop }\end{array}$ & Actinides; 0.02 & $5.0 \mathrm{E}-2$ & $8.0 E-1$ & $4.0 E-4$ \\
\hline \multirow{2}{*}{$\begin{array}{l}\text { Final filter } \\
\text { failure }\end{array}$} & Actinides; 0.2 & $3.0 \mathrm{E}-3$ & $2.0 E 00$ & $6.0 \mathrm{E}-3$ \\
\hline & Total Preclosure & e Risk & & $1.0 \mathrm{E}-2$ \\
\hline
\end{tabular}

(a) Population doses are 50-year whole-body dose commitments.

(b) $F P=$ Various fission products.

draft reports that contain additional information. As a result, it is difficult to reproduce the results. The repository preclosure risk estimates were based on disposal of reprocessing wastes, which is not consistent with the current OCRWM system for disposal of unreprocessed spent fueT. Some useful information was presented on the frequencies of the postulated accidents, such as the elevator drcp and final filter failure. The data on 
filtration efficiency is also a good starting point for further evaluation of this important parameter, which is often neglected.

\subsubsection{HLW Preclosure Systems Safety Analysis}

This report (Harris et al. 1985) presented the results of Phase 1 of the NRC High Level Waste Preclosure Systems Safety Analysis Project. The overall objectives of the project were to:

- develop and demonstrate the applicability of a systematic methodology that will identify and quantify the importance of structures, components, systems, and operations that are important to safety during the preclosure phase of a high level nuclear waste repository in basalt

- evaluate and rank the relative importance of potential repository components and systems to assist the NRC staff in regulatory planning and decision-making.

The first phase of the project was primarily devoted to gathering, organizing, and assembling information needed for safety assessment. Specific issues addressed included:

- detailed analyses of a conceptual repository design to identify potentially important initiating events and accident scenarios

- evaluation of available consequence models

- evaluation of available importance ranking measures for evaluating event and fault trees

- development of event and fault tree models for important initiating events

- compilation of specific data needed for risk assessment

- selection of accident scenarios to be quantified in the next phase.

The basis for the study was a basalt repository with a total capacity of 28,000 waste canisters that contain the equivalent of 47,400 MTU of waste. Twenty percent of the waste was BWR spent fuel, $29 \%$ was PWR spent fuel, and the remainder was solidified $\mathrm{HLW}$. For this potential repository, 153 potential initiating events were identified and classified by occurrence frequency (high, medium, low, very low) and type and severity of consequences (high, medium, low). Event trees were drawn for these initiating events and from 
the resulting event trees, a small subset of scenarios leading to public radiological exposure was selected as a sample problem to demonstrate the overal1 methodology in the next phase of the project. Although methods and some basic data for consequence analysis were described, the consequences of these scenarios were not quantified in this report.

Nonradiological accident data were collected and tabulated in this study. A sample of these data are shown in Table 4.12.

\section{Evaluation}

This was an initial effort that provided a sound basis for further work toward a repository preclosure probabilistic risk assessment. No attempt was made to estimate the numerical frequencies and consequences of radiological accidents or the consequences of routine releases. The tables of nonradiological occupational injury rates in Table 4.12 were the only quantitative information on consequences generated in Phase 1 . The report, however, contains many useful suggestions, qualitative estimates of event frequencies, and other useful data for risk assessment.

\subsubsection{Deaf Smith Environmental Assessment}

This report (DOE 1986d) evaluated the suitability for characterization of a potential HLW repository site in salt as specified in the NWPA. Most of the technical analyses useful for preclosure risk assessment were contained

TABLE 4.12. Nonradiological Injury Rates for Miners Per 200,000 Work-Hours Per Year (Harris et a1. 1985)

\section{Classification}

Fall of rib

Fall of roof

Drilling

Tramming

Rail haulage

Electrical

Fire/ignition

Total

\section{Fatality Rate}

0

0.094

0

0.016

0.049

0.010

0

0.169
Injury Rate

1.17

3.58

0.059

0.165

0.927

0.048

0.179

6.128
Nonfatal Avg. Days Lost

0.26

2.63

0.036

0.032

0.510

0.019

0.36

3.856 
in the supporting document by Waite et a1. (1986), which included analyses for six salt sites in Texas, Mississippi, Louisiana, and Utah. A combined review of these two documents is presented to avoid repetition.

The reference repository in salt was assumed to have a capacity of 36,000 MTU of spent fue1, 36,000 MTU of commercial HLW, and 3,510 MTU of DHLW. The fuel was assumed to be 6.5 years old, and the average and maximum receipt rates were 634,000 and $1,100,000$ rods/yr, respectively. Radiological consequence analyses (50-year dose commitment) were presented for routir.e releases during construction and operations and for accidents during operations.

Repository construction was estimated to produce 30 million metric tons of salt from which natural radionuclides would be released for 34 years. Routine releases during operations will arise from rods that become damaged during fuel element disassembly and consolidation. A conservative estimate of $1 \%$ of the rods were assumed to become stuck in the disassembly equipment; $50 \%$ of these were assumed to be damaged during their removal. Radionuclide releases were based on release quantities derived in the GEIS, and included average annual and maximum annual releases of $\mathrm{H}-3, \mathrm{C}-14, \mathrm{Kr}-85$, and I-129.

Five "representative" accidents were selected from the GEIS to i11ustrate the consequences of potential accidents. These five accident scenarios were:

- shaft drop of commercial HLW

- shaft drop of spent fuel

- spent fuel handling accident involving crushing of shipping cask

- remote-handled TRU waste shaft drop accident

- contact-handled TRU waste drum puncture accident.

Release source terms were estimated for each accident for H-3; C-14; Mn-54; Co-60; Ni-63; Sr-90; Y-90; Nb-95; Ru-106; I-129; Cs-137; Ce-144; Eu-154; $\mathrm{Pu}-238,-239,-240$, and $-241 ; \mathrm{Am}-241$; and $\mathrm{Cm}-244$. No attempt was made to estimate the frequencies of these accidents. 
Maximally exposed individual exposures and $80-k i l o m e t e r$ population exposures were estimated using mean wind speed, the most common stability class, and population densities for each of the six salt sites. Releases were from ground level and from 61 meters. Doses from the ingestion pathway were estimated using the PABLM computer code (INTERA 1983). The assessment of inhalation and submersion pathways was performed using the ISDOSE code described by waite et al. (1986).

Annual and 50-year whole body dose commitments from inhalation, submersion, and ingestion were estimated for the maximally exposed individual and the population within an 80-kilometer radius of the sites. These estimates are presented in Table 4.13 for routine releases and in Table 4.14 for releases from accidents.

Nonradiological occupational injury and fatality rates were also presented in the environmental assessments (not included in Waite st al. 1986) based on industry averages. Projected injuries and fatalities were not presented because it was indicated they could not be predicted until the designs become final.

IABLE 4.13. Radiation Exposure From Normal Construction and Operation (Waite et al. 1986)

\begin{tabular}{lc} 
Exposure Category & $\begin{array}{c}\text { Estimated 50-yr } \\
\text { Dose Commitment }\end{array}$ \\
\cline { 2 - 2 } $\begin{array}{l}\text { Construction } \\
\text { Maximally Exposed Individual } \\
\text { - Annual } \\
\text {-50-yr }\end{array}$ & $0.044 \mathrm{mrem}$ \\
& $0.42 \mathrm{mrem}$ \\
80-km Population & \\
-50-yr & $2.0 \mathrm{E}+4$ person-mrem \\
Operation & \\
Maximally Exposed Individual \\
-Annual \\
-50-yr \\
$\begin{array}{l}\text { 80-km Population } \\
\text {-50-yr }\end{array}$
\end{tabular}


TABLE 4.14. Radiation Exposure from Accidents (Waite et al. 1986)

\begin{tabular}{|c|c|c|}
\hline Accident & $\begin{array}{l}\text { Maximally Exposed } \\
\text { Individual (mrem) }\end{array}$ & $\begin{array}{l}\text { Population } 50-y r \\
\text { Dose Commitment } \\
\text { (person-mrem) }\end{array}$ \\
\hline Spent Fuel Drop & $4.68 \mathrm{E}+1$ & $2.99 \mathrm{E}+3$ \\
\hline Commercial HLW Drop & $2.74 \mathrm{E} 00$ & $1.75 E+2$ \\
\hline Spent Fuel Handling & $3.98 \mathrm{E}-2$ & $1.29 \mathrm{E}+3$ \\
\hline Remote TRU Drop & $3.10 \mathrm{E}-3$ & $1.98 \mathrm{E}-1$ \\
\hline Contact TRU Puncture & $2.07 E-9$ & $6.70 E-5$ \\
\hline
\end{tabular}

\section{Evaluation}

The analyses by Waite et al. (1986) were of high quality and used standard methods and assumptions. The analysis used to develop estimated releases is relatively detailed and considers both facility construction and operations. Some data important to consequence calculations were presented. However, no attempt was made to $\mathrm{place}$ the accident scenarios on a probabilistic basis so the results were not presented in terms of population risks. The bases for consequence analysis results were specific to the potential first repository sites and the current configuration of the waste management system, particularly the assumption that spent fuel will be consolidated prior to its disposal. The population dose estimates useful for illustrating the effects of population distribution and weather assumptions with all other variables held constant. These can be seen by comparing the input parameters and accident results for the different sites.

\subsubsection{Hanford Environmenta.l Assessment}

This report (DOE 1986c) evaluated the suitability for characterization of a potential HLW repository site in basalt. The assessment was based on a conceptual design from 1982 and a series of engineering studies. The total repository capacity in the 1982 conceptual design was 47,400 MTU of spent fuel with an average receipt rate of 1,072 spent-fuel containers per year or the heavy metal equivalent in commercial HLW. Risk assessment results in the environmental assessment have been adjusted to reflect the current design requirement for a 70,000 MTU capacity for spent fuel and a receipt rate of $3,000 \mathrm{MTU} / \mathrm{yr}$ (26 assemblies/day) of 10-year-0ld fuel where appropriate. 
The risk estimates presented in the environmental assessment included nonradiological construction injuries and fatalities as well as public radiological exposures from routine operations and accidental releases during the operations phase.

Estimates of nonradiological occupational injuries and fatalities during construction were adapted from the GEIS.

Estimates of routine radionuclide emissions from waste handling during operations conservatively assumed that $1 \%$ of the fuel rods became stuck in the disassembly equipment and $50 \%$ of these rods were damaged during their removal. Failed fuel rods were assumed to release $30 \%$ of their gaseous inventory. Only the $\mathrm{Kr}-85$ was included in the assessment. Al1 releases were assumed to be at ground lever. The environmental assessment estimated a maximum individual dose at the site boundary (24 kilometers away from the release point) at $0.001 \mathrm{mrem} / \mathrm{yr}$. Population doses were not estimated.

Eight accident scenarios taken from another study were discussed:

- Occupational exposure events

- undetected contaminated

- shipping cask

- breached cask or drum

- unsealed hot cell port

- unshielded waste container

- Public exposure events

- fuel assembly drop

- naturar phenomena

- explosion and fire.

Only the public exposures from the hoist drop accident were estimated. It was indicated that this accident was expected to present the greatest potential for breaching the waste package and releasing radioactive material to the environment.

Radionuclide release source terms for the shaft drop accident were taken from the GEIS; decontamination by filtration was assumed to be a factor of 1.OE-7. The 70-year whole-body dose commitment from the hoist drop accident to a maximally exposed individual located $1.6 \mathrm{kilometers}$ from the site was estimated to be 1.2 mrem. No estimates of 80 -kilometer population exposures were included. 
Construction of the surface facility was estimated to yield 40 disabling injuries and 1 fatality; underground mining operations were estimated to yield 976 disabling injuries and 21 fatalities. Radiation exposure from mine spoils was not included in construction health effects.

\section{Evaluation}

Since this was an environmental assessment, it focused on the information necessary for such a document, including estimates of doses to maximally exposed individuals from radiological accidents and from routine operations. It was shown that these maximally exposed individual doses were well below the EPA standard for public exposures of $25 \mathrm{mrem} / \mathrm{yr}$ (see 40 CFR 191). No estimates of integrated population doses for radiological routine releases or accidents were included in this assessment. No attempt was made to estimate the frequencies of accidents, so risk information was not provided. The source terms for the only accident analyzed were taken from another study, so no additional information was presented that was not already available. Only the estimates of nonradiological occupational injuries and fatalities can be used directly in this study.

\subsubsection{Yucca Mountain Environmental Assessment}

This report evaluated the suitability for characterization of a potential HLW repository site in a tuff geologic medium. It described three potential repository designs:

- a "reference repository design concept" on which the draft environmental assessment and Jackson et al. (1984) were based

- a "two-stage repository design concept" on which the final environmental assessment was based

- a "current design concept" that was described in the 1985 OCRWM Mission Plan (DOE 1985).

These designs are significantly different, and some care is required to prevent confusion among their associated risk estimates. In general, the radiological risk information in the environmental assessment was based on a repository design capacity of 70,000 MTU of spent fuel only, with a maximum annual receipt rate of $3,000 \mathrm{MTU} / \mathrm{yr}$. The environmental assessment summarized 
radiological risk and exposure estimates developed in the GEIS (DOE 1980), Jackson et a1. (1984), and Dennis et al. (1984). Separate reviews of these reports will noi be repeated here.

The tuff environmental assessment included estimated population doses from routine radiological emissions during construction and operations, occupational doses from routine construction and operation activities, and public and occupational risks from accidents during the operations phase. Emissions of nonradiological pollutants, such as carbon monoxide, nitrogen oxides, sulfur dioxide, and hydrocarbors were also estimated. Nonradiological accident risks were not evaluated. The environmental assessment also does not quantify the risks associated with the decommissioning and retrieval phases, although Dennis et a1. (1984) estimated the occupational exposures during the retrieval phase.

Estimated radiological emissions from construction of a potential tuff repository were based on information from the GEIS on natural radionuclide emissions from granite rock, which has a similar radionuclide content to the Yucca Mountain tuff. The population and worker doses from these emissions were scaled to the expected volume of mine spoils and population density around the Yucca Mountain site, relative to the GEIS. The regional (80-kilometer) population doses were estimated at 0.9 person-rem over 7 years for the waste emplacement concept in which waste containers will be placed in horizontal boreholes and 0.3 person-rem over 7 years for the vertical emplacement concept (there are significant differences between these concepts in the volume of mined rock). The collective doses to construction workers were estimated at 1,500 person-rem and 450 person-rem for vertical and horizontal emplacement, respectively.

Occupational doses during operations were estimated based on an assumed waste mix of $50 \%$ spent fuel and $50 \%$ commercial HLW (reference repository). Source term inventories were from the ORIGEN2 code. The occupational dose estimates in the environmental assessment were taken from Dennis et al. (1984) and are summarized in Table 4.15. Annual occupational doses were estimated to be about 70 person-rem/yr or about 2,000 person-rem for the 28-year operating period. 
IABLE 4.15. Occupational Dose During Potential Tuff Repository Operation (DOE 1986b).

\begin{tabular}{|c|c|c|}
\hline Activity & $\begin{array}{l}\text { Number of } \\
\text { Workers }\end{array}$ & $\begin{array}{l}\text { Collective Dose } \\
\text { (Person-rem/yr) }\end{array}$ \\
\hline Receiving & 35 & 44.8 \\
\hline Handling and Packaging & 16 & 6.9 \\
\hline $\begin{array}{l}\text { Surface Storage to } \\
\text { Emplacement Horizon }\end{array}$ & 14 & 6.0 \\
\hline \multicolumn{3}{|l|}{ Emplacement } \\
\hline Vertical & 18 & 12.4 \\
\hline Horizontal & 7 & 8.7 \\
\hline
\end{tabular}

Quantitative estimates of public doses from routine releases were not estimated, because they were considered to be negligible.

Accident assessments for the Yucca Mountain site were described in a supporting document (Jackson et al. 1984). This report presented preliminary estimates of public, maximaliy exposed individual, and occupational exposures from "worst-case" abnormal radionuclide releases from preclosure operation of a potential repository in tuff. Three main categories of accidents were considered, including natural phenomena, external man-made events, and operational accidents. The estimated frequencies of these accidents were taken from other documents. No new probabilistic analyses were included. The reader is referred to Section 4.1 .11 for a summary of the accident risk results estimated by Jackson et a1. (1984).

The tuff environmental assessment included an assessment of the annual traffic accidents associated with repository-related traffic. Route-specific assessments of vehicle-miles on various segments of the access routes to the potential repository were performed. The results of these assessments were combined with accident data for the specific highway segments to develop estimates of the baseline (without repository) and repository traffic-related accidents. It was projected that seven additional traffic accidents, four additional injuries, and two additional fatalities would occur as a result of increased repository-related traffic in 1995. The incremented impacts in 
1988 were estimated to be nine additional traffic accidents, five additional injuries, and no additional fatalities.

\section{Evaluation}

The tuff environmental assessment included the most recent radiological accident and routine emission data of all the environmental assessments. Routine occupational exposures were based on comprehensive time-and-motion studies of actual tuff repository conceptual designs. The standard consequence analys is methods were used. Postulated accidents were admittedly "worst-case" occurrences but they represented the most comprehensive identification and evaluation of potential accident sequences in the literature. Release source terms were based on previous data from the GEIS and should be used only after a careful review of the specific accident conditions and waste form characteristics. No new probabilistic analyses were performed. Estimates of nonradiological accidents risks were also not included. Decommissioning accidents and routine risks were not evaluated numerically. However, occupational exposures for the retrieval phase were estimated (see Section 4.1.1.10).

\subsubsection{Occupational Exposures for a Potential Repository in Tuff}

This document (Dennis et al. 1984) was prepared to support the conceptual design of a potential repository in tuff. It contained estimates of occupational radiation exposures during spent fuel and HLW receiving, handling, packaging, emplacement, and retrieval operations. Operating and personnel requirements were identified for specific tasks and combined with estimated radiation dose rates to estimate the occupational doses. The overall purpose of the study was to determine whether or not any specific individuals would receive more than the maximum permissible exposure limit ( $5 \mathrm{rem} / \mathrm{yr}$ ) or the $1-\mathrm{rem} / \mathrm{yr}$ design objective. It was predicted that all annual worker exposures would be less than $5 \mathrm{rem} / \mathrm{yr}$ and that seven worker positions could exceed the $1-\mathrm{rem} / \mathrm{yr}$ design goal.

Some of the important bases for the occupational dose estimates were as follows. Dose rate maps for transportation casks and facility transfer casks were developed using a three-dimensional point-kernal shielding code named PATH. Dose rates in hot cell operating galleries were assumed to be 
$0.01 \mathrm{mrem} / \mathrm{min}$, and dose rates for crew members performing waste transport operations underground were assumed to be $0.005 \mathrm{mrem} / \mathrm{min}$. Background dose rates were assumed to be $0.001 \mathrm{mrem} / \mathrm{min}$. Occupational doses were estimated for two designs for transferring waste underground (shaft and ramp access to underground facilities) and for two emplacement configurations (horizontal and vertical borehole designs). The annual waste receipt rates used in the study were 2,165 BWR and 2,730 PWR canisters/yr plus $660 \mathrm{DHLW}$ and $500 \mathrm{CHLW}$ canisters/year.

The annual collective doses estimated by Dennis et al. (1984) are summarized in Table 4.16. As shown, the occupational exposures were dominated by shipping-cask receiving and handling operations, which account for approximately $60 \%$ of the total emplacement doses. The transfer and emplacement concept with the lowest doses was the combination of ramp access and horizontal emplacement. According to the estimates, horizontal emplacement was favored over vertical emplacement hecause of approximately $23 \%$ lower doses for this activity. Ramp access was estimated to have $20 \%$ 1ower occupational exposures. However, only small differences in total annual doses (about 5\%) were estimated for the highest- and lowest-dose combinations because the largest portion of the dose is received during other activities.

\section{Evaluation}

This document presented a detailed and comprehensive evaluation of potential tuff repository occupational exposures for spent-fuel and HLW operations. Detailed time-and-motion estimates form the basis for the exposure estimates. This was the only document reviewed that included a comprehensive evaluation of projected occupational exposures during emplacement and retrieval activities. The report assumed that spent fuel would be consolidated prior to disposal, which was consistent with system design assumptions. It also contained risk information that was specific to the potential tuff repository site, which is desirable in this report. The calculations were based on receipt rates of 1,500 MTU/year of spent fuel and 1,500 MTU-equivaient/year of HLW. This assumption is not consistent with the current configuration of the system, but the results are judged to be representative of a $100 \%$ spent-fuel repository because many of the operations 
TABLE 4.16. Summary of Annual Occupational Exposures for Spent-Fuel and HLW Operations at a Potential Tuff Repository (Dennis et a1. 1984)

\begin{tabular}{|c|c|c|}
\hline Operation & $\begin{array}{l}\text { Total Number } \\
\text { of Workers }\end{array}$ & $\begin{array}{l}\text { Total Annual dose } \\
\text { (person-rem/yr) }\end{array}$ \\
\hline Receiving & 35 & 44.6 \\
\hline Handling and Packaging & 22 & 12.3 \\
\hline \multicolumn{3}{|l|}{$\begin{array}{l}\text { Transfer to Underground } \\
\text { Facilities }\end{array}$} \\
\hline Shaft Access & 9 & 3.35 \\
\hline Ramp Access & 7 & 2.68 \\
\hline \multicolumn{3}{|l|}{ Emplacement in Boreholes } \\
\hline Vertical & 18 & 12.4 \\
\hline Horizontal & 7 & 9.59 \\
\hline \multicolumn{3}{|l|}{ Retrieval from Boreholes } \\
\hline Vertical & 22 & 12.6 \\
\hline Horizontal & 6 & 8.86 \\
\hline Return to Surface (Ramp) & 5 & 2.68 \\
\hline $\begin{array}{l}\text { Handling, Packaging, Shipping } \\
\text { Totals(a) }\end{array}$ & 17 & 20.48 \\
\hline Shaft Access/Vert. Empl. & & 72.68 \\
\hline Shaft Access/Horiz. Empl. & & 69.84 \\
\hline Ramp Access/Vert. Empl. & & 71.98 \\
\hline Ramp Access/Horiz. Empl. & & 69.17 \\
\hline
\end{tabular}

(a) Totals do not include retrieval and loadout operations.

are the same for both HLW and spent fuel. The results are also judged to be representative of other potential repository designs.

\subsubsection{Safety Assessment for a Potential Repository in Tuff}

This report (Jackson et al. 1984) developed preliminary estimates of "worst-case" accident risks for potential accidents during the operational period of a potential repository in tuff. Potential accidents were postulated in three categories: 1) natural phenomena, 2) external man-made events, and 3) operational accidents. Scenarios were developed and analyzed 
for accidents involving spent fuel and solidified $\mathrm{HLW}$. The radionuclide inventories used were typical of 10-year-old spent PWR fuel, commercial HLW from reprocessing 10-year-old fuel, and West Valley HLW. Both surface facility and underground accidents were included. The results of this report were summarized in the tuff environmental assessment (DOE 1986b).

Release source terms for the postulated accidents were based on the physical and chemical characteristics of the waste forms, containment barrier characteristics, and the accident conditions. The release fractions were developed from data published in the GEIS (DOE 1980) and by Wilmot et al. (1983). Isotope-specific release fractions and release quantities were tabulated for each accident in a series of tables. Releases were mitigated for some accidents by their passage through the building ventilation system, which included a roughing filter, two banks of HEPA filters, and a 30-meter exhaust stack. The roughing filter was assumed to remove $90 \%$ of the particles larger than 6 microns in diameter and each HEPA filter bank removed 99.7\% of the particles 0.3 microns in diameter and 1arger. The total decontamination factors used were $1.0 E+$ ? for particulates and $1.0 E+6$ for radionuclides volatilized by heat (e.g., for accidents including fires).

The exposure pathways considered in the study included cloudshine, groundshine, air immersion, inhalation, and ingestion of contaminated foods. Population doses were estimated using the AIRDOS-EPA computer code (Moore et a1. 1979), which uses a standard Gaussian plume diffusion model. Pasquill stability $c$ lasses $D$ and $E$ were used. The dispersion factors were based on probabilistic-weighted average annual wind speed and frequency around the tuff site. The ALLDOS computer code (Strenge et al. 1980) was used to calculate personnel and maximally exposed individual doses, because AIRDOSEPA does not estimate a first-year dose commitment. The site-specific population data that was used indicated that a total of 19,908 persoris lived within an 80 -kilometer radius of the potential repository. The maximally exposed individual was assumed to be located about 4 kilometers from the surface facilities at the time of an accident but did not permanently reside there. The results presented by Jackson et al. (1984) are shown in Table 4.17 for the maximally exposed public individual and workers and in Table 4.18 for the population risks. 
TABLE 4.17. Estimated 50-Year Whole-Body Dose Commitmen to the Public, Maximally Exposed Individual, and Workers

from Accidents (Jackson et a1. 1984)

\begin{tabular}{|c|c|c|c|}
\hline Accident Scenario & $\begin{array}{l}\text { Maximally } \\
\text { Exposed } \\
\text { Individual } \\
\text { Dose (rem) }\end{array}$ & $\begin{array}{l}80 \mathrm{~km} \text { Popu- } \\
\text { lation Dose } \\
\text { (person-rem) }\end{array}$ & $\begin{array}{c}\text { Worker } \\
\text { (person-rem) }\end{array}$ \\
\hline \multicolumn{4}{|l|}{ Natural Phenomena } \\
\hline Flood & $2.8 E-11$ & $1.2 E-9$ & $5.0 E-10$ \\
\hline Earthquake & $2.4 E-4$ & $3.1 E-3$ & 0.37 \\
\hline Tornado & $2.4 E-4$ & $3.1 E-3$ & 0.37 \\
\hline \multicolumn{4}{|l|}{ Marl-made Events } \\
\hline Aircraft Impact & $6.8 E-2$ & 110 & 5.5 \\
\hline Nuclear Test & $2.4 E-4$ & $3.1 E-3$ & 0.37 \\
\hline \multicolumn{4}{|l|}{ Operational Accidents } \\
\hline $\begin{array}{l}\text { Fuel Assembly Drop } \\
\text { Loading Dock Fire }\end{array}$ & $5.3 E-6$ & $8.0 E-5$ & $8.1 E-3$ \\
\hline Spent Fuel & $2.1 E-2$ & $6.8 E-3$ & $8.9 E-3-3.5^{(a)}$ \\
\hline Commercial HLW & $3.6 E-3$ & $9.2 E-4$ & $1.5 E-3-0.6^{(a)}$ \\
\hline $\begin{array}{l}\text { Waste Handling Ramp } \\
\text { Fire }\end{array}$ & $1.8 \mathrm{E}-7$ & $3.6 \mathrm{E}-7$ & $3.8 E-8-64(b)$ \\
\hline $\begin{array}{l}\text { Emplacement Drift } \\
\text { Fire }\end{array}$ & $1.8 E-7$ & $3.6 E-7$ & $3.8 E-8-180^{(b)}$ \\
\hline
\end{tabular}

(a) The first value represents the estimated dose to workers at the site surface and subsurface facilities; the second value is for the worker exposures at the loading dock.

(b) The first value is for the doses to workers in the surface facilitios; the second value is for underground waste emplacement workers. 
TABLE 4.18. Preliminary Risk Estimates for Postulated Accidents

at a Potential Repository in Tuff (Jackson et a1. 1984)

\begin{tabular}{|c|c|c|c|}
\hline Accident Scenario & $\begin{array}{c}\text { Estimated } \\
\text { Frequency } \\
\text { (events/yr) }\end{array}$ & $\begin{array}{c}50-y r \text { Dose } \\
\text { Commitment } \\
\text { (person-rem) }\end{array}$ & $\begin{array}{l}\text { Population Risk } \\
\text { (person-rem/yr) }\end{array}$ \\
\hline \multicolumn{4}{|l|}{ Natural Phenomena } \\
\hline Flood & $1.0 \mathrm{E}-2$ & $1.2 \mathrm{E}-9$ & $1.2 \mathrm{E}-11$ \\
\hline Earthquake & $<1.3 \mathrm{E}-3$ & $3.1 \mathrm{E}-3$ & $<4.0 \mathrm{E}-6$ \\
\hline Tornado & $<9.1 E-11$ & $3.1 E-3$ & $<2.8 \mathrm{E}-13$ \\
\hline \multicolumn{4}{|l|}{ Man-made Events } \\
\hline Aircraft Impact & $<2.0 \mathrm{E}-10$ & $1.1 \mathrm{E}+2$ & $<2.2 \mathrm{E}-8$ \\
\hline Nuclear Test & $<1.0 \mathrm{E}-3$ & $3.1 \mathrm{E}-3$ & $<3.1 \mathrm{E}-6$ \\
\hline \multicolumn{4}{|l|}{ Operational accidents } \\
\hline Fuel Asse:ibly Drop & $1.0 \mathrm{E}-1$ & $8.0 E-5$ & $8.0 E-6$ \\
\hline \multicolumn{4}{|l|}{ Loading Dock Fire } \\
\hline Spent Fuel & $<1.0 \mathrm{E}-7$ & $6.8 \mathrm{E}-3$ & $<6.8 \mathrm{E}-10$ \\
\hline Commercial HLW & $<1.0 \mathrm{E}-7$ & $9.2 E-4$ & $<9.2 E-11$ \\
\hline $\begin{array}{l}\text { Waste Handling Ramp } \\
\text { Fire }\end{array}$ & $<1.0 \mathrm{E}-7$ & $4.8 E-7$ & $<4.8 E-14$ \\
\hline $\begin{array}{l}\text { Emplacement Drift } \\
\text { Fire }\end{array}$ & $<1.0 \mathrm{E}-7$ & $4.8 E-7$ & $\leq 4.8 \mathrm{E}-14$ \\
\hline Total & & & $1.5 E-5$ \\
\hline
\end{tabular}

\section{Evaluation}

This document presented a relatively comprehensive evaluation of the frequencies and consequences of accidental releases from a potential tuff repository. As such, the results are useful to this study. The release source terms and frequencies were based on information in the GEIS; no new probabilistic evaluations of accident frequencies were performed. Therefore, the results must be used with caution. The consequence analysis methods used are standard and utilize probabilistic-weighted weather conditions based on actual meteorological data for the tuff site. Population distributions were also site specific. This document should form part of the basis for further accident risk evaluations. 


\subsubsection{First Repository Site-Selection Methodology Document}

This document (DOE 1986f) was prepared to support the decision to characterize three potential first repository sites. The document describes the multiattribute utility analysis methodology as well as its application to selection of the three preferred sites. This methodology was applied to the postclosure and preclosure performance of the potential repository sites and to the transportation impacts associated with shipping wastes to the sites. Only the preclosure aspects of the document, specifically the radiological and nonradiological impacts, is reviewed in this section. The postclosure performance ranking of the repositories was taken from the environmental assessments, which are discussed in Section 4.2.

The preclosure risk categories discussed in the ranking document include radiological risks to miners from naturally occurring radionuclides, radiological public risks during operations, nonradiological risks to workers during facility construction and operation, and public risks from nonradiological emissions during repository construction. The radiological risk data was based on the information in the environmental assessments (DOE $1986 \mathrm{~b}, \mathrm{c}, \mathrm{d}$ ), including personnel requirements, population distributions around the potential sites, and relative land-use patterns (specifically agricultural use) in the vicinity of the sites. The radiological risk estimates for the population surrounding the sites were developed from a set of qualitative ranking criteria that assumed the worst possible level of impact would be three radiological fatalities. A scale was then developed from one to three fatalities. Each category on the scale represented a different combination of population data, predominant wind directions, and food-crop production levels. The potential repository sites were then placed in one of the categories, depending upon the specific combination of data that were applicable to each site, and an overall risk value was developed. This is believed to be a reasonable basis for site ranking purposes.

Radiological risks to workers were also used to rank the sites. Occupational risks to workers included exposures to radon during subsurface construction and exposures to radiation emitted from waste containers during waste handling operations at the surface and underground. Radon exposures 
were estimated by multiplying the number of construction workers by the average exposure to radon ( $\mathrm{rem} / \mathrm{yr}$ ) and the number of construction years. A similar approach was used to estimate the worker doses during operations. The assumed average exposure rate for radiation workers was $0.5 \mathrm{rem} / \mathrm{yr}$ per worker. The labor force requirements were derived from the most recent repository cost estimates (Weston 1986) and are shown in Table 4.19. The total worker risk estimates are summarized in Table 4.20, after they were

TABLE 4.19. Average Staffing Levels for the Repositories (full-time equivalents) (DOE 1986f)

$\begin{array}{ccccc}\text { Deaf Smith } & \frac{\text { Yucca Mountain }}{\text { Con- }} & \text { Emplace- } & \text { Hanford } \\ \text { ment } & \text { struction } & \text { Emplace- } & \text { Con- } & \text { Emplace- } \\ \text { struction } & \text { struction } & \text { ment }\end{array}$

Iype of Worker struction ment struction ment struction ment Surface

$\begin{array}{lrrrrrr}\text { Radiation } & 0 & 380 & 0 & 276 & 0 & 487 \\ \text { Nonradiation } & 765 & 450 & 398 & 596 & 552 & 575 \\ \text { Subtotal } & 765 & 830 & 398 & 972 & 552 & 1062\end{array}$

Underground

$\begin{array}{lrrrrrr}\text { Radiation } & 0 & 26 & 0 & 12 & 0 & 23 \\ \text { Nonradiation } & 783 & 434 & 439 & 273 & 933 & 573 \\ \text { Subtotal } & 783 & 460 & 439 & 285 & 933 & 596\end{array}$

TABLE 4.20. Total Radiological Worker Fatalities from Construction and Emplacement Periods of Three Alternative Potential Repository Sites

\begin{tabular}{|c|c|c|c|c|}
\hline \multirow[b]{2}{*}{$\begin{array}{c}\text { Geologic } \\
\text { Medium }\end{array}$} & \multicolumn{4}{|c|}{ Radiological Fatalities (a) } \\
\hline & $\begin{array}{l}\text { Underground } \\
\text { Construction }\end{array}$ & $\begin{array}{l}\text { Underground } \\
\text { Operations }\end{array}$ & $\begin{array}{c}\text { Waste } \\
\text { Handling } \\
\text { Operations }\end{array}$ & Total \\
\hline Salt & $1.4 E-2$ & 4. $4 E-2$ & $1.5 \mathrm{E} 00$ & $1.6 \mathrm{E} 00$ \\
\hline Tuff & $7.7 E-1$ & $4.0 E 00$ & $1.0 \mathrm{E} 00$ & $5.8 \mathrm{E} 00$ \\
\hline Basalt & $1.6 E 00$ & $5.4 E 00$ & $1.9 \mathrm{E} 00$ & $8.9 E 00$ \\
\hline
\end{tabular}

(a) Based on 5-year construction and 26-year emplacement operations period. 
converted to fatalities using a dose-to-health-effects relationship of 280 fatalities/milition person-rem.

The site ranking document also developed estimated nonradiological accident risks to repository workers. The total number of nonradiological fatalities were estimated based on fatality rates for surface and subsurface operations. A fatality rate of 0.17 fatalities/million man-hrs was used for surface facility construction accidents, based on the rate used in the GEIS. The underground construction fatality rate was 0.55 fatalities/million manhrs, based on a historical 5-year average for both metal and nonmetal underground mines. These fatality rates were multiplied by the total number of man-hours for construction and operation of the surface and underground facilities. The labor requirements were obtained by multiplying the number of fu11-time-equivalents by the number of years (i.e., 5 construction years or 26 operating years) and by an assumed factor of 2,000 man-hrs/ful1-timeequivalent. The results are shown in Table 4.21 .

\section{Evaluation}

This document presented risk estimates for a number of risk categories that were used to distinguish among the preclosure performance of potential first repository sites. As such, it used as its basis the current configuration of the waste management system. It was found that the results were reproducible and consistent with the bases and assumptions indicated in the document.

TABLE 4.21. Total Nonradiological Worker Fatalities from Construction and Operation of Repositories in Three Geologic Media (DOE 1986f)

\begin{tabular}{|c|c|c|c|c|c|}
\hline \multirow{3}{*}{$\begin{array}{l}\text { Geologic } \\
\text { Medium }\end{array}$} & \multicolumn{5}{|c|}{ Nonradiological Fatalities } \\
\hline & Surface & ility & Undergrounc & acility & \\
\hline & Construction & Operation & Construction & Operation & Total \\
\hline Salt & 1.3 & 7.9 & 4.3 & 15.1 & 28.6 \\
\hline Tuff & 0.7 & 8.0 & 2.4 & 7.2 & 18.3 \\
\hline Basalt & 0.9 & 12.2 & 5.1 & 24.8 & 43.0 \\
\hline
\end{tabular}


The analyses of nonradiological accident risks to workers considers fatality rates that should be applicable to current mining and construction techniques and used the latest repository construction and operating personnel requirements. Radiological risks to underground workers from exposure to radon and its daughter products were evaluated. This is the only document reviewed in which this risk category was addressed. Worker risks from waste handling operations were also evaluated; however, it was assumed for comparison purposes that each worker would receive the same amount of radiation. Other studies are available in which occupational doses were estimated for specific individual work stations. These other studies would produce more accurate results. The analysis of radiological public risks presented in the document is only applicable to the site ranking methodology; more definitive results are available in other documents.

\subsubsection{Section 175 Report}

This report (DOE 1988) was prepared in response to requirements contained in Section 175 of the Amendments Act. Section 175 directed the Secretary of Energy to evaluate the impacts of locating a repository at the Yucca Mountain Site in Nevada and develop recommendations for mitigating the impacts. The report contained a description of the baseline and identification of impacts in the following technical areas:

- education

- public health

- Tais enforcement

- fire protection

- medical care

- cultural and recreational needs

- social services

- availability of energy

- general administrative needs of local governments

- vocational training and employment services 
- tourism and economic development

- population growth

- transportation

- accident management.

As shown, most of these impact areas are not necessarily related to the radiological or nonradiological safety of the potential repository and are thus not in the scope of this document.

The report provided estimates for one risk category that was not addressed in any other waste management document that was reviewed here. This category is the nonradiological accident risks associated with workers driving to and from the potential repository site during all phases of facility operation. These risk estimates were developed by assuming that the number of traffic accidents will rise proportionately with the increased traffic volume that will use the highways. The approach was to multiply together an average accident rate, the average number of trips to the potential repository site, and the average round-trip travel distance. The results of these calculations are shown in Table 4.22. As shown in the

TABLE 4.22. Projected Accidents Involving Repository-Generated Traffic and Comparisons with Baseline Projections (DOE 1988)

\begin{tabular}{|c|c|c|}
\hline Phase & Injury Accidents (a) & Fatal Accidents (a) \\
\hline Site Characterization & 21 to 24 & 2 \\
\hline Construction & 99 to 129 & 8 to 9 \\
\hline Operation & 660 to 806 & 51 to 57 \\
\hline Closure & 38 to 46 & 3 \\
\hline Totals & 821 to 1,002 & 67 to 71 \\
\hline $\begin{array}{l}\text { Base-Case (without } \\
\text { potential repository } \\
\text { traffic) }\end{array}$ & 53,421 & 2,029 \\
\hline
\end{tabular}

(a) Ranges result from four different population growth forecasts and allocation of the forecasts among the counties that are potentially affected by the repository. 
table, traffic accidents are projected to increase by approximately $1.5 \%$ as a result of repository-generated traffic.

\section{Evaluation}

The Section 175 Report provided significant information on primarily the socioeconomic effects of locating a potential repository at the Yucca Mountain Site. It establishes a baseline and evaluated the potential impacts in a number of areas, including the effects on services and facilities, tourism, economic development, and transportation services. However, the only quantitative risk information provided in the Section 175 Report were the injuries and fatalities projected to result from traffic accidents involving reposttory workers driving to and from the Yucca Mountain Site.

\subsubsection{Site Characterization P1an - Conceptual Design Report}

The Site Characterization Plan - Conceptual Design Report (SCP-CDR) presented a description of the potential Yucca Mountain repository facilities in support of the Site Characterization Plan (MacDougall et al. 1987). The report described the design and operations of the potential repository as we 11 as the design bases, design and performance criteria, and the design analyses performed. The then-current status of the preclosure performance objectives was also addressed. Quantitative accident risk information from Jackson et a1. (1984) was summarized in the SCP-CDE. The results of this study are addressed elsewhere in this report and are not repeated here. Only areas in which new information was presented will be addressed in this section. Of particular importance to this review is Appendix F of the SCP-CDR, which presented a preliminary preclosure radiological safety analysis. The purpose of this preliminary analysis was to support the identification of systems, components, and structures important to safety and waste isolation (Q-1ist). The definition of a Q-1ist item is one that is essential to preventing or mitigating an accident that could lead to an offsite dose greater than $0.5 \mathrm{rem}$.

The preclosure safety analysis used a PRA-based methodology to assess the frequencies and dose consequences of potential accident scenartos. The approach included the following major activities: 1) identify and screen internal and external initiating events that could result in significant 
offsite releases, 2) develop event trees and fault diagrams to evaluate the frequencies of accidents, and 3 ) assess the release quantities and dose consequences projected to result from the accidents. The frequencies and doses for a total of 21 event trees were evaluated representing 149 accident scenarios.

A fair amount of detail was presented in the report on an evaluation of the particulate releases that could occur as a result of the accidents. Radionuclide retention factors were developed for various levels of radionuclide containment, including fuel cladding, transport casks, canisters, disposal containers, buildings, and hot cells. Atmospheric dispersion modeling was performed for worst-case conditions only (Pasquill Stability Class $F$ and wind speed of $1 \mathrm{~m} / \mathrm{s}$ ). Only external exposure (immersion) and inhalation pathways were considered in the analysis. Ingestion and other pathways were excluded from this analysis. Based on these preliminary analyses, it was determined that the critical human organ for releases of particles from spent fuel was bone. The major radionuclide contributors to these doses were Pu$238(36 \%), \mathrm{Pu}-241(30 \%), \mathrm{Am}-24 \mathrm{1}(10 \%), \mathrm{Pu}-240(10 \%), \mathrm{Pu}-239(6 \%), \mathrm{Sr}-90(5 \%)$, and $\mathrm{Cm}-244(4 \%)$. For releases involving solidified HLW, the limiting critical organ was again bone, with most of the bone dose resulting from Pu-238 $(80 \%)$ and $\operatorname{Sr}-90(16 \%)$.

Based on these analyses, it was determined that a total of four internally initiated accident scenarios and nine externally-initiated accidents (a11 nine were initiated by earthquakes) would result in offsite radiation doses in excess of $50 \mathrm{mrem}$. This is one-tenth the 500 -mrem criterion for Q-1ist items. Additional accident sequences were found to result in higher doses; however, it was determined that the annual frequencies of these sequences were less than $10^{-9} / \mathrm{yr}$, and they were judged to be not credible. The results for the credible accident sequences are summarized in Table 4.23.

\section{Evaluation}

This report presented a credible preliminary estimate of the accident risks associated with the preclosure phases of a potential repository at Yucca Mountain. It provided a comprehensive identification of potential accidents and used current methods and data to assess their frequencies and

\subsection{1}


TABLE 4.23. Frequencies and Consequences of Accident Scenarios Projected to Result in Offsite Doses Greater than

0.05 Rem (MacDouga11 et a1. 1987)

\section{Accident Scenario Description}

\section{Internally Inttiated Events}

Crane drops shipuing cask, cask breached

Crane drops fuel assembly in hot ce11, HVAC fails

Crane drops open consolidated fuel container, HVAC fails

Container dropped in storage vault, filtration system fatls to activate
Frequency, per year

$5 \mathrm{E}-6$

$1 \mathrm{E}-8$

$1 E-9$

$3 E-8$

230

\section{Externally Initiated Events (a11 caused by earthquake)}

Crane fails, falls on or drops cask in receiving area

$5 \mathrm{E}-8$ 340

Train falls on cask

$5 E-8$ 290

Structural object falls on fuel in cask

$5 \mathrm{E}-7$

110 unloading cell

$1 E-6$

110 cask unloading cell

Structural object falls on fuel in

$5 E-7$ consolidation cell

Crane fails, falls on or drops fuel in consolidation cell

$1 E-6$

110

Structural object falls on fuel in

$5 E-7$

330 packaging cell

Crane fails, falls on or drops fuel in

$1 E-6$

1100 packaging ce11, HVAC fails

Structural object falls on fuel in

$5 E-7$

200 transfer tunnel 
consequences. Unlike most other reports reviewed here, the SCP-CDR also presented an assessment of radionuclide transport from the affected source through the facility and into the environment, including an assessment of radionuclide retention by various levels of radionuclide containment barriers. Worst-case atmospheric dispersion modeling was performed. Estimates of individual doses at the site boundary were then calculated. However, no attempt was made to estimate the population doses that would result from these accidents because this was not necessary to satisfy the objectives of the allalysis (i.e., support development of the Q-1ist). Because population doses were not estimated, this report is not used in Chapter 5.0 to evaluate preclosure repository risks.

\subsubsection{Preliminary Analys is of Routine Doses at Yucca Mountain}

This paper (Jardine et a1. 1988) presented a preliminary assessment of the population doses from normal operation of the potential tuff repository. Major waste handling activities were examined to identify potential sources of airborne emissions of radioactive materials. After the potential sources were identified, the source terms were estimated based primarily on information from the literature. Releases from intact and failed fuel were then estimated. Release quantities were then calculated based on decontamination factors for a two-stage system of HEPA filters. The filter efficiencies were estimated to be $10^{-4}$ for particulates. All of the gaseous radionuclides released within the surface facilities were assumed to pass through the HEPA filter systein and enter the environment. It was estimated that $97 \%$ of the radioactivity released in the waste handling building of the potential repository came from $\mathrm{Kr}-85$ and $3 \%$ from $\mathrm{H}-3$. The remaining radionuclides contributed less than $0.01 \%$ of the total activity released to the environment.

The radioactive source terms were then used to develop population dose estimates. A multisector atmospheric dispersion analysis was performed (i.e., 16 compass directions and 4 distances). Annual average wind data from the Yucca Mountain site were used; however, since atmospheric stability data were not yet available, worst-case conditions (Pasquill Stability F) were used in the calculations. Radionuclide pathways considered in the dose 
analysis included immersion and inhalation. Ingestion was apparently not included. The results of the population radiation dose calculations are summarized below:

- Maximally exposed individual dose. The maximum whole-body dose to an offsite individual ( 5 kilometers) from inhalation was estimated at $0.01 \mathrm{mrem} / \mathrm{yr}$. Contributions from $\mathrm{Co}-60$ accounted for about $55 \%$ of the dose followed by $\mathrm{H}-3(30 \%)$ and $\mathrm{Kr}-85$ (15\%).

- Population dose. The population dose was determined using the population within 80 kilometers of the potential repository (about 11,000 persons). The annual whole-body total population dose was estimated at about 0.004 person-rem/yr from inhalation.

\section{Evaluation}

This paper presented a credible estimate of the maximally exposed individual and population exposures that are projected to result from routine releases of radioactive material from a potential repository at Yucca Mountain. Credible methods and data were used to develop these estimates. Actual weather data were used to the extent possible to incorporate sitespecific meteorological conditions into the analysis. The document was based on the current system configuration and appears to represent a comprehensive analysis. One iechnical area that was not included in the analys is was the ingestion pathway.

\subsubsection{Reports Selected For Use in This Study}

The risk and dose information from the reports reviewed in Section 4.1 .1 are used in Section 5.1 to develop estimates of the risks from the construction, operations, and decommissioning of repositories in two system configurations. Reports that most closely fit the needs of this study are selected in this section to establish the basis for these estimates. The selection of reports was based on the qualitative criteria listed in Table 4.1.

An overview of the risk categories addressed in the repository preclosure literature is presented in Table 4.24. As shown, some risk categories were addressed in several documents while other categories were covered by only a single document. The available literature primarily addresses the operations phase of the repository. The risk categories addressed most frequently are: 1) public radiological accident risks, 2) public exposures 


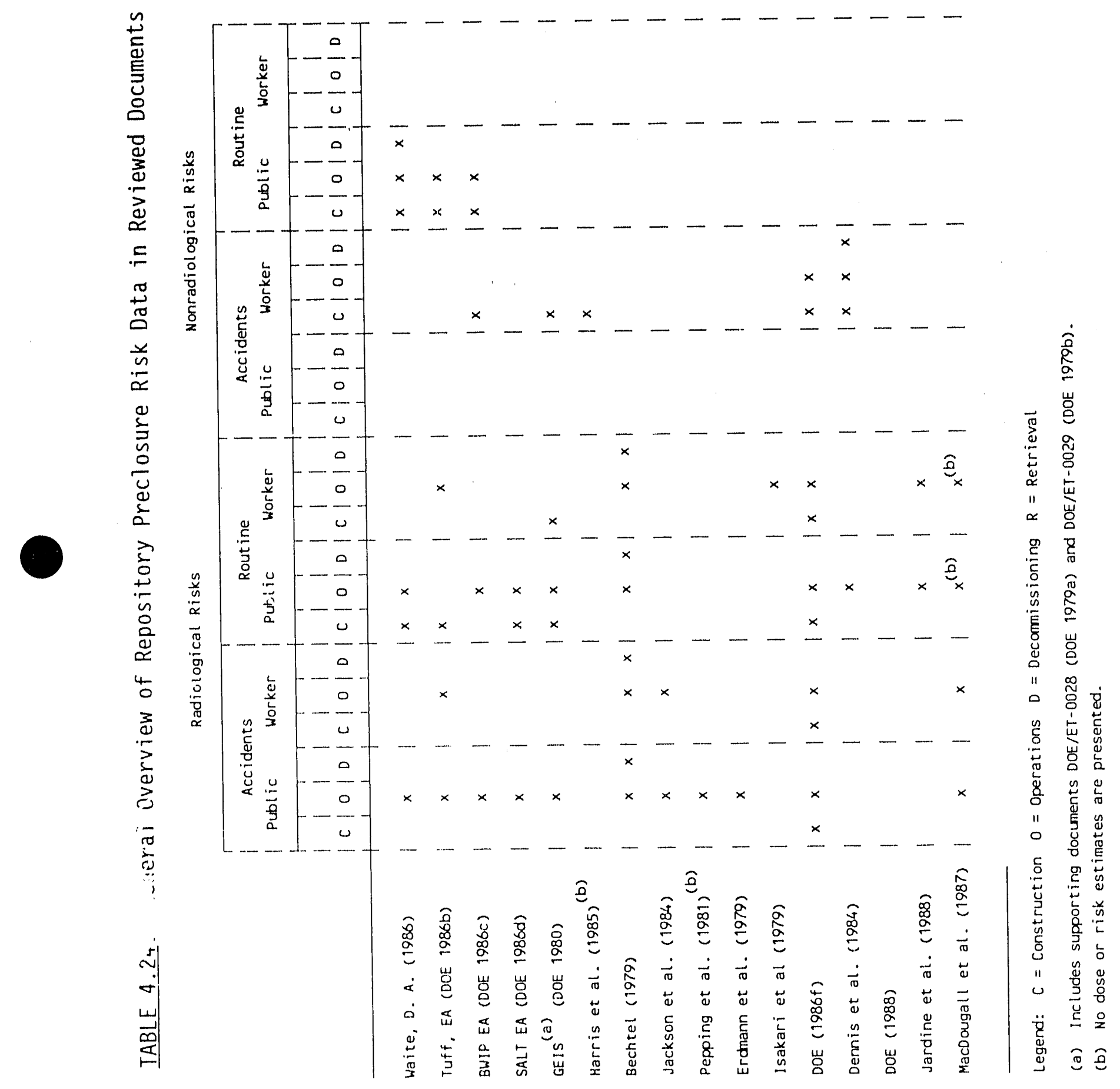


from routine operations, and 3) occupational routine exposures. These areas are addressed most frequently because they are often used as the basis for decision-making and facility licensing. Nonradiological accident risks were addressed in only a few documents. Routine nonradiological emissions were quantified in some documents, but health effects from nonradiological emissions were not estimated. Most of these studies compared estimated concentrations of nonradiological pollutants to EPA limits.

The radiological risk and exposure values contained in the reviewed reports are summarized in Table 4.25 . The results are presented in the table as they were found in the references. No attempt has been made to present the results on a consistent basis. The table illustrates the risk categories that have been addressed and the forms of the raw data contained in the literature. As indicated in Section 4.1.1, the studies vary widely in scope, assumptions, data, methods, and facility designs. The table also illustrates the range of the risk estimates found in the literature to the extent the results are comparable. The Basalt Waste Isolation Project (BWIP) Environmental Assessment (DOE 1986c) was not included in the table because the results were presented only for the maximally exposed individual. The Deaf Smith environmental assessment was not included because the population risk estimates contained in the document were described in more detail by Waite et a 1. (1986). DOE (1988) was not included because it presented only nonradiological risk information.

Routine public risks during construction will arise from releases of radon and its daughter products from mined rock that is stored on the surface. This category of risk was addressed in three documents: the GEIS (DOE 1980), the tuff environmental assessment (DOE 1986b), and Waite et al. (1986). Al1 three documents will approximately equal in terms of technical accuracy, realism, and modeling sufficiency criteria (see Table 5.1). However, Waite et al. (1986) is more applicable to the current system configuration and presents risk values that are specific to the Deaf Smith site $(\mathrm{salt})$. As a result, the waite et al. (1986) document was judged to contain the best available information in this category. 


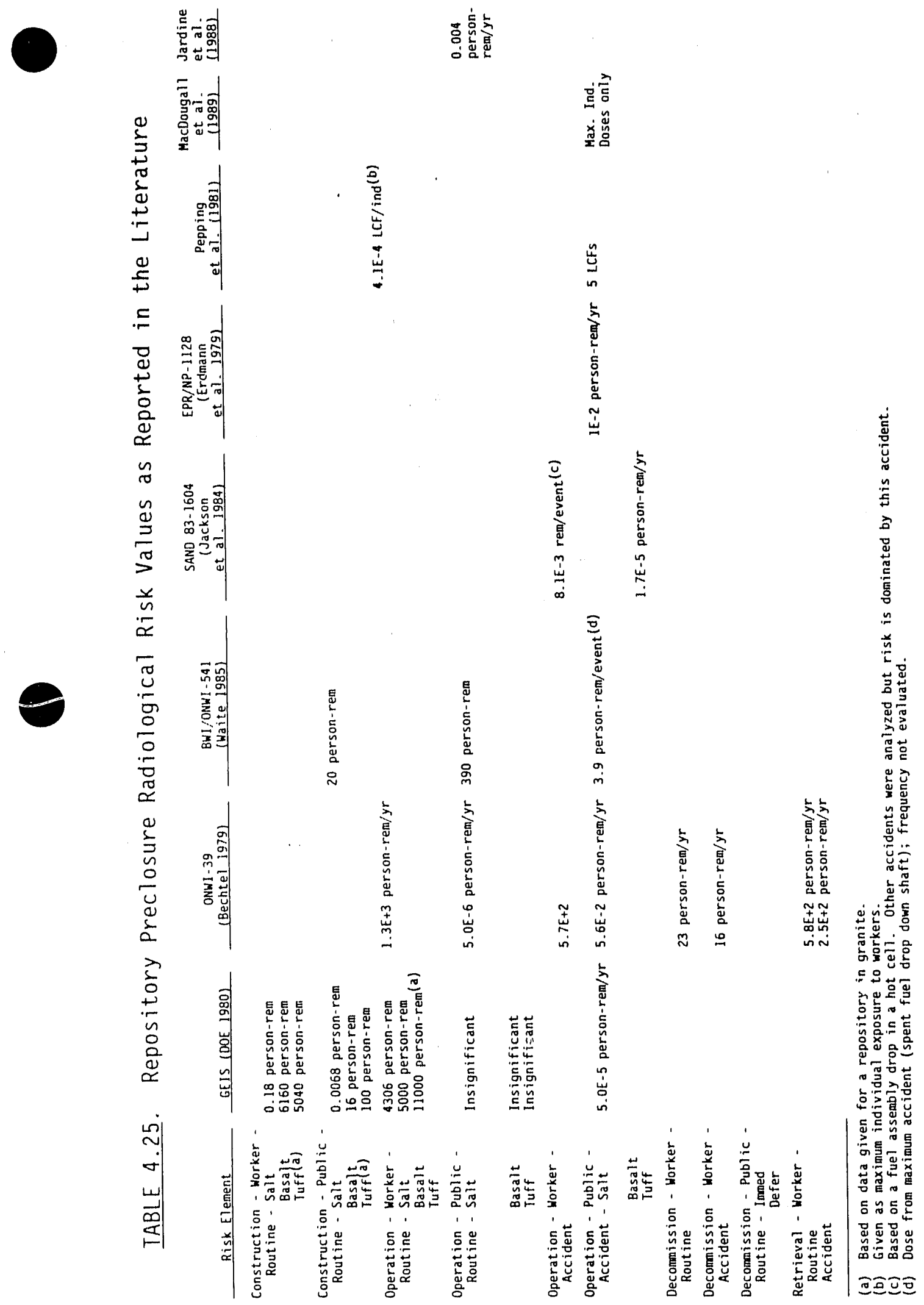


Routine occupational risks during construction were addressed in three documents: the GEIS (DOE 1980), the tuff environmental assessment (DOE 1986b), and the first repository site-selection document (DOE 1986f). A11 three studies estimated the exposures of underground construction workers to radon and daughter products. Since the estimates contained in the tuff environmental assessment (DOE 1986b) and DOE (1986f) were based on the most recent estimates of underground personnel requirements and mined rock volumes, they were used in Section 5.1.

Occupational exposures during repository operations are given in the GEIS (DOE 1980), Bechtel (1979), Dennis et a1. (1984), the tuff environmental assessment (DOE 1986b), and Isakart et a1. (1980). The results from these studies were converted to a consistent basis of person-mrem/MTU so they could be compared. The comparable values are shown in Table 4.26. The unit dose results ranged from about 17 to over 260 person-mrem/MTU. This range reflects the variability of methods and data used to derive these estimates. The results that are believed to be most representative of actual doses are those derived from time-and-motion and personnel occupancy studies based on repository conceptual designs. These were presented by Isakari et a1. (1980) and Dennis et al. (1984). The basis for the estimates in the GEIS and in Bechte1 (1979) were not as clear, nor were they reproducible. Many conservative assumptions were made in the latter documents, such as the assumption that $60 \%$ of the total surface facility work force were radiation workers.

IABLE 4.26. Comparison of Unit Occupational Dose Estimates from the Literature

\begin{tabular}{|c|c|}
\hline Document & Dose (persor \\
\hline Isakari et al. (1980) & 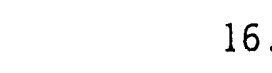 \\
\hline GEIS & 90 \\
\hline Dennis et al. (1984) & 23 \\
\hline Bechtel (1979) & 260 \\
\hline \multicolumn{2}{|l|}{ DOE $1986 f$} \\
\hline $\begin{array}{l}\text { Salt } \\
\text { Basalt } \\
\text { Tuff }\end{array}$ & $\begin{array}{r}110 \\
140 \\
70\end{array}$ \\
\hline
\end{tabular}


The results in the site-ranking document (DOE 1986f) were based on the assumption that all surface facility radiation workers would receive an average annual dose of $0.5 \mathrm{rem} / \mathrm{yr}$. This was an adequate approach for siteranking purposes but did not represent a detailed and comprehensive analysis. As a result, the occupational exposure estimates developed by Isakari et al. (1980) and Dennis et a1. (1984) were judged to best meet the needs of this study.

Routine public risks during the repository operating phase were addressed explicitly by waite et a1. (1986) for the potential salt repository and by Jardine et a1. (1988) for the potential tuff repository. These analyses included consideration of radicactive materials released during rodconsolidation operations, which was believed to be the most significant source of routine emissions. That study was selected as the basis for the risk estimates presented here because it was directly applicable to the current waste system, incorporates site-specific weather and population data, uses adequate models, and presents reproducible results. The GEIS (DOE 1980) and Bechtel (1979) were not selected because they were not as applicable as Waite et al. (1986) to the current system configuration.

Occupational risks from accidents were addressed in only two documents: Bechtel (1979) and Jackson et a1. (1984). Jackson et a1. (1984) clearly addressed a more applicable system configuration and was thus selected as the basis for this risk category. In addition, it was difficult to reproduce the results in Bechtel (1979), which were based on a fuel reprocessing plant that assumed underwater unloading of spent fuel transportation casks.

Public accident risks during operations were addressed in five studies, as shown previously in Table 4.25. None of these analyses were considered to include a comprehensive identification and evaluation of a11 possible accident sequences. Most of the studies emphasized postulated "worst-case" or "design-basis" accidents and then demonstrated that the consequences of the accidents were within permissible levels. There is no evidence that these estimates included the accidents that dominates the total risk values. For comparison purposes, the results from the accident risk studies were 
converted to a consistent basis. The resulting risk values, on a personrem/MTU basis, are presented in Table 4.27. As shown, the magnitudes of the public risk values were much lower than the occupational risks. They ranged from about 2.0E-6 to $6.0 \mathrm{E}-10$ person-rem/yr. Some of the values were based on single accidents while others are based on five or more accidents.

Jackson et a1. (1984) was directly applicable to the current system configuration. Waite et a1. (1986) was not as applicable as Jackson et al. (1984) but provided supplementary information that was not included by Jackson et a1. The GEIS (DOE 1980) and Erdmann et a1. (1979) were less applicable than the Waite and Jackson studies and thus were not reviewed further. In addition, the former two studies included analyses of other waste types so in this context are more comprehensive. It should be noted that Harris et a1. (1985) contains a comprehensive identification of accident sequences but does not include analyses of their probabilities and consequences. The SCP-CDE did not quantify population doses and so was excluded from the quantification of risks in Chapter 5.0. As a result, Waite et a1. (1986) and Jackson et al. (1984) were selected as the bases for the public accident risk values.

One should exercise caution when interpreting the values presented in Tables $4.25,4.26$, and 4.27 . For instance, it should be recognized that "routine" doses result from an expected exposure during plant activities that are of a continuous nature. On the other hand, the major portion of the

TABLE 4.27. Comparison of Normalized Public Accident Risk Values from Various Studies

\begin{tabular}{lcll}
\multicolumn{1}{c}{ Document } & $\begin{array}{c}\text { Risk } \\
\text { (person-rem/MTU) }\end{array}$ & & \multicolumn{1}{c}{ Comment } \\
\hline GEIS & $8.4 E-9$ & & One accident \\
Bechte1 (1979) & $1.1 E-10$ & & One accident \\
Waite et al. (1986) & $1.7 E-8$ & & Five accidents \\
Jackson et a1. (1984) & $5.7 E-9$ & & Ten accidents \\
Erdmann et al (1979) & $1.8 E-6$ & & Seven accidents \\
Pepping et a1. (1981) & $6.3 E-10$ & & One accident
\end{tabular}


dose from an accident is received at the time of the accident, which may or may not occur in any particular year. Whereas the probability of receiving a "routine" dose over a given period of time is essentially 1.0 for an operating facility, the probability of an "accident" dose over a given time period is likely to be much less than 1.0. Routine dose per year is expected to occur (although magnitude may vary). However, accident doses are relatively rare events. Both are considered as "risk," a term that generally implies the product of a consequence with a related probability and both have the same units, person-rem/yr. The dose values themselves should also be carefully interpreted. Some are 50-year commitments; some are 70-year commitments; some are the total received over a set number of years with, perhaps, an assumed dose-commitment period added.

Only two risk categories for decommissioning activities were addressed in the literature: 1) routine worker exposures and 2) accident risks. Bechtel (1979) was used as the basis for the risk estimates developed in Section 5.1. It should be noted that the repository environmental assessments addressed decommissioning impacts but did not quantify them. It was concluded in the environmental assessments that no significant impacts are expected.

Nonradiological accident risks for repository construction and operation were estimated in three documents: the GEIS (DOE 1980), the site Selection Methodology (DOE 1986f), and the Section 175 report (DOE 1988). The fatality rates for surface facility construction and operation were the same in the GEIS and in DOE (1986f). DOE (1986f) used more recent accident statistics for underground operations than were used in the GEIS. In addition, the results presented in DOE (1986f) were based on the most recent estimates of repository personnel requirements. As a result, it was used as the basis for the nonradiological risk estimates in Section 5.1 .

\subsection{REPOSITORY POSTCLOSURE}

In the 1970s, there were a number of outstanding efforts to understand and quantify the potential safety impacts of deep geologic repositories. Examples are the work of Claiborne and Gera (1974), Burkhol ter et al. (1976), 
and $\mathrm{Hill}$ and Grimwood (1978). Although this early work is not reviewed here, it did lay the groundwork for most of the more recent studies.

In the United States, repository risk analysis and performance assessment work has been carried out in support of several major federal actions. The DOE performed work to support its eventual decision to select deep geologic repositories as the preferred disposal method for HLW and TRU wastes. This work and the resulting decision were documented in the GEIS (DOE 1980).

The EPA and U.S. Nuclear Regulatory Commission (NRC) have both done work in support of their regulatory activities. The EPA's work supported the development of the performance standards for the repository. The NRC did work to evaluate their performance requirements and to comment on the EPA standard. The NRC also has work ongoing to develop and demonstrate methods that can be used to show compliance with the standard and to develop methods and expertise to evaluate the license application that will eventually be submitted by DOE.

The major efforts in postclosure performance and risk analysis are being carried out by or in behalf of DOE to support its decisions on selecting the first potential repository site, and to develop the methods and data that will be needed to support a license application to the NRC. The DOE has also done work to provide information to select a reference waste form for HLWS from defense activities that will require disposal in geologic repositories. A number of other countries are also developing waste management systems for their commercial nuclear programs. Repository risk information has also been developed in these programs.

\subsubsection{Review of Repository Postclosure Risk Literature}

The literature review presented in this section is organized around the major activities discussed above. The selection of major activities for grouping the postclosure literature allows the discussion of work that has common objectives in the same sections. The purpose, scope, and basis of each study are discussed, and the results are summarized and evaluated. A brief comparative summary follows the discussion of the literature representing each major performance assessment activity. 
Much of the work does not present actual risk results. Also, much of the work to date has focused on the technical challenges involved with predicting the amounts of material that would be released from the waste form under various conditions and modeling the transport of radionuclides through the geosphere.

\subsubsection{The Postclosure Risk Assessment Supporting the DOE's Final Environmental Impact Statement}

The GEIS (DOE 1980) contained a generic postclosure risk assessment. This assessment provided the information needed to select deep geologic disposal as the preferred waste disposal method. The GEIS presented risk analyses that provided a starting point for more sophisticated and sitespecific work required for future decisions.

The scope of the postclosure risk assessment work reported in the GEIS was consistent with the need for a bounding estimate of postclosure risks from the geologic disposal activity. The scope was limited to an evaluation of the consequences of worst-case scenarios for a generic repository. The scenario consequence calculations were generic in the sense that host rock properties were not taken into account. The only differences between host rock were in the different inventories that, at that time, were thought to be likely for each host-rock type. The inventories that would be put into the different rock types being considered at that time were: 122,000 MTHM spent fuel for basalt or granite; 64,000 MTHM for shale; and 51,000 MTHM for salt. The difference in capacity between the current repository design (70,000 MTU) and the basalt and granite repositories in the GEIS would amount to a factor of 2, which was not significant in terms of the order-of-magnitude estimates made in the GEIS. Engineered barrier system assumptions were limited to the consideration of conservative leaching rates for the waste form after exposure to groundwater was initiated by some process or event scenario.

Some highly unlikely scenarios were treated in the GEIS, such as repository breach by a meteorite strike and the solution mining of salt. The meteor strike scenario is now considered too unlikely to be a significant contributor to risk (DOE 1986b, EPA 1985a). The solution mining scenario, perhaps more likely, was not to be modeled according to an assessment by the 
DOE Salt Repository Project (DOE 1986b) because the assumptions made in order to evaluate the consequences of this scenario included: 1) the denial of the partial effectiveness of passive markers, 2) the idea that future generations will not understand radioactivity and its hazard, and 3) that future generations will have the technology to initiate a complex human intrusive event but will not have the competence to assess the risks and take remedial actions at the same level of technolngical complexity.

The remaining scenarios evaluated in the GEIS were: 1) faulting resulting in surface water contamination by flow through a small stream, surface water contamination by groundwater flow, and contaminated groundwater reaching a well; and 2) drilling bringing the content of a canister to the surface.

In the faulting scenarios, a major fault was assumed to expose the waste form in the repository, reduced only by radioactive decay, to a batch of water for 1 year. The fault was assumed to occur at 1,000, 100,000 or $1,000,000$ years after closure. Water containing dissolved waste was assumed to flow 1) as a sma11 stream or 2) as groundwater into a river about $10 \mathrm{kilo-}$ meters from the repository. A domestic well 3 kilometers downstream from the repository, which withdrew $20 \mathrm{l} / \mathrm{min}$ of potable water, constituted the third hypothetical case considered for the faulting scenario. The leach rate of the spent fuel waste form was $1.0 . E-5 \mathrm{~g} / \mathrm{cm}^{2} /$ day.

In the surface-water transport/contamination case, the maximally exposed individual drank this water at the point just before it entered the river, watered all his animals and irrigated his crops with it, and found recreation and food in and alongside the river. The maximum lifetime (70-years) whole body dose commitment from this 1-year exposure scenario ranged from nearly 5 rem to 10 rem for nonsalt cases, for the three times considered. The salt case was altered since the salt water would prevent the stream itself from being used directly for domestic or agricultural purposes. The contaminated water could not be used until it had mixed with the river at the inflow point. The maximally exposed individual in this case received a 70 -year dose commitment ranging from 0.2 rem to 0.3 rem for the times considered. 
In the surface water transport case, population dose estimates were based on the level of contamination in the river. With an assumed regional population size of a few mflition and an assumed correlation of 200 health effects for every milliton person-rems, approximately 40 to 60 health effects could be expected if this catastrophic scenario occurred. Health effects included latent cancer fatalities (somatic effects) as well as genetic effects. The scenario itself was estimated at a probability of 2.0E-13, resulting in an annual risk of $3.0 E-11 / y r$. Flow into the oceail was also considered, but the resulting dose commitment was only an additional $1 \%$ of background to individual doses.

In the groundwater transport case, the largest 70-year dose commitment to a maximally exposed individual was $1 \mathrm{rem}$. Since the ratio of the percapita whole body dose to the maximally exposed individual whole body dose for the surface water transport case was 15 , the same ratio was assumed in this groundwater transport case. For a 2 milition person regional population, a 2.0E+5 person-rem 70-year dose commitment was calculated, which corresponds to a $1 \%$ increase over naturally occurring background radiation.

The GEIS also examined a case in which the same faulting scenario resulted in contamination entering a well after the repository was breached by the fault. Assumptioris were similar to those used in the river contamination case except that 1,000 to 2,500 years is required for the groundwater to travel from the repository to the we11. In this case, the repository water was assumed to dissolve 2,550 assemblies over 10,000 years. The contamination would not reach the well for 4,000 to 10,000 years depending on the time at which the fault was assumed to occur. The dose to the maximally exposed individual from this scenario was relatively high, but there was little possibility of exposing large numbers of people, so that risk from the scenario was negligible.

The drilling scenario assumed that the well was drilled directly through a waste canister. One fourth of the canister contents was assumed to be brought to the surface and distributed over a 0.5 hectare area of 1 and on which the maximally exposed individual spent 12 hours per day breathing dust and growing crops. A probability was not assigned for the initiation of 
we11-drilling, but the GEIS reported that the repository geometry would ind cate that the chance of intersecting a canister would be about 0.005 per we11 drilled. This event resulted in a 940 rem 70 -year whole body dose in the maximally exposed person for spent fuel in the reference container that was assumed in the GEIS. Such a dose would have a small chance, according to the GEIS, of causing a health effect. Since a sma11 area is affected, population consequences would be negligible.

\section{Evaluation}

The GEIS represented a successful attempt to provide bounding estimates of maximum risks to future generations for the postclosure deep geologic disposal option. Bounds on the worst-case risks offers little that can be reliably used as best estimates of societal risks, however, because 1) there is little that is site-specific about these analyses and 2) the scenarios are highly unlikely and even where there are probability estimates assumed for the initiating events, they are not defensible estimates. This is i11ustrated by the controversy over the probability of faulting between the DOE and EPA, which was documented in the footnotes of the GEIS. The GEIS i11ustrated that the purpose for which a risk analysis is done determines the uses that can legitimately be made of the results.

\subsubsection{Risk Assessments Supporting the EPA Standard}

The EPA and its contractors have done a number of risk assessments in support of the development of the Environmental Standards for the Management and Disposal of Spent Nuclear Fuel, High-Level, and Transuranic Radioactive Wastes, 40 CFR Part 191 (EPA 1985a). These risk assessments are described by Smith et a1. (1982a,b) and in EPA (1985b).

The purpose of the postclosure repository risk assessments done by the EPA and its contractors was to help define quantitative limits on 10,000-year cumulative radionuclide releases into the accessible environment.

The final repository performance standard developed by EPA (EPA 1985a) was based on the acceptability of a cumulative release to the accessible environment resulting in 1,000 health-effects over 10,000 years from a 100,000 MTHM repository. This particular level of acceptable risk was based 
on risk assessments of urantum ore bodies (Williams 1980). These studies estimated the health effects produced from the uranium ore. The final standard was within the range of the results reported in these studies. The standard was set at a level that would result in public consequences at or below the level that could have been expected had the uranium never been mined (EPA 1985a).

The 1982 EPA risk assessments (Smith et a1. 1982a,b) attempted to bound risks for hypothetical repositories in basalt, granite, bedded salt, domed salt, and shale. Although the properties of these rock types were used to an extent, the purpose was to provide insight inio the generic standard that was being developed for application to any repository in any rock type. No effort was made, therefore, to simulate the actual locations being considered as candidates for repositories by DOE, and results were especially pessimistic for the Yucca Mountain candidate location because of inappropriate pathway and population assumptions.

In 1985, the EPA reported revised estimates of risks from generic repositories in basalt, bedded salt, tuff, and granite (EPA 1985b). These revised risk estimates used improved information regarding repositories at proposed candidate sites, as well as impruved models for pathway and dose analyses.

In the supporting documents published by EPA, the population risks from the undisturbed generic repositories were based on estimates of radionuclide releases through an aquifer into a river (Smith et a1. 1982). The use of groundwater as a direct water supply was not considered, and a generic river was assumed for each generic site. Irrigation with contaminated river water and human intrusion scenarios brought radionuclides to the soil surface. Resuspension of nuclides deposited on land surfaces was considered in the consequence calculations. Pathways in which the river and air sources deposited materials in the oceans were also examined. All of these sources of radionuclides were then analyzed for dose contributions through applicable food chains. Somatic and genetic effects were reported separately and summed to yield "health effects," such as premature deaths from cancers in the exposed and following generations. 
The 1985 revisions of this 1982 work included more site-specific information regarding the potential repository and the host-rock. The 1982 work by Smith et al. reported results for their reference case analyses that are summarized in Table 4.28. These estimates were revised in the 1985 EPA work in support of the final rule (EPA 1985b). The major differences between the 1982 and 1985 assessments lies in the nature of the data used to describe the repository and its environment. Very low probability scenarios were also not included since their risk contributions were negligible. The results of the 1985 assessment are presented in Table 4.29.

\section{Evaluation}

The EPA underscored the importance of recognizing the limitations of the generic risk estimates provided in support of the development of the EPA standard (EPA 1985a). In one of the EPA's supporting documents (Smith et al. 1982b), it was made clear that relatively unsophisticated models were used that were intended to overestimate risks, not underestimate them. That this strategy limits the uses to which the results can be put was made clear by Smith et a1. (1982b):

TABLE 4.28. Expected Health Effects Over 10,000 Years for Hypothetical 100,000 MTHM Repositories in Basalt, Bewad Salt, Shale, and Granite (Smith et al. 1982a)

\begin{tabular}{|c|c|c|c|c|}
\hline Scenario & Basalt & Bedded Salt & Shale & Granite \\
\hline \multicolumn{5}{|l|}{ Somatic Effects } \\
\hline Undisturbed & 1,420 & 0 & 1,420 & 11 \\
\hline $\begin{array}{l}\text { Drilling (misses } \\
\text { canister) }\end{array}$ & 2,960 & 181 & 5,910 & 747 \\
\hline $\begin{array}{l}\text { Drilling (hits } \\
\text { canister) }\end{array}$ & 2 & 5 & 5 & 0.6 \\
\hline Faulting & 3 & 0.007 & 0.1 & 0.1 \\
\hline Breccia pipe & - & 0.001 & - & - \\
\hline Meteorite & 0.003 & 0.003 & 0.003 & 0.003 \\
\hline Volcano & 0.2 & 0.03 & 0.03 & 0.03 \\
\hline Total Somatic Effects & 4,390 & 186 & 7,340 & 760 \\
\hline Total Genetic Effects & 153 & 2 & 200 & 13 \\
\hline Total Health Effects & 4,543 & 188 & 7,540 & 773 \\
\hline
\end{tabular}


TABLE 4.29. 1985 Revised EPA Estimates of 10,000-Year Health Effects for 100,000 MTHM Repositories in Basalt, Bedded Salt, Tuff, and Granite (EPA 1985b)

\begin{tabular}{|c|c|c|c|c|}
\hline Scenario & Basalt & Bedded Salt ${ }^{(a)}$ & Tuff & Granite \\
\hline Undisturbed & 97 & 0 & 0 & 184 \\
\hline $\begin{array}{l}\text { Drilling (misses } \\
\text { canister) }\end{array}$ & 2.30 & 3.16 & 0 & 0.92 \\
\hline $\begin{array}{l}\text { Drilling (hits } \\
\text { canister) }\end{array}$ & 1.73 & 3.41 & 0.44 & 0.44 \\
\hline Faulting & 24.4 & $\underline{0}$ & 3.00 & 8.49 \\
\hline Total Health Effects & 125 & 6.57 & 3.44 & 194 \\
\hline
\end{tabular}

(a) Palo Duro. Basin

(b) Drilling accidents that miss canisters have larger risk values than accidents that hit canisters because the probability of missing a canister is larger than hitting a canister.

"... these analyses can not be used to judge the risks from a specific disposal system at a specific site. The detailed data and particular circumstances associated with that specific site must be considered.... However, we do believe that the analyses described in this report provide reasonable upper bounds of the risks from geologic repositories -- given the specific assumptions for each analysis. Accordingly, the Agency has used these analyses as an important tool in selecting the long-term containment requirements in its proposed standards for disposal of high-level wastes."

The 1985 EPA risk estimates were improved because they were more sitespecific in terms of host-rock properties, but the other properties of the potential repository/environment system were generic, as before. The 1985 EPA study similarly caveated its results:

"Because of the generic nature of the analysis, the results of the risk calculations cannot purport to project the actual risk expected at these particular sites; such projections will not be possible before the potential sites are fully characterized."

The annual population risks calculated in this conservative, generic assessment ranged from $1.0 \mathrm{E}-2$ to $1.0 \mathrm{E}-4$ health-effects per year. Both the EPA risk analyses (Smith et al. 1982a,b) listed the use of generic assumptions, estimated parameters, and simplified models as significant sources of uncertainty. Both analyses contained parameter variation study results 
(Smith et a1. 1982b; EPA 1985b). The EPA (1985b) parameter variation results underscored the importance of the assumed waste-form "leach rate" in the modeling and that host-rock permeability was generally more important to the determination of risk than were reasonable variations in retardation and solubility numbers. Whether or not there was fracture flow rather than just matrix flow in unsaturated tuff was very important.

\subsubsection{Risk Assessment Supporting the Selection of the Reference Defense Waste Form}

The Savannah River Plant (SRP) in Aiken, South Carolina, is the defense waste form production facility. The NWPA called for a decision on whether or not defense waste was to be disposed of in the civilian nuclear waste repository. Therefore, prior to 1983, the SRP sponsored its risk assessments for a defense waste repository. Borosilicate glass was the waste form used in those risk assessments.

There was a need to evaluate risks to support research regarding an advanced waste form. This evaluation activity had many facets, but the one of interest here was a risk assessment by Cheung et a1. (1982) in which the doses resulting from having either the advanced or the reference waste form in the repository were compared. The comparative risk analyses were performed for two hypothetical repositories, one in bedded salt and one in basalt, with the reference and the advanced waste forms as the variable while all other conditions were kept constant.

The defense waste repositories were modeled using data and assumptions that approximated candidate bedded salt or basalt sites, hence the results did not specifically address the sites presently of interest. The methodology did illustrate a Monte Carlo technique, however, and an effort was made to assign probabilities to some scenarios and to analyze them. The objective of the work was to compare waste forms to see if the reference waste form was suitable. Background dose was used as the unit of measure upon which the comparison would be based.

The results showed an expectation of low population and individual dose rates for both waste forms in both repositories. The advanced waste form was generally an order of magnitude below the reference waste form in terms of 
best-estimate releases ( 0.5 confidence level) to the biosphere and resulting doses; at higher confidence levels ( 0.9 to 1 imiting), there were no significant differences. The doses from the reference waste form were already quite low, on the order of 2,000 person-rem over a million years at the 0.9 confidence level for either a repository in basalt or in bedded salt. For the basalt location, the Columbia River system was used as the recipient of contaminated water and the pathway to the population. For the bedded salt location, a scenario was examined that included drilling a well only one mile from the repository. This scenario yielded doses that were a fraction of background, namely 3,000 person-rem over a million years at the 0.9 confidence level for the bedded salt location.

\section{Evaluation}

The decision has been made to commingle defense and civilian waste in the repository, and the contribution of defense waste to the total potential repository risk ma, be of interest but was not addressed in the study by Cheung et a1. (1982). For the purpose of this literature review, the glass waste form risk results are not useful for estimating a spent fuel repository's postclosure risks. In addition, the assumption of convective flow in salt was ultraconservative and, according to Cheung et al. (1982), greatly overestimated radionuclide movement out of the repository for the undisturbed case, or perhaps simulated the effects of disruptive events conservatively. An uncertainty analyses emphasized the importance of the source-term (radionuclide release rate from the waste form) assumptions.

\subsubsection{Waste Isolation Systems Panel (WISP) Assessments of Hypothetical Repository Risks at OGR Candidate Repository Locations}

The Waste Isolation Systems Panel (WISP) of the National Research Council Board on Radioactive Waste Management was asked to review the state of the technologies available for the isolation of radioactive waste in mined geologic repositories and to assess their performance benefits.

In order to assess the performance benefits of the technologies available for deep geologic disposal, the WISP panel performed a number of expected dose calculations for hypothetical repositories in basalt, granite, 
tuff, and salt. In the WISP (1983) report, groundwater transport of radionuclides to the biosphere and the resulting average annual doses to individuals was calculated. Both a surface water (river) and a well water scenario were included for all sites evaluated except the Nevada tuff site, for which only the well into contaminated groundwater was considered. As much as possible, then available (1979 to mid-1982) rock type and site-specific and hydrogeologic-region-specific information were used in these analyses.

For the basalt contaminated river water scenario, calculations resulted in negligible doses because the large flow volume of the Columbia River diluted the pollutants to minute concentrations. This is a realistic assessment, since high-flow surface water would tend to dilute any pollutant, but the results are not particularly useful to this study. Therefore, the well water scenarios have been given primary attention in this review.

Calculations were deterministic, and used best-estimate parameter values. The concentration of inventory radionuclides was calculated, including decay and daughters, as a function of time and distance from the potential repository location. Exact analytical solutions were used for onedimensional advective transport with dispersion through a porous medium. Source terms were calculated assuming that waste forms were in contact with the porous host rock or other materials that were similar to the host rock in hydrologic properties. Release was modeled as either congruent dissolution at a constant rate of 1 part in 10,000 per year, or each radionuclide was assumed to continually be at its solubility limit in the solution contacting the waste form. In both cases, dilution took place as a function of distance from the surface depending on the groundwater flow rate. This approach is similar to that used in the Swedish SKBS (SKBF 1983) concept, although the KBS work included consideration of tortuosity, which may decrease the dissolution rates by a factor of 10 according to the WISP authors.

The granite rock case in the WISP (1983) report was done as a variant of the basalt case. A three-fold greater groundwater flow rate was assumed and the flow of the river was assumed to be 28 times less than the Columbia River, which was used for the basalt case. These groundwater and surfacewater flow-rate estimates have been used in previously published generic 
crystalline rock repository performance calculations (Burkholder 1982; cloninger and Cole 1981). Since there is as yet no proposed site location for a candidate crystalline repository, and since crystalline rock and site characteristics could be highly variable, depending on location, the crystalline rock case is not evaluated in Section 5.2. Only the basalt, bedded salt, and tuff cases are addressed in Section 5.2, and since the WISP (1983) report explicitly addresses the basalt rock case, its similar treatment of the crystalline rock case will not be reviewed here.

Worst case assumptions are used to calculate maximum annual doses to individuals. These individuals are assumed to drink the contaminated water exclusively, to let their food animals drink it, and to irrigate their selfconsumed crops with this water. Seventy-year lifetime dose commitments were calculated. ICRP-30 (ICRP 1979,1980) corrections were made to dose conversion factors for radionuclides that contributed to dose.

The dose calculations for the potential repository in tuff assumed saturation, which is definitely conservative for the candidate repository horizon at Yucca Mountain if the water flux rate assumptions are correct (DOE 1986b). For the basalt case, a spent fuel repository was also modeled, and the differences between the spent fuel and HLW cases were said to be directly applicable to the salt and tuff cases. For all cases, waste form dissolution commences at permanent closure.

A number of tables showing the dose rates from each contributing radionuclide taken into account were prepared for the 10,000 year groundwater travel time HLW cases. Where appropriate, the adjustments suggested in the WISP report were made to simulate a spent fuel repository. Only for the basalt case were calculations done for both spent fuel and HLW. The values in these tables were taken from figures in WISP (1983), therefore they are only approximations.

For the purposes of this survey, the results shown in the WISP report were normalized to a 10,000-year groundwater travel time, or a 10,000-year water travel period after waste form dissolution begins, with the calculated doses being those attributable to groundwater used from a well after the water had traveled for a period of 10,000 years. This time frame for making 
comparisons may be somewhat arbitrary, but it represents the period of applicability established in the EPA 40 CFR 191 standard.

The analyses in the WISP report were mainly for solidified HLW, since these studies were completed during the time when spent fuel reprocessing was still considered to be commercially viable. Therefore, the results for all the repositories (except basalt) were for HLW disposal exclusively. The report suggested that the differences in the results for spent fuel and $H L W$ observed in the basalt case calculations would be similar in all cases. These differences included:

1. For the spent fuel waste form, there would be a three-fold increase in $\mathrm{Np}-237$ dose because of increased Pu-241 in the inventory.

2. For a spent fuel repository there would be a 37 -fold increase in Pu-239 dose because of increased inventory.

3. For the spent fuel case there would be, in the near field, a four-fold increase in $\mathrm{Ra}-226$ dose because of increased $\mathrm{U}-234$ and $\mathrm{Pu}-238$ inventory and in the far field (i.e., at the 10,000-year time frame selected for this review, a 100-fold increase in Ra-226 dose because of increased U-238 inventories.

4. For spent fuel, there would be a sharp increase in I-129 doses because insoluble AgI was assumed for the reprocessing case, essentially deleting its dose contributions.

5. There may be approximately a 500-fold increase in C-14 dose expected for the spent fuel case because the release rate for $\mathrm{C}-14$ is no longer solubility controlled, and it is assumed to be congruently released at a constant fraction of $1.0 \mathrm{E}-4 / \mathrm{yr}$.

Dispersion attenuates peak doses as travel time increases and is less important if releases occur over very long periods of time compared to the travel time. Axial dispersion was estimated to be $50 \mathrm{~m}^{2} / \mathrm{yr}$ for the solubility-limited dissolution cases, which represented dissolution rates that are orders of magnitude smaller than the congruent-dissolution case in which a $1.0 \mathrm{E}-4 / \mathrm{yr}$ dissolution rate was assumed. Where radionuclides were not highly insoluble, no solubility-limited dissolution case was calculated; the 1.0E-4/yr congruent-dissolution assumption was applied; and no dispersion was taken into account, so effects of inventory, decay, travel time, and sorption would be emphasized. 
The 10,000-year groundwater travel time annual doses to the maximally exposed individual whose well taps polluted groundwater were presented for the basalt, salt, and tuff cases. For all cases, waste form dissolution commenced at the time of permanent closure.

\section{Basalt}

After 10,000 years of groundwater travel time, the estimated dose rate to the maximally exposed individual who uses contaminated groundwater are shown in Table 4.30. Values given in this table were estimated from WISP report graphs and are only approximations of the data presented. A11 results were converted to units of rem/yr from the original Sv/yr, and values of less than $1.0 \mathrm{E}-3 \mathrm{rem} / \mathrm{yr}(1.0 \mathrm{E}-5 \mathrm{SV} / \mathrm{yr})$ are not shown.

The basalt cases shown here were calculated for an estimated groundwater flow rate of $3.2 E+4 \mathrm{~m}^{3} / \mathrm{yr}$. In the case of congruent dissolution, higher flow TABLE 4.30. Maximum Individual Dose Rates (rem/yr) Estimated for a
Hypothetical Repository in Basalt $(a)$

\section{High Level Waste from 100,000 MTHM Fuel}

\begin{tabular}{ccc} 
Radionuclide & $\begin{array}{c}\text { Congruent } \\
\text { Dissolution } \\
\text { No Dispersion }\end{array}$ & $\begin{array}{c}\text { Solubility } \\
\text { Limited } \\
\text { Dissolution/ } \\
\text { Dispersion }\end{array}$ \\
\hline Se-14 & $8.0 E+2$ & $3.0 E+0$ \\
Tc-99 & $2.0 E-2$ & $3.0 E-3$ \\
$I-129$ & $9.0 E+0$ & $<1.0 E-3$ \\
Cs-135 & $9.0 E-1$ & $<1.0 E-3$ \\
Pb-210 & $4.0 E+0$ & $n . C .(b)$ \\
Ra-226 & $9.0 E+0$ & $<1.0 E-3$ \\
$U-234$ & $5.0 E-1$ & $<1.0 E-3$ \\
$\mathrm{~Np}-237$ & $8.0 E-1$ & $<1.0 E-3$ \\
$\mathrm{Pu}-239 / 242$ & $5.0 E+3$ & $<1.0 E+0$ \\
& $<1.0 E-3$ & $<1.0 E-3$
\end{tabular}

(a) Interpreted from WISP (1983).

(b) n.c. = not calculated. 
rates would reduce dose rates while lower flow rates would increase dose rates. For solubility-controlled release, the effect would not be as straightforward.

\section{$\underline{\text { Salt }}$}

The potential salt repository was modeled by postulating a highly unlikely intrusive event that allowed groundwater to flow into the repository, become contaminated, and flow out at a rate of $1.3 E+3 \mathrm{~m}^{3} / \mathrm{yr}$. The probability of such a catastrophic occurrence is probably vanishingly sma11; yet, assuming it did occur, and with dissolutioning beginning shortly after closure, the doses shown in Table 4.31 were estimated.

\section{Tuff}

The potential tuff repository was modeled using the published information available at the time of the calculations, hence the repository was

TABLE 4.31. Maxima17y Exposed Individual Dose Rates (rem/yr) Estimated for a Hypothetical Repository for HLW in Salt (a)

\section{High Level Waste from 100,000 MTHM Fuel}

\begin{tabular}{rcc} 
Radionuclide & $\begin{array}{c}\text { Congruent } \\
\text { Dissolution } \\
\text { No Dispersion }\end{array}$ & $\begin{array}{c}\text { Solubility } \\
\text { Limited } \\
\text { Dissolution } \\
\text { Dispersion }\end{array}$ \\
\hline C-14 & $2.0 \mathrm{E}+4$ & $7.0 \mathrm{E}+1$ \\
Se-79 & $5.0 \mathrm{E}+0$ & $3.0 \mathrm{E}-2$ \\
TC-99 & $<1.0 \mathrm{E}-3$ & $<1.0 \mathrm{E}-3$ \\
$\mathrm{I}-129$ & $3.0 \mathrm{E}+1$ & $<1.0 \mathrm{E}-3$ \\
$\mathrm{CS}-135$ & $7.0 \mathrm{E}+2$ & $(4.0 \mathrm{E}+2)$ \\
$\mathrm{Pb}-210$ & $7.0 \mathrm{E}+2$ & $<1.0 \mathrm{E}-3$ \\
$\mathrm{Ra}-226$ & $8.0 \mathrm{E}+1$ & $<1.0 \mathrm{E}-3$ \\
$\mathrm{U}-234$ & $5.0 \mathrm{E}+1$ & $<1.0 \mathrm{E}-3$ \\
$\mathrm{~Np}-237$ & $2.0 \mathrm{E}+5$ & $5.0 \mathrm{E}+1$ \\
$\mathrm{Pu}-239 / 242$ & $3.0 \mathrm{E}-1$ & $<1.0 \mathrm{E}-3$
\end{tabular}

(a) Interpreted from WISP (1983) 
assumed to be located in the saturated zone. The potential tuff repository would, as has since been made known, be located well above the water table. The report acknowledged this and suggested that 10,000 years should be added to the travel times shown in the calculated results. The assumed water flow rate of $9.9 E+4 \mathrm{~m}^{3} / \mathrm{yr}$ was perhaps applicable to the aquifer below the potential repository. Even so, the groundwater travel time from the proposed repository location to the nearest settlement, in this report, were thought to be 10,000 years. For the present purposes, results for the 10,000-year groundwater travel time assumption are given in Table 4.32 .

\section{Evaluation}

To aid the evaluation of the risk assessments provided by the WISP report, a summary of only those radionuclides contributing to dose greater than 1.OE-3 rem/yr (greater than 1.OE-5 SV/yr) was prepared for this report. The results are shown in Table 4.33 .

\section{TABLE 4.32. Maximum Individual Dose Rates (rem/yr) Estimated for a Hypothetical Repository for HLW in Tuff (WISP 1983) \\ High Level Waste from 100,000 MTHM Fuel}

\begin{tabular}{|c|c|c|}
\hline Radionuclide & $\begin{array}{l}\text { Congruent } \\
\text { Dissolution/ } \\
\text { No Dispersion }\end{array}$ & $\begin{array}{l}\text { Solubility } \\
\text { Limited } \\
\text { Dissolution/ } \\
\text { Dispersion } \\
\end{array}$ \\
\hline$C-14$ & 2. $. O E+2$ & $6.0 E-1$ \\
\hline Se-79 & $1.0 E-2$ & $7.0 E-4$ \\
\hline Tc-99 & $4.0 E+0$ & $\ll 1.0 E-3$ \\
\hline $1-129$ & $4.0 E-1$ & $\ll 1.0 \mathrm{E}-3$ \\
\hline$C s-135$ & $4.0 E+0$ & n.c. (a) \\
\hline$P b-210$ & $4.0 E+0$ & $\ll 1.0 \mathrm{E}-3$ \\
\hline$R a-226$ & $1.0 E-1$ & $\ll 1.0 E-3$ \\
\hline$U-234$ & $4.0 E-1$ & $<1.0 \mathrm{E}-3$ \\
\hline$N p-237$ & $2.0 E+3$ & $4.0 E-1$ \\
\hline $\mathrm{Pu}-239 / 242$ & $1.0 E-3$ & $\ll 1.0 E-3$ \\
\hline
\end{tabular}

(a) n.c. = not calculated. 
TABLE 4.33. Summary of Maximum Individual Dose Rates (rem/yr) for Hypothetical Repositories in Basalt, Salt, and Tuff (WISP 1983)

Hypothetical Repository in Basalt Solubility Limited Dissolution with Dispersion

(Parentheses Indicate Congruent Dissolution at $1.0 \mathrm{E}-4 / \mathrm{yr}$. Assumed) Groundwater Dose Contributors at $>1.0 \mathrm{E}-3 \mathrm{rem} / \mathrm{yr}$.

Radionuclide
$C-14$
Se -79
$1-129$

Cs -135

$\mathrm{Np}-237$
Calculated

Dose for HLW Case

$$
\begin{gathered}
3.0 \mathrm{E}+0 \\
3.0 \mathrm{E}-3 \\
<<1.0 \mathrm{E}-3 \\
(1.0 \mathrm{E}-2) \\
1.0 \mathrm{E}+0
\end{gathered}
$$

Calculated Dose

For Spent Fuel Case

$$
\begin{gathered}
(5.0 E+2) \\
3.0 E-3 \\
(9.0 E-1) \\
(1.0 E-2) \\
1.0 E+0
\end{gathered}
$$

Hypothetical Repository in Salt Solubllity Limited Dissolution with Dispersion

(Parentheses Indicate Congruent Dissolution at $1.0 \mathrm{E}-4 / \mathrm{yr}$. Assumed) Groundwater Dose Contributors at $>1.0 \mathrm{E}-3 \mathrm{rem} / \mathrm{yr}$.

$$
\begin{gathered}
\text { Radionuclide } \\
\hline C-14 \\
S n-126 \\
I-129 \\
C s-135 \\
N p-237
\end{gathered}
$$$$
\text { Calculated }
$$

$\begin{gathered}\text { Calculated } \\ \text { Dose for HLW Case }\end{gathered}$
$\begin{gathered}6.0 \mathrm{O}+1 \\ 1.0 \mathrm{E}-2 \\ <<1.0 \mathrm{E}-3 \\ (4.0 \mathrm{E}+2) \\ 5.0 \mathrm{E}+1\end{gathered}$

Caiculated Dose

For Spent Fuel Case

$$
\begin{aligned}
& (3.0 E+4) \\
& 1.0 E-2 \\
& (9.0 E-1)(a) \\
& (4.0 E+2) \\
& 2.0 E+2
\end{aligned}
$$

Hypothetical Repository in Tuff Solubility Limited Dissolution with Dispersion (Parentheses Indicate Congruent D/ssolution at $1.0 E-4 / \mathrm{yr}$. Assumed) Groundwater Dose Contributors at $>1.0 \mathrm{E}-3 \mathrm{rem} / \mathrm{yr}$.

$$
\frac{\text { Radionuclide }}{C-14} \begin{gathered}
\text { Se }-79 \\
I-129 \\
C s-135 \\
N p-237
\end{gathered}
$$

$$
\text { Calculated }
$$

Dose for HLW Case

$$
\begin{gathered}
6.0 \mathrm{E}-1 \\
7.0 \mathrm{E}-4 \\
<1.0 \mathrm{E}-3) \\
(2.0 \mathrm{E}-2) \\
4.0 \mathrm{E}-1)
\end{gathered}
$$

Calculated Dose

For Spent Fuel Case

$$
\begin{aligned}
& (3.0 E+2) \\
& 7.0 E-4 \\
& (9.0 E-1)(a) \\
& (2.0 E-2) \\
& 1.0 E+0
\end{aligned}
$$

(a) Assumed to be the same as in the basalt case. 
As shown by these results, the solubility-1imited dissolution case with dispersion is the most realistic case, because, as the WISP authors noted, sparingly soluble radionuclides cannot be released at the same rate that the glass matrix is dissolved. Since the solubility-limited fractional dissolution rate for uranium was estimated to be about 4.0E-9/yr in the WISP report, it may be seen that the congruent dissolution rate used for the spent fuel case is highly pessimistic.

Table 4.33 summarizes the results from WISP (1983) and shows the dose rates from each contributing radionucitde taken into account for the 10,000 year groundwater travel time HLW cases. Where appropriate, the adjustments suggested in the WISP report were made to simulate a spent fuel repository. Only for the basalt case were calculations done for both spent fuel and HLW.

It should be reemphasized that saturation conditions were assumed for the dose calculations for the potential repository in tuff. This is a conservative assumption for the candidate repository horizon at Yucca Mountain if current water flux estimates are correct (DOE 1986c).

From these summary tables, it may be seen that the more important radionuclides are C-14, Se-79, Sn-126, I-129, Cs-135, and Np-237. It is difficult to assess the importance of the numerical values in the tables because of the numerous and generally conservative assumptions made in these evaluations. The WISP authors acknowledged that 1ittle is known about the $\mathrm{C}-14$ in spent fuel, and its location and characteristics could have an impact on the numbers shown here. For example, the assumption of the congruent dissolution of this radionuclide at a rate of $1.0 \mathrm{E}-4 / \mathrm{yr}$ may be ultraconservative if $\mathrm{C}-14$ is largely in a form that depends on the dissolution rate of either Zircaloy or uranium dioxide for release. At the present time, however, the chemical forms in which C-14 may exist in the spent fuel are not well known.

The WISP (1983) risk assessment results represented an earlier work based on the very preliminary data that was available at that time. The study was performed at approximately the same time as the preliminary EPA risk assessments (Smith et al. 1982a, b). The later EPA risk assessments (EPA 1985b), using more appropriate data, resulted in risk estimates at least an order of magnitude below previous estimates. The same order of pessimism was 
probably inherent in the WISP report. For example, comparison of the data and assumptions used in the WISP report with corresponding information from the more recent repository environmental assessments indicates that some key data in WISP is many orders of magnitude too conservative. Because more recent analyses are avallable, the older WISP risk estimates were not used in the evaluations of Section 5.2 .

\subsubsection{Repository Environmental As sessments}

In accordance with the provisions of the NWPA and pursuant to NEPA, the DOE was directed to prepare an environmental assessment for each site nominated as suitable for site characterization. The environmental assessments that were prepared for the five sites chosen contained preliminary postclosure performance assessments (DOE 1986a,b,c,d,e). Three sites were nominated for site characterization, one each in basalt (DOE 1986a), bedded salt (DOE 1986b), and tuff (DOE 1986c). The preliminary postclosure performance assessments in the latter three environmental assessments are reviewed here.

The purposes of the environmental assessment preliminary postclosure performance assessments were given in the general siting guidelines (10 CFR Part 960, DOE 1984). In essence, the environmental assessment postclosure assessments were to provide, in part, a preliminary indication that it was unlikely that the probabilistic cumulative release requirement would not be met.

The scope of the environmental assessment preliminary performance assessments was limited to addressing the regulatory requirements in a preliminary way that would not include the explicit incorporation of disruptive event scenarios (EPA 1985a; NRC 1983b). The undisturbed, expected cases were modeled, except in the case of the potential salt repository where a preliminary evaluation of human intrusion consequences was also made. In every case the calculational endpoint of the modeling were the 10,000- and 100,000-year cumulative releases across the accessible environment boundary (no more than 5 kilometers in any direction from the original location of the waste and the ground surface of the repository; EPA 1985a). Results were expressed in terms of the ratios of the calculated releases to the allowed 
releases defined by the EPA standard (40 CFR Part 191; EPA 1985a), except that in the tuff case curle releases were also given. Two cases were addressed, an expected case wherein the engineered barrier functioned as indicated by subsystem performance assessments, and a performance 1 imits case where a containment time of 300 years and radionuclide release rates were assumed to be at the rates allowed for each radionuclide by 10 CFR Part 60 . Since the performance limits case was highly unrealistic for each of the sites for which these calculations were reviewed (DOE 1986a,b,c), they are not considered further in this report.

A simplified system model was used in the basalt case (DOE 1986a) to perform probabilistic analyses that addressed the EPA standard's quantitative cumulative release limits to the accessible environment. The potential repository was modeled as a point source, water flow was linear, and dispersion and decay were neglected. A cumulative probability curve for groundwater travel time to the accessible environment ( 5 kilometers), which was based on hydrologic data for Hanford basalt flow tops, was used as input to the model. Ranges of radionuclide-specific solubilities and retardation coefficients were used in conjunction with the groundwater travel times to assess radionuclide arrival times at the accessible environment. The containment period, followed by a distributed waste package failure rate, was based on subsystem analyses. A Monte Carlo routine was used to select a data set for each simulation, and the results of many simulations were plotted in a cumulative probabllity distribution function describing the likelihood of exceeding a fraction of the EPA release 1 imit.

The expected conditions in the bedded salt repository (DOE 1986b) were such that not enough water was available for corroding the overpack, the sacrificial metal barrier that will be placed around the container. Hence, no releases were expected in the undisturbed case for we11 beyond 100,000 years. The scope of the performance assessments did not include consideration of disruptive or intrusive events, but these were addressed in the case of salt where a maximum of 30 boreholes $/ \mathrm{km}^{2}$ of repository area (123 boreholes for any 10,000 year period) was assumed. Based on geometric arguments, the likelihood of a borehole intersecting a canister was $0.00 \mathrm{~b}$, and the entire inventory of an intersected canister was assumed to be accessed by 200 cubic 
meters of groundwater that is rapidly discharged to the accessible environment. After 300 years, the waste was assumed to be diffusing outwards from each package and the probability of a borehole intersecting radionuclides increases gradually until it becomes 1 at 10,000 years. All of these assumptions are pessimistic and highly unlikaly.

In the tuff analysis (DOE 1986c), the potential repository was simulated as a planar source term. The mass released from the repository into the unsaturated zone water flux was set equal to the mass released from a representative waste package multiplied times the number of waste packages being released from the repository into the unsaturated zone water flux. The flux was assumed to be downward, and estimates ranged from $1.0 \mathrm{E}-7$ to $0.5 \mathrm{~mm} / \mathrm{yr}$. The upper bound was used in the reference case calculation. Congruent release was assumed at a rate of $2.5 \mathrm{E}-9 / \mathrm{yr}$. The containment period was taken to be 3,000 years, the lowest value in the calcuiated range. Water flow times from the disturbed zone (50 meters below the potential repository) to the aquifer directly below the repository were distributed over a range from 30,470 to 56,070 years for the simulation. Radionuclide transport was calculated using an analytic solution in one dimension, and dispersion was neglected. Retardation factors specific to welded and nonwelded tuffs were used, where available, and WISP (1983) estimates were used for the retardation of lead, tin, thorium, and zirconium.

Results for the 10,000-year expected cases for the three repositories are given in Table 4.34 .

\section{Evaluation}

The site-specific environmental assessments used the most recent data available in terms of the potential repository and the candidate sites. Therefore, they represented the best available information for estimating postclosure risks. The major limitation of the studies was the consideration of only the undisturbed case. A second limitation was that results were reported as cumulative releases to the accessible environment. In those terms, the results cannot be readily used to characterize potential repository risks. 
TABLE 4.34. Expected Case Releases, Normalized to the EPA 10,000-Year Cumulative Release Stalldard, for Hypothetjcal Repositories in Basalt, Salt, and Tuff $(a)$

\begin{tabular}{|c|c|c|c|}
\hline \multirow[b]{2}{*}{ Host Rock } & \multicolumn{2}{|c|}{ Cumulative Release Ratios } & \multirow[b]{2}{*}{ Remarks } \\
\hline & $10,000-$ Year & $100,000-Y e a r$ & \\
\hline Basalt & 0 & 0.29 & $\begin{array}{l}50 \% \text { confidence } \\
\text { level values }\end{array}$ \\
\hline & $0.045(b)$ & 0.45 & $\begin{array}{l}95 \% \text { confidence } \\
\text { level values }\end{array}$ \\
\hline Salt & o(b) & 0 & Undisturbed case \\
\hline & $0.04(c)$ & $0.006(c)$ & $\begin{array}{l}\text { Intrusive we } 11 \mathrm{~s} \\
\text { scenario, } 97.5 \% \\
\text { confidence } 1 \mathrm{evel}\end{array}$ \\
\hline Tuff & $<0.0000001^{(b)}$ & 0.0000002 & Expected value \\
\hline
\end{tabular}

(a) Sources: DOE $1986 a, b, c, f$.

(b) Values used in Section 5.2 risk comparison.

(c) Intrusive case for salt is too conservative and was meant to provide only a qualitative indication of safety based on a conditional probability of unity for the occurrence of the intrusive scenario.

\subsubsection{A Bounding Analysis for the Yucca Mountain Hypothetical Potential Repository}

Thompson et a1. (1984) presented results of a computation of doses to individuals and populations exposed by using groundwater from a well $10 \mathrm{kil}$ ometers downstream from the potential Yucca Mountain repository site.

The purpose of this risk assessment was to attempt to place upper bounds on the consequences that may be expected from placing a repository at Yucca Mountain, Nevada. Only undisturbed repository performance was addressed to establish a baseline case for performance assessment. The risk analysis assumed that a water well at 10 kilometers downstream from the potential repository was used by a maximally exposed individual and by a small local population for drinking water only. 
The conceptualization of the repository included a 175-meter downward travel path through the unsaturated zone and an 11,126-meter horizontal travel path through the saturated zone to the water we11. The unsaturated zone was divided into welded and nonwelded tuff zones, each of which had different geochemical and hydrological properties.

A congruent-dissolution rate of about $1.0 \mathrm{E}-7 / \mathrm{yr}$ was assumed. The unsaturated zone flow was characterized by conservatively assuming a $2 \mathrm{~mm} / \mathrm{yr}$ pore-water velocity, which was four times higher than the upper bound of the expected range for this value (DOE 1986c). The water was assumed to flow over a 1,500-acre repository area. A $5 \%$ porosity and a $65 \%$ saturation estimate combined with the velocity and area allowed a rough estimate of $5 \mathrm{gpm}$ of polluted water entering the regional water table.

The saturated zone was assumed to be 81 meters high and groundwater was assumed to flow through the saturated zone at $175 \mathrm{gpm}$. Dispersion spread the plume over the entire height of the saturated zone by the time the plume reached the well at a $10-k i l o m e t e r$ distance. This is because transverse dispersion was estimated to spread the contaminants 1 meter in directions tangential to the flow for every 10 meters of horizontal travel distance. The dilutions resulted in the contaminated water being about $3 \%$ of the total water that is pumped.

A maximally exposed individual was assumed to be located at the wellhead, and a 10,000 person regional population received its drinking water from the we11. Organ doses to the population were calculated using the PABLM code (Napier et a1. 1980).

The earliest travel time to the well 10 kilometers from the potential repository was calculated to be about 25,000 years. This was not sufficient time for the radionuclides to pass through the unsaturated zone in the environmental assessment calculations for the expected case (DOE 1986C).

Two peak dose periods were identified, 27,000 years for nonsorbing radionuclides, and 250,000 years for sorbing radionuclides. Results of dose calculations are presented in Table 4.35 . 
TABLE 4.35. Seventy-Year Cumulative Maximally Exposed Individual and Regional Population Doses for the Two Peak Dose. Periods for a Potential Tuff Repository

Maximally Exposed Individual Doses from the Home Garden as Sole Source of Vegetables Irrigation Scenario for Iwo Future Times (person-rem)

\begin{tabular}{lcc} 
Organ & $\begin{array}{c}\text { Accumulated } \\
\text { Dose at the } \\
27,000-\text { Year Peak }\end{array}$ & $\begin{array}{c}\text { Accumulated } \\
\text { Dose at the } \\
\text { 250,000-Year Peak }\end{array}$ \\
\cline { 1 - 1 } Total Body & 0.2 & 0.2 \\
Bone & 0.6 & 3.0 \\
Thyroid & 2.0 & 2.0 \\
Gastro-intestinal & 4.0 & 2.0
\end{tabular}

Lifetime Population Doses from the Drinking Water Scenario for Two Future Times (person-rem)

Organ

Total Body

Bone

Thyroid

Gastro-intestinal

\begin{tabular}{c} 
Accumulated \\
Dose at \\
27,000 Years \\
\hline
\end{tabular}

2.0

4.0

600

200 \begin{tabular}{c} 
Accumulated \\
Dose at \\
250,000 Years \\
\hline
\end{tabular}

200

4,000

600

400

The maximally exposed individual received 70-year lifetime body and bone doses largely from C-14, thyroid dose from 1-129, and the gastrointestinal (GI) dose from TC-99 at 27,000 years. The 70-year dose to the GI tract was about 4 rem. This was the largest organ dose and was equivalent to an annual dose of 60 mrem.

At 250,000 years, the 70-year body and bone doses were higher than at 27,000 years. These doses were largely the result of U-234 intake. Thyroid and gastrointestinal doses remain the results of I-129 and Tc-99 intake but were lower than at 27,000 years, because of the radioactive decay of TC- 99 .

The population model assumed that the only contact the population had with the contaminated water was through drinking of the well water. The flow 
volume precluded any greater agricultural use than for a family garden. The assumed population of 10,000 at 27,000 years received at most a 600 personrem dose to the thyroid from I-129. This corresponded to an average individual dose of $0.9 \mathrm{mrem} / \mathrm{yr}$, or $1 \%$ of background.

At 250,000 years, the population might receive a dose of as much as 4,000 person-rem to the bone from $U-234$. The average person would receive about $60 \mathrm{mrem} / \mathrm{yr}$, which is just over half of background. A rough estimate for this scenario's health-effects impact would be somewhat less than 0.05 health-effects per 70-year generation from this hypothetical 47,000 MTHM repository.

\section{Evaluation}

The simplicity of these scoping calculations gave them considerable appeal. Compared with the tuff environmental assessment assumptions (DOE 1986c), the flux through the repository used in these calculations was higher than the reference upper bound flux value by a factor of 4 . In addition, the fractional release rate was conservative by an order of magnitude. Taking these two conservatisms into account should reduce this conditional risk to the 10,000 person population, for the peak 10,000 year release period, proportionally. This is because the flux of water available for transport and the rate of waste release from the waste package directly affect the amount of mass that can be transferred and the rate of transfer.

The sum of the lifetime dose consequence values reported by Thompson et a1. (1984) and used in Section 5.2 is 5,200 person-rem per 70 years, which corresponds to the 250,000-year peak dose period result. The value for the 25,000-year peak release period, or a zero person-rem value for the 10,000year period, could also have been used and justified. The reason for using the number that represented the peak releases of sorbing radionuclides to the postulated water well was that the accessible environment definition was changed from no more than 10 kilometers at the time of the work by Thompson et al. to no more than 5 kilometers in the final standard (EPA 1985a). The work by Thompson et al. attempted to define peak risk periods at the accessible environment boundary. A 5-kilometer boundary would experience these peaks at an earlier time as well as at a higher dose rate. Therefore, the 
more conservative 10-kilometer, 250,000-year dose was selected for the risk comparison in Section 5.2 to compensate for the change to a less distant accessible environment (EPA 1985a).

\subsubsection{Studies Supporting NRC Activities}

In 1983, Sandia National Laboratories published the results of a simplified repository performance analysis that addressed the EPA standard cumulative release limits (EPA 1985a). The two reports that described these simplified analyses for hypothetical basalt, salt, and tuff repositories were: Pepping et al. (1983a,b); and Siegel and Chu (1983). In addition, Pepping et a1. (1983b) evaluated a potential salt repository in terms of both the EPA cumulative release standard and health-effects consequences. The objective of this work was to perform system performance assessments, including intrusive and disruptive events, to demonstrate the application of existing analytical tools for the assessment of compliance with the EPA standard. The standard was in draft form at the time the studies were performed.

The assessments contained in Pepping et a1. (1983a,b) and Siegel and Chu (1983) addressed the EPA standard and did not provide dose or health-effects estimates. They did provide probabilistic analyses that included postulated disruptive and intrusive event scenarios for which probabilities were estimated. The report for the potential bedded salt repository (Pepping et al. 1983b) provided a parallel study to one published the same year by Pepping et al. (1983a). The report did not contain probability estimates for its scenarios, but did calculate dose and health-effect consequences. This latter report is reviewed in detail in this section.

The evaluation described by Pepping et a1. (1983b) included consideration of the following scenarios: 1) a borehole through to a lower aquifer, with wells into and drawing from the lower aquifer; 2) a U-tube, connecting the upper aquifer with the repository so as to cause flow, with withdrawal from the upper aquifer; 3) a dissolution cavity in communication with the upper aquifer, with withdrawal from the upper aquifer; 4) a borehole through the repository; 5) a U-tube without withdrawal from the upper aquifer; and 6) a borehole intersecting a canister. 
Key study assumptions included the use of small Darcy velocities in the salt and surrounding shales assuming a downward gradient through the salt, a 100-year moratorium on human intrusions, a zero waste package lifetime, and instant resaturation. All properties were assumed to be steady-state (i.e., time invariant).

The assumptions included ranges of data values and distributions. The data included: 1) distribution coefficients for $\mathrm{Cm}, \mathrm{Am}, \mathrm{Pu}, \mathrm{U}, \mathrm{Th}, \mathrm{Ra}, \mathrm{Np}$, $\mathrm{Pb}, \mathrm{Pa}, \mathrm{Ac}, \mathrm{I}, \mathrm{Sn}$, and $\mathrm{Tc} ; 2$ ) solubilities for $\mathrm{Pu}, \mathrm{U}$, Th, $\mathrm{Ra}, \mathrm{Np}, \mathrm{Pb}, \mathrm{Pa}, \mathrm{Sn}$, and Tc; 3) dispersivity; 4) release duration (i.e., rate); 5) conductivities for upper and lower aquifers and vertical features; 6) porosities of vertical features; 7) time of onset of migration; 8) number of boreholes; and 9) number of rooms.

The data on radionuclide solubilities in brine used in this study reveals a large degree of uncertainty for some of the radionuclides. The ranges of solubility that were presented varied from 3 to 18 orders of magnitude. In Table 4.36 these solubility ranges are compared with the single values reported in the salt potential repository site environmental assessment (DOE 1986b), which in turn were largely based on the values given in the WISP (1983) report. Uranium, thorium, and technetium solubility values used in the WISP (1983) study seemed to be at the nonconservative ends of the ranges used by Pepping et a1. (1983b), but it was difficult to judge the realism of either data set at this point.

In Table 4.37, the Pepping et a1. (1983b) ranges for the distribution coefficients are compared with those used in the WISP (1983) study.

From Table 4.37 it may be seen that the ranges used in Pepping et al. (1983b) encompass the WISP (1983) assumptions for every case in which both studies reported a value. From this comparison it may be seen that the WISP (1983) values are generally near the midpoints of the Pepping et al. (1983a,b) ranges. This suggests that either these values represent the same basic source of information, or, if these values represent the study of independent sources, that there is reasonable agreement between these sources. It is to be expected that site-specific data would provide narrowed ranges for these parameter values. 
TABLE 4.36. Radionuclide Solubility Ranges in Brine as Used by Pepping et a1. (1983b)

\begin{tabular}{|c|c|c|c|c|}
\hline $\begin{array}{l}\text { Radio- } \\
\text { Nuclide }\end{array}$ & $\begin{array}{c}\text { Solubility } \\
\text { Range }\end{array}$ & Units & $\begin{array}{c}\text { Assumed } \\
\text { Distribution }\end{array}$ & $\begin{array}{l}\text { Value Used in } \\
\text { DOE (1986b) }\end{array}$ \\
\hline $\mathrm{Pu}$ & $5.0 \mathrm{E}-14$ to $1.3 \mathrm{E}-01$ & $g / g$ & $\log (10)$ norma 1 & $1.0 \mathrm{E}-9$ \\
\hline U & $1.6 \mathrm{E}-09$ to $2.5 \mathrm{E}-03$ & $g / g$ & $\log (10)$ normal & $1.0 E-9$ \\
\hline Th & $1.0 \mathrm{E}-09$ to $6.3 \mathrm{E}-06$ & $g / g$ & $\log (10)$ norma 1 & $1.0 E-9$ \\
\hline $\mathrm{Ra}$ & $7.9 \mathrm{E}-12$ to $1.3 \mathrm{E}-05$ & $\mathrm{~g} / \mathrm{g}$ & $\log (10)$ norma 1 & not stated \\
\hline$N p$ & $2.0 \mathrm{E}-24$ to $7.9 \mathrm{E}-06$ & $g / g$ & $\log (10)$ normal & $1.0 \mathrm{E}-9$ \\
\hline $\mathrm{Pb}$ & 2.5E-11 to $4.0 \mathrm{E}-05$ & $g / g$ & $\log (10)$ norma 1 & not stated \\
\hline $\mathrm{Pa}$ & $1.3 \mathrm{E}-07$ to $7.90 \mathrm{E}-04$ & $g / g$ & $\log (10)$ normal & not stated \\
\hline $\mathrm{Sn}$ & $6.3 \mathrm{E}-15$ to $1.6 \mathrm{E}-02$ & $g / g$ & $\log (10)$ norma 1 & $1.0 \mathrm{E}-5$ \\
\hline Tc & $1.0 \mathrm{E}-09$ to $1.0 \mathrm{E}-04$ & $g / g$ & $\log (10)$ normal & $1.0 E-9$ \\
\hline c & not stated & $g / g$ & & $6.0 E-8$ \\
\hline Se & not stated & $g / g$ & & $1.0 E-9$ \\
\hline $\mathrm{Sr}$ & not stated & $g / g$ & & $8.0 E-5$ \\
\hline I & not stated & $g / g$ & & $6.0 \mathrm{E}-1$ \\
\hline Cs & not stated & $g / g$ & & $6.0 \mathrm{E}-1$ \\
\hline Am & not stated & $g / g$ & & $1.0 \mathrm{E}-10$ \\
\hline $\mathrm{Cm}$ & not stated & $g / g$ & & $1.0 \mathrm{E}-9$ \\
\hline
\end{tabular}

The results of the Pepping et a7. (1983b) study for the bedded salt case are presented in terms of peak conditional cancer risks in Table 4.38. The conditional cancer risks are defined as the lifetime probability of a person receiving a latent, fatal, somatic cancer.

\section{Evaluation}

Carbon was not modeled in the Pepping et al. (1983b) arialyses, and the greatest contributors to releases from the intrusive/disruptive scenarios were Pu-239, Am-241, Ra-226, Tc-99, and Th-229. Doses from Am, Ra, and Rn were found to violate the EPA standard in the spent-fuel study reported by Pepping et a1. (1933b). It is likely that the simplified source-term model, which assumed that the waste form dissolved at a high rate after contact with groundwater, was responsible for these hypothetical violations. A previous study for a potential repository containing HLW found that only Am might 
TABLE 4.37. Distribution Coefficients for Radionuclides

in Brines Used by Pepping et a1. (1983)

Compared with WISP (1983) Values

\begin{tabular}{|c|c|c|c|c|}
\hline $\begin{array}{l}\text { Radio- } \\
\text { Nuclide }\end{array}$ & $\begin{array}{r}\text { Distribution } \\
\text { Coefficient } \\
\text { (Kd) Range } \\
\end{array}$ & Units & $\begin{array}{c}\text { Assumed } \\
\text { Distribution }\end{array}$ & $\begin{array}{l}\text { Value Used in } \\
\text { WISP (1983) }\end{array}$ \\
\hline $\mathrm{Pu}$ & $1.0 \mathrm{E}-2$ to $1.0 \mathrm{E}+4$ & $\mathrm{~m} 1 / \mathrm{g}$ & $\log (e)$ normal & $2.0 E+1$ \\
\hline U & $1.0 \mathrm{E}-2$ to $1.0 \mathrm{E}+4$ & $\mathrm{ml} / \mathrm{g}$ & $\log (e)$ normal & $2.0 E+0$ \\
\hline Th & $1.0 \mathrm{E}-2$ to $1.0 \mathrm{E}+4$ & $\mathrm{ml} / \mathrm{g}$ & $\log (e)$ normal & $1.0 E+2$ \\
\hline $\mathrm{Ra}$ & $1.0 \mathrm{E}-2$ to $5.0 \mathrm{E}+2$ & $\mathrm{ml} / \mathrm{g}$ & $\log (e)$ norma 1 & $5.0 E+0$ \\
\hline $\mathrm{Np}$ & $1.0 \mathrm{E}-2$ to $5.0 \mathrm{E}+1$ & $\mathrm{~m} 1 / \mathrm{g}$ & $\log (e)$ normal & $5.0 E+0$ \\
\hline $\mathrm{Pb}$ & $1.0 \mathrm{E}-2$ to $1.0 \mathrm{E}+4$ & $\mathrm{ml} / \mathrm{g}$ & $\log (e)$ norma 1 & $2.0 E+0$ \\
\hline $\mathrm{Pa}$ & $1.0 \mathrm{E}-2$ to $1.0 \mathrm{E}+4$ & $\mathrm{ml} / \mathrm{g}$ & $\log (e)$ norma 1 & not stated \\
\hline Sn & $1.0 \mathrm{E}-2$ to $5.0 \mathrm{E}+2$ & $\mathrm{ml} / \mathrm{g}$ & $\log (e)$ norma 1 & $1.0 E+1$ \\
\hline Tc & $1.0 \mathrm{E}-2$ to $5.0 \mathrm{E}+2$ & $\mathrm{ml} / \mathrm{g}$ & $\log (e)$ norma 1 & $5.0 \mathrm{E}-1$ \\
\hline c & not stated & $\mathrm{m} 1 / \mathrm{g}$ & & 0 \\
\hline $\mathrm{Se}$ & not stated & $\mathrm{ml} / \mathrm{g}$ & & $2.0 E+1$ \\
\hline $\mathrm{Sr}$ & not stated & $\mathrm{ml} / \mathrm{g}$ & & $1.0 E+1$ \\
\hline I & $1.0 \mathrm{E}-2$ to $1.0 \mathrm{E}+2$ & $\mathrm{~m} 1 / \mathrm{g}$ & $\log (e)$ norma 1 & 0 \\
\hline Cs & not stated & $\mathrm{m} T / \mathrm{g}$ & & $1.0 E+1$ \\
\hline Am & $1.0 \mathrm{E}-2$ to $1.0 \mathrm{E}+5$ & $\mathrm{ml} / \mathrm{g}$ & $\log (e)$ normal & $1.0 E+2$ \\
\hline $\mathrm{Cm}$ & $1.0 \mathrm{E}-2$ to $1.0 \mathrm{E}+5$ & $\mathrm{ml} / \mathrm{g}$ & $\log (e)$ normal & $1.0 E+2$ \\
\hline
\end{tabular}

violate the standard. One of the study conclusions was that there was an order of magnitude greater risk from spent fuel when compared with HLW. This conclusion results directly from assumed differences in inventories of radionuclides in spent fuel and HLW, since all other assumptions and variables were comparable between the two studies.

Uncertainty and sensitivity were addressed by Pepping et a1. (1983b) through parameter-variation exercises. It was found that the methodology was most sensitive to gross features such as onset of release, rate of release, and inventory. The simple source-term model was, therefore, an important determinant of the results. Output scatter could be related to the ranges assumed for the input parameters. 
TABLE 4.38. Peak Conditional Cancer Risks Due to Ingestion for the 100,000 Year Postclosure Pertod for a 90,000 MTU Spent Fuel Repository in Bedded Salt (a)

\begin{tabular}{|c|c|c|}
\hline $\begin{array}{l}\text { Scenarto (Number) } \\
\text { And Description }\end{array}$ & $\begin{array}{l}\text { Zone 1: Area From } \\
\text { Repository to River } \\
40 \mathrm{~km} \text { Away, Plus } 6 \mathrm{~km} \\
\text { Along River } \\
\end{array}$ & $\begin{array}{l}\text { Zone 2: Area } \\
\text { Bounded by a } 4 \\
\text { Stretch of Riv } \\
2 \mathrm{~km} \text { Along Bot } \\
\end{array}$ \\
\hline $\begin{array}{l}\text { Borehole(s) with } \\
\text { Lower Aquitfer } \\
\text { Wells }\end{array}$ & $8.0 \mathrm{E}-2$ & 8.0E-7 \\
\hline $\begin{array}{l}\text { U-Tube with Upper } \\
\text { Aquifer Wells }\end{array}$ & $2.0 E-1$ & $4.0 E-6$ \\
\hline $\begin{array}{l}\text { Dissolution } \\
\text { Cavity with Wells }\end{array}$ & $3.0 \mathrm{E}-1$ & $7.0 E-6$ \\
\hline Borehole (s) & $1.0 \mathrm{E}-6$ & $1.0 E-6$ \\
\hline$U$-Tube & $2.0 \mathrm{E}-6$ & $1.0 \mathrm{E}-6$ \\
\hline $\begin{array}{l}\text { Borehole(s) inter- } \\
\text { secting a } \\
\text { Canister }\end{array}$ & $3.0 \mathrm{E}-6$ & $2.0 \mathrm{E}-6$ \\
\hline
\end{tabular}

(a) Pepping et a1. (1983b).

This work demonstrated that there was a methodology available for assessing repository risk, but uncertainties in the input data and in the applicability of the simplistic source-term model demonstrated the need for more precise data and more appropriate modeling. In this study, it was found that the rate of radionuclide release from the waste container and the time of the intrusion into the dissolved waste were very sensitive parameters. The rate of radionuclide release was assumed to range from $1.0 \mathrm{E}-3$ to $1.0 E-7 / y r$. This range may be conservative by about 3 orders of magnitude.

A sensitivity analysis of the health-effects calculations in the Pepping et a1. (1983b) study showed that the important variables in the health-effect analysis were the diffusion coefficient of Ra, the leach time (radionuclide release rate), aquifer conductivities, time of onset of release, and the amount of radionuclide at the source (a function of their "access" vartable, which is the time of the intrusive occurrence). As noted in the previous 
paragraph, the difference between the assumed value ranges for these key varlables and the actual ranges that may be expected were cructal for determining the credibility of the resulting calculated risks. Perhaps more important, however, may be the likel thood that sensitivity analys is results that indicate the importance of input variable assumptions may not be of much use if important physical and chemical processes operative in the repository system are not properly accounted for in the model.

The Pepping et a1. (1983b) studies results have been questioned in terms of the realism of the system description, the scenarios analyzed, and the applicabllity of the models used. These questions were partly addressed in a study done for the DOE Office of Nuclear Waste Isolation (INTERA 1985) in which the two scenarios with the highest modelled consequences were reanalyzed. Significantly lower consequences were predicted in the INTERA (1985) study, but since the performance measure in that study was cumulative releases for only the given scenario, the results are not of particular interest here.

The INTERA (1985b) results do suggest that the health-risks of Pepping et a1. (1983) are probably at least 4 orders of magnitude too high, judging from differences in expected Ra-226 levels released. Even this comparison is not straightforward, however, since the differences in results are functions of major differences in assumptions as well as lesser differences in tools and data. The INTERA (1985) study used more realistic radionuclide dissolution rates, yet it suggested that until site-specific and system-design data are available, calculations such as these must be considered very preliminary and are designed to be conservative.

The probabtlity assumed for the occurrence of the scenarios modeled in Pepping et a1. (1983b) (as in INTERA 1985) was unity. For those scenarios, such as the $U$-tubes that did not involve the recurrent drilling of wells, one occurrence was modeled for the 100,000 year period. The tining of the occurrence was then sampled from a distribution that was uniform over a time period from 100 to 100,000 years. For the borehole scenarios, up to 80 wells were drilled and the assumption was made that drilling became more likely at later times. The likelihood of all 80 wells having been drilled reached 
unity sometime before the end of the 100,000-year pertod. This meant, as Pepping et a1. (1983a,b) were careful to point out, that the risks calculated were "conditional" (that is, the probability of occurrence has been arbitrarfly set to unity) and the health-risks were risks resulting as a condition of the scenario's occurrence.

It is likely, judging from the INTERA (1985) radionuclide release results, that the conditional risk estimates of Pepping et al. (1983b) were in the neighborhood of 4 to 10 orders of magnitude too high in the cases of the higher consequence scenarios. The dissolution cavity assessment, especialiy, seems to be highly speculative, and without the probability for the event and for the assumptions that determine the consequences, this result may be particularly misleading.

The conditional cancer risk in zone 1 for the U-tube and dissolution cavtty scenartos were selected for use in comparing calculations of potential bedded salt repository risks in Section 5.2. Even though these values may be many orders of magnitude inigher than will be indicated by more realistic analyses using more site-specific data, they still represent the results of one of the more complete published risk assessments avallable for a bedded salt repository.

The results of the other assessments done on behalf of the NRC for reposttories in basalt and tuff (Pepping et a1. 1983a; Siegel and Chu 1983) demonstrated different applications of the same analytical framework, modified by different flow and transport models, as used in the pepping et al. (1983b) study. Therefore, the results of these other assessments are used in Section 5.2, but their analytical framework is not analyzed in detail here.

\subsubsection{International Repository Performance/Risk Assessments}

This section reviews repository risk information developed in international repository research programs. A Swedish postclosure risk assessment of a hypothetical repository in granitic rocks of the Fennoscandian shield is reviewed first because its results are used for comparative purposes in Section 5.2. Other international postclosure performance/risk assessments were also reviewed, including a Swedish survey of national radioactive waste 
management programs; Finnish, Canadian, and Swiss studies of hypothetical repositortes in crystalline rocks; and a German analysis of a hypothetical repository in a salt dome.

\section{Swedish Risk Assessnients for a Generic Crystall ine Repository}

A scoping safety study for a generic crystalline rock repository was reported by Brotzen (1983). Of greater interest to this review, however, are the sertes of safety assessments by the Swedish Nuclear Fuel Supply Company, Division KBS, which were done to evaluate the concept of disposing of HLW in stable crystallitne rock formations. The latest of those safety assessments was known as the KBS-3 report (SKBF 1983). Of particular interest in this review was the review and recalculation of the KBS-3 work carried out by SKI, the Swedish Nuclear Power Inspectorate (Andersson et a]. 1984). The SKI recalculation was, in essence, a regulatory review of the KBS-3 work.

The purpose of the KBS-3 safety assessments was to show that the concept of deep geologic disposal is safe. A regulatory requirement to provide proof of safety to the Swedish government was being addressed by those assessments.

The scope of the postclosure assessments included the performance of the total disposal system in terms of release rates and doses to individuals. No intrusive or disruptive event scenartos were evaluated in the preliminary assessments performed to date.

The basis for the KBS-3 assessment, according to its reviewers (Andersson et a1. 1984; NAGRA 1985) consisted of a number of conservative assumptions, and overestimated doses. As pointed out by Andersson et al. (1984), however, there was much uncertainty in the then-current knowledge of some very basic aspects (e.g., hydrology), of the system described in the KBS-3 report, and therefore the conservatism seemed warranted.

The central case was described by the KBS-3 authors as being conservative in that values for parameters were chosen toward the pcssimistic side whenever there was a range from which to choose. The central case involved a repository with 4,400 canisters containing 1.4 MTHM each. The spent fuel inside the copper canisters had lead or copper added to fill void spaces. 
The reference repository was 500 meters below the surface in the granitic rocks of the Fennoscandian Shield. About 100 miles from the waste, a fracture zone was assumed to exist that provided a preferential flow path to the biosphere. Canister penetration was assumed to begin after 100,000 years. The canisters were assumed to fall uniformly between 100,000 and 1,000,000 years after closure. This was a conservative time frame, since the canisters were expected to maintain their integrity for multiple millions of years. The waste form dissolves congruentiy, with the rate a function of uranium oxide solubility in an oxidizing system. The oxidizing conditions were an expected localized phenomenon resulting from the aipha-irradiation of the groundwater.

oxidizing conditions would make thorium and plutontum less soluble than reducing conditions. As canisters falled, $10 \%$ of the $C S$ and I would be instantiy released. Diffusion through the bentonite backfill would remove mass from the dissolution zone, and sumewhere in the host rock reducing conditions would be encountered precipitating $U, \mathrm{~Np}$, and Tc. Flow rates in the host rock were expected to be on the order of $0.011 / \mathrm{m}^{2} / \mathrm{yr}$. Surface sorption, matrix diffusion, and volume sorption (sorption by rock interior surfaces after matrix diffusion) macie the process only slowly reversible.

The effect of the matrix diffusion assumption on the outcome of the calculations was studied by Andersson et a1. (1984). They found that this assumption increased the release rates of Th-229 and Np-237 by 4 or 5 orders of magnitude but had smaller effects on less-strongly sorbing nuclides. Although the KBS-3 report presented good explanations of the matrix diffusion phenomenon and a few good arguments for its reality and effectiveness, clearly this effect is important enough to need to be firmly established as actualiy occurring in the system under consideration.

The scenario examined assumed that groundwater flow brings the radionuclides into a lake. Doses were calculated for a iariety of paths from the lake into the human domain. Individual doses were calculated that showed two distinct maxima at about 5 million years and about 5 billion years. Doses for these maxima were $4.0 \mathrm{E}-5$ and $2.0 \mathrm{E}-5 \mathrm{rem} / \mathrm{yr}$ respectively. The contributors to the first maximum were I-129, Cs-135, and Tc-99, and the second 
maximum was the result of $\mathrm{Ra}-226, \mathrm{~Pa}-231$, and Th-230, in descending order. If conditions in the geosphere ware oxidizing instead of reducing, or if $\mathrm{col}$ loidal transport could increase migration rates of the more strongly sorbed nuclides, the predicted doses would be an order of magnitude higher. The central or base case results were 3 orders of magnitude below natural background.

In the calculations done by Andersson et al. (1984), the KBS-3 case was redone using slightly different, somewhat more conservative values for some parameters. The results represented the checking of the implementing agency's assessment by the regulatory authority. There is no basis on which to decide which is the better analysis. The doses from this study were generally about the same or slightly higher than the KBS-3 values, due to somewhat more conservative parameter-value assumptions. Therefore, the Andersson et a1. (1984) results are reported here as conservative peak dose estimates for a potential repository in the Fennoscandian Shield (Table 4.39).

\section{Evaluaticn}

The KBS-3 safety assessment (SKBF 1983) was favorably reviewed in detai1 in the United States by the National Academy of Sciences and in Sweden by the SKI, the Swedish nuclear regulatory authority. In the SKI calculations done

TABLE 4.39. Peak Dose Values (rem/yr) for a Nuclear Waste Reppsitory in Crystalline Rock of the Fennoscandian Shield(a)

\begin{tabular}{ccr} 
Radionuclide & Peak Indiv. Dose & Ye: s to Peak Value \\
\hline Zr-93 & $3.4 E-11$ & $8,000,000$ \\
I -129 & $1.1 E-4$ & 50,000 \\
Cs -135 & $7.2 E-6$ & $2,000,000$ \\
Np-237 & $2.9 E-8$ & $10,000,000$ \\
Th-229 & $1.8 E-8$ & $10,000,000$ \\
Ra-226 & $8.4 E-6$ & $5,000,000,000$ \\
Pb-210 & $4.0 E-5$ & $5,000,000,000$
\end{tabular}

(a) Andersson et al. (1984). 
by Andersson et a1. (1984), the KBS-3 case was redone using slightly different, somewhat more conservative, parameter values for some parameters. The results represented the checking of the implementing agency's assessment by the regulatory authority.

The assessinent results reported in Table 4.39 represent the results of a peer-review of the SKI analysis of a disposal system that has a number of features that are similar to the proposed U.S. repository in basalt. The extremely long containment times of the Swedish concept will not be applicable to the waste containers contemplated for use in the basalt site (DOE 1986a), but disregarding the container failure times, and therefore, the peak dose rate times, should give an indication of peak risks that are roughly comparable with the proposed U.S. basalt and Swedish granite sites. Therefore, the SKI results of Table 4.40 are considered in the risk comparison of Section 5.2.

\section{Survey of International Performance/Risk Assessments}

In a Swedish survey of national radioactive waste management programs that reflected materials available to 1984 , the status of the U.S. performance assessment program was characterized as being immature (Parker et al. 1984). The WISP (1983) study was cited as an example of an immature calculation. Other assessments were reviewed, and were also judged to lack maturity, and no results were given.

The status of performance and risk assessment work in other nations was also addressed in this survey by Parker et al. (1984). The results of this review are summarized below. For more information on the events and processes covered in the various release scenarios (e.g., the well scenario, river and well scenario, etc.), the reader is referred to the source documents.

- Belgium - For the Mol clay site, a faulting scenario was been evaluated in which a preferential upward path to a well was created. The Monte Carlo simulation resulted in a 5 order of magnitude dose range. For $99 \%$ of the simulations, doses were between 100 and $0.01 \mathrm{mrem} / \mathrm{yr}$. 
TABLE 4.40. Preliminary Peak Individual Doses for a Mjxed Nuclear Waste Repository in a Salt Dome(a)

Peak Individual

Radionuclide (b)

\section{C -14}

Se -79

Tc-99

I -129

Cs -135

U-236

Np-237

$U-238$

$U-234$

$R a-226$

$P b-210$

Ac -227
Dose

(millirem/year)

4. $0 E-4$

8. OE-4

$1.05-2$

$1.0 \mathrm{E}-3$

1. OE-4

2. $0 E-4$

$3.0 E-3$

2. $0 E-4$

2. $0 E-3$

1. $0 E-4$

4. OE-4

1. $0 \mathrm{E}-4$
Years to Peak Value

7. $0 E+3$

8. $0 E+3$

9. $0 E+3$

7. $0 E+3$

1. $0 \mathrm{E}+4$

1. $0 \mathrm{E}+4$

2. $5 \mathrm{E}+4$

1. $.0 E+4$

1. $0 E+4$

$>5 . \mathrm{OE}+4$

$>5.0 E+4$

5. $0 E+4$

(a) Source: PSE 1985a.

(b) Nuclides that contributed less than $1.0 \mathrm{E}-4 \mathrm{rem} / \mathrm{yr}$ are not listed.

- Canada - Preliminary Monte Carlo simulations of 1,730 scenarios (parameter value realizations) resulted in about 1,000 scenarios that led to any releases. Doses were typically less than $1 \%$ of background and never greater than $20 \%$. The well scenarios, where domestic wells used contaminated groundwater, yielded the greatest doses, and the likelihoods of their occurrences are being evaluated. Highest doses resulted from deep wells with low flow rates and short, straight flow paths.

- Federal Republic of Germany - No preliminary assessments are available at this time. Research is considering the role of anhydride passageways from the salt dome surface to the repository horizon, allowing relatively rapid brine migration, as one scenario. 
- France - No preliminary consequence analysis has been performed for disposal in granite. After 100 years, a $1.4 \mathrm{E}-5 \mathrm{~g} / \mathrm{cm}^{2} /$ day release rate occurs. River and well scenarios were considered using a onedimensional flow model. The model allowed four distinct zones and included diffusion coefficients. More scenarios gave acceptable consequence results (i.e., less than $500 \mathrm{mrem} / \mathrm{yr}$ ). Sensitivity study results suggested the following parameters were critical in determining consequences: release rate, diffusion coefficients, travel time and flow rate, and river-water flow rate. Disruptive scenario evaluations are yet to be done.

- Switzerland - The Swiss National Cooperative for the Storage of Radioactive Waste (NAGRA) Guarantee Project is underway, but results were not yet available at the time of the review.

- The United Kingdom - Only very preliminary generic assessments have been made. For an inland granite site, making unrealistically pessimistic assumptions, doses of 500 to $6000 \mathrm{mrem} / \mathrm{yr}$ were calculated. Peak doses occurred after 10,000 years. With a seaside location, these doses fell two orders of magnitude, presumably due to dilution.

A preliminary safety analysis for a hypothetical coastal crystalline rock repository in Finland was presented by Peltonen (1984); therefore, it was not covered in the survey by Parker et a1. (1984).

Selected risk assessments are reviewed in further detail in this section. Finnish, Canadian, Swiss, and German work is reviewed here. Swedish assessments, since they were used for comparative purposes in Section 5.2, are reviewed in Section 4.2 .

\section{Finnish Crystalline Rock Analys is}

A preliminary safety analysis for a hypothetical coastal crystalline rock repository in Finland was reported by Peltonen (1984). The potential repository site was a small granitic rock island in the Baltic Sea, where the repository was to be located at a depth of 100 meters below the surface. The inventory included LLW and intermediate level wastes. A radionuclide inventory was assumed in the analysis, but none was given in the paper.

A compartmentalized modeling effort was described involving release from the waste packages, groundwater transport, migration into compartments of the geosphere, and entry into the biosphere with pathway and dose calculations. Population dose results were calculated in terms of a surface water scenario. 
By about 1,000 years after closure, the cumulative dose for the Baltic Sea regional population had been largely received. Between 1 and 10,000 personrem had been accumulated. With a $1.0 E+7$ population in the Baltic Sea region, this dose gave a range of possible collective dose to background dose ratios from between 1.0E-10 to 1.0E-4 of the collective background dose. The report described that dose as an insignificant population risk.

\section{Canadian Risk Assessment for a Generic Crystall ine Repository}

The most recent Canadian risk assessment was reported by Wuschke et al. (1985). Their report described the methods being developed and presented preliminary results. This was the second safety assessment for the Canadian program. The first, very preliminary and conservative assessment was published by Wuscke et al. (1985).

The purpose of the preliminary Canadian risk assessment work reported by Wuschke et al. (1985) was to permit evaluation of the performance assessment methodology and provide information for the design and planning of a deep geologic repository. Ultimately, these assessments were to be used to predict the impact of the disposal system on the human environment.

The scope of the Canadian safety assessment was the preliminary determination of the maximum annual dose equivalent to an individual. Collective tose may be addressed in subsequent studies. The individual of interest is representative of the population living their entire lives in the area where raciionuclides reach the ground surface.

The basis for the Canadian performance calculations consisted of a number of detailed considerations considered in their system model SYVAC (Systems Variability Analysis Code), a stochastic system model composed of three main modular submodels: 1) the vault submode1, 2) the geosphere submode1, and 3) the biosphere submode1. The more recent work used an improved version of the model called SYVAC2-C to probabilistically estimate doses to the maximally exposed individual from a repository that contained CANDU spent fuel.

In the 1985 report, details of the data used in the submodels in the SYVAC2-C code were presented. Ranges and distributions were presented for 
the major parameters used in the calculations. Major assumptions and features modeled in the Canadian assessment included:

- The inventory was 334,000 MTHM of spent fuel. Spent fuel was placed in titanium containers with voids filled by molten leadantimony alloy.

- Congruent dissolution of the waste form under reducing conditions was assimed. A small fraction $(0,0,1-0,1)$ of the Se, I, and Cs were assumer to be instantly released scion/waste package failure.

- Waste packages failed according to a uniform distribution with a mean of 18,100 years and a standard deviation of 1,485 years.

- Once a package failed, container, sheaths, and other materials in the container were ignored.

- Horizontal and vertical flow through the vault were considered.

- Geosphere data included assumptions regarding path length, hydrology, hydraulic gradient, and surface sorption coefficients.

- Biosphere modeling assumed a number of pathways. We11, 1ake, and agricultural land were considered assuming present day conditions.

- External radiation and inhalation exposures were also considered, but sedimentation was not considered.

- Doses were calculated for a reference group composed of individuals that were defined as taking plant, animal, and aquatic food that had been watered with contaminated groundwater or surface waters, and drinking contaminated groundwater or surface water.

- No disruptive events were considered in the analyses.

The results of the assessment indicated:

- No consequences for tens of thousands of years after disposal.

- Out of 1,000 scerarios analyzed using a Monte Carlo parameter selection methoc to define each calculational case, only $7 \%$ resulted in doses greater than $1.8 \mathrm{mrem} / \mathrm{yr}$ (1 percent of background dose).

- Iodine-129 was the predomirant dose contributor. It was the only nuclide that produced an arnual dose greater than $0.1 \mathrm{mrem} / \mathrm{yr}$.

- The geosphere was the most important and effective barrier. 
- The highest doses resulted from using a contaminated well as the source of household water. I-129 and Tc-99 were the largest contributors to dose. The only other source of importance was the ingestion of terrestial plants. This source ranked second if a well was the household water source, and first if the lake was the household water source.

- All doses greater than $30 \mathrm{mrem} / \mathrm{yr}$ were given by the well scenario. About $95 \%$ of the lake scenario results were below $1 \%$ of background.

\section{Evaluation}

The stochastic systems modeling effort used in this study represented the state of the art, and the results showed that expected risks to maximally exposed individuals would be low. As in the U.S. program, the problems related to the inclusion of disruptive and intrusive scenarios and their consequences have not yet been explicitly addressed.

\section{Swiss Risk Assessment for a Generic Crystalline Repository}

NAGRA published the results of its safety assessment for a hypothetical repository in crystalline rock in Switzerland. The English language summary of their report (NAGRA 1985) was consulted for this review.

The NAGRA safety studies addressed a governmental requirement to show that the population would not be exposed to unreasonable risks from the final disposal of radioactive wastes. The continued operation. of swiss nuclear power plants depended on the demonstration of a permanent, safe disposal method for all categories of radioactive waste (NAGKA 1985).

The scope of the NAGRA safety studies was very similar to the scope of the Swedish safety analysis--an evaluation of disposal system safety that used a deterministic modeling approach and realistic yet conservative parameter values that described a generic crystalline rock site. The calculational endpoint was dose rates (mrem/yr) that represented the total dose equivalent integrated over 50 years following radionuclide intake.

The basis of the NAGRA safety assessment was the deterministic simulation of a hypothetical HLW repository in crystalline rock with a flowpath that was 5,000 kilometers long, with an initial 500-meter segment at a $70^{\circ}$ 
angle upward, a long horizontal section, and a $45^{\circ}$ angled final section into fluvial gravels of the Rhine River basin.

The annual total flow through the hypothetical repository was conservatively estimated at $4.3 \mathrm{~m}^{3} / \mathrm{yr}$. The canister was assumed to disappear at 1,000 years, although the canister corrosion products ensured reducing chemical conditions around the waste matrix over the entire release period.

Leaching surfaces were assumed to be 12.6 times the emplaced waste surface area, and the glass was modeled as equivalent spheres with an initial radius of $2.1 \mathrm{~cm}$. A water volume of $0.7 \mathrm{~L} / \mathrm{yr}$ was assumed available to leach contents from each canister.

Radionuclide releases were assumed to be 1 imited either by elemental solubility or by the glass corrosion rate. Colloidal release was assumed to be prevented by filtration through the bentonite backfill material. The glass corrosion rate was $1.0 E-7 \mathrm{~g} / \mathrm{cm}^{2}$-day, giving a dissolution time of 155,000 years. The long-term effects of the bentonite on the transport of long-lived radionuclides were ignored. Spacing only short half-life radionuclides were considered in the transport-dose calculations and were assumed to be retarded by the bentonite.

Host rock transport occurred in veins that ran through deeply dipping zones of weakness and alteration products called kakirite zones. Retardation was calculated for the 500 meter kakirite flow path, then ignored for the remainder of the flow path, although substantial dilution took place prior to entering the fluvial gravels of the Rhine. As radionuclides entered the fluvial gravels, an 80 -fold dilution was assumed and the resulting concentrations were distributed over a number of compartments such as soil, soil water, groundwater, and the Rhine River. Consumption of water, foodstuffs grown on contaminated 1 and, and fish from the Rhine River were used to calculate doses to a population of adults.

In terms of calculational results, release of the $\mathrm{Np}-237$ and $\mathrm{U}-238$ decay chains was discussed. In both cases the precursor transuranics (Am-241 and Cm-246) were matrix-release limited, and the main long-lived nuclides were solubility controlled so that their releases were spread over 20 million and 200 million years, respectively. The only significant fission/activation 
products released from the backfil1 were Se-73, 1C-99, Pd-107, Sn-126, and Cs-135. All of these nuclides are solubility limited except for Cs -135 .

Resulting doses for the base case of realistically-conservative assumptions were completely insignificant, according to the report. The highest doses were estimated to result from two fission products, Cs-135 and $\mathrm{Pd}-107$, and amounted to $6.0 \mathrm{E}-8 \mathrm{mrem} / \mathrm{yr}$.

\section{Evaluation}

A parameter variation study was performed to see what hypothetical doses would have resulted from taking less conservative values for hydrological and geochemical parameters into the calculations. Changes in the geological setting, the assumption of a well rather than a fluvial gravel area to receive the contaminated water, and a variation in the dose conversion factors were also analyzed. Some of these analyses yielded more significant dose commitments, such as 1.OE-3 mrem/yr and 3.1E0-3 mrem/yr for Se-179 and Sn-126, respectively, which were considered nonsorbing. The combinations of conservatisms used to obtain these results cannot be considered to represent any actual expected case, however, and without a probabilistic evaluation of the possibility of encountering such pessimistic conditions throughout the transport system, little significance should be attached to the analytical results. Their chief use is in guiding and challenging site studies to establish as realistically as possible the range of site parameters.

Alternative future scenarios were also discussed, including climate changes, volcanism, erosion, tectonics, meteorites, and earthquakes. These were dismissed as either being so destructive as to make dose increases inconsequential risks in comparison, or as not being able to materially increase the expected doses. Even a well above the potential repository that took all water from the 500-meter near-vertical path without dilution only resulted in a 140-fold increase in doses above the base case, or about 1.0E-5 mrem/yr, mostly from Cs -135 .

Base-case dose calculation results were compared with KBS-3 and other safety study results. The 1.0E-6 mrem/yr individual jose calculated for the NAGRA (1985) study is lower than that calculated for most of the other studies, which were labeled conservative while this one was labeled 
realistic. The best-estimate results to be used in 1 ifcensing the Swiss repository are expected to be much lower.

A Prel iminary Safety Assessment for a Hypothetical Repository in a Salt Dome in Germany

Chapter 4.0 of the Summarized Final Report of Projekt Sicherheitsstudien Entsorgung (PSE 1985a) contained a preliminary safety assessment for a saltdome repository. The purpose of Projekt Sicherhetsstudien Entsorgung (PSE) was to provide the safety assessment methodology needed to support German nuclear waste disposal activities. The testing of these methodologies and the evaluation of proposed disposal systems are future objectives. A preIiminary performance assessment for the planned Gorleben salt dome nuclear waste disposal system was performed as part of this study.

In the PSE report (1985a), the Gorleben salt dome regional model was explained in some detail, as were the mine and its workings. About $3 \%$ of the waste volume was planned to be HLW, about $12 \%$ intermediate level waste, and the rest LLW. It appeared that somewhat over 1,000 MTHM would be deposited in this facility.

The filled mine would be backfilled and sealed with dikes of porous materials placed at strategic points. These dikes would create cells that were isolated from each other, and the repository was modeled in terms of these cells surrounded by diffusion barriers. Each cell had its own internal convective circulation, and mass transfer process from cell to cell and out of the system was modeled as brine extrusion, brine exchange, and diffusion. Sorption was included in the model. The source of the brine was a large inflow of water assumed to occur prior to final closure.

Releases were modeled to occur when there was a release of brine from the sealed facility. A $5 \mathrm{~m}^{3} / \mathrm{yr}$ steady-state brine extrusion into the overlying rock/groundwater was assumed, mainly the result of convergence within the mine after sealing. Transport to the biosphere was modeled, and groundwater consumption of $500 \mathrm{~L} /$ person-yr was assumed. Irrigation of food crops and livestock watering was also assumed. Dose was calculated for a maximally exposed individual that was assumed to be drinking, irrigating, and watering animals at the most disadvantageous location. A 1-year dose was assumed, 
with consequences modeled over 50 years. Results for the approximately 1,000 MTHM inventory are presented in Table 4.40.

\section{Evaluation}

It is clear that the flow paths at Gorleben are being modeled as if they were short and flow was rapid, although the facllity was to be located 800 meters beneath the land surface. The first chapter of this report series (PSE 1985b) gave 1.0E-2 rem/yr (the T'c-99 dose given in Tabla 4.40) as the maximum postclosure individual dose, expected 7,000 years after closure as a result of water intrusion into the repository soon after permanent closure, and subsequent extrusion as 1 ithostatic pressures were restored. The probability of this scenario, according to the same source, was rot quantified. Hence, no risk can as yet be calculated. The modeled scenario seems unrealistic, in that it postulates a highly unlikely inflow of large amounts of water prior to repository closure. The design of the Gorleben repository, its geologic setting, its inventory, and its assumed disruptive event scenario are each significantly different from what would be expected for any salt repository that may be built in the United States (DOE 1986b,d,e). Therefore, the PSE $(1985 a, b)$ results are useful for making comparison's with U.S. risk assessment results in Section 5.2 .

\subsubsection{Reports Selected for Use in This Study}

The previous section provided a review and evaluation of the literature that deals with postclosure risks from repositories. The major objective of this study was to use this available literature to develop estimates of the risks from the waste management system. Estimates of postclosure risks are developed in Section 5.2. This section presents the rationale for selecting the reports that are used as the basis for those estimates.

Table 4.41 provides a brief overview of the major postclosure risk assessment documents reviewed in this report. The information in the table demonstrates that postclosure risk assessment is st 111 a developing area. None of the available literature provided a complete risk assessment for a geologic repository. Much of the literature analyzed only the expected performance of the potential repository to preliminarily evaluate the $1 \mathrm{ikel}$ ihood of demonstrating compliance with regulatory requirements. Studies that 


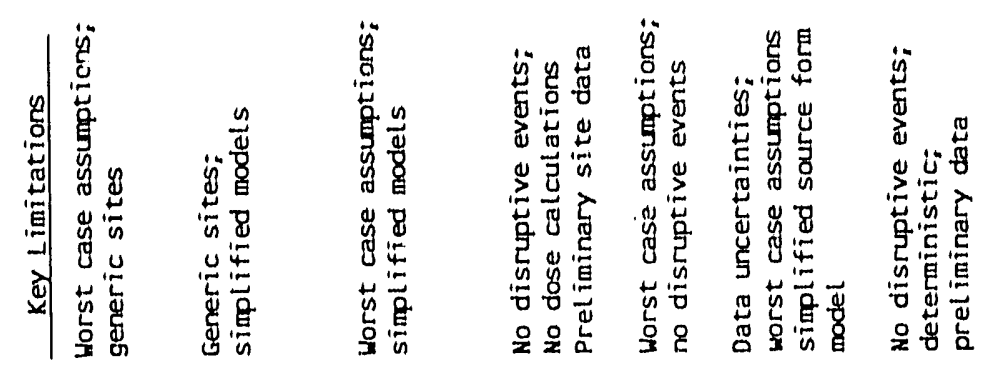

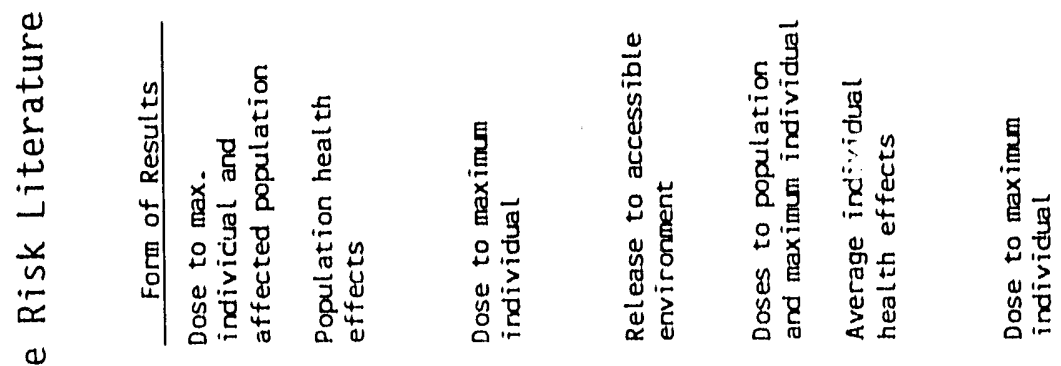

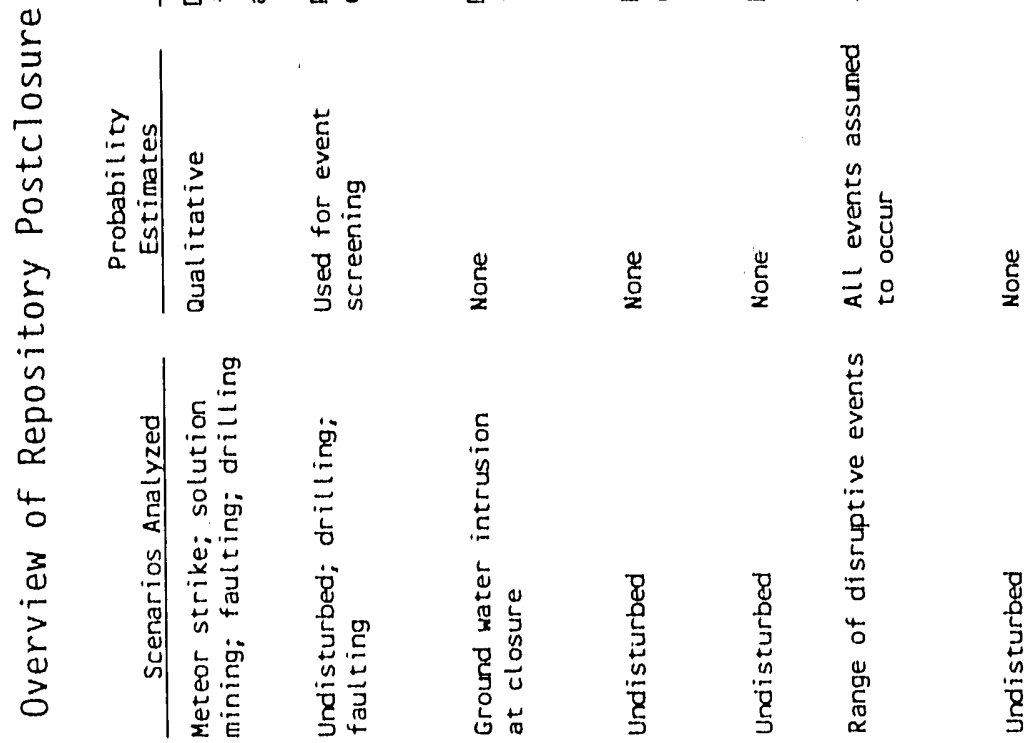

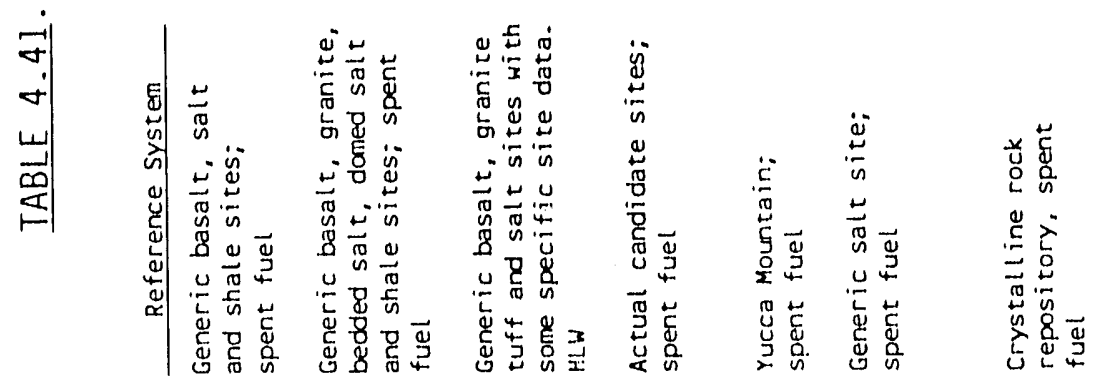

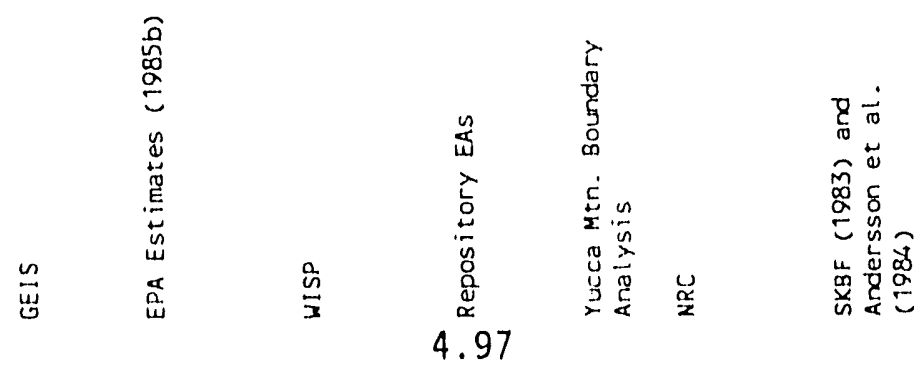


include disruptive events typically only addressed selected events. A varlety of time hortzons were considered in the studies as well, ranging from 10,000 to $1,000,000$ years. Large uncertainties surrounded the probabiltties of the disruptive events. There are major uncertainties in other data used in the assessments as we11. Extenstve programs are underway to characterize the reposttory site and develop sound site-specific data that can form the basis for credible performance assessments and risk estimates. None of the existing studies had sufficient site-specific data on which to base a definitive analysis. Many of the studies used generic site assumptions with very conservative estimates of about host media characteristics. Dose modeling was also typically based on very conservative assumptions.

Given the state of development of postclosure risk analysis, it will not be possible to develop definitive estimates of the risks from the postclosure phase of the repository in this report. However, sufficient information is available to develop crude, conservative estimates that can lend perspective to the consideration of postclosure risks.

The criteria presented in Table 4.1 have been used to select the documents that are used in Section 5.2 to develop these estimates. Because few of the studies presented results in risk terms, the first criteria had to be discarded in the selection process. Selection was based primarily on the degree to which the data and assumptions represented a credible model of the postclosure performance of the repository at a given site and the extent to which the source document included the major elements of a risk analysis. Selection of the reports used to develop the estimates for each of the potential repository media is discussed below.

\subsubsection{Basalt}

The more credible and site-specific postclosure performance assessments for a hypothetical repository in basalt were those in the Environmental Assessment, Reference Repository Location, Hanford Site, Washington (DOE 1986a) and in A Simplified Analys is of a Hypothetical Repository in a Basalt Formation (Pepping et al. 1983a). 
In addition, the EPA (1985b) provided a generic but complete $r$ isk assessment, and the crystalline rock repository risk estimates of Andersson et a1. (1984) provided an order-of-magnitude comparison for an analogous geologic setting. The calculations in the Hanford environmental assessment considered only the expected case, without intrusive and disruptive event scenarios, while the pepping et a1. (1983a) study included 1imtted consideration of unexpected event scenario consequences in terms of the creation of large and small high-conductivity zones. Both of these studies addressed the EPA's CFR Part 191 standard's limits on 10,000-year cumulative releases to the accessible environment.

The general site-system cunsequence categories of the potentially significant unexpected event scenarios identified by a DOE expert panel (DOE 1986f) may have been covered in both the EPA (1985b) and Pepping et al. (1983a) analyses.

\subsubsection{Salt}

The Environmental Assessment, Deaf Smith County Site, Texas (DOE 1986b) reported analyses suggesting that a zero release to the accessible environment would be expected for up to 100,000 years. This result readily translated into a zero population risk for the expected, undisturbed repository case. However, the DOE expert panel that was used in the process of choosing three sites for characterization from among the five nominated, judged that there was a significant likelihood for large-scale exploratory drilling and incomplete sealing of the shafts and the potential repository to ultimately result in some releases (DOE 1986f). Analyses that do not consider these unlikely, yet somewhat probable events are not complete in terms of the regulatory performance assessment requirements specified in 40 CFR Part 191 (EPA 1985a).

Using the criteria in Table 4.1 for selecting from the avallable literature leci to the analysis of Pepping et al. (1983b) in terms of completeness and appropriateness, and to the analyses of Pepping et a1. (1983c), and the EPA (1985b) since these studies continued calculations to conditional healtheffects risks. 


\subsubsection{Tuff}

As in the basalt and salt cases already discussed, the tuff environmental assessment, Environmental Assessment, Yucca Mountain Site, Nevada Research and Development Area, Nevada (DOE 1986c), was selected from the available literature using the criteria of Table 4.1. This environmental assessrient reported preliminary performance assessment results that addressed the EPA standard, but only for the expected case, not considering intrusive or disruptive event scenarios. The expert panel on site selection felt that the appearance of unexpected features and the occurrence of extrusive magmatic events were scenarios that should be evaluated for the Yucca Mountain location (DOE 1986f). The latter scenario was considered to have a low probability, however.

Also selected from the literature was the analysis by Siegel and Chu (1983) because it addressed the unexpected features scenario by assuming a number of different site system descriptions that were considered likely by these authors. Other studies selected using the criteria of Table 4.1 were the simplified analysis of Thompson et al. (1984), and the most complete but perhaps least appropriate risk assessment reported by the EPA (1985b). The relative inappropriateness of the EPA (1985b) work is largely the result of the assumed existence of a generic river pathway in the risk assessment.

\subsection{MONITORED RETRIEVABLE STORAGE}

This section provides a discussion of the literature that contains information on potential risks that would result from construction, operation, and decommissioning of the MRS facility. The concept of an MRS facility as an integral part of the waste management system has been developed by DOE over the last several years. The DOE has concluded that the MRS facility will make the waste system easier to implement and operate because of the flexibility that it provides (DOE 1985b). The information in the literature related to the safety and risk of the MRS facility has primarily been developed by DOE over the last several years as part of the MRS facility design and system development efforts it has been conducting under provisions of the NWPA. The MRS concept evolved from previous concepts to provide storage for 
spent fuel away from reactor sites (Independent Spent Fuel Storage-ISFS). Some of the information developed in studies of ISFS concepts is also applicable to the MRS facility and is included in these reviews.

\subsubsection{Review of MRS Risk Literature}

This section provides a brief overview of the contents of each of the documents that were selected for review. The scope and technical basis of each study are summarized and results potentially applicable to the risk characterization in Section 5.3 are described. A brief evaluation of the applicability of these results to OCRWM's needs for information on the risks from the MRS facility is also provided. The various studies are compared in Section 4.3.2 and the rationale for selecting the values used in Section 5.3 is presented.

\subsubsection{MRS Facility Environmental Assessment}

An environmerical assessment was prepared as part of the DOE submission to Congress under Section 141 of the Nuclear Waste Policy Act. Submission of the package to Congress was delayed by legal proceedings, but a draft of the environmental assessment was released. This draft (DOE 1986g) is reviewed here. This was a ful1. scope environmental assessment that described potential environmental effects from construction, operation, and decommissioning of the MRS facility. Impacts from transporting spent fuel to and from the facility were also included. Effects on air quality, water quality, 1 and use, surrounding ecosystems, esthetics, natural resources, and public health were ilaracterized. The study described these effects for three potential MRS facility sites in Tennessee ( $\mathrm{Clinch}$ River, Oak Ridge, and Hartsville) and two possible designs for the storage system: storage casks and field drywells. In addition, the need for and feasibility of the MRS facility were analyzed in detail. Because this was an environmental assessment, it contained limited information on the risks from the facility. Radiological doses from routine emissions from the facility were estimated, the consequences of selected accident scenarios were calculated and potential radiological and nonradiological impacts during construction and decommissioning were discussed. As part of the need and feasibility study, the occupational radiation exposure in the MRS facility was estimated. These categories of 
information have been reviewed in detail because they are potentially applicable to the development of the MRS facility risk estimates needed for this study. The remaining portions of the assessment were not reviewed.

All of the impact estimates contained in the environmental assessment were based on operation of the facility at its assumed maximum receipt rate of 3,600 MTU of spent fuel per year. The facility was assumed to have a 26year operating lifetime and total throughput of 53,000 MTU of fuel. Ninety percent of the fuel was assumed to have a burnup of $33,000 \mathrm{Mwd} / \mathrm{MTU}$ and $10 \%$ a burnup of 55,000 Mwd/MTU. The study emphasized that most of the calculations used conservative assumptions and methods to develop upper-bound estimates of the impacts. The environmental assessment presented results for both storage concepts at all three sites. Only minor differences were found among the sites and storage concepts. Results are described here only for the Clinch River site and the storage cask design concept. These are representative of the results obtained for the ocher facility/site combinations.

Routine emissions of radioactive material occurred from cask venting and fuel consolidation operations. The routine emission calculations assumed that there was one fuel assembly drop accident in the hot cell every year. Emissions from this accident were included in the routine dose calculations. Conservative assumptions were used to characterize these releases. The study assumed that $0.01 \%$ of the fuel rods in each cask arriving at the facility had failed during transit, releasing the volatile fission products to the cask cavity. These materials were assumed to be released through the facility ventilation system when the cask cavity was vented prior to removing the fue1. Consolidation operations were assumed to rupture $0.15 \%$ of the fuel rods, resulting in release of the volatile fission products. The fuel assembly drop accident was assumed to rupture all of the rods in the fuel assembly. Release fractions from fuel with a 33,000 Mwd/MTU burnup were taken from NRC Regulatory Guide 1.25. Release fractions for 55,000 Mwd/MTU fuel were assumed to be 30 to $50 \%$ higher. Releases were assumed to include tritium, krypton, iodine and cobalt. A filter transmission factor of $2.0 \mathrm{E}-9$ was used. All releases were assumed to occur from the stack. 
The results of the dose calculations for routine emissions are given in Table 4.42. The maximally exposed individual was assumed to reside at the site boundary. Population doses used actual population distributions out to 80 kilometers from the site. Dose calculations were performed with the ALLDOSE computer code. Annual average dispersion factors were used. Dispersion calculations were performed with the XOQDOQ code, which uses a standard Gaussian plume dispersion model.

Four accident categories were described in the report. These categories were based on the expected frequency of occurrence of the accident and included:

- Category I - routine operations

- Category II - reasonable chance of occurring once per year

- Category III - reasonable chance of occurring once during the lifetime of the facility

- Category IV - unlikely to occur, but require consideration.

Consequences from Category I were included in the routine dose calculations. A representative accident was selected for each of the remaining categories and an estimate of the consequences was calculated. The fuel assembly drop accident was used for Category II; a cask drop accident in the hot cell was used for Category III, and a storage cask overturn accident was used for Category IV. For the cask drop accident, $1 \%$ of the fuel assemblies were assumed to fail and release $57 \%$ of the volatile fission products to the ventilation system when the cask was opened. A rail cask containing 36 BWR

TABLE 4.42. Radiation Exposures from Routine Operations at the MRS Facility

\begin{tabular}{lcc} 
& \multicolumn{2}{c}{$\begin{array}{c}50 \text {-Year Dose Commitment } \\
\text { from Annual Release }\end{array}$} \\
\cline { 2 - 3 } $\begin{array}{c}\text { Pathway and Location } \\
\text { in the Body }\end{array}$ & $\begin{array}{c}\text { Maximally Exposed } \\
\text { Individual }(\text { rem) }\end{array}$ & $\begin{array}{c}\text { Population } \\
\text { (person-rem) }\end{array}$ \\
\cline { 1 - 3 } Total Body & $2.4 \times 10^{-4}$ & $2 \times 10^{1}$ \\
Bone & $3.0 \times 10^{-6}$ & $1 \times 10^{-1}$ \\
Lungs & $2.4 \times 10^{-4}$ & $2 \times 10^{1}$ \\
Thyroid & $1.3 \times 10^{-3}$ & $1 \times 10^{2}$
\end{tabular}


assemblies was used to represent this scenario. The storage cask drop was assumed to fail $5 \%$ of the fuel pins in the cask. Again $57 \%$ of the volatile fission products was assumed to be released to the ventilation system when the cask was returned to the $\mathrm{R} \& \mathrm{H}$ area for inspection and repackaging of the fuel. The results of the dose calculations from these releases are presented in Table 4.43. Accident dose calculations were performed using the same methods and data as the routine dose calculations.

Occupational dose estimates were provided for each of the major operations in the MRS facility. These estimates are summarized in Table 4.44.

The estimates were based on actual experience with spent-fuel handling operations at reactors and fuel-storage facilities, adjusted for the specific design parameters of the MRS system. It was assumed that $30 \%$ of the fuel entering the MRS facility arrived by truck and $70 \%$ by rail. Outgoing shipments were assumed to travel exclusively in rail casks.

The study provided quantitative estimates of the amounts of nonradioactive materials released from the site during construction and operations.

TABLE 4.43. Radiological Impacts of Potential MRS Facility Accidents for Sealed Storage Cask at the Clinch River Site

\begin{tabular}{|c|c|c|c|}
\hline \multirow{2}{*}{ Accident } & \multirow[b]{2}{*}{$\begin{array}{l}\text { Location } \\
\text { in the body }\end{array}$} & \multicolumn{2}{|c|}{$\begin{array}{c}\text { 50-Year Dose Commitment } \\
\text { to the Public } \\
\end{array}$} \\
\hline & & $\begin{array}{l}\text { Maximally Exposed } \\
\text { Individual (rem) }\end{array}$ & $\begin{array}{l}\text { Population } \\
\text { (person-rem) }\end{array}$ \\
\hline Fuel Assembly Drop & $\begin{array}{l}\text { Total Body } \\
\text { Bone } \\
\text { Lungs } \\
\text { Thyroid }\end{array}$ & $\begin{array}{l}4.4 \times 10^{-3} \\
1.4 \times 10^{-4} \\
4.6 \times 10^{-3} \\
2.9 \times 10^{-2}\end{array}$ & $\begin{array}{l}3 \times 10^{-2} \\
7 \times 10^{-3} \\
3 \times 10^{-2} \\
2 \times 10^{-1}\end{array}$ \\
\hline Shipping Cask Drop & $\begin{array}{l}\text { Total Body } \\
\text { Bone } \\
\text { Lungs } \\
\text { Thyroid }\end{array}$ & $\begin{array}{l}9.1 \times 10^{-4} \\
3.0 \times 10^{-5} \\
9.6 \times 10^{-4} \\
6.0 \times 10^{-3}\end{array}$ & $\begin{array}{l}6 \times 10^{-3} \\
1 \times 10^{-3} \\
6 \times 10^{-3} \\
3 \times 10^{-2}\end{array}$ \\
\hline Storage Cask Drop & $\begin{array}{l}\text { Total Body } \\
\text { Bone } \\
\text { Lungs } \\
\text { Thyroid }\end{array}$ & $\begin{array}{l}8.9 \times 10^{-4} \\
2.9 \times 10^{-5} \\
9.3 \times 10^{-4} \\
5.9 \times 10^{-3}\end{array}$ & $\begin{array}{l}6 \times 10^{-3} \\
1 \times 10^{-3} \\
6 \times 10^{-3} \\
3 \times 10^{-2}\end{array}$ \\
\hline
\end{tabular}


TABLE 4.44. Cccupational Dose from MRS Facility Operations (DOE 1985b)

Operation

Receipt and Unloading

Consolidation

Loading Consolidated

Fuel Rods

Maintenance/Monitoring

Emplacement and

Retrieval

Total
Unit Occupational

(person-rem/1,000 MTU)

58

6

9

2

$\underline{20}$

95

These were compared with regulatory limits and found to be within the limits. No health effects estimates were made for these releases. Radioactive and nonradioactive releases during decommissioning were not quantified but the assertion was made that these would be very small and would produce no significant effects.

\section{Evaluation}

Because this was an environmental assessmenic it contained limited information that could be used to develop estimates of the risks associated with the MRS facility. An environmental assessment does not deal with consequences on a probabilistic basis and most of the impacts were estimated using bounding calculations. This was appropriate for the purposes of the environmental assessment process, but produced results of limited use in characterizing risks. The accident analysis treated only representative scenarios, rather than a complete set of possible accidents. Approximate frequencies were provided for the representative scenarios, but they were not used to make risk estimates. The routine dose calculations may be useful for making estimates of the risks from routine operations, although they probably substantially overstate the actual effects. The environmental assessment did not quantify the radiological and nonradiological impacts from decommissioning and the nonradiological impacts from construction and operations. Statements were made that these impacts are insignificant. These general insights 
are useful for the purpose of this study and quantitative health effects estimates are needed for the risk estimates that are presented in Chapter 5.0 .

\subsubsection{Safety Evaluation of MRS Storage Concepts}

This study (Ligon et a1. 1983) was performed to evaluate the safety of the tunnel rack dry well storage concepts that were being considered in the early stages of the MRS Program. The study addressed only public radiological risks from accidents during operation of an MRS facility. A quantitative assessment was provided only for the dry well concept. Accident sequences were identified for the tunnel rack concept, but probabilities and consequences of these accidents were not developed. The study was based on preliminary conceptual designs developed before detailed evaluation of the MRS concept was authorized in the NWPA. The reference facility had a receipt rate of 2,880 spent fuel assemblies per year (approximately 900 MTU.) The facility was assumed to receive fuel for 36 years and to store the fuel for 100 years before it was shipped to a disposal site. The reference fuel was 5 years old when it was received and had a burnup of 33,000 Mwd/MTU. The anaTysis was restricted to the interface and storage areas. It did not include the R\&H and packaging activities.

The study used a combination of engineering judgment and Failure Modes and Effects (FMEA) analysis to develop a list of accident initiators. The FMEA was used to identify initiators that originate inside the plant. Engineering judgment was used to identify external initiators. A screening method based on qualitative assessments of the probability and consequences of the initiating events was used to select those events that were analyzed in detail. Event trees were used to develop the accident scenarios for the selected initiating events. A detailed fault tree was developed to estimate the failure frequency of the ventilation system. Probabilities for the other events in the accident sequences were estimated directly. A large fraction of the event probabilities were based on engineering judgment. Others were adapted from related studies. Distribution functions were assumed for each event probability. These were carried through the analysis and used to illustrate che $5 \%$ and $95 \%$ confidence limits on the results. The study 
acknowledged that the probabilities were generally conservative because design details were not available. Engineered safety features could substantially reduce the probability of some of the scenarios. A set of release categories was developed and each of the accident scenarios was assigned one of the release categories. The release categories and release fractions associated with each category are summarized in Table 4.45. The study acknowledged that the release fractions are were conservative.

The study results are summarized in Table 4.46. This table lists the accident scenarios analyzed, the scenario frequency, the release category assigned and the consequences calculated. The risk from each scenario (frequency times consequence) is also provided. Consequences for accidents during the retrieval phase were lower than for the same accident during emplacement phase because the fuel was older and less radioactive (i.e., it was assumed to have decayed for up to 100 years). However, this effect would be reduced if the fuel and waste package had deteriorated or been damaged. It can be seen that only the accidents resulting from transporter movement during the emplacement and retrieval operations contribute significantly to the overall risk. A risk curve was also developed in the study. This curve is shown in Figure 4.1.

The consequence calculations were performed using information taken from the GEIS (DOE 1980). The dose conversion factors developed for the reference site used in the GEIS were used directly to estimate the consequences from releases from the MRS facility by using the ratios of the source terms from the two studies. The reference site had 2 million people within an 80 -kilometer radius. Health effects conversion factors were based on WASH1400. Doses to the maximally exposed individual were estimated for most of the accident scenarios and found to be less than 1 mrem in nearly all cases.

\section{Evaluation}

The study represented a credible initial attempt to develop an accident risk analysis for the MRS facility. A comprehensive list of accident scenarios was developed for the portions of the facility considered. Release fraction, probability, and consequence estimates were generally very conservative. The report did not provide details of the analysis in many areas, 
TABLE 4.45. Release Categories (Ligon et a1. 1983)

\begin{tabular}{|c|c|c|c|c|}
\hline $\begin{array}{l}\text { Release } \\
\text { Category }\end{array}$ & $\begin{array}{l}\text { Release Type } \\
\text { (Generic Event) }\end{array}$ & $\begin{array}{l}\text { Assumed Damage Per } \\
\text { Canister Involved } \\
\text { In Event } \\
\end{array}$ & \multicolumn{2}{|c|}{$\begin{array}{c}\text { Fraction Release o } \\
\text { Radionuclides to } \\
\text { Environment }\end{array}$} \\
\hline I & $\begin{array}{l}\text { Filtered gap release } \\
\text { (canister impact in } \\
\text { the Interface areas) }\end{array}$ & $\begin{array}{l}\text { Gap inventory from } \\
10 \% \text { pins released } \\
\text { through filters }\end{array}$ & $\begin{array}{c}\text { Gases: } \\
\text { I : }\end{array}$ & $\begin{array}{l}3.0 E-2 \\
3.0 E-4\end{array}$ \\
\hline II & $\begin{array}{l}\text { Limited gap release } \\
\text { (canister leak) }\end{array}$ & $\begin{array}{l}\text { Gap inventory from } \\
1 \% \text { pins (assumed to } \\
\text { develop leaks while } \\
\text { in storage) released } \\
\text { via leaks and exit } \\
\text { channels }\end{array}$ & $\begin{array}{r}\text { Gases: } \\
\text { I: }\end{array}$ & $\begin{array}{l}3.0 \mathrm{E}-3 \\
5.0 \mathrm{E}-4\end{array}$ \\
\hline III & $\begin{array}{l}\text { Unlimited gap release } \\
\text { (canister impact in } \\
\text { storage areas) }\end{array}$ & $\begin{array}{l}\text { Complete gap } \\
\text { inventory from } 10 \% \\
\text { pins }\end{array}$ & $\begin{array}{r}\text { Gases: } \\
\text { I: }\end{array}$ & $\begin{array}{l}\text { 3. } 0 E-2 \\
3.0 E-2\end{array}$ \\
\hline IV & $\begin{array}{l}\text { Elevated temperature } \\
\text { release (temporary } \\
\text { loss of cooling) }\end{array}$ & $\begin{array}{l}\text { Complete inventory } \\
\text { of gases and I and } \\
1 \% \text { of volatiles } \\
\text { released via leaks } \\
\text { and exit channels }\end{array}$ & $\begin{array}{l}\text { Gases: } \\
\text { I: } \\
\text { Cs, Ru: }\end{array}$ & $\begin{array}{l}1.0 E+0 \\
1.7 E-1 \\
1.0 E-4\end{array}$ \\
\hline V & $\begin{array}{l}\text { Exposed fuel release } \\
\text { (severe canister } \\
\text { impact) }\end{array}$ & $\begin{array}{l}10 \% \text { of fuel exposed } \\
\text { neleasing gap } \\
\text { invistory, volatiles, } \\
\text { and particulates. } \\
\text { Remainder releases } \\
\text { gap inventory via } \\
\text { leaks and exit } \\
\text { channels }\end{array}$ & $\begin{array}{c}\text { Gases: } \\
\text { I: } \\
\text { Cs, Ru: } \\
\text { Particles: }\end{array}$ & $\begin{array}{l}3.0 \mathrm{E}-1 \\
6.0 \mathrm{E}-1 \\
1.0 \mathrm{E}-3 \\
1.5 \mathrm{E}-6\end{array}$ \\
\hline VI & $\begin{array}{l}\text { Exposed heated-fuel } \\
\text { release (severe } \\
\text { canister impact } \\
\text { with fire) }\end{array}$ & $\begin{array}{l}\text { As in } V \text {, with } \\
\text { increased releases }\end{array}$ & $\begin{array}{c}\text { Gases: } \\
\text { I: } \\
\text { Cs, Ru: } \\
\text { Particles: }\end{array}$ & $\begin{array}{l}\text { 1.OE }+0 \\
2.0 E-1 \\
5.1 E-3 \\
3.0 E-6\end{array}$ \\
\hline
\end{tabular}

(a) Gases include $\mathrm{C}-14, \mathrm{H}-3$, and $\mathrm{Kr}-85$. 
TABLE 4.46. Summary of MRS Drywe11 Risk Ana7ysis (Ligon et al. 1983)

\begin{tabular}{|c|c|c|c|c|}
\hline & $\begin{array}{l}\text { Frequency } \\
\text { Per Year }\end{array}$ & $\begin{array}{l}\text { Release } \\
\text { Category }\end{array}$ & $\begin{array}{c}\text { Latent } \\
\text { Cancer } \\
\text { Fatalities } \\
\end{array}$ & Risk \\
\hline \multicolumn{5}{|l|}{$\begin{array}{l}\text { Transporter collision during } \\
\text { emplacement }\end{array}$} \\
\hline - no fire & $1.7 \mathrm{E}-8$ & III & $3.4 E-5$ & $5.8 E-11$ \\
\hline - fire & $6.1 E-7$ & IV & $1.9 \mathrm{E}-3$ & $1.2 \mathrm{E}-9$ \\
\hline \multicolumn{5}{|l|}{$\begin{array}{l}\text { Transporter collision during } \\
\text { retrieval }\end{array}$} \\
\hline - no pin failure; no fire & $8.9 E-3$ & II & $5.9 E-7$ & $5.3 \mathrm{E}-9$ \\
\hline - pin failure; no fire & $2.8 \mathrm{E}-2$ & III & $3.8 \mathrm{E}-5$ & $1.1 E-6$ \\
\hline - no pin failure; fire & $1.4 \mathrm{E}-4$ & IV & $2.6 \mathrm{E}-6$ & $3.6 \mathrm{E}-12$ \\
\hline - pin failure; fire & $1.4 \mathrm{E}-4$ & IV & $2.6 \mathrm{E}-4$ & $3.6 \mathrm{E}-8$ \\
\hline \multicolumn{5}{|l|}{$\begin{array}{l}\text { Transporter motion with } \\
\text { canister partially in place }\end{array}$} \\
\hline - emplacement & $8.6 \mathrm{E}-2$ & $v$ & $1.8 \mathrm{E}-2$ & $1.5 \mathrm{E}-2$ \\
\hline - retrieval; no pin failure & $8.9 E-3$ & II & $5.9 \mathrm{E}-7$ & $5.3 E-9$ \\
\hline - retrieval; pin failure & $1.4 \mathrm{E}-1$ & v & $1.6 \mathrm{E}-3$ & $2.2 E-4$ \\
\hline Canister drop - emplacement & $1.7 \mathrm{E}-8$ & I & $3.9 \mathrm{E}-6$ & $6.6 \mathrm{E}-14$ \\
\hline Canister drop - retrieval & $1.1 \mathrm{E}-2$ & I & $9.9 \mathrm{E}-7$ & $1.1 \mathrm{E}-8$ \\
\hline Plane crash; no fire & $4.0 E-10$ & $v$ & $2.6 \mathrm{E}-1$ & $1.0 E-10$ \\
\hline Plane crash; fire & $7.4 \mathrm{E}-9$ & VI & $1.3 E+0$ & $9.6 \mathrm{E}-9$ \\
\hline Earthquake; no pin failure & $4.8 \mathrm{E}-9$ & II & 6.1E-2 & $2.9 \mathrm{E}-10$ \\
\hline $\begin{array}{l}\text { Earthquake; pin failure } \\
\text { Total }\end{array}$ & $4.3 E-8$ & II & $3.3 E+0$ & $\frac{1.4 E-7}{1.7 E-3}$ \\
\hline
\end{tabular}

making it difficult to confirm the results and evaluate implementation of the method. Several of the study bases were substantially different from those being used to develop the risk estimates in Section 5.3. These differences include: the study did not address receiving and packaging operations; the throughput and operating life of the facility were very different from the current MRS facility concept; it only dealt with one of the design 


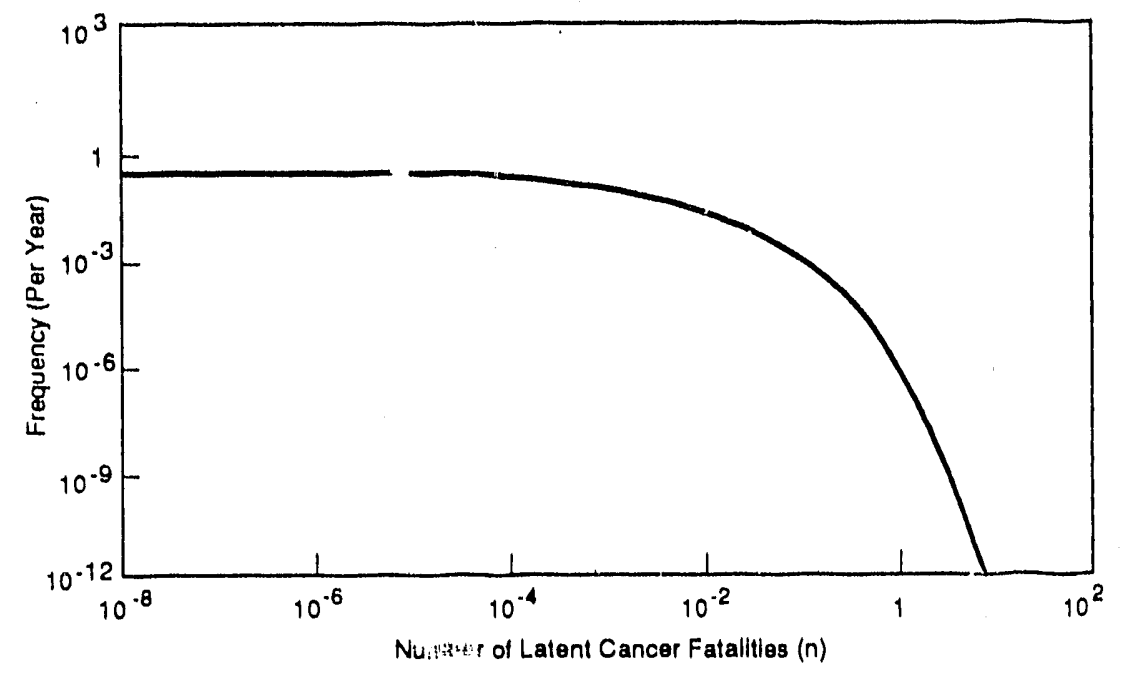

FIGURE 4.1. MRS Dry Wel1 Risk Curve (Ligon et a1. 1983)

concepts being considered for the MRS facility; and the reference site was substantially different from the sites currently being considered for the MRS facility.

\subsubsection{Comparison of Cask and Drywell Storage Concepts}

This study (Ganley 1982) compared a number of performance parameters for the drywell and storage cask design concepts for an MRS facility. The study emphasized life-cycle costs and the effect on size and throughput rate of changing waste system parameters such as disposal and reprocessing schedules. Effects on the facility design of handling TRU wastes were also considered. Safety was considered only in a preliminary way in the comparison. The study did not develop any new risk information, but relied on previous studies to characterize the safety performance of the two design concepts. Risks for the storage cask concept were extracted from the GEIS (DOE 1980). Results for the drywell concept were taken directly from Ligon et a1. (1983). Because this study contained no new information, the results were not reviewed in detail.

\subsubsection{Review of Dry Storage Concepts}

Orvis (1984) provided a comparative risk analysis of three design concepts for dry storage of spent nuclear fuel at reactor sites. His report 
considered only radiological risks to the public from accidents during the storage operations. Storage concepts considered were drywe11, storage cask, and vault. An analysis of the risks from pool storage was also presented for comparison purposes. The drywell and storage cask concepts are currently beirg considered for an MRS facility, so this study was reviewed to identify risk information potentially applicable to estimates of the risk from the MRS facility. The refersice reactor used in the study was a 1000-MWe PWR. The reactor was assumed to discharge 60 spent fuel assemblies per year to the fuel storage basin. The assemblies were transferred to the dry storage facility after they had cooled in the storage pool for 5 years. The dry storage area has a total storage capacity of 2,400 assemblies. The fuel was placed in canisters before being placed in the dry storage facility. The canister used for the drywell concept contained one assembly; whereas the canister for the storage cask concept contained 24 assemblies. The dry storage facility was assumed to be located on the reactor site, but in a separate building from the storage pool. The analysis was based on preliminary design information for all of the storage concepts. Many assumptions about design details were necessary to complete the analysis.

Fault tree analysis was used to define the accident scenarios for each of the design concepts and to develop the accident probabilities. A comprehensive set of scenarios was developed. External events as well as equipment failures and human error were considered as accident initiating mechanisms. The Reactor PRA Procedures Guide (NRC 1983b) was used to identify external events of interest in the analysis. Extensive use was made of external event analysis in recent reactor PRA studies to estimate the frequency and damage produced by external events for each of the storage concepts. Event frequencies were taken from a number of reliability databases and reactor risk studies.

An extensive review of the literature was performed to develop the release fractions used in the analysis. The release fractions used are summarized in Table 4.47. The release fractions were based on the assumption that $1 \%$ of the fuel was failed before the accident takes place. The results of the risk analysis are summarized in Table 4.48 for the two design concepts potentially applicable to the MRS facility. The accident scenarios are

\subsection{1}


TABLE 4.47. Spent Fuel Release Fractions (Orvis 1984)

Release Fraction

\begin{tabular}{|c|c|c|c|c|c|c|c|}
\hline & Release Category & $\mathrm{kr}$ & I & $\mathrm{Cs}$ & $\mathrm{Sr}$ & $\mathrm{Co}$ & Actinides \\
\hline 1. & $\begin{array}{l}\text { Bare fuel fractured } \\
\text { underwater }\end{array}$ & 0.20 & $3.0 E-6$ & - & - & - & - \\
\hline 2. & $\begin{array}{l}\text { Canister or cask opened } \\
\text { at normal temperature. } \\
\text { Preexisting leakage } \\
\text { from damaged rods. }\end{array}$ & 0.002 & $1.5 \mathrm{E}-8$ & $1.0 \mathrm{E}-8$ & - & 0.03 & - \\
\hline 3. & $\begin{array}{l}\text { Canister or cask opened } \\
\text { at normal temperature. } \\
\text { Fuel exposed to air for } \\
\text { one month }\end{array}$ & 0.40 & $2.0 \mathrm{E}-3$ & $2.0 E-5$ & $2.0 \mathrm{E}-6$ & 0.03 & - \\
\hline 4. & $\begin{array}{l}\text { Canister or cask opened } \\
\text { in } 24 \text {-hour fire. Release } \\
\text { only from previously } \\
\text { failed fuel }\end{array}$ & 0.005 & $7.0 E-b$ & $2.0 E-5$ & $2.0 E-8$ & 0.03 & - \\
\hline 5. & $\begin{array}{l}\text { Cask or canister opened } \\
\text { followed by } 24 \text {-hour fire. } \\
\text { Fuel exposed to air for } \\
\text { one month }\end{array}$ & 0.50 & $7.0 \mathrm{E}-3$ & $2.0 E-3$ & $2.0 E-6$ & 0.03 & $2.0 E-6$ \\
\hline
\end{tabular}

listed along with the release fraition used, the estimated frequency, consequences, and risk (probability times consequences.) The main body of the report did not provide the consequence numbers listed in the table. These were developed from information provided in one of the report appendices and used to produce the risk estimates presented in the table.

Conservative consequence calculation methods were used in the study. Population distributions used were from the Zion nuclear power plant site. Standard Gaussian plume modeling techniques were applied. Only one weather condition was analyzed ( $1 \mathrm{~m} / \mathrm{sec}$ wind with stability class $\left.D_{\text {. }}\right)$ The dispersion calculations were carried out to a distance of 200 miles for the reactor site. This included one of the major population centers in the country. Dose conversion factors from WASH-1400 (NRC 1975) were used. Doses were converted to health effects using a conversion factor of 100 latent cancer 
TABLE 4.48. Summary of Results (Orvis 1984)

\begin{tabular}{|c|c|c|c|c|c|}
\hline Accident Scenario & $\begin{array}{l}\text { Frequency } \\
\text { (events } / y r \text { ) }\end{array}$ & $\begin{array}{l}\text { Number of } \\
\text { Assembl ies }\end{array}$ & $\begin{array}{l}\text { Release } \\
\text { Category }\end{array}$ & $\begin{array}{l}\text { Consequence } \\
\text { (LCF) }\end{array}$ & $\begin{array}{c}\text { Risk } \\
(L C F / Y r)\end{array}$ \\
\hline Fuel Assembly Drop During Loading & $1 E-1$ & 1 & 1 & $4 E-5$ & $4 E \cdot 6$ \\
\hline $\begin{array}{c}\text { Drop of Transport Cask During Loading } \\
\text { Cask } \\
\text { Drywell }\end{array}$ & $\begin{array}{l}4 E-3 \\
7 E-?\end{array}$ & $\begin{array}{l}10 \\
10\end{array}$ & $\begin{array}{l}1 \\
1\end{array}$ & $\begin{array}{l}4 E-4 \\
4 E-4\end{array}$ & $\begin{array}{l}2 E \cdot 6 \\
3 E-5\end{array}$ \\
\hline $\begin{array}{c}\text { Veriting of Cask During Transport } \\
\text { Cask } \\
\text { Drywell }\end{array}$ & $\begin{array}{l}2 E-3 \\
3 E-2\end{array}$ & $\begin{array}{r}24 \\
1\end{array}$ & $\begin{array}{l}2 \\
2\end{array}$ & $\begin{array}{l}1 E-1 \\
4 E-3\end{array}$ & $\begin{array}{l}2 E-4 \\
1 E-4\end{array}$ \\
\hline $\begin{array}{c}\text { Collision During Transport } \\
\text { Cask } \\
\text { Drywell }\end{array}$ & $\begin{array}{l}2 E-4 \\
2 E-5\end{array}$ & $\begin{array}{r}24 \\
1\end{array}$ & $\begin{array}{l}3 \\
3\end{array}$ & $\begin{array}{l}1 E-1 \\
4 E-3\end{array}$ & $\begin{array}{l}2 E-5 \\
8 E-8\end{array}$ \\
\hline $\begin{array}{c}\text { Collision with Fire During Transport } \\
\text { Cask } \\
\text { Drywell }\end{array}$ & $\begin{array}{l}2 E-6 \\
2 E-7\end{array}$ & 24 & $\begin{array}{l}5 \\
5\end{array}$ & $\begin{array}{l}5 E-1 \\
2 E-2\end{array}$ & $\begin{array}{l}9 E-6 \\
4 E-9\end{array}$ \\
\hline $\begin{array}{c}\text { Canister Drop During Emplacement } \\
\text { Drywell }\end{array}$ & $1 E-6$ & 1 & 3 & $4 E \cdot 3$ & $4 E-9$ \\
\hline $\begin{array}{c}\text { Canister Shear During Emplacement } \\
\text { Drywell }\end{array}$ & $2 E-6$ & 1 & 3 & $4 E-3$ & $8 E \cdot 9$ \\
\hline $\begin{array}{c}\text { Cask Drop During Emplacement } \\
\text { Cask }\end{array}$ & $1 E-5$ & 24 & 3 & $1 E-1$ & $1 E-6$ \\
\hline $\begin{array}{c}\text { Tornado Missile Penetration } \\
\text { Cask } \\
\text { Drywell }\end{array}$ & $\begin{array}{l}6 E-6 \\
1 E-4\end{array}$ & $\begin{array}{l}10 \\
10\end{array}$ & $\begin{array}{l}3 \\
3\end{array}$ & $\begin{array}{l}4 E-2 \\
4 E-2\end{array}$ & $\begin{array}{l}2 E-7 \\
4 E-6\end{array}$ \\
\hline $\begin{array}{c}\text { Plane Crash Topples Cask with Fire } \\
\text { Cask }\end{array}$ & $6 E-9$ & 24 & 5 & $5 E-1$ & $3 E-9$ \\
\hline $\begin{array}{c}\text { Plane Crash Plids Fire } \\
\text { Casil } \\
\text { Drymell }\end{array}$ & $\begin{array}{l}9 E-9 \\
2 E-7 \\
2 E-8\end{array}$ & $\begin{array}{r}24 \\
1 \\
10\end{array}$ & $\begin{array}{l}5 \\
5 \\
5\end{array}$ & $\begin{array}{l}5 E-1 \\
2 E-2 \\
2 E-1\end{array}$ & $\begin{array}{l}4 E-9 \\
4 E-9 \\
4 E-9\end{array}$ \\
\hline $\begin{array}{l}\text { Cask } \\
\text { Drwell }\end{array}$ & $\begin{array}{l}4 E-6 \\
4 E-8 \\
8 E-6 \\
8 E-7 \\
2 E-8\end{array}$ & $\begin{array}{r}24 \\
2400 \\
1 \\
10 \\
2400\end{array}$ & $\begin{array}{l}3 \\
3 \\
3 \\
3 \\
3\end{array}$ & $\begin{array}{l}1 E-1 \\
1 E+1 \\
4 E-3 \\
4 E-2 \\
2.4\end{array}$ & $\begin{array}{l}4 E-7 \\
4 E-7 \\
3 E-8 \\
3 E-8 \\
5 E-8\end{array}$ \\
\hline & Total Risk: & $\begin{array}{l}\text { Cask } \\
\text { Drywell }\end{array}$ & & $\begin{array}{l}2.3 E-4 \\
1.4 E-4\end{array}$ & \\
\hline
\end{tabular}


fatalities per million rems of population dose. Individual doses were well below levels that would produce acute effects.

\section{Evaluation}

This study was a credible effort to identify a comprehensive set of accident scenarios for dry storage design concepts. The study made good ust of the available literature to develop the scenarios and estimate the scenario frequencies. Release fraction estimates were based on a thorough review of the literature and an attempt to correlate the information in the literature with the physical conditions anticipated in the accident scenarios developed. The results must be considered preliminary, however, because of the limited design information available.

There are substant.... differences between the reference facility used in this study and the current design of the MRS facility. Most of the differences are in the size of the facility. The MRS facility will handle about 150 times as much fuel annually as the reactor dry storage facility and has a maximum capacity about 50 tines larger. This is not as significant a difference as it may first appear, however, because most of the accident scenarios for the MRS facility only invoive a few assemblies at one time. The reference drywell in this study only held one assembly and the reference storage cask held 24 assemblies. These are also less than the current design basis for the MR.S facility.

The consequence analysis performed for this study had a very limited scope. The major purpose of the study was to compare design concepts, which does not require detailed consequence analysis. The consequence numbers estimated in the study were generally very conservative and did not reflect the full range of possible weather conditions that would be encountered at the site. The reference reactor site was also substantially different from the reference MRS site. The population distribution at the site used in this study was much higher than the population at th? reference MRS site.

\subsubsection{Occupational Dose Estimates for an Mis Facility}

This study (Harty and Stoetzel 1986) was done in conjunction with the design and evaluations performed by DOE to prepare a report to Congress on 
the MRS facility. It provided estimates of the radiation doses to workers during normal operation of an MRS facility. The evaluations were based on the detailed conceptual design study done by the DOE architect-engineer contractor (Parsons 1985). The reference facility was very close to the current reference design for the MRS facility, although some design changes have been made since the study was completed. The objective of the study was to develop uppei-bound estimates of the occupational exposures in the facility and to identify areas in which future design or operational changes might be needed to reduce worker exposures to levels consistent with the ALARA philosophy. Dose estimates were provided for both the drywe 11 and the storage cask design concepts. A facility throughput rate of 3,600 MTU/yr was assumed. The effects on occupational dose of changes in some of the major design and operating parameters were also described.

The dose estimates were based on assessments of the tasks performed by various facility workers, the time required to perform these tasks, and the estimated dose rates in the areas where these tasks were performed. Manpower requirements, tasks, and time on task were taken from the conceptual design documents where available. Conservative estimates were made to provide missing information. Dose rates for receiving and storage operations were based on shielding calculations done in the design studies. Dose rates in the other operating areas were assumed to be at the maximum expected dose in this area. Radiation workers were assumed to spend 5 hours per day in radiation zones, with the remainder of their day in areas with relatively low background dose rates. The results for the storage cask design concopt are summarized in Table 4.49.

\section{Evaluation}

The reference facility and other design information used in this study is very similar to the current version of the MRS facility design. The occupational exposure estimates are admittedly conservative. They probably substantially overestimate the doses that would be accumulated at a real operating facility. It is clear from the study that further design refinements will be made to lower the occupational doses in the facility, 
TABLE 4.49. Summary of Occupational Doses from MRS

Facility Operations (Harty and Stoetzel 1986)

Operation

Receipt, Inspection, Unloading

Transfer to Storage Casks

Emplacement in Storage Area

Surveillance in Storage Area

Retrieval from Storage Area

Transfer to Process Cells

Shipment to Repository

Total (person-rem/yr)

148.0

6.2

7.2

5.3

7.1

4.0

$\underline{140.9}$

318.7

consistent with the ALARA philosophy. The study does provide reasonable bounding estimates of the doses, based on a detailed analysis of the operations.

\subsubsection{Radiological Doses in Alternative Waste Management Systems}

This study (Schneider et a1. 1986) analyzed the effects of nine waste management system operating alternatives on pubic and worker radiological risks froll routine operations and accidents. The study specifically dealt with a waste management system that did not include an MRS facility, but some of the operations conducted at the repository in this system conf:iguration were identical to operations that would be carried out at the MRS facility in. the improved-performance system. Occupational radiation dose estimates from routine operation of these portions of the repository would be applicable to the corresponding operations in the MRS facility. Where available, occupational dose estimates were based on data from operating experience for similar operations in other facilities. Where applicable data was not available, simple models based on time-and-motion studies were used to estimate. doses. Attempts were made to develop realistic estimates where possible. It was assumed that operations would be conducted efficiently because of the experience levels that the operating crews would attain. Dose rate and manpower estimates for operations that would be similar to those performed in 
the MRS facility were based on information in the MRS facility conceptual design report. Results potentially applicable to the MRS facility are summarized in Table 4.50 .

\section{Evaluation}

Although limited in scope, the applicable information provided in this study can be used to develop estimates of occupational radiation exposure during operation of the MRS facility. The operations analyzed are very similar to the corresponding operations in the MRS facility. The data and methods used should provide reasonable estimates, given the limited design information available at this time.

\subsubsection{Generic Environmental Impact Statement}

The GEIS (DOE 1980) and its supporting document (DOE 1979b) presented an analysis of the environmental impacts associated with a number of possible configurations of the nuclear waste management system. The overall scope, bases, and analytical approaches used in the document were reviewed in Section 4.1 and will not be repeated here. The study included an assessment of a number of the potential risks from an independent spent fuel storage facility. Several storage design concepts were assessed including the cask storage and drywell concepts currently heing considered for the MRS facility. Risk information presented for tilese design concepts is summarized below.

The reference fuel storage facility in the GEIS had a receiving capacity of 2,000 MTU/yr and a total storage capacity of 20,000 MTU. The facility consists of an R\&H building common to all of the storage concepts and a

TABLE 4.50. Occupational Dose Estimates for Selected MRS Operations (Schneider et al. 1986)

Operation

\section{Consolidate and package fuel}

Consolidate and package non-fuel components Receiving and unloading - Truck - Rail
Occupational Dose (person-mrem/1,000MTU)

\section{6}

1.1 
storage area that varied with the design concept being analyzed. The fuel was received and packaged in the R\&H building and then transferred to the storage area. The reference drywell canister contained 3 PWR or 6 BWR assemblies. The reference storage cask contained 4 PWR or 9 BWR assemblies.

The study analyzed routine radiological and nonradiological risks to the public during construction and operations. Estimates of occupational radiation exposures during normal operations were also presented. In addition, estimates were presented of the frequency and public consequences of some representative accident scenarios that couid release radioactive materials. The study concluded that nonradiological releases during construction were below EPA standards and thus produced no discernible effects. There were no radiological effluents during construction and no routine nonradiological effluents during operations. Routine radiological effluents were estimated effluents during operations. Routine radiological effluents were estimated to be the same for the two design concepts. These effluents were estimated to be $1.3 \mathrm{E}-2 \mathrm{C} i$ of $\mathrm{Kr}-85$ and $7 \mathrm{E}-8 \mathrm{Ci}$ of $\mathrm{I}-129$ per year of facility operation. The 70-year population dose commitment from this release was $4.0 E-6$ man-rem whole body equivalent. The estimated annual occupational radiation exposures were 78 man-rem for the storage cask concept and 41 man-rem for the drywe11 concept. Two accident scenarios were analyzed. These scenarios applied to both of the design concepts potentially applicable to the MRS facility. These scenarios are characterized in Table 4.51. The study provided doses to

TABLE 4.51. Summary of Accident Scenarios in GEIS

\begin{tabular}{|c|c|c|c|c|c|c|}
\hline \multirow[b]{2}{*}{ Accident Scenario } & \multirow[b]{2}{*}{ Frequency } & \multicolumn{5}{|c|}{$\begin{array}{c}\text { 70-Year Maximally Exposed Individual } \\
\text { Dose Commitment (rem) }\end{array}$} \\
\hline & & Skin & $\begin{array}{l}\text { Total } \\
\text { Body } \\
\end{array}$ & Thyroid & Lung & Bone \\
\hline $\begin{array}{l}\text { Failure of package } \\
\text { during storage }\end{array}$ & $0.1 / \mathrm{yr}$ & $1.0 E-4$ & 1. $1 E-6$ & 1. $2 E-5$ & $1.1 \mathrm{E}-6$ & NA \\
\hline $\begin{array}{l}\text { Fuel assembly drop } \\
\text { in hot cell }\end{array}$ & $0.1 / \mathrm{yr}$ & $9.0 \mathrm{E}-4$ & $2.8 E-5$ & $1.3 E-4$ & $3.0 E-5$ & $9.6 \mathrm{E}-6$ \\
\hline
\end{tabular}

NA. Information not available. 
the maximally exposed individual for all of the accident scenarios. Population dose estimates were presented only for the scenario involving failure of a storage canister. Comparison of the doses for the maximally exposed. individual suggested that the population dose for the assembly drop accident is about 10 times larger than the dose for the storage canister failure scenario.

\section{Evaluation}

The reference facility and site used in the GEIS were reasonably representative of the reference MRS facility and site being used in this study. The storage cask capacity in the GEIS was about 10 times less than the capacity of the MRS storage cask. As a result, the doses for storage cask loading, emplacement, surveillance, and unloading would be higher for equivalent throughput rates, than more recent estimates. The MRS drywell capacity is essentially the same as the drywell design used in the GEIS. Because throughput rates and handling and packaging operations would be about the same for the two reference systems, GEIS estimates of routine effluents and occupational exposures should be applicable to the MRS facility with or without fuel consolidation operations. Accident risks were presented for only a few representative scenarios. They probably did not provide a good basis for an accident risk estimate for the MRS facility. All of the estimates presented in the GEIS were based on preliminary design information and represented bolinding calculations for the factors calculated.

\subsubsection{Decommissioning Spent Fuel Storage Installations}

This study (Ludwick and Moore 1984) presented an analysis of the technology, safety, and costs of decommissioning an independent spent fuel storage facility. Several design concepts for the facility were considered including storage casks and drywells. The emphasis of the study was on outlining the operations that would be required to decommission the facilities and estimating the costs. Estimates of the occupational radiation exposure that would be accumulated during these operations were included. The study addressed three decommissioning modes: decontamination, safe storage, and entombment. Only the results for decontamination are presented here. 
The reference facility had a storage capacity of 2,000 MTU. Results were also given for a 4,000-MTU facility. The results for the 1arger faci1ity are presented here because it more closely approximates the MRS facility. The facility included a receiving and packaging facility and the storage area. Fuel consolidation operations were not included. The study estimates that the occupational radiation exposure accumulated during decontamination of a dryweil facility was 128 person-rem. Doses for the cask storage facility were 120 person-rem. About $90 \%$ of the dose was accumulated in the decommissioning activities in the receiving and packaging facility. The dose estimates were based on fairly detailed activity and manpower estimates that were performed to estimate the costs of the decommissioning operations. Dose rates are based on operating data in spent fuel storage facilities that used water basin technology and conservative estimates for areas in which applicable data were not available. The dose estimates assumed that chemical decontamination was used to reduce dose rates where feasible and that an effective health physics program was in place to minimize exposures. The study also provides estimates of the routine exposures associated with shipping the radioactive wastes from the decontamination operations to a disposal facility. These estimates are 0.027 person-rem of public dose and 0.28 person-rem occupational exposure.

\section{Evaluation}

This study provided credible estimates of the occupational exposures associated with decommissioning a facility similar to the MRS facility. The storage capacity of the reference facility was about 7 times smaller than the MRS facility, but the results may be generally applicable because most of the dose was accumulated in the receiving and packaging facility. The size of this portion of the facility was relatively independent of the storage capacity.

\subsubsection{Reports Selected for Use in This Study}

Information from the reports reviewed in Section 4.3.1 is used in Section 5.3 to develop estimates of the risks from construction, operation, and decommissioning of an MRS facility. Reports that most closely meet the needs of this study were selected from the available literature to form the bas is 
for these estimates. This section provides the rationale for choosing the reports used in Section 5.3 from among those reviewed. The selection was based on the criteria presented in Table 4.1 .

An overview of the risk categories addressed in the MRS facility risk 1iterature is presented in Table 4.52. The available literature primarily addresses three risk categories: 1) radiological risks to the public from accidents during facility operation, 2) radiological risks to the public from routine emissions during plant operations, and 3) radiological risks to plant workers from normal operations. These three areas have been important considerations in licensing and policy-making proceedings, so it is understandable that much of the work has been concentrated on these topics. The table shows that nonradiological risks have not been treated extensively in previous work. Routine nonradiological emissions have been analyzed as part of environmental assessments, but no other work in this area was found in the literature reviews.

The radiological risk values contained in the reference documents are summarized in Table 4.53. The results are presented in this table as they were extracted from the documents in Section 4.3.1. No attempt is made here to present the results on a consistent basis. Presentation of the raw results does illustrate the areas in which numerical results are available and the form of the results. As the reviews in Section 4.3.1 indicated, there are substantial differences among the studies in the scope of the analysis, key assumptions, data, and the reference facilities used. To the extent that results from various sources are comparable, the table also illustrates the range of risk estimates that have been produced.

Four of the risk categories dealing with radiological consequences were not addressed at all in the literature that was examined. These were radiological risks to workers from accidents during construction, operations and decommissioning, and radiological risks to the public from accidents during construction. Both the MRS environmental assessment and the GEIS concluded that there would be no radioactive materials onsite during construction.

This was used as the basis for the conclusion that there would be no routine radiological effects during construction. It can be inferred from this that 


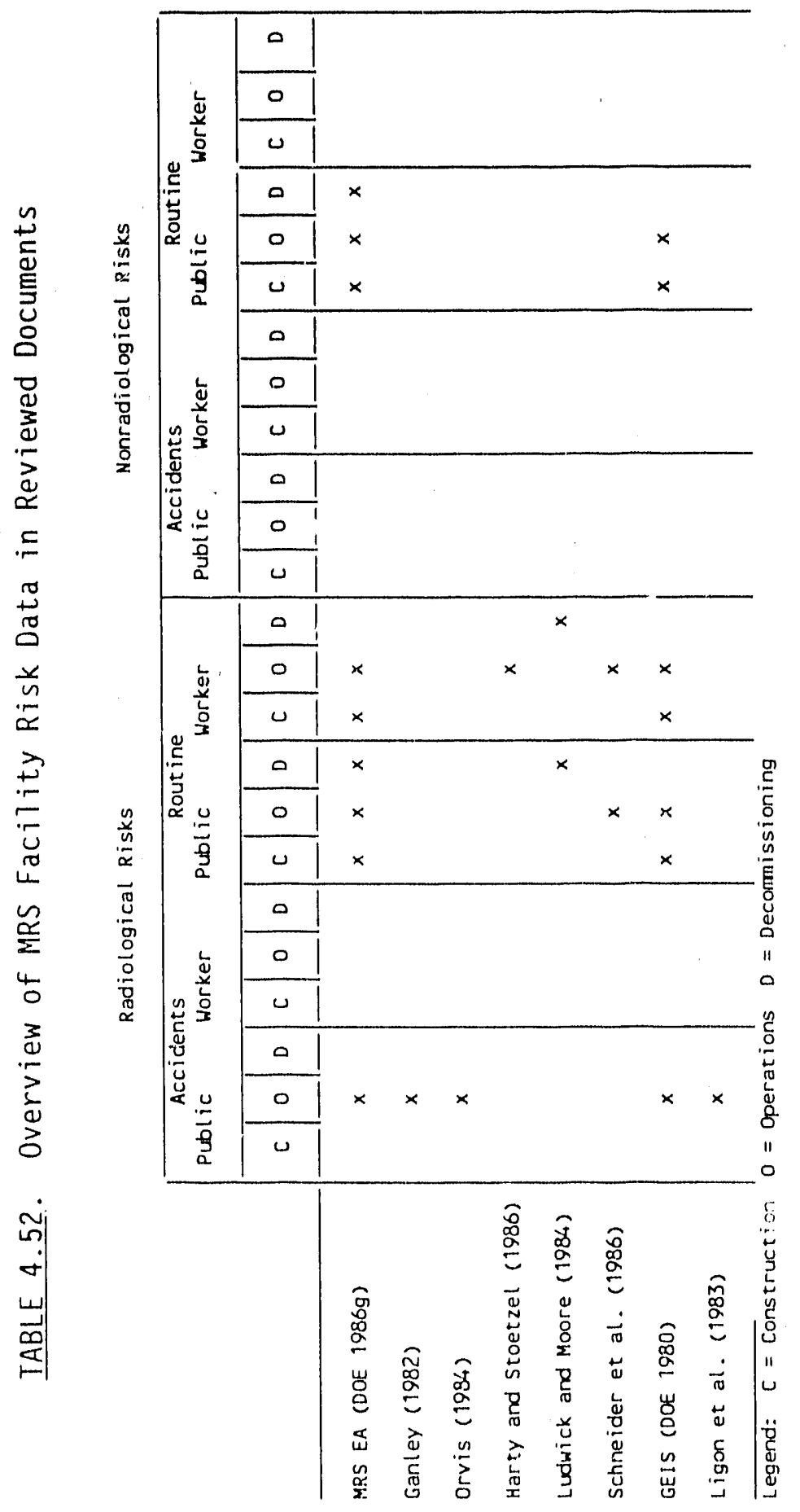

4.122 


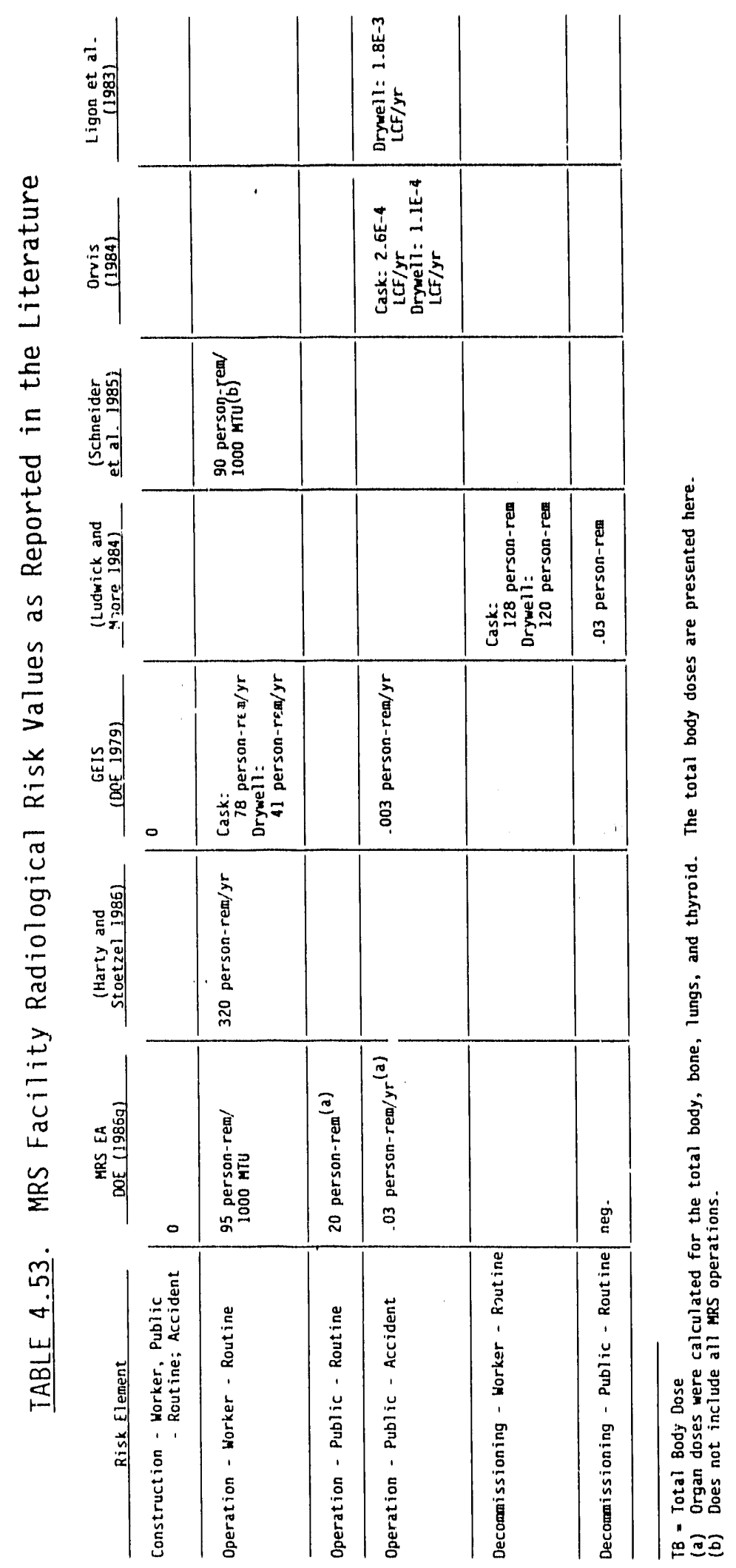

4.123 
there would also be no accidental radiological effects. One report (Jackson et a1. 1984) reviewed in the discussion of potential repository preclosure risks contained some information on radiological risks to workers from accidents during operations. Because of the similarities between the operations in the integral MRS facility and the repository receiving, handling, and packaging operations, the information from this source is used in Section 5.3 to develop rough estimates for this risk category for the MRS facility.

There were only tivo radiological risk categories in which multiple risk estimates are available--routine doses to workers and public risks from accidents. Four sources provided estimates of the routine radiological dose to workers during operation of the MRS facility. For a facility that receives 3,600 MTU of fuel per year, the MRS environmental assessment estimated a worker radiation dose of 340 person-rem per year. This was very consistent with the estimate of 320 person-rem per year developed by Harty and Stoetze 1 (1986). The estimate contained in Schneider et a1. (1986) only dealt with the handling and packaging operations that would be conducted at the MRS facility. For the categories that it covered, it was consistent with the study by Harty and Stoetzel (1986) and the environmental assessment. The reference facility in the GEIS was substantially different from the current design of the MRS facility. Because more directly applicable information is available from the other sources, the GEIS estimate was not used. The estimate from Harty and Stoetzel (1986) was used as the basis for the MRS facility risk estimates provided in Section 5.3. This was a more detailed study than the one performed for the environmental assessment and provided the most technically defensible estimate.

There were also four sources of information on risks to the public from radiological accidents at the MRS facility. None of these studies provided a comprehensive assessment of the risks from a facility that closely resembles the current MRS facility design concepts. The EA and the GEIS only analyzed a few selected accident scenarios. This met the needs of the environmental assessment process, but was not comprehensive enough to provide a sound basis for a risk estimate. The Ligon et al. (1983) study only dealt with some of the operations at an MRS facility. It provided a comprehensive assessment of those portions of the facility, but it was not a complete assessment. The 
Orvis (1984) study was the most comprehensive assessment. It developed a reasonably complete set of accident scenarios, estimated release fractions based on the best available information, and provided reasonable probability estimates. The consequence anaiysis was very conservative and limited in scope. The reference facility was much smaller than the current MRS facility design, although the study illustrated that the risk-dominant accident scenarios occur during handling operations. The consequences of these accidents would be independent of the size of the facility. The frequency of the accidents, however, would depend on the facility throughput rate. Because it was the only study that dealt with all of the potential operations at an MRS facility and aiso developed a comprehensive set of accident scenarios, the Orvis (1924) study was used as the basis for the risk estimates developed in Section 5.3 .

For the remaining radiological risk categories for which information was available, only one numerical estimate of the risks was identified from the 1iterature. These estimates are used in Section 5.j. Neither the MRS environmental assessment nor the GEIS provided numerical estimates of the health effects from routine nonradiological en.,ssions during construction, operation, and decommissioning of the MRS facility. Both studies concluded that the nonradiological effects from these activities were negligible.

\subsection{TRANSPORTATION}

This section presents a discussion of the literature that contains information on the potential risks of transporting spent fuel and other radioactive wastes. Two subsections are provided: Section 4.4 .1 provides a brief summary of the documents selected for review and Section 4.4.2 presents the rationale for selecting the risk and dose values used later to develop transportation system risk estimates. The scope of this section is limited to transportation operations (i.e., construction and decommissioning of transportation equipment is not included). Transportation risk information has been developed primarily by the DOE and the NRC over the last 10 years in support of environmental documentation, facility licensing, and regulatory activities. Some of these studies have been detailed and comprehensive while others were narrow in scope and used simple methods and limited data. 


\subsubsection{Review of the Transportation Risk Literature}

A brief overview of the scope and technical basis for a selected set of transportation risk studies is presented in this section. Results from the literature that are potentiaily applicable to the transportation system risk characterization discussed in Section 5.4 are also summarized. Spent fuel transportation is emphasized in this section because spent fuel has been the subject of most of the past studies. Risk information is also presented, where appropriate, on transportation of HLW and secondary wastes expected to be generated at the MRS facility and the repositories.

\subsubsection{Final Environmental Statement on the Transportation of Radioactive Material by Air and Other Modes (NRC 1977)}

The NRC prepared this final environmental statement to reevaluate the regulations existing at the time on the air transportation of radioactive materials. Its scope was subsequently expanded to examine other modes, primarily from the standpoint of the adequacy of regulations governing packaging effectiveness and other regulations related to the safety and security of radioactive material transportation.

This document included analyses of the impacts of transporting all types of radioactive materials within the United States, including import and export shipments, bui excluded shipments of nuclear weapons, nuclear weapon components, and other shipments in support of defense programs. The scope included uranium fuel cycle shipments, medical-and industrial-use isotopes, and radioactive waste materials. Risk categories evaluated in the document included radiological routine public and occupational exposures and accident risks as well as noniadiological accident risks. A survey of a sample of NRC 1 icensees was performed to determine the quantities and types of shipments of radioactive materials being transported. The results of the survey were used to define the quantities and characteristics of radioactive material shipments for the reference year (1975) and also to project these data to a later year (1985).

Population exposures from normal transport were calculated using the RADTRAN computer code described by NRC (1977). This code is briefly 
described elsewhere in this document (see the review of Madsen et a1. 1986). Transportation accident risks were also calculated using RADTRAN.

The results from NRC (1977) that are of most interest to this study were those presented for spent nuclear fuel shipments. These results are presented in Table 4.54. The normal population doses were estimated assuming the dose rate emitted from the casks were at the regulatory limit (i.e., $10 \mathrm{milli}$ rem $/ \mathrm{hr}$ at 2 meters from the cask). Accident risk results assumed that $100 \%$ of the released material was in the form of respirable particles. For both routine exposures and accident risks, the shipping distances were assumed to be 2,530 kilometers one-way for truck shipments and 1,210 kilometers one-way for rail shipments. The number of shipments in 1975 was sased on the results of the licensee survey, and the 1985 shipments were based on a total projected quantity of 2,849 MTU. The assumed truck and rail cask capacities were 0.5 MTU and 3.2 MTU, respectively.

\section{Evaluation}

The final environmental statement represented one of the first comprehensive evaluations of the risks of transporting radioactive materials. The NRC concluded, based on the results presented in the document, that:

"... the environmental impacts of normal transportation of radioactive material and the risks attendant to accidents involving radioactive material shipments are sufficiently small to allow continued shipment by all modes...." The NRC further concluded that no immediate changes to the regulations were needed at that time. While these conclusions are still believed

TABLE 4.54. Summary of Results from the NRC for Spent Fuel Shipments (NRC 1977)

\begin{tabular}{rlccc} 
Year & Mode & $\begin{array}{c}\text { Shipments } \\
\text { Per Year }\end{array}$ & $\begin{array}{c}\text { Normal } \\
\text { Population } \\
\text { Dose, } \\
\text { (person-rem/yr) }\end{array}$ & $\begin{array}{c}\text { Accident Risk, } \\
\text { Latent Cancer } \\
\text { (fatalities/yr) }\end{array}$ \\
\cline { 3 - 5 } & Truck & 254 & 93.80 & 0.047 \\
1985 & Rail & 17 & 7.78 & 0.021 \\
& Truck & 1,530 & 565.0 & 0.29 \\
Rail & 652 & 298.0 & 0.8
\end{tabular}


to be valid, the methods and data used in the analysis are somewhat dated and not directly applicable to the currently envisioned waste management system. Significant changes to the RADTRAN computer code have been implemented and more realistic assumptions, yet still conservative, have replaced some of the accident data. As a result, more recent analyses of transportation risks would be more appropriate for use in this study.

\subsubsection{Transportation of Radionuclides in Urban Environs: Draft Environmental Assessment (Finley et al. 1980)}

This report was one of the initial studies of the impacts of transporting radioactive materials in urban areas. The initial draft version of this study (Ducharme et a1. 1978) predicted that as many as several hundred latent fatalities could occur from a successful sabotage event in a densely populated urban area. Finley et al. (1980) included revised estimates of fewer than 100 latent fatalities based on a reevaluation of the released quantities of radioactive materials. A third version of the sabotage event analysis (Sandoval et a1. 1983) estimated fewer than 10 latent fatalities, based on experimentally-derived release quantities. A review of the Sandoval et al. (1983) document is presented later in this section. Thus, it is not necessary to present a review of the sabotage event analysis portions of the document. The portions of finley ei al. (1980) that are reviewed here include the analysis of routine population exposures, accident risks, and economic consequences. The scope of these analyses included all types of radioactive materials, including industrial-and medical-use isotopes, fuel cycle materials, and radioactive wastes. All modes of transport were considered, including highway, rail, air, and water.

The analysis of routine population exposures was performed using models similar to those developed for NUREG-01\% (NRC 1977). The dose calculations were based on the assumption that the shipping container was a point source of ionizing radiation. The point-source equation was combined with a term to account for the time of exposure given that the vehicle was in motion (i.e., the exposure ceased after the shipment passed by). This basic relationship was used to estimate the doses to the following groups:

- pedestrians 
- people in vehicles

- people in buildings

- crew of the transport vehicle

- warehouse personnel while the shipment is in storage

- package handlers

- people at rail terminals

- people sharing the transport link

- people along the rail right-of-way

- people in freight docks

- people at air passenger terminals

- people at air freight terminals.

Some of the important input parameters for these calculations were the population density in the surrounding areas or the liumber of exposed individuals, the dose rate at the external surface of the package, the amount of structural shielding provided for persons in buildings, the distance between the source (package) and target (people), and travel speed. The numbers of shipments and the characteristics of each type of shipment were based on the shipment survey performed for NUREG-0170 (NRC 1977). The results of this survey were used to estimate the number of shipments of each type of radioactive material that travel on specific routes that originate within, travel through, or have destinations within New York City.

The results of the routine population exposure analysis are summarized in Table 4.55. The total exposures to each population subgroup shown in the table include all shipments. The breakdown for the doses by end-use was: medical-use, $74 \%$; industrial-use, $18 \%$; fuel cycle, $8 \%$; and waste, less than $1 \%$. The breakdown by transport mode was: air, 35\%; truck, $65 \%$; and rail and barge, none (i.e., no rail shipments were identified; see Table 4.55 for explanation of barge shipment results).

The analysis of accident risks was performed using a computer code called METRAir, which was roughly equivalent to the accident portions of RADTRAN 
TABLE 4.55. Summary of Radiological Impacts from Routine Transport by Dose Group (Finiey et a1. 1980)

\begin{tabular}{|c|c|c|}
\hline Dose Group ${ }^{(a)}$ & $\begin{array}{l}\text { Total Dose } \\
\text { (person-rem/yr) }\end{array}$ & Percent of Total \\
\hline Handlers & 2.5 & $\sim 35$ \\
\hline People in Vehicles & 1.6 & 22 \\
\hline Warehouse Personnel & 1.2 & 17 \\
\hline Pedestrians & 1.0 & 14 \\
\hline Crew & 0.6 & $\sim 8.4$ \\
\hline $\begin{array}{l}\text { People in Air } \\
\text { Passenger Terminals }\end{array}$ & 0.2 & $\sim 3$ \\
\hline People in Buildings & 0.015 & -0.2 \\
\hline
\end{tabular}

(a) No impacts were calculated for people in dock areas since all shipments were "through" shipments for the area of New York City that was analyzed.

(see Section 4.4.1.7). METRAN considered accidents involving releases of radioactive materials as well as those that reduced the shielding provided by the package. The code calculated accident risks for four population subgroups: crew, pedestrians, people in vehicles, and people in buildings. Accidents could be modeled as occurring on freeways, one-way streets, and two-way streets. For accidents involving releases, the exposure estimates included inhalation, cloudshine, groundshine, and resuspension pathways.

Two atmospheric dispersion models were used to predict downwind concentrations of radioactive material. The first predicted concentrations within a short distance from the release point anc the other was for long distances. This was done primarily because of the street canyon effects that serve to channel the release in a specific direction. Both models were based on a Gaussion puff dispersion model and were combined with special functions to evaluate the effects of wind turbulence, eddies, and surface roughness. Probabilistically based wind speeds and directions specific to New York City were used in the atmospheric dispersion calculations.

The "severity category" approach was used to define the quantities of released material for the various types of shipments. Assumed parameters 
were used to define the fraction of material released and the fraction that was in the form of respirable particles for each severity category. Release fractions ranged from 0 to 1.0 . The release source term for spent fuel shipments consisted solely of co-60.

The expected radiological risk values for each package type are presented in Table 4.56. "The results labeled "cask" shipments are spent fuel truck shipments. The number of shipments is shown as well as the estimates of latent cancer fatalities/yr, fatal genetic effects/yr, and early morbidities/yr. It was indicated in the document that the health effects were due solely to the groundshine pathway; direct inhalation was not a significant contributor except in high-consequence/low-probability accidents which did not contribute significantly to the expected risk.

Finley et al. (1980) also developed the basis for estimating the economic risks of accidents in urban areas. The economic risks were calculated by replacing the health effects consequence terms in the risk equation with economic consequences. The economic costs of accidents consisted of immediate emergency response costs, cleanup and recovery costs, evacuation costs, security costs, and costs for denial of land use. Each of these costs was a function of accident severity (amount of material released) and the desired cleanup level. The economic risk model combines a large number of cost parameters that are related to the release quantities, contaminated areas, level of emergency and cleanup activities, land values, and cleanup time. The economic risks estimated by Finley et al. (1980) for the New York City

IABLE 4.56. Expected Radiological Risk Values from Vehicular Accidents per Year of Shipping Activity

\begin{tabular}{cccccc}
$\begin{array}{c}\text { Package } \\
\text { Type }\end{array}$ & $\begin{array}{l}\text { Amount } \\
\text { Shipped } \\
(\mathrm{C} i / y r)\end{array}$ & $\begin{array}{c}\text { No. of } \\
\text { Shipments } \\
\text { per year }\end{array}$ & $\begin{array}{c}\text { Number } \\
\text { of Laterit } \\
\text { Cancer } \\
\text { Fatalities }\end{array}$ & $\begin{array}{c}\text { Expected } \\
\text { Number of } \\
\text { Genetic } \\
\text { Effects }\end{array}$ & $\begin{array}{c}\text { Expected } \\
\text { Number } \\
\text { of Early } \\
\text { Morbidities }\end{array}$ \\
\cline { 1 - 3 } B & $2.4 E+4$ & $2.5 E+4$ & $5.8 E-4$ & $7.9 E-4$ & - \\
Cask & $9.2 E+4$ & $2.7 E+3$ & $2.2 E-4$ & $3.0 E-4$ & - \\
Drum & $2.6 E+6$ & $1.2 E+1$ & $6.1 E-4$ & $8.1 E-4$ & $2.7 E-5$ \\
Total & $9.7 E-3$ & $7.0 E+1$ & $8.9 E-7$ & $1.2 E-6$ & - \\
& $2.7 E+6$ & $2.8 E+4$ & $1.4 E-3$ & $1.9 E-3$ & $2.7 E 5$
\end{tabular}


study area are summarized in Table 4.57. Again, the "cask" package type represents spent fuel truck shipments. The same number of shipments shown in Table 4.56 apply to this table.

\section{Evaluation}

This document represented a detalled analysis of health and economic risks of all types of radioactive material shipments through New York City. A significant amount of effort was spent modeling incident-free exposures to a large number of population subgroups, meteorological conditions within New York City, accident consequences, and economic costs of accidents. As a result, the methods were generally sound. In particular, the analysis of the economic risks of accidents represented a step forward in the development of methods and data to perform such analyses. The analysis was very broad in scope and contained many useful results. An artifact of this broad scope, however, was that detailed evaluations of all types of radioactive materials, specifically spent fuel and radioactive wastes, was not possible. In addition, the scope was limited to radiological and economic impacts in New York City with generic extensions to other urban areas, Consequently, the results

TABLE 4.57. Expected Economic Risk Values from Vehicular Accidents (Finley et al. 1980)

$\begin{array}{lc}\text { End-use } & \begin{array}{c}\text { Estimated Value } \\ \text { of Economic Risk } \\ \text { per year }(\$ / y r)\end{array} \\ \text { Medical } & 1.4 E+6 \\ \text { Industrial } & 1.9 E+4 \\ \text { Fuel Cycle } & 3.1 E+4 \\ \text { Waste } & \underline{5.1 E 00} \\ \quad \text { Total } & \sim 1.5 E+6 \\ \text { Package Type } & \\ \text { A } & 1.4 E-6 \\ \text { B } & 6.2 E+4 \\ \text { Cask } & 3.1 E+4 \\ \text { Drum } & 4.1 E 00 \\ \quad \text { Totals } & -1.5 E+6\end{array}$


are not directly applicable to a nation-wide transportation system, such as the system that will be used to transport spent fuel and HLW to interim storage and disposal facilities. It is judged that the results are of 1 ittle usefulness to this study of waste management system risks.

\subsubsection{An Analysis of the Risk of Transporting Spent Nuclear} Fuel by Train (Elder et al. 1981)

The objective of this study was to quantitatively assess the risks of spent fuel rail transportation accidents. A similar study of spent fuel truck transportation risks was completed several years prior (Elder et al. 1978) to this study. In general, the following discussion is applicable to both the truck and rail transportation risk studies.

A comprehensive risk analysis metho:ology was used by Elder et a1. (1981) to define and evaluate a broad spectrum of potential accident sequences that could release radioactive materials from the cask. These events ranged from severe traffic accidents that breached the cask to human errors that allowed small amounts of internal cavity coolant to escape from the cask. The latter types of accidents could not occur during future OCRWM shipments because the fuel to be transported to the repositories would have cooled longer ( 5 years) than the fuel used by Elder et 21 . as their basis (180 days). This cooling period would reduce the thermal output of the fuel and eliminate the need for an internal water coolant. A fault tree analysis methodology was utilized to identify, display, and screen the accident sequences. The resulting accident sequences or "cut-sets" were subjected to further evaluations in which their associated release source terms and the population health effects were determined.

Three general categories of incidents that could result in a release were identified using the fault tree, including:

- transportation accident forces

- substandard package construction or package degradation

- package closure errors.

The probability of cask failure during an accident was estimated based on the overall accident frequency data developed by the U.S. Department of 
Transportation (DOT) combined with structural analyses designed to estimate the mechanical strength of the shipping cask, the forces or stresses that can be produced in an accident, and the probability of these stresses being produced given the occurrence of the accident. Mechanical and thermal analyses of spent fuel shipping casks and spent fuel assemblies were performed to determine the fallure threshold or the level of applied stresses that could potentially result in a release. Combinations of mechanical forces and thermal transients from fires were considered. The cask failure analysis was performed using a combination of energy absorption analyses and a finite element model to predict cask failure due to distortion of seals and closures.

A survey of past spent fuel shipments was performed to determine the conditions of the cask during routine shipments. The survey collected information on cask loading and closure to establish the basis for estimating the frequencies of cask closure errors, including the $1 \mathrm{id}(\mathrm{s})$ and any penetrations into the cask cavity.

The accident sequences identified in the fault tree were grouped into eight categories that correspond to releases of increasing magnitude. Release fractions were then developed for each accident category based on information in the literature, knowledge of the accident environment, and engineering judgment. Four mechanisms were identified that could lead to a release from the fuel cladding to the internal cask cavity. These mechanisms were:

1. gap release: venting of fission gases from the gap between fuel pellets and the peliets and cladding

2. vaporization: volatilization of low melting point fission products

3. leaching: caused by direct contact of fuel pellets with water coolant

4. oxidation: results from gross cask rupture in which significant quantities of air contact the fuel; this mechanism would be enhanced by a hot, long-duration fire.

It should be noted that for 5 -year-cooled fuel a significant oxidation reaction is not physically possible without a long-duration fire. This is because the cooler fuel would not be susceptible to a "self-heating" effect 
that is possible for short-cooled fuel. Based on the physical and chemical characteristics of the spent fuel, information on these releases mechanisms, and the calculated thermal and mechanical environments of potential accidents, release fractions were developed for five radionuclide categories in each accident category. These radionuclide categories were: 1) noble gases, 2) radioiodine, 3) cesium and ruthenium, 4) all other fission products, and 5) actinides.

The next step was to estimate the public health consequences that could potentially be produced by each of the eight accident categories. A standard Gaussian atmospheric dispersion model was used to predict the downwind concentrations of radioactive materials released from the shipping cask. Average windspeed/stability characteristics were developed based on weather data from the entire continental United States. A probability distribution of these weather conditions was then developed with wind speeds ranging from 1 to $18 \mathrm{~m} / \mathrm{sec}$. The calculated downwind concentrations were then combined with a demographics model and dose conversion factors for specific isotopes to estimate population doses. Only the inhalation pathway is considered in the population dose estimates. The population doses are then converted to health effects using conversion factors derived from statistics developed by the BEIR Committee.

The accident risk estimates generated by Elder et al. (1978) for spent fuel truck shipments and Elder et a1. (1981) for rail shipments are summarized in Table 4.58. The risk spectra developed in these two documents are shown in Figure 4.2 , along with risk spectra for other events to place the spent fuel transportation risks in perspective.

\section{Evaluation}

The two spent fuel transportation risk studies represented the most comprehensive identification and evaluation of transportation accidents in the literature. No other spent fuel transportation risk studies have attempted to identify all potential release sequences. The dose estimates in the studies considered only inhalation and "cloud shine." Food chain and "ground shine" doses were judged to be of less importance and were not calculated. The atmospheric dispersion, population dose, and health effects 
TABLE 4.58. Summary of Spent Fuel Truck and Rafl Transportation Risks (Elder et a1. 1978, 1981)

\section{Annual Average}

Quantity Shipping

Shipped, Distance,

Model/Fuel Age (MTU/yr)

$(\mathrm{km})$

Number of

Truck

$$
\text { 180-day }
$$

$4-y r$

380

380

690

690

912

912

471

471

Rail
Probability of One or More (LHE/Yr)

$\begin{array}{lllll}180 \text {-day } & 1,474 & 912 & 471 & 5.5 E-5 \\ 4-y r & 1,474 & 912 & 471 & 8.3 E-7\end{array}$

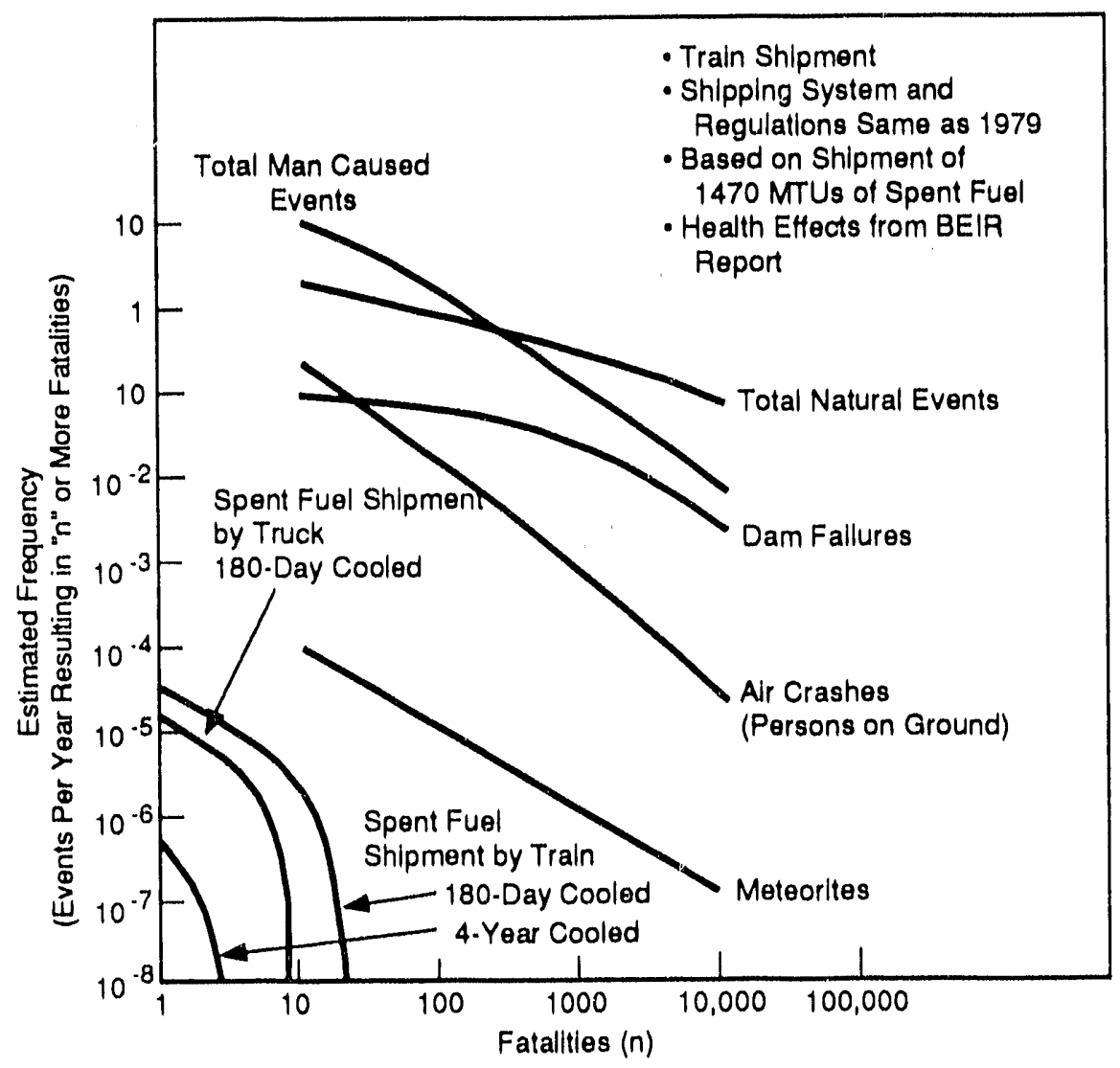

FIGURE 4.2. Risk Spectra for Spent Fuel Shipments by Train for $100 \mathrm{GW}$ Nuclear Capacities and for Other Events in the United States (Elder et a1. 1981) 
models are consistent with currently utilized models, although the data are somewhat out of date. The mechanical and thermal fallure threshold analyses used adequate methods but they are not the curront state of the art. However, they represent the only application found in the literature of these analytical tools to determination of release fractions. In general, however, because the fuel age and cask design assumptions are not consistent with the future generations of spent fuel shipping casks, the usefulness of this information source to the current risk characterization study is limited.

\subsubsection{An Assessment of the Safety of Spent Fuel Transportation in Urban Environs (Sandoval et al. 1983)}

This study was performed to assess the radiological consequences of a hypothetical sabotage attack on a spent fuel truck shipping cask in a densely-populated urban area. This was e'sisentially a revision of a previous study (Ducharme et a1. 1978) in which it was predicted that several hundred latent cancer fatalities (LCF) could result from a successful sabotage attack. A second version of this study (Finley et a1. 1980) reduced the consequences to fewer than 100 LCFs based on a reevaluation of the released quantities. Both of the previous studies used assumed release source terms that were intended to bound the actual release quantities (i.e., higher consequences would not be expected). These bounding assumptions were made because actual experimental data were not available. The third revision of this study (Sandoval et a1. 1983) included a program of experiments as well as analytical modeling to produce source term and consequence estimates that were as accurate as possible.

The primary objectives of the study were: 1) to evaluate the effectiveness of selected high-energy devices (HED) in breaching spent-fuel shipping casks, 2) to characterize the material released from such an event, and 3) to estimate the health consequences, based on the experimental data, that could result from a successful sabotage attack in a densely-populated area. An extensive survey and testing program was performed to select a reference HED that showed the greatest potential for breaching a shipping cask and dispersing radioactive material to the environment. Next, subscale and full-scale tests on truck casks were performed using the reference HED to develop 
estimates of the quantities of material released and the quantity of material released as a radioactive aerosol. Tests on single fuel pellets were then performed to correlate the observed effects of the high-energy environimint on surrogate spent fuel to irradiated fuel. The results of this testing program indicated an upper-1imit release value of $17 \mathrm{~g}(3.4 \mathrm{E}-3 \%)$ of aerosolized respirable irradiated fuel for a 1 -PWR assembly truck cask and $34 \mathrm{~g}$ (2.4E-3\%) for a 3-PWR assembly truck cask.

The final step in the study was to estimate the human health effects from a successful sabotage attack using the reference HED in an urban area. The attack was assumed to occur on a 3-PWR assembly truck cask with 150-day cooled fuel in the borough of Manhattan in New York City. The CRAC consequence assessment code was used to predict the radiological consequences of this accident scenario (Wall et a1. 1977). CRAC was also used by Ducharme et a1. (1977) and Finley et a1. (1980) to predict the radiological health consequences of a similar scenario. CRAC uses calculated airborne and ground radionuclide concentrations to estimate external exposures to a passing cloud and internal exposures from the inhalation and ingestion pathways. Based on these exposures, CRAC estimates the number of early and latent health effects that would be produced by the released materials.

The expected health consequences were calculated using the experimentally determined release fractions for solid particulate material and noble gases. The particulate release fractions were discussed previously. Release fractions for noble gases were determined to be 0.5 and 0.34 for 1 -PWR and 3-PWR assembly truck casks, respectively, based on the mass loss sustained in the full-scale tests. Cask inventories were based on PWR fuel with burnup of $33,000 \mathrm{MWd} / \mathrm{MTU}$ at a power density of $40 \mathrm{~kW} / \mathrm{kg}$. The population distribution was equivalent to the Manhattan borough and included a population density of 39,000 persons $/ \mathrm{km}^{2}$ within $10 \mathrm{kilometers}$ and 16,000 persons $/ \mathrm{km}^{2}$ from 10 to 16 kilometers from the release point. Doses were calculated out to an 88 kilometers radius from the release point. Meteorological data consisted of over 100 sequences of New York City weather conditions.

The results of the CRAC calculations for the 1-PWR and 3-PWR assembly events cask indicated there would be zero early fatalities as the threshold 
dosage was never exceeded. For the 1-assembly cask event, a total of 2 mean $/ 7$ peak LCFs was predicted, and for the three-assembly cask, the number of LCFs predicted was 4 mean/14 peak. The estimate for the single assembly cask event was smaller by a factor of $350 / 423$ (mean/peak) than the original estimate produced by Ducharme et a1. (1977).

\section{Evaluation}

Because this study was limited to a single-event scenario, it is only of limited use to this assessment of transportation risks. It was, however, an extremely in-depth treatment of a particular event that is a concern to the general pubitic and state and federal regulatory agencies. This analysis was one of the few that used experimentally-derived release characteristics rather than conservative bounding assumptions. It was shown that by using the more realistic experimental data, the overall consequences were reduced by more than 2 orders of magnitude relative to the bounding analysis.

\subsubsection{Iransportation Impacts of the Commercial Radioactive Waste Management Program (Cashwell et al. 1986)}

This document was prepared in support of the environmental assessments for the potential first repository sites and was briefly summarized in Appendix $A$ of the final environmental assessments. This analysis was also cited in the MRS environmental assessment (DOE 1985b). Thus, to avoid duplication, the transportation impacts described in the environmental assessments will not be reviewed in this section.

The objective of this study was to develop the relative costs and risks of transporting radioactive wastes to each of nine potential repository sites. The analysis included consideration of both basic system configurations: the authorized system in which spent fuel and HLW were transported directly to the repositories and the improved-performance system in which spent fuel was first shipped to an integral MRS facility and then to the repositories. This was the third in a series of transportation cost/risk analyses. The first two documents in this series were wilmot et a1. (1983) 
and Neuhauser et a1. (1984). The major changes incorporated into this analysis were the assumptions in potential repository system parameters, the use of future-generation cask designs, and the anaiysis of the improvedperformance system.

The scope of the transportation impact analysis included incident-free occupational and public doses as well as accident risks. The analysis included two primary modal assumptions, $100 \%$ truck and $100 \%$ rail, to provide bounding estimates of the actual impacts. For the MRS system cases, all rail shipments were assumed to move by dedicated train. Actual reactor locations were used to define shipping distances and fractions of travel in rural, suburban, and urbar, jopulation zones. Spent fuel shipped from reactors to the repository in the cases in which there is no MRS Facility, was assumed to be aged 5 years. For the system with an MRS Facility, spent fuel that was shipped from reactors to the MRS facility was assumed to be 5 -years old. The fuel was aged an additional 5 years prior to shipment from the MRS facility to the repositories. Spent fuel was also assumed to be consolidated at the MRS facility. This reduced the number of shipments required between the MRS facility and the repository. Commercial and defense HLW were shipped directly to the repository in both cases. In addition, secondary wastes generated at the MPS facility were shipped by dedicated rail to the repository. Variations on the reference cases were also analyzed, including different packaging options at the MRS facility, the use of 100 -ton versus 150 -ton casks for MRS-to-repository shipments, and different options for spent fuel generated by reactors in the west (the candidate first repositories would be located in the western United States and the MRS facility would be located in the east). Reactor-specific spent fuel discharge data and projections were used to generate estimates of annual shipment quantities and numbers of shipments from each reactor.

The transportation risk analysis was performed using "unit-factors". Radiological unit-risk factors were generated using the RADTRAN III computer code (Madsen et al. 1986). These radiological unit factors were expressed in units of risk/shipment-km. Nonradiological unit-risk factors were developed from DOT accident statistics (DOT 1985) and represented the risk of injuries and fatalities per unit distance of travel. RADTRAN III models both 
incident-free or routine transportation exposures as well as the risk (combination of probabilities and consequences) of transportation accidents. The RADTRAN III code is discussed in more detail in Section 4.4.1.7.

The results developed by Cashwell et al. (1986) are presented in Table 4.59 for the system without an MRS facility. Table 4.60 summarizes the total transportation risks for the system with an MRS facility, assuming all spent fuel is shipped to the MRS facility and 150-ton casks are used to transport consolidated, non-overpacked spent fuel rods. Only the risk analysis results for the three potential first repository sites are shown in the tables. As shown, the public and occupational routine risks and accident risks, in terms of total latent health effects (i.e., the sum of latent cancer fatalities and genetic effects) have been added together to provide an overall radiological risk figure-of-merit for each site. Total nonradiological fatalities are also shown in the tables.

\section{Evaluation}

This document provided direct support to the final repository environmental assessments and the MRS environmental assessment, and as such is directly applicable to the configuration of the waste management system analyzed in this document. The radiological risk results can be used with little more modification than converting the risks in terms of health effects to population exposures in units of person-rem. No adjustments are needed to account for different throughput rates, fuel age and burnup, or cask capacities. Nonradiological risks are based on the most recent DOT accident statistics. As a result, the transportation risk analysis results are more applicable to this study of waste management system risks than any other past study.

\subsubsection{Exposures and Health Effects From Spent Fuel Transportation}

\section{(Sandquist et a). 1985)}

This document was prepared in response to public comments on the draft repository environmental assessments to provide estimates of doses to individuals rather than to an entire population. The objective of the study was to provide generic estimates of risks to individuals and populations from transportation of spent fuel to repositories or the MRS facility. The study 
TABLE 4.59. Summary of the Total Transportation Risks for the System Without an MRS Facility

\begin{tabular}{ll} 
& \multicolumn{2}{c}{ Repository Location } \\
Mode & Deaf \\
\hline
\end{tabular}

$100 \%$ Truck from origin

SF to Repository

$\begin{array}{lccc}\text { Radiological (a) } & 6.2 & 9.2 & 10 \\ \text { Nonradiological (b) } & 18 & 29 & 31\end{array}$

HLW to Repository

$\begin{array}{llll}\text { Radiological } & 1.7 & 2.1 & 2.1 \\ \text { Nonradiological } & 6.2 & 7.4 & 7.4\end{array}$

$100 \%$ Rail from origin

SF to Repository
Radiological
0.18
0.24
0.25
Nonradiological
1.0
1.6
1.6

HLW to Repository
Radiological
Nonradiological
0.063
0.079
0.074
0.64
0.84
0.79

TOTALS

Truck from origin

Radiological

Nonradiological

$\begin{array}{rrr}7.9 & 11 & 12 \\ 24 & 36 & 38\end{array}$

Rail from origin

$\begin{array}{llll}\text { Radiological } & 0.24 & 0.32 & 0.32 \\ \text { Nonradiological } & 1.6 & 2.4 & 2.4\end{array}$

(a) Radiological health effects include lethal cancer fatalities and
genetic effects in all generations.
(b) Nonradiological fatalities. 
TABLE 4.60. Summary of the Total Transportation Risks for the System With an MRS Facility

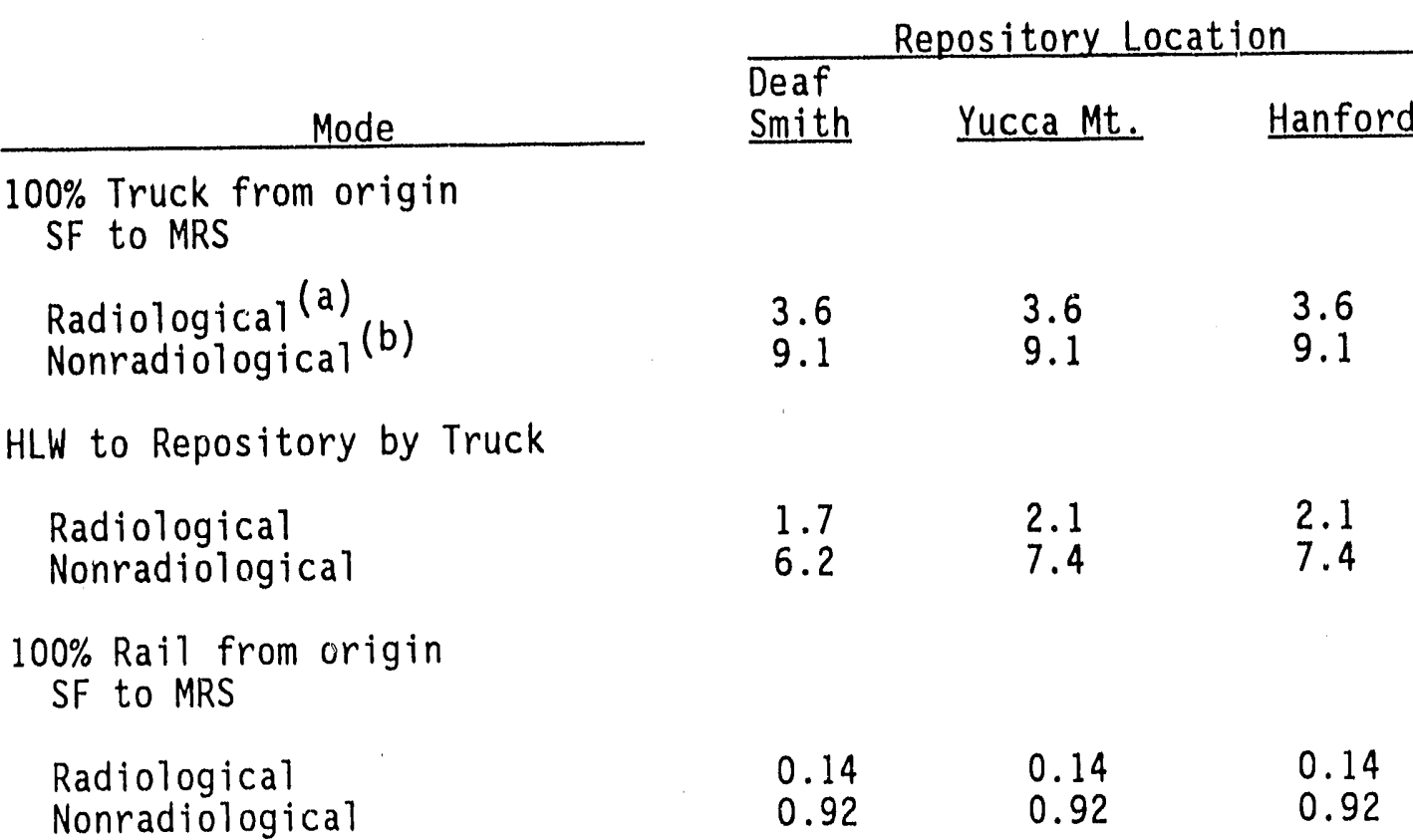

HLW to Repository by Rail
Radiological
0.063
0.079
0.074
Nonradiological
0.64
0.84
0.79

150T Rail from MRS
Radiological
Nonradiological
0.035
0.054
1.0
0.042
3.8
6.1

TOTALS

Truck from origin, 150T Rail from MRS
Radiological
Nonradiological
19.3
5
18 $\left(\begin{array}{l}8 \\ c\end{array}\right)$
5.7
23

Rail from origin, 150T Rail from MRS
Radiological
Nonradiological
0.24
0.27
0.26
5.3
12
7.8
(a) Radiological health effects include lethal cancer fatalities and genetic effects in all generations.
(b) Nonradiological fatalities
(c) An error was found in the source document. The value in this table is believed to be correct.


was summarized in the repository environmental assessments, therefore, the information will not be repeated here.

The scope of the analysis was limited to transportation of 5-year-cooled spent fuel. Routine occupational and public exposures from truck and rail shipments were estimated as well as public exposures from severe rail cask accidents. The report also gave estimates of areas that might become contaminated from releases caused by accidents and presented some cost estimates for cleanup of the contaminated areas.

The analysis of routine exposures included calculations of the gamma and neutron dose rates emitted from the shipping casks. Dose rate maps were developed based on the assumption that the maximum dose rate at 2 meters from the outer edges of the conveyance (truck trailer or railcar) was less than $10 \mathrm{millirem} / \mathrm{hr}$, which is consistent with DOT regulations. The calculations assumed a uniform line source to represent the fuel assemblies. Radiation buildup due to atmospheric and ground scattering were conservatively accounted for in the dose rate calculations.

Individual radiation exposures were calculated by estimating the amount of time specific individuals spent in a particular dose field and multiplying these estimates by the appropriate dose rate. These exposure time estimates, dose rates, and total individual doses are presented in Table 4.61 for typical truck shipments and in Table 4.62 for rail shipments. It should be noted that most of these exposure events will not necessarily occur during each shipment nor will they affect the same individual. Sandquist et al. (1985) also indicated that the distance and time estimates were chosen to represent unlikely values that result in "maximum credible individu?l exposures."

The consequences to individuals of rail accidents were also estimated. The analysis considered three potential accident categories for air-cooled rail casks: 1) severe impact followed by mechanical rupture of the fuel rods and cask; 2) severe impact and fire, including mechanical and thermal (or burst) rupture of the fuel rods; and 3) the same accident as 2) with enhanced release due to fuel oxidation. Release quantities were estimated for each of these accident categories for eight isotopes, including Co-60 (as crud), 


\section{TABLE 4.61. Projected Maximum Individual Exposyres from Normal Spent Spent Fuel Transport by Truck Cask(a)}

\begin{tabular}{|c|c|c|c|}
\hline (Service or Activity) & $\begin{array}{l}\text { Distance to } \\
\text { Center of Cask } \\
\end{array}$ & $\begin{array}{c}\text { Exposure } \\
\text { Time }\end{array}$ & $\begin{array}{c}\text { Maximum } \\
\text { Dose Rate } \\
\text { and Total Dose } \\
\end{array}$ \\
\hline \multicolumn{4}{|l|}{ Caravan } \\
\hline $\begin{array}{l}\text { Passengers in vehicles traveling } \\
\text { in adjacent lanes in the same } \\
\text { direction as cask vehicle }\end{array}$ & $10 \mathrm{~m}$ & $30 \mathrm{~min}$ & $\begin{array}{l}40 \mu \mathrm{rem} / \mathrm{min} \\
1 \mathrm{mrem}\end{array}$ \\
\hline \multicolumn{4}{|l|}{ Traffic obstruction } \\
\hline $\begin{array}{l}\text { Passengers in stopped vehicles in } \\
\text { lanes adjacent to the cask vehicle } \\
\text { which have stopped due to traffic } \\
\text { obstruction }\end{array}$ & $5 \mathrm{~m}$ & $30 \mathrm{~min}$ & $\begin{array}{l}100 \mu \mathrm{rem} / \mathrm{min} \\
3 \mathrm{mrem}\end{array}$ \\
\hline \multicolumn{4}{|l|}{ Residents and Pedestrians } \\
\hline $\begin{array}{l}\text { Slow transit (due to traffic } \\
\text { control devices through area with } \\
\text { pedestrians) }\end{array}$ & $6 \mathrm{~m}$ & $6 \mathrm{~min}$ & $\begin{array}{l}70 \mu \mathrm{rem} / \mathrm{min} \\
0.4 \mathrm{mrem}\end{array}$ \\
\hline $\begin{array}{l}\text { Truck stop for driver's rest. Ex- } \\
\text { posures to residents and passers-by. }\end{array}$ & $40 \mathrm{~m}$ & $\begin{array}{l}8 \text { hours } \\
\text { (assumes overnight) }\end{array}$ & $\begin{array}{l}6 \mu \mathrm{rem} / \mathrm{min} \\
3 \mathrm{mrem}\end{array}$ \\
\hline $\begin{array}{l}\text { Slow transit through area with } \\
\text { residents (homes, businesses, etc.) }\end{array}$ & $15 \mathrm{~m}$ & $6 \mathrm{~min}$ & $\begin{array}{l}20 \mu r \mathrm{rm} / \mathrm{min} \\
0.1 \mathrm{mrem}\end{array}$ \\
\hline \multicolumn{4}{|l|}{ Iruck Servicing } \\
\hline Refueling (100 gallon capacity) & $\begin{array}{l}7 \mathrm{~m} \\
\text { (at tank) }\end{array}$ & & $60 \mu \mathrm{rem} / \mathrm{min}$ \\
\hline $\begin{array}{l}\text { - } 1 \text { nozzle from } 1 \text { pump } \\
-2 \text { nozzles from } 1 \text { pump }\end{array}$ & & $\begin{array}{l}40 \mathrm{~min} \\
20 \mathrm{~min}\end{array}$ & $\begin{array}{l}2 \text { mrem } \\
1 \text { mrem }\end{array}$ \\
\hline Load inspection/enforcement & $\begin{array}{c}3 \mathrm{~m} \\
\text { (near personnel } \\
\text { barrier) }\end{array}$ & 12 min & $\begin{array}{l}160 \mu \mathrm{rem} / \mathrm{min} \\
2 \mathrm{mrem}\end{array}$ \\
\hline $\begin{array}{l}\text { Tire change or repair to cask } \\
\text { trailer }\end{array}$ & $\begin{array}{l}5 \mathrm{~m} \\
\text { (inside tire } \\
\text { nearest cask) }\end{array}$ & $50 \mathrm{~min}$ & $\begin{array}{l}100 \mu \mathrm{rem} / \mathrm{min} \\
5 \mathrm{mrem}\end{array}$ \\
\hline State weight scales & $5 \mathrm{~m}$ & $2 \min$ & $\begin{array}{l}80 \mu r \mathrm{~mm} / \mathrm{min} \\
0.2 \mathrm{mrem}\end{array}$ \\
\hline
\end{tabular}

(a) These exposures should not be multiplied by the expected number of shipments to a repository in an attempt to calculate total exposures to an individual; the same person would probably not be exposed for every shipnent, nor would these maximum exposure circumstances necessarily arise during every shipment. 
TABLE 4.62. Projected Maximum Individual Exposures from Normal

Spent Fuel Transport by Rail Cask(a)

Distance to Center of Cask

$20 \mathrm{~m}$

$10 \mathrm{~min}$

Exposure Time

Maximum

Dose Rate and Total Dose

Caravan

Passengers in rail cars or highway vehicles traveling in same direction and vicinity as cask vehicle

\section{Iraffic Obstruction}

Exposures to persons in vicinity of stopped/slowed cask vehicle due to rail traffic obstruction

\section{Residents and Pedestrians}

slow transit (through station or due to traffic control devices) through area with pedestrians

slow transit through area with residents (homes, bus inesses, etc.)

Train stop for crew's personal needs (food, crew change, first aid, etc.)

\section{Train Servicing}

Engine refueling, car changes, train maintenance, etc.

Cask inspection/enforcement by train, state or federal officials

Cask car coupler inspection/ ma intenance

Axle, wheel or brake inspection/ lubrication/maint enance on cask car
$6 \mathrm{~m}$

$25 \mathrm{~min}$

\begin{abstract}
$8 \mathrm{~m}$
\end{abstract}
$10 \mathrm{~min}$

$70 \mu r e m / m i n$

0.7 mrem

$20 \mathrm{~m}$

$10 \mathrm{~min}$

$30 \mu \mathrm{rem} / \mathrm{min}$

$0.3 \mathrm{mren}$

$50 \mathrm{~m}$

2 hours

$5 \mu \mathrm{ren} / \mathrm{min}$

$0.6 \mathrm{mrem}$

$\begin{array}{llr}10 \mathrm{~m} & 2 \text { hours } & 50 \mu \text { rem } / \mathrm{min} \\ 6 \mathrm{mrem} & & 200 \mathrm{mrem} \\ 3 \mathrm{~m} & 10 \mathrm{~min} & 2 \mathrm{mrem} \\ 9 \mathrm{~m} & 20 \mathrm{~min} & 70 \mu \mathrm{rem} / \mathrm{min} \\ & 1 \mathrm{mrem} \\ 7 \mathrm{~m} & 30 \mathrm{~min} & 90 \mu \mathrm{rem} / \mathrm{min} \\ & 3 \mathrm{mrem}\end{array}$

(a) These exposures should not be multiplied by the expected number of shipnents to a repository in an attempt to calculate total exposures to an individual; the same person would probably not be exposed for every shipment, nor would these maximun exposure circumstances necessarily arise during every shipment. 
$\mathrm{Kr}-85, \mathrm{Sr}-90, \mathrm{Ru}-106, \mathrm{I}-129, \mathrm{Cs}-134, \mathrm{Cs}-137$, and Pu-239. Respirable fractions were also developed for each isotope, ranging from 5 to $15 \%$ of the solid fission products released during an accident for impact and impact/ burst/oxidation accidents, respective1y, to $100 \%$ of the $\mathrm{Kr}-85$ in a11 three accident categories. Environmental pathways considered included ingestion, inhalation, and submersion (including both ground and cloud gamma doses). A standard Gaussian puff atmospheric dispersion model was used to calculate the downwind concentrations of radioactive materials and particulate deposition from the cloud onto the ground. Neutral stability conditions (Pasquil stability class D) were assumed. Population doses were estimated for two demographic regions; urban with a population density of 3,860 persons $/ \mathrm{km}^{2}$, and rural with a density of 6 persons $/ \mathrm{km}^{2}$.

Maximum individual doses and population 50-year dose commitments (out to 80 kilometers) were then estimated for each accident category. Doses to the maximally exposed individual are presented in Table 4.63 , and population dose commitments are given in Table 4.64.

Exposure estimates were also generated assuming the accidents occurred in an appropriate setting to maximize the water ingestion pathway exposures. The releases for the three accidents were assumed to be transported over a

IABLE 4.63. Maximum Individual Radiation Dose Estimates for Rail Cask Accidents

\begin{tabular}{|c|c|c|c|}
\hline \multirow[b]{2}{*}{ Accident Class } & \multicolumn{3}{|c|}{ Dose (mrem) ${ }^{(a)}$} \\
\hline & Inhalation & $\begin{array}{l}\text { Plume } \\
\text { Gamma }\end{array}$ & $\begin{array}{l}\text { Ground } \\
\text { Gamma }\end{array}$ \\
\hline Impact & 179 & 10.7 & 12.3 \\
\hline Impact and Burst & 6,130 & 71.1 & 90.9 \\
\hline $\begin{array}{l}\text { Impact, Burst and } \\
\text { Oxidation }\end{array}$ & 8,950 & 547 & 707 \\
\hline
\end{tabular}

(a) The maximally exposed individual dose occurs about 70 meters downwind of the release point and assumes that the individual remains at this location for the duration of the passage of the plume of nuclides that are released. 
TABLE 4.64. 50-Year Population Dose Estimates for Spent Fuel Rail Cask Accidents (a) (no cleanup of deposited nuslides)

\begin{tabular}{|c|c|c|c|c|c|c|c|c|}
\hline \multirow[b]{2}{*}{ Accident Class } & \multicolumn{4}{|c|}{ Urban Area $\left(3,860\right.$ people $\left./ \mathrm{km}^{2}\right)$} & \multicolumn{4}{|c|}{ Rural Area (6 people $/ \mathrm{km}^{2}$ ) } \\
\hline & Inhalation & $\begin{array}{l}\text { Plume } \\
\text { Camma }\end{array}$ & $\begin{array}{l}\text { Ground } \\
\text { Gamma }\end{array}$ & Total & Inhalation & $\begin{array}{l}\text { Plume } \\
\text { Gama }\end{array}$ & $\begin{array}{l}\text { Ground } \\
\text { Gamma }\end{array}$ & Total \\
\hline \multicolumn{9}{|l|}{1 mpact } \\
\hline $\begin{array}{l}\text { Dose (person-rem) } \\
\text { Latent Heal th } \\
\text { Effects }\end{array}$ & 3.09 & 0.33 & 936 & $\begin{array}{r}939 \\
0.19\end{array}$ & 0.005 & 0.0005 & 1.45 & $\begin{array}{l}1.45 \\
0.00029\end{array}$ \\
\hline \multicolumn{9}{|l|}{ Impact and Burst } \\
\hline $\begin{array}{l}\text { Dose (person-rem) } \\
\text { Latent Hegl th } \\
\text { Effects }\end{array}$ & 106 & 2.23 & 13,400 & $\begin{array}{r}13,500 \\
2.7\end{array}$ & 0.16 & 0.0034 & 20.8 & $\begin{array}{l}21 \\
0.0042\end{array}$ \\
\hline $\begin{array}{l}\text { Impact, Burst and } \\
\text { Oxidation }\end{array}$ & & & & & & & & \\
\hline $\begin{array}{l}\text { Doseg (person-rem) } \\
\text { L.HE }\end{array}$ & 154 & 17.2 & 112,000 & $\begin{array}{r}112,000 \\
22\end{array}$ & 0.24 & 0.27 & 174 & 174 \\
\hline
\end{tabular}

(a) The ground gamma dose is what would be received if each menter of the population stayed at the same location for 50 years. The irihalation dose is a 50 -year dose commitment from inhalation of the passing plume. Doses are for the population within 80 kilaneters of the rolease point. It is assumed that there is no cleanup of deposited nuclides and that no other measures are used to reduce radiation exposures.

(b) Based on 1 person-rem $=2.0 E^{-4}$ LHEs. An LHE is defined here as an early cancer death by an exposed person or'a serious genetic health problem in the two generations after those exposed. About half of the LHEs are expected to be cancers and the rest genetic heal th problems.

large reservoir used solely for domestic purposes. It was conservatively assumed that $1 \%$ of the water would be ingested by humans through drinking water. It was assumed there would be no cleanup of the deposited radionuclides. The population dose commitments estimated for this scenario are shown in Table 4.65.

Cleanup time and cost estimates were also estimated for the three accident classes. The computer model used for the population dose analysis also developed estimates of the contaminated land area for a range of contamination levels. For example, the impact/burst/oxidation accident was estimated to contaminate a land area of $110 \mathrm{~km}^{2}$ at a level of $2.0 \mathrm{E}-7 \mathrm{ci} / \mathrm{m}^{2}$ or 1 ess to an area of $2.2 \mathrm{~km}^{2}$ at a level of $1.0 \mathrm{E}-5 \mathrm{ci} / \mathrm{m}^{2}$ or less (it was indicated that a level of $5.0 \mathrm{E}-6 \mathrm{Ci} / \mathrm{m}^{2}$ corresponds to a dose rate of $500 \mathrm{mrem} / \mathrm{yr}$ ). Rough estimates were presented for the costs of removing contaminated soil to a level that limits individual dose rates to $500 \mathrm{mrem} / \mathrm{yr}$. The soil removal 
IABLE 4.65. Population Radiation Exposure from Water Ingestion for Severe but Credible Spent

Fuel Rail Cask Accidents

\begin{tabular}{|c|c|c|}
\hline Accident Class & $\begin{array}{l}\text { Total Release } \\
\text { from Rail Cask (Ci) }\end{array}$ & $\begin{array}{l}\text { Population Dose } \\
\text { Effects from Water Ingestion }\end{array}$ \\
\hline Impact & 8.07 & $\begin{array}{l}182 \text { person-rem } \\
0.036 \mathrm{LHE}(b)\end{array}$ \\
\hline Impact and Burst & 153 & $\begin{array}{l}6870 \text { person-rem } \\
1.4 \text { LHE(b) }\end{array}$ \\
\hline Impact, Burst & 1379 & $\begin{array}{l}63,000 \text { person-rem } \\
12.6 \mathrm{LHE} \text { (b) }\end{array}$ \\
\hline
\end{tabular}

(a) The noble gas $\mathrm{Kr}-85$ is omitted because of its negligible uptake by a surface water body.

(b) LHE estimates are based upon 1 person-rem $=2.0 \mathrm{E}-4$ LHE.

costs included components for monitoring, excavation, loading, packaging, transportation to a burial site, disposal, and site restoration (such as the costs for fill material, spreading, and reseeding). The resulting cleanup costs are shown below:

\begin{tabular}{|c|c|c|}
\hline & Cleanup & $\operatorname{Cost}(\$)$ \\
\hline Accident Class & Low & High \\
\hline Impact & $2.0 E+5$ & $9.5 E+6$ \\
\hline Impact/burst & $1.4 E+6$ & $7.0 E+7$ \\
\hline $\begin{array}{c}\text { Impact/burst/ } \\
\text { oxidation }\end{array}$ & $1.3 E+7$ & $6.2 E+8$ \\
\hline
\end{tabular}

\section{Evaluation}

This document presented conservative estimates of individual exposures that could result from routine transport of spent fuel and from accidents involving releases of radioactive material. Few previous analyses have shown these individual doses. However, the consequences of accidents were not placed on a probabilistic basis so no risk values were developed. The routine doses were calculated for "maximum" exposure conditions that might or 
might not be encountered in each shipment and certainly would not affect the same individuals. In addition, the routine dose analyses assumed a uniform line source when estimating close-proximity (i.e., less than 10 meters) doses. This would tend to overestimate close-proximity doses. The longerdistance doses would not be overestimated as much. Estimates of the routine population exposures for a single shipment were not in the study scope. As a result, this document is of 1 imited usefiliness to the present study. However, the information on the high-consequence/low-probability accidents is applicable.

\subsubsection{Nonradiological Impacts of Transporting Radioact tve Matertal (Rao et al. 1982)}

The objective of this document was to develop a methodology for quantifying the routine nonradiological impacts of transporting radioactive materials. These nonradiological impacts could arise from the generation and dispersal of nonradiological pollutants, such as carbon monoxide, sulfur oxides, nitrogen oxides, and hydrocarbons, from the combustion of fossil fuels. The nonradiological impacts of accidents were also addressed. These impacts considered the accidents and injuries that resulted from vehicular accidents that did not release radioactive materials. These methodologies were developed so a more complete assessment of the environmental impacts of radinactive material transportation could be performed (previousiy, radiological impacts were emphasized in environmental impact documentation). It should be noted that nonradiological impacts of radioactive material shipments are identical to those of nonradioactive shipments.

The concentration of pollutants emitted from a passing diesel-powered truck or a locomotive are a function of the emission rate and the atmospheric dispersion. Atmospheric dispersion was modeled assuming a line-source dispersion model and assumes that a $3 \mathrm{~m} / \mathrm{sec}$ wind is blowing in a direction perpendicular to the highway or railroad. Neutral atmospheric stability conditions in an urban area were also assumed.

Source terms (or emission rates) for the atmospheric dispersion equation were expressed in units of grams $/ \mathrm{km}$ of trave1. Three separate source terms were needed: 1) pollutants from combustion of diesel fuel, 2) particulates 
from abrasion of rubber tires on paved surfaces, and 3) fugttive dust generated in the turbulent wake of a moving vehicle. The emission rates from truck and ratl shipments were developed from recommendations made by the EPA. These emtssion rates are adjusted for an assumed $24 \mathrm{~km} / \mathrm{hr}$ (15 mph) speed.

The dispersion model results and source terms were combined to estimate the incremental change in pollutant concentrations in urban areas due to passage of one shipment per hour. Only travel through urban areas was considered. The changes in pollutant concentrations were converted to incremental health effects using a linear regression technique that was applied to existing epidemiological data on the effects of different pollutants. It was recognized that the health effects relationships were conservative and included large uncertainty bands.

The results of this exercise were presented in terms of unit risk factors, which were expressed in units of latent cancer fataltities per unit diztance of travel $(\mathrm{LCF} / \mathrm{km})$. The unit factors given by Rao et al. are shown below:

$$
\frac{\text { Truck }}{1.0 \mathrm{E}-7 \mathrm{LCF} / \mathrm{km}} \quad \frac{\mathrm{Rail}}{1.3 \mathrm{E}-7 \mathrm{LCF} / \mathrm{km}}
$$

Nonradiological impacts from accidents were derived from accident fatality statistics complied by the DOT, based on data from the years 1976 and 1977 . Then, injury rates were determined by multiplying the fataltiy rates by the ratio of fatalities to injuries taken from an older document. The resulting unit fatality and injury rates per $\mathrm{km}$ of travel are shown below:

$\begin{array}{llll} & \text { Truck } & & \text { Rail } \\ \text { Injuries } / \mathrm{km} & 5.1 \mathrm{E}-7 & & 4.6 \mathrm{E}-7 \\ \text { Fatalities/km } & 3.0 \mathrm{E}-8 & & 3.4 \mathrm{E}-8\end{array}$




\section{Evaluation}

This document represented the first attempt at estimating the nonradiological risks attributable to the emission of pollutants from mobile sources. It was acknowledged in the document that uncertainties existed in the analysis as well as in the pessimistic estimates of health effects from pollutants. Little has been done on this specific subject since the publication of Rao et a1. (1982), so this document still represents the only source of readily avallable information on the routine nonradiological risks of transportation. The nonradiological accident risk factors also represented an initial analysis of the DOT accident and injury statistics. The risk factors were based on relatively old data (1976 and 1977) but are still approximately equal to results from current efforts. It is judged that the results of more recent and detailed analysis of DOT accident statistics presented by Cashwe 11 et al. (1986) is the best avallable information. This is because Cashwe11 et al. reports the unit fatality and injury factors for travel through different population zones.

\subsubsection{OCRWM Transportation ALARA Study}

This report (Schneider et a1. 1987) developed estimates of the routine radiation doses resulting from operation of a postulated system for transporting spent fuel from reactors to the potential repository. The scope of the study included assessments of routine radiation doses from shipping cask handling at reactors and the repository as well as the doses from in-transit transportation activities. Doses to the public, cask-handling personnel, and transport workers were evaluated. The resulting dose information was used to identify high dose-producing activities that were then used to identify and evaluate alternatives that could reduce the doses associated with activities. Evaluations of the alternatives included assessments of the dose and cost impacts that would result from their implementation.

The approach used to develop the radiation dose estimates consisted of developing time/distance/occupancy information to describe the activities involved in handling and transporting shipping casks and then combining these data with estimated radiation dose rates to estimate the collective and maximally exposed individual exposures. Time/distance/occupancy evaluations 
were performed to determine the amount of time and number of persons exposed at various distances from the shipping casks. Shielding calculations were performed to estimate the radiation dose rates as functions of distance from the tops, bottoms, and sides of truck and rail shipping casks. To develop estimates of the collective radiation doses, the dose rates were multiplied by the number of persons exposed and the amount of time spent in the vicinity of the casks. The results of these calculations are presented in Table 4.66 . Doses to maximaliy exposed individuals were estimated by multiplying the dose rates times the total amount of time spent by individuals in the vicinity of the casks. The doses to the maximally exposed individuals are not addressed further here because they are out of the scope of this document. Similarly, the results of the cost and dose calculations for the alternatives are not included here.

\section{Evaluation}

This report presented a comprehensive detailed assessment of the routine radiation exposures to the public and workers from transportation operations

TABLE 4.66. Summary of Collective Radiation Doses from Postulated Reference Transportation System Activities

\begin{tabular}{|c|c|c|c|c|c|}
\hline & & & $\begin{array}{l}\text { oses, pe } \\
\text { y Shipme }\end{array}$ & 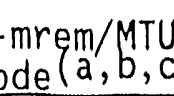 & \\
\hline LoC & ation & & lic & To $\mathrm{W}$ & Ser \\
\hline of $A$ & ctivity & Rail & Truck & Rail & Truck \\
\hline Reac & tor & (d) & (d) & $62 / 77$ & $293 / 314$ \\
\hline In-T & ransit & $6 / 6$ & $495 / 495$ & $10 / 10$ & $231 / 231$ \\
\hline Repo & sitory & (d) & (d) & $72 / 70$ & $300 / 299$ \\
\hline & tal & $6 / 6$ & $495 / 495$ & $144 / 157$ & $824 / 844$ \\
\hline $\begin{array}{l}\text { (b) } \\
\text { (c) }\end{array}$ & $\begin{array}{l}\text { Values } \\
\text { for pro } \\
\text { (shipme } \\
\text { the res } \\
\text { Shown } \\
\text { Values } \\
\text { signifi } \\
\text { to that }\end{array}$ & $\begin{array}{l}\text { for ei } \\
\text { d dose } \\
\text { ractio } \\
\text { WR/BWR } \\
\text { shown } \\
\text { figur } \\
\text { el. }\end{array}$ & $\begin{array}{l}100 \% \text { rai } \\
\text { nult iply } \\
\text { and truck } \\
\text { ant fuels. } \\
\text { solculatec } \\
\text { hown is }\end{array}$ & $\begin{array}{l}100 \% \text { tr } \\
\text { values } \\
\text { es by } 0\end{array}$ & $\begin{array}{l}\text { k transport; } \\
0.7 \\
\text { then sum } \\
\text { number of } \\
\text { imply accuracy }\end{array}$ \\
\hline
\end{tabular}


in the waste management system. The methods and data used were state of the art. The calculations were well documented and appeared to be internally consistent. The analyses tended to be conservative (e.g., dose rates from the shipping casks were normalized to the regulatory limits, average truck stop times en route appear to be high), and thus the results are likely to be somewhat overstated. The results are applicable to the current configuration of the waste management.

\subsubsection{Reports Selected for Use in This Study}

The documents reviewed in this study and the risk categories addressed in each document are shown in Table 4.67. As shown, the emphasis in the literature has been to evaluate the risks of transportation accidents and routine exposures to the public. The documents in the table establish a relatively comprehensive basis for estimating transportation risks in all categories. It is judged that transportation risk analyses are more advanced than the risk analyses of the other elements of the system. For this reason, the uncertainties asscciated with the transportation risks are probably

TABLE 4.67. General Overview of Transportation Operations Risk Data in Reviewed Documents

\begin{tabular}{|c|c|c|c|c|c|c|c|c|}
\hline & \multicolumn{4}{|c|}{ Radiologica! Risks } & \multicolumn{4}{|c|}{ Non-Radiological Risks } \\
\hline & \multicolumn{2}{|c|}{ Accidents } & \multicolumn{2}{|c|}{ Routine } & \multicolumn{2}{|c|}{ Accidents } & \multicolumn{2}{|c|}{ Routine } \\
\hline & Public & Worker & Public & Worker & Public & Worker & Public & Worker \\
\hline Cashwell et al. (1986) & $k$ & $x$ & $x$ & $x$ & $x$ & $x$ & $x$ & \\
\hline $\operatorname{DOE}(1986 b, c, d)^{(a)}$ & $x$ & & $x$ & $x$ & $x$ & $x$ & $x$ & \\
\hline Sandquist et al. (1985) & $x$ & & $x$ & & & & & \\
\hline NRC (1977) & $x$ & & $x$ & $x$ & $x$ & & & \\
\hline Elder et al. (1978) & $x$ & & & & & & & \\
\hline Elder et al. (1981) & $x$ & & & & & & & \\
\hline Finley et al. (1980) & $x$ & & $x$ & & & & & \\
\hline Rao et al. (1982) & & & & & $x$ & & $x$ & \\
\hline Schneider et al. (1987) & & & $x$ & $x$ & & & & \\
\hline
\end{tabular}

(a) Identical appendices that address the transportation impacts for all potential first repository media are included in the repository enviromental assessments. 
smalier than the uncertainties associated with the other elements. One possible exception is the radiological accident risks of transportation, which are based, for the most part, on assumed release fractions and accident probabilities derived from nonradiological accident data.

It is important to note that the general conclusion of studies in Table 4.67 is that the risks of transporting radioactive materials are small. Many of the studies compared their calculated results with the population health effects projected to be caused by natural background radiation. The conclusions were that the health effects estimated to be produced by transcortation are only a small fraction of the health effects estimated to be caused by natural background radiation. In addition, studies that analyzed both radiological and nonradiological risks have determined that nonradiological risks are greater than radiological risks.

Nonradiological risks from transportation accidents were addressed in only a few studies. The method used in all of these studies to develop nonr diological risk estimates was to derive unit risk factors (fatalities and injuries per unit distance of travel) from DOT accident statistics. As a result, the study that uses the most recent DOT statistics will be representative of current trends toward increased safety in the transportation industry. Cashwell et a1. (1986) used the most recent DOT statistics that are available (DOT 1985), and so it will be used in subsequent sections of this report.

Nonradiological routine risk estimates in the 1 iterature were al1 based on the methodology developed by Rao et al. (1982). In fact, the unit risk values used by Cashwell et al. (1986) and referenced in the repository environmental assessments were the same as those derived by Rao et al. Since Cashwell et a1. was based on the current configuration of the waste management system, those results will be used in this study of system risks. 


\subsection{ASSESSMENT OF WASTE MANAGEMENT SYSTEM RISKS}

This chapter presents preliminary estimates of the annual and total system life-cycle risks associated with each element of the waste management system. Risks for the operating phase are estimated for a fully functioning waste management system operating at a throughput rate of 3,000 MTU/yr. Levelized annual risks are presented for the construction and decommissioning phases. The risks are prorated over the length of the construction and decommissioning phases. Because repository retrieval system designs and operations descriptions are not yet well characterized, risk estimates for retrieval operations are not included in this section. The annual risks are then used to estimate the total life-cycle system risks for system configurations with and without an MRS facility. The rationale for selecting the risk information from the literature used in these estimates was presented in Chapter 4.0. In this chapter, separate sections are presented for discussions of annual repository preclosure risks (Section 5.1), postclosure risks (Section 5.2), MRS facility risks (Section 5.3), and transportation system risks (Section 5.4). Sources of uncertainty in the risk estimates are discussed for each system element. Economic risks are discussed in Section 5.5 and total system 1 ife-cycle risk estimates are presented in Section 5.6.

Previous risk studies used a wide range of bases and assumptions to develop the risk estimates. To develop annual risk values that are more comparable, the risk estimates taken from the literature were adjusted, or normalized, to a common basis. Adjustments were made to normalize the risk estimates to a 3,000 MTU/yr throughput rate and a maximum repository capacity of 70,000 MTU. All radiological risk values were converted to equivalent latent health effects/yr (LHE/yr). A conversion factor of 2.OE-4 LHE/person-rem was used.

\subsection{REPOSITORY PRECLOSURE RISKS}

This section presents a preliminary estimate of the preclosure risks for the potential tuff repository at the Yucca Mountain Site. Risks were estimated for both major system configurations (i.e., systems with and without an MRS facility). A description of the conceptual repository designs in the 
tuff media was presented in Chapter 3.0. The results presented here have many uncertainties associated with them because of the current lack of adequate site-specific data, the wide variety of approaches and methods used to assess risks, and the lack of definitive design details.

\subsubsection{Repository Preclosure Risk Values}

This section discusses the adjustments made to the risk values in the literature to normalize them to a common basis. Separate subsections are provided for radiological and nonradiological risk estimates.

\subsubsection{Radiological Health Risks}

The estimated routine radiological risks during construction are based on information from the GEIS (DOE 1980) and the site ranking methodology report (DOE 1986f). The annual whole body exposures given in the GEIS were adjusted to account for the different repository design assumptions by multiplying the annual occupational doses during construction from the GEIS (see Table 4.2$)$ by the ratios of the total repository capacities $(70,000 / 126,000=$ 0.56). The results were then converted to estimates of annual LHEs by multiplying the resulting annual doses by the health effects conversion factor for whole body exposures (2.0E-4 LHE/person-rem). The repository in granite analyzed in the GEIS was used to represent the potential tuff repository because the uranium and thorium contents were approximately the same.

The occupational doses given in DOE (1986f) for repository construction were based on an average "working level" of radon exposure for the potential tuff repository media. The average working level given for the potential tuff repository was converted to an average dose rate and then multiplied by the number of construction workers and number of years of construction. The resulting dose was then multiplied by the health effects conversion factor of 2.0E-4 LHE/person-rem (a value of 2.8E-4 was used in DOE 1986f). The annual number of health effects based on the results in the GEIS and DOE (1986f) are shown in Table 5.1 .

The estimated health effects from both documents agreed well for tuff. Because the results in DOE (1986f) were based on the most recent construction worker estimates and repository designs, the results in that document were 
TABLE 5.1. Annual Construction Worker Risks (DOE 1980, 1986f)

\begin{tabular}{lc} 
Source & $\begin{array}{c}\text { Annual Risk } \\
\text { (LHE/yr) }\end{array}$ \\
\hline $\operatorname{DOE~(1986f)~}$ & $1.1 \mathrm{E}-1$ \\
GEIS & $8.0 \mathrm{E}-2$
\end{tabular}

judged to be applicable for this study. Since the amount of rock removed from the repositories was approximately equal in both system configurations, these values were applicable to both systems.

Routine public radiation doses from construction were estimated in the GEIS (DOE 1980), Waite et al. (1986), and the tuff environmental assessment (DOE 1986b). The estimates in the GEIS were based on very high population densities ( 2 million persons within 50 miles) relative to the population density surrounding the tuff site. Population doses given in the GEIS (shown in Table 4.2) were 100 person-rem over a 7-year construction period for the tuff geologic media. After normalization to a 70,000 MTU repository capacity and conversion of doses to health effects, the normalized risk value was $2 \mathrm{E}-3 \mathrm{LHE} / \mathrm{yr}$.

The routine doses calculated by waite et al. (1986) for a potential salt repository amounted to 20 person-rem over an 8 -year construction period. The annual dose of 2.5 person-rem/yr was then multiplied by the $2.0 \mathrm{E}-4$ LHE/ person-rem conversion factor to produce an estimated value of 5.0E-4 LHE/yr. The routine construction doses presented in the tuff environmental assessment were 0.3 person-rem over a 5 -year construction period. This results in an annual population dose of 0.06 person-rem/yr. An annual risk value of 1.2E-5 LHE/yr was estimated. The results from the different studies are relatively close together. The quantities of mined rock brought to the surface at the repository are not expected to be greatly different between system configurations so the expected risks of construction should not be greatly different. The value taken from the environmental assessment was used to calculate total life-cycle risks because they are more consistent with current operating and siting assumptions. 
Routine occupational radiation exposures during repository operation were estimated in six documents. A comparison of these estimates was presented in Section 4.1.2. The most detailed results were developed by Dennis et a1. (1984) for the potential tuff repository. These estimates were based on time-and-motion studies of conceptual repository operations. Thus, data from Dennis et al. (1984) was used as the primary basis for estimating occupationat doses.

The doses estimated by Dennis et a1. (1984) were based on receiving and processing 1,500 MTU/yr of spent fuel and the same amount of HLW. To more accurately reflect the current system configuration, the doses for spent fuel operations were separated from the HLW operations doses and adjusted to reflect the current receipt rates. This separation procedure was performed using the ratios of spent fuel to HLW cask receipts and spent fuel to HLW disposal packages to estimate the fraction of the dose from each function that was due to spent fuel and HLW. After the fractions were determined, they were multiplied by the annual dose given by Dennis et a1. (1984) for the appropriate function and then multiplied by the ratio of the current system throughput rate to the throughput rate used by Dennis et al. (1984). The results for each function were then added together to estimate the total annual occupational doses which were then converted to health effects. This resulted in an estimate of $2.1 \mathrm{E}-2$ LHE/yr.

The occupational doses for the repository in a system with an MRS facility was somewhat lower because the spent fuel consolidation function was transferred to the MRS facility. The occupational dose estimates were deve1oped by subtracting the doses associated with consolidation operations from the total dose shown above. Consolidation doses estimated by Dennis et al. (1984) were about 3.1 person-mrem/PWR assembly or 6.7 person-mrem/MTU. This equates to an annual dose of approximately 20.2 person-rem/yr for a 3,000 MTU/yr facility. This represents approximately $19 \%$ of the total occupational exposures. This fraction was used to reduce the adjusted occupational exposures given above to develop estimates for the repository in a system with an integral MRS facility. The resulting occupational dose estimate was $1.7 \mathrm{E}-2 \mathrm{LHE} / \mathrm{yr}$. 
Public risks from routine releases of radioactive materials during repository operations are based on data in Jardine et a1. (1988). This document provided numerical estimates for routine public exposures during operation of the potential tuff repository. The results were presented in terms of the annual dose commitment to the population within 80 kilometers of the repository. The annual population dose commitment was estimated to be approximately 0.004 person-rem/yr. After converting this value to health effects, the normalized public risk was $8.0 \mathrm{E}-7 \mathrm{~L}$ !IE/yr.

The radiation exposures calculated by Jardine et al. (1988) were for a potential repository that did not perform consolidation of spent fuel (i.e., the system that includes an MRS facility and a potential repository). Routine releases analyzed by waite et al. (1986) included releases from consolidation activities as well as from fuel damaged during transport. Waite also stated that the latter releases would not contribute significantly to the total population dose because only six fuel rods were estimated to be damaged during transport, whereas 6,400 were estimated to be damaged during consolidation operations. The ratio of fuel damaged during consolidation to fuel damaged during transport and the poputation dose from Jardine et a1. (1988) were used to estimate the dose for the repository that performs rod consolidation operations. The estimated annual public health effect for the potential tuff repository in this system configuration was $8.5 \mathrm{E}-4$ LHE/yr.

Occupational accident risks were taken from Jackson et a1. (1984), This study provided estimates of total-body dose commitments to repository personnel for a range of potential accidents. Estimated frequencies were also given for these accidents as well as some indication of the personnel affected (e.g., surface facility workers, underground crew, etc.). The dosecommitments, frequencies, and number of affected personnel were multiplied together for each accident to develop an estimated risk from accidents of 1.1 person-rem/yr. After multiplying this value by the health effects conversion factor, the annual repository worker risks from accidents were 5.8E-5 LHE/yr.

The individual doses and frequencies from Jackson et al. (1984) were also used to develop occupational risk estimates for accidents at the 
potential tuff repository in the MRS system. The values given above were adjusted because there are expected to be fewer workers in the repository in a system with an MRS Facility. The number of workers was not given in DOE (1986f) so the ratio of the personnel requirements for the repository in the system with or without an MRS facility was estimated from data given published by DOE (1986e). This ratio was multiplied by the staffing requirements in DOE (1986f) to estimate the staffing requirements for the MRS system repository. After the staffing estimates were calculated, they were multiplied by the accident frequencies and dose commitments given by Jackson et a1. (1984) and the health effects conversion factor to develop an estimate of the annual occupational accident risks. The resulting risk value was $4.5 \mathrm{E}-5 \mathrm{LHE} / \mathrm{yr}$.

A comparison of public accident risk estimates from six documents was also presented in Section 4.1.2. These documents evaluated from 1 to 10 accidents and produced risk estimates that ranged from $1 E-10$ to $2 E-6$ personrem/MTU. The most comprehensive study was performed by Jackson et a1. (1984). An additional five accidents were analyzed by Waite et al. (1986). To approximate a risk value based on a more comprehensive assessment of potential accidents, risk values from Jackson et al. (1984) were combined with risk values estimated from data in Waite et al. (1986) to develop overall accident risks.

The sum of the accident risk values estimated by Jackson et al. (1984) for the potential tuff repository was $1.5 E-5$ person-rem/yr (see Table 4.18). The population doses for the five accidents evaluated by Waite et al. (1986) were shown in Table 4.14. Al1 but the contact handled TRU (CH-TRU) waste puncture accident were extremely unlikely. The frequency of the shipping cask crush accident was assumed to be 1.0E-5/yr (DOE 1979a; Jackson et a1. 1984, respectively). The frequency of the $\mathrm{CH}$-TRU waste puncture accident was assumed to be less than $1 / y r$ (based on a frequency of $3.0 \mathrm{E}-5 /$ drum given in (DOE 1979a). Multiplying these frequencies by the estimated doses and summing over the accident scenarios produced a total risk estimate of $1.3 \mathrm{E}-5$ person-rem/yr. The shaft drop accidents analyzed by waite et a1. were not applicable to the potential tuff repository because it was assumed that the ramp access concept was used. 
The overall accident risks for the potential tuff repository were then estimated by adding the total risk value in Jackson et al. (1984) and the sum of the shipping cask crush and $\mathrm{CH}$-TRU waste puncture accidents based on Watte et a1. (1986). The resulting risk value was $2.8 \mathrm{E}-5$ person-rem/yr or $5.6 \mathrm{E}-9$ LHE/yr.

Decommissioning of the repository surface facilities is expected to produce a smal1 dose to the public, primartly due to airborne effluents released during decommissioning operations. The transportation of radioactive wastes generated during decommissioning to a disposal facility has not been addressed at this time. The public radiation dose for routine releases during immediate decommissioning was estimated to be $5.6 \mathrm{E}-7$ person-rem at a reference Independent Spent Fuel Storage Installation (ISFSI) (Ludwick and Moore 1984). This value represented a 50 -year dose commitment equivalent to the total population within a 50 -mile radius of the site. Immediate decommissioning of the reference ISFSI was estimated by Ludwick and Moore (1984) to require an average of 0.8 years of active decommissioning following shutdown. This yielded a public radiation dose estimate of 7.0E-07 personrem/year. This estimate was dominated by the dose to the lung. After converting this lung dose to an equivalent whole body dose using a factor of 0.12 (Waite et a1. 1986) and multiplying by the health effects conversion factor, an estimate of 1.7E-11 LHE/yr was obtatned. This value was used to represent the public risks from decommissioning a repository.

Ludwick and Moore (1984) also estimated the routine occupational exposures for decommissioning the reference ISFSI at approximately 155 personrem/yr. After converting these exposures to health effects, the annual risks in this category were 3.1E-2 LHE/yr. This value was also assumed to be representative of the risks from repository decommissioning. No information was available on the risks of accidents during decommissioning.

The repository preclosure risk estimates are summarized in Table 5.2.

\subsubsection{Nonradiological Health Risks}

This subsection provides estimates of nonradiological risks for each phase of repository operations. The estimated nonradiological accident risks, given in units of fatalities/yr, were calculated in DOE (1986) by 
TABLE 5.2. Estimated Annual Radiological Risks from the Preclosure Phases of the Potential Tuff Repository

\begin{tabular}{|c|c|c|c|c|c|c|c|c|}
\hline \multirow{3}{*}{$\begin{array}{l}\text { Operating } \\
\text { Phase/ } \\
\text { Medium }\end{array}$} & \multicolumn{4}{|c|}{ System Without MRS (LHE/yr) (a) } & \multicolumn{4}{|c|}{ System with MRS (LHE/Yr) (a) } \\
\hline & \multicolumn{2}{|c|}{ Routine } & \multicolumn{2}{|c|}{ Accident } & \multicolumn{2}{|c|}{ Routine } & \multicolumn{2}{|c|}{ Accident } \\
\hline & Public & Worker & Publtc & Worker & Public & Worker & Public & Worker \\
\hline Construction & $1 E-5$ & $1 E-1$ & (b) & (b) & $1 E-5$ & $1 E-1$ & (b) & (b) \\
\hline Operations & $9 E-4$ & $2 E-2$ & $6 \mathrm{E}-9$ & $6 E-5$ & $8 E-7$ & $2 E-2$ & $6 E-9$ & $5 E-5$ \\
\hline Decommissioning & $2 E-11$ & $3 E-2$ & (c) & (c) & $2 E-11$ & $3 E-2$ & (c) & (c) \\
\hline
\end{tabular}

(a) LHE includes latent cancer fatalities plus first and second generation genatic effects.

(b) No risks in this category.

(c) Insufficient information available to develop preliminary risk estimates for these categories.

multiplying the number of workers by an estimated accident rate. Annual nonradiological fatalities were estimated using projected work force requirements (DOE 1986e) and historical incidence rates for operations performed during each repository phase. These fatality estimates were added to the estimated fatalities produced by repository-generated traffic from DOE (1988) to develop the total repository-related nonradiological fatality estimates.

The fatality rates used in DOE (1986f) to estimate the nonradiological fatalities were derived from several sources. A fatality rate of 0.17 fatalities per million man-hours of construction was based on statistics compiled by the National Safety Council. This rate was the same as the rate used in the GEIS. This fatality rate was also used to estimate the nonradiological risks of surface facility operation. This is conservative because construction of the facilities is more hazardous than operations, with respect to nonradiological accidents. The underground mining fatality rate used was 0.55 fatalities per million man-hours, based on historical accident data. The mining fatalty rate was a combination of rates for both metal and nonmetal underground mining and was used for all three potential repository sites.

These fatality rates were multiplied by repository labor-force requirements for construction and operation to produce the total nonradiological 
fatality estimates summarized prevtousiy in Table 4.21. The total fatalities were converted to annual fatalities by dividing the fatalities for the construction phase by 5 years and those for the operations phase by 26 years. The annual and total nonradiological fatality estimates are presented in Table 5.3 .

Nonradiological fatalities from accidents during decommissioning operations were estimated using the same approach that was used for other operating phases. However, staffing requirements for decommissioning were not spectfied in DOE (1986f). Decommissioning personnel requirements were taken from the tuff environmental assessment (DOE 1986b) and multiplied by the surface factlity and underground nonradtological fatality rates used previously. The annual fatality estimates for the decommissioning phase of the repository are shown in Table 5.3. The estimates for the repository in a system with an MRS facility were obtained by multiplying the fatality estimates for the repository in a system without an MRS factilty by the ratio of the labor requirements given in DOE (1986e).

Construction and operation of the repository will generate additional traffic-related fatalities from workers traveling to and from the site. The total traffic-related risks for the potential tuff repository were given in DOE (1988) and were summartzed in Table 4.22 of this report. The annual

TABLE 5.3. Annual and Total Nonradiological Fatalities for Each Phase of the Lif: Cycle of a Potential Repository

Facility/Location

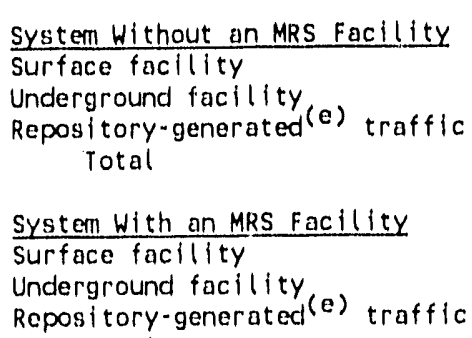
Total

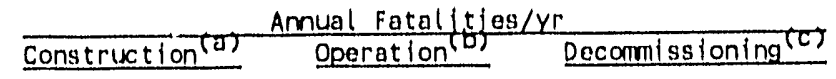

Total Fatalities

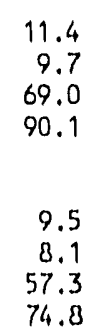

(a) Construction period of 5 years was assumed.

(b) Operations period of 26 years was assumed.

(c) A 7-year decommissioning period was assumed.

(d) Decomissioning of the underground facility consists primarily of backfilling operations and is assumed to occur during the operations period.

(e) Includes accidents involving worker as woll as public fatalities, 
fatalities were estimated by dividing the largest value in the ranges given in Table 4.22 by the number of years for construction ( 5 years), operation (26 years), and closure (to represent decommisstoning, 8 years) of the potentlal tuff repository. The resulting traffic-related annual fatality estimates are given in Table 5.3 as well as the total site plus trafficgenerated annual fatalities. As shown, the traffic-generated fatalities are significantly larger than the fatalities generated at the MRS faclifty site.

\subsubsection{Discussion of Uncertainties in the Risk Estimates}

Values calculated using analytical techniques generally have uncertainties that reflect the more basic uncertainties associated with the parameters used and with the models used. There is also an additional uncertainty assoclated with risk analysis that is related to how well the scenarto descriptions and probability estimates truly reflect reality. These general sources of uncertainty in risk analysis were discussed in Chapter 2.0. The risk values used in this section were based on the results of calculations by others. Since little or no uncertainty data was provided in the references reviewed, this section only addresses the reasons for possible vartations in calculated results. The reasons can, for the most part, be related to inconsistencies in the parameters chosen, different assumptions, and different definttions.

A general level of uncertainty in the risk estimates was estimated based on the ranges of results presented in the documents reviewed. For example, the occupational radiological doses for construction of the repository in salt ranged from 8.0E-6 to 2.OE-3 LHE/yr (DOE 1980, 1986f). The occupational construction doses for the other two potential repository sites were much closer together (less than a factor of 10). The primary reason for the large difference between the construction doses for the potential salt reposttory was the assumptions regarding the dose rate in the underground portions of the repository. Additional data are needed to develop more realistic exposure estimates.

Routine public doses during construction also exhibited similar levels of uncertainty. The potential salt repository construction doses ranged from 3.OE-7 to 5.OE-4 (DOE 1980, 1986b,c,d). The estimates for the basalt and 
salt sites were factors of 2 and $15 \mathrm{different,}$ respectively. Again, better data on the radionuclide content of bedded salt, as well as tuff and basalt, are needed to develop better estimates.

As indicated in Table 4.24, routine occupational dose estimates during the operations phase ranged from about 17 (Isakari et a1. 1980) to about 260 person-rem/MTU of spent fuel processed. These estimates are only about a factor of 15 apart, which is considered to be a small uncertainty given the preliminary nature of the studies reviewed.

Public exposures from routine operations were quantified in only one study, which utilized conservative assumed release source terms for spent fuel consolidation operations. The methods used to estimate population doses were adequate, and the best available site-specific weather data and population distributions were used. As a result, it is believed that the routine population dose estimates derived in this section will be at or near the upper end of the range of actual doses.

Al1 categories of decommissioning risks and exposures have large assoclated uncertainties. The plans and procedures for these activities are not yet well defined. None of the studies reviewed adequately addressed repository decommissioning risks. Closure of the subsurface factlities is an area in which little or no risk information is available.

The nonradiological risk values presented here are considered to be conservative. These estimates were based on fatality rates for industrial facility construction and underground mining activities. The surface facility construction fatality rate is probably adequate for preliminary estimates, but could be made more realistic by developing fatality rates for specific construction activities (e.g., concrete work, structural steel work, heavy equipment operations, etc.) and combining them with a similar breakdown of personnel requirements. More detailed personnel requirements for these activities are also needed. An additional level of conservatism arises from using the surface facility construction fatality rate to calculate fatalities from surface facility operations. In general, construction is much more hazardous than operations. 
The underground mining fatality rate could also be refined to reflect differences in mining operations at the sites. For example, the potential salt repository is planned to be excavated using boring or drilling equipment, whereas basalt and tuff repositories are planning to use conventional dri11-and-blast techniques. The differences in fatality rates for these processes should ultimately be reflected in more realistic nonradiological risk estimates.

An important source of uncertainty in the public and occupational accident risk estimates is the lack of a comprehensive evaluation of all posstble accident sequences. Although several different accidents have been evaluated, there is no assurance that the most important accident sequences, or risk-dominant accidents, were considered. Most accident assessments emphasized the "worst-case" or "maximum-credible" accidents, which produce the highest offsite doses. However, these accidents are generally characterized by a very low frequency of occurrence, which causes the individual risk values for the accidents to be low. It is likely that relatively frequent accidents that produce relatively low population doses are the riskdominant accidents. This point is illustrated by Jackson et al. (1984) in which a relatively frequent accident (fuel assembly drop) with small offsite doses contributes a large fraction of the total annual risk. Consequently, the accident risk values estimated in Section 5.1.1 probably linderestimate the actual risks.

An overview of some of the more important basic areas in which input data between two or more independent calculations can differ is shown on Figure 5.1. Under "waste characterization," for example, varying age and burnups for the waste material were used in a number of the studies reviewed. Some studies assumed spent-fuel assemblies only, while others assumed only other types of waste such as vitrified commercial high level waste. Under "inventory," the "process rate" of waste through the repository, for example, was different in a number of the reports that were reviewed. The "release fractions" were not mechanistically established and varied among studies. In no case was the transport of the radioactive materials in the facility mechanistically treated. Some assumed a plate-out and settling fraction; others did not. Some assumed filtration before release to the environment; some did 


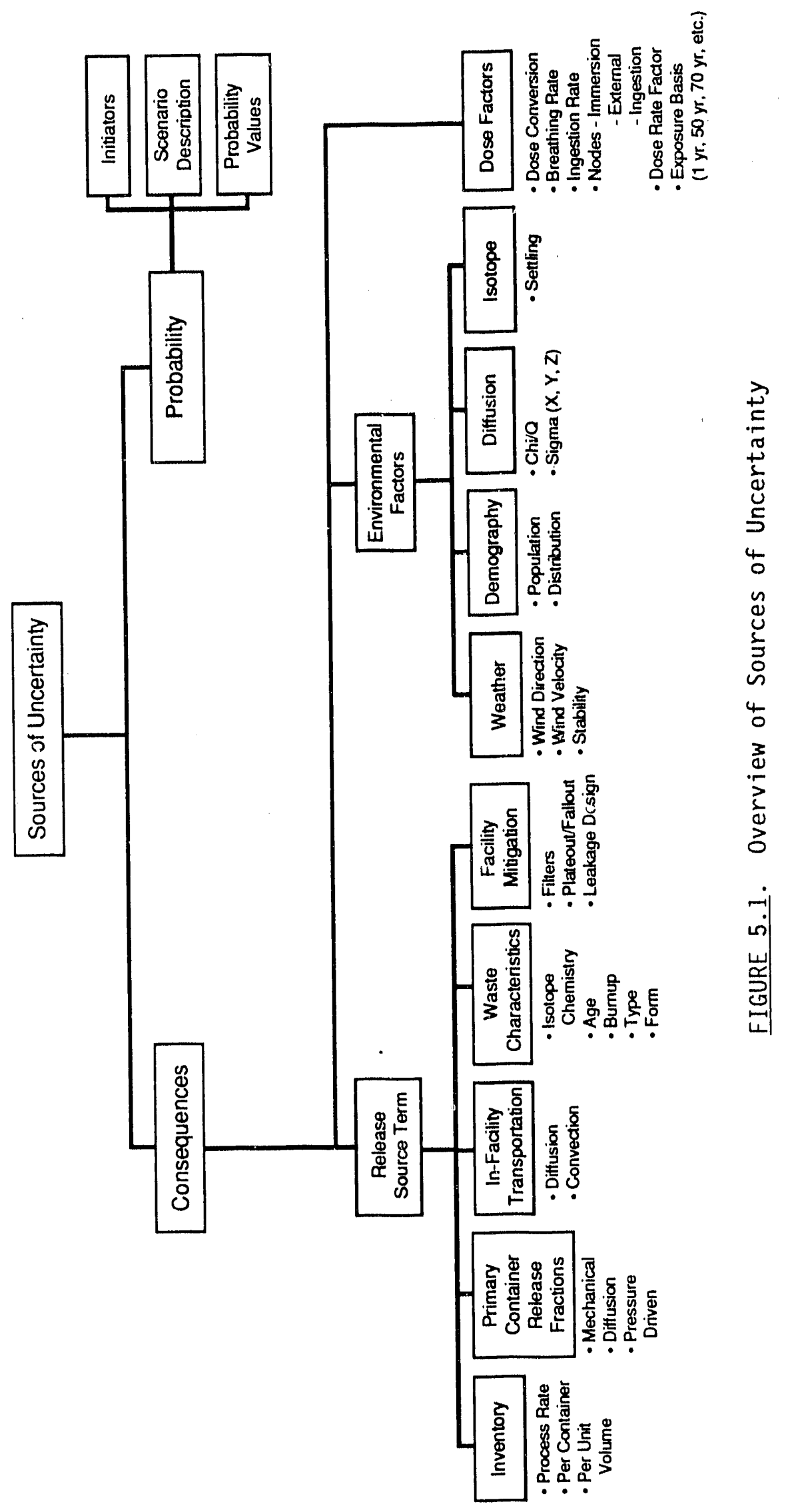

5. 13 
not. For those that did assume filtration, varying filter efficiencies were used. Once in the environment, some studies applied generic weather, demography, and diffusion data to all sites while others were more site-specific. Even when generic data were used, the values selected sometimes differed among studies. There were also differences in the bases for the dose estimates. Some used a 50-year commitment period, others used a 70-year period. Some studies calculated first-year doses while others added a commitment period following the release period.

In general, there has been little or no attempt to perform studies in a consistent manner that allows a comparison of absolute risk values among facility designs, siting alternatives, and system configurations. One can, at most, only estimate a general level of the risk associated with the various elements of the repository. This, in turn, provides an initial identification of the areas of concern. With the available data, relative risks could be clearly determined only when the risks differ by orders of magnitude. There is a clear need in future studies to establish consistency and to apply a more deterministic methodology, to preclosure safety analyses, especially in those areas to which the results are most sensitive.

Additional areas in which future work is needed to reduce the uncertainties in repository preclosure risk estimates include the following:

- The physical, chemical, and mechanical conditions produced in accidents need to be correlated with the behavior of waste materials and radionuclides under these conditions to develop more accurate accident release source terms. More definitive source terms of routine releases are also needed.

- Site-specific meteorological and demographic data should be used to calculate population doses. A number of computer codes that provide reasonable results are available but the specific code used is not as important as the input parameter data used to estimate atmospheric dispersion and radionuclide uptake by the surrounding population.

- Cose rates are normally based on maximum permissible radiation levels in occupied areas. This is a very conservative approach.

- Pessimistic assumptions are typically used for the efficiency of filtered ventilation systems. Realistic decontamination factors, based on experimental data, should be developed. 
- Task descriptions, exposure times, and distances from radioactive sources are subject to uncertainty because of the conceptual nature of facility designs. Therefore, more definitive estimates will be available when facility design details become finalized.

- A consistent set of nonradiological fatality rates for specific construction and operations activities needs to be developed.

- Plans and procedures for decommissioning and retrieval phases need to be developed so that the radiological risks and exposures can be estimated.

\subsection{REPOSITORY POSTCLOSURE RISKS}

This section presents the most representative and credible of the available postclosure repository risk estimates for hypothetical repositories in basalt, salt, and tuff. The nature of postclosure performance or risk assessment, and representative published assessments, were described in Section 4.2 .

\subsubsection{Postclosure Risk Values}

The differences in results from the studies reviewed in Section 4.2 in large part reflect the different purposes for which the studies were done. Some studies presented preliminary assessments of performance standards. The nature of the performance standard dictates whether the results were expressed in terms of health-effects, doses to maximally exposed or representative individuals, population dose, fraction of background radiation, or cumulative radionuclide releases to a boundary within the geosphere. Differences in the regulatory time frames being addressed may also vary from 10,000 years to over 1 million years. These differences among postclosure analyses tend to be greater obstacles to comparing results than differences in the assumed inventories or in the functioning of the engineered barrier system, given rough comparability in the natural system conceptualization and data.

In considering the comparisons that are discussed below, it must be remembered that the studies presented very preliminary work, used presitecharacterization data from a variety of non-site-specific sources, and were exploratory in terms of the analytical tools used. The presence or absence 
of intrusive and disruptive event scenario consequence analyses is important in determining the completeness of a risk analysis, but if a probability other than unity is assigned for a given scenario, the defensibility of the assigned probability becomes an open question. And if a probability of unity is assigned, the results may be overly conservative. Nevertheless, an effort is made to place, on a roughly comparable basis, all the performance estimates judged to represent the better of those available by the criteria of Table 4.1 .

\subsubsection{Risks for a Hypothetical Repository in Tuff}

The tuff environmental assessment (DOE 1986b) was selected from the available Titerature using the criteria described in Table 4.1. This environmental assessment reported preliminary performance assessment results that addressed the EPA standard, but only for the expected case. It did not consider intrusive or disruptive event scenarios. The expert panel on site selection felt that the appearance of unexpected features and the occurrence of extrusive magmatic events were scenarios that should be evaluated for the Yucca Mountain location (DOE 1986f). The latter scenario was considered to have a low probability, however. The DOE (1988) discussion of the existence of nearly 9,000 independent scenario classes suggests that site characterization and other investigations including performance assessments and sensitivity analyses needed to provide a basis for screening out low-probability/ low-consequence scenarios prior to the performance of a licensing assessment.

Also selected from the literature was the analys is by Siegel and Chu (1983) because it addressed the unexpected features scenario by assuming a number of different site system descriptions that were considered likely by these authors. Some are more likely than others, however, and the results of the more normative cases (e.g., mixing cell model rather than leach-rate model for source term, no significant changes in the height of the water table, occurrence of reversible sorption in certain tuff formations) were considered in this evaluation. A potential saturated tuff repository was assumed, and that assumption was labeled conservative by the authors.

Although a conservative label suggests erring on the side of safety, it may be that in the case of Yucca Mountain a saturation assumption was simply 
unrealistic. Nearly all the analyses that resulted in showing releases in excess of the EPA standard were described as cases where the stochastic technique had selected hydraulic property values that resulted in unrealistically high flow rates. The assumed existence of a flowing well 1 mile from the potential repository needs further evaluation as to likelihood, but it is the assumed location of radionuclide discharge to the accessible environment in most of the scenarios considered by Siegel and Chu (1983).

The third study selected using the criteria of Table 4.1 was the simplified analysis of Thompson et al. (1984). This study was selected because it provided a population dose estimate. Their estimate was used here after adjustment for newer information on repository size and on the likely water flux through Yucca Mountain, as given in the Yucca Mountain environmental assessment (DOE 1986b).

The fourth and last analysis selected for comparison was the EPA (1985b) work that has also been cited for the basalt and salt risk evaluations. It: was included because it is complete, even though its assumption of a generic river scenario, as in the EPA generic release/health-effects conversion, was particularly inappropriate for this arid site and may not be conservative. However, the assumed population density for this generic case was inappropriately high for the tuff site and may compensate for the other possibly nonconservative assumption. The comparison is made in Table 5.4.

The Table 5.4 comparison is a difficult one to judge. Of all the analyses, DOE (1986b) reflected the best conceptualization of the site, and Thompson et a1. (1984) results appeared to be the next most appropriate and most complete. The Siegel and Chu (1983) work was complete, but its unrealistic hydrologic parameter variations made it less appropriate. The EPA (1985b) work seemed the least appropriate. Both the Siegel and Chu (1983) and Thompson et al. (1984) analyses assumed wells, but at different locations.

The adjusted Thompson et a1. (1984) results in Table 4.30, approximately $1 E-3$ health effects per year, probably should be considered the more reasonable upper limit interim risk estimate until new, more complete and 
TABLE 5.4. Population Health-Effects (Premature Cancer Deaths per Year) for a Hypothetical Repository in Unsaturated Tuff

Health Effects

$1.0 \mathrm{E}-19(\mathrm{a})$

$2.0 E-1(b)$

$7.0 \mathrm{E}-4(\mathrm{C})$

$3.0 \mathrm{E}-4(\mathrm{~d})$

\author{
Rock Type \\ Unsaturated tuff \\ Saturated tuff \\ Unsaturated tuff \\ Unsaturated tuff
}

\author{
Modified From \\ DOE (1986b) \\ Siegel and Chu (1983) \\ Thompson et a1. (1984) \\ EPA (1985b)
}

(a) Approximated using the $<1.0 E-7$ (rounded off to E-7) EPA 1imits released over the first 10,000 years, times 10 health-effects per 10,000 years per EPA standard release, divided by 10,000 to approximate an annual risk. Expected case only, no intrusive or disruptive scenarios evaluated.

(b) Approximated using the 1.8-2.2 range of the base cases (rounded off to 2.0) EPA limits released over the first 10,000 years with a cumulative probability slightly above 0.99 , times 10 health-effects per 10,000 years per EPA standard release, divided by 10,0000 to approximate an annual risk. Undue conservatism stemming from unrealistic flow rates suspected but not quantifiable.

(c) Approximated using the summed 5200 person-rem/70-yrs population dose, divided by 70 to approximate an annual dose, multiplied by 2 to reflect new inventory assumptions, divided by 4 to reflect new water flux estimates, divided by 10 to reflect current waste-form dissolution rate estimates, and by 5,000 to convert to a healtheffects estimate. A 10,000 person regional population is assumed, and the exposure scenario is a water well located $10 \mathrm{~km}$ from the potential repository. This 250,000-year peak value is used to compensate for the we $11^{\prime} \mathrm{s}$ being at $10 \mathrm{~km}$ rather than at $5 \mathrm{~km}$, which is the accessible environment boundary.

(d) Obtained by dividing the 3.44 total expected population healtheffects for the 10,000-year regulatory period by 10,000 to approximate an annual risk.

site-specific analyses can be done. Tiis risk is equivalent to the risk of cancer death from exposure to natural and authropogenic radiation sources in current society.

\subsubsection{Discussion of Uncertainties in the Risk Estimates}

There are a number of sources of uncertainty in postclosure risk assessments: 
- Uncertainties in the data, which include such issues as the completeness of the site characterization, spatial variability, and measurement error.

- Uncertainties in the conceptualization of the system and in the identification of its operative processes.

- Uncertainties in the model of the conceptual system and its operative processes.

- Uncertainties stemming from the need to estimate frequencies of low probability events by the use of conservative estimates where little is known, and bounding estimates where essentially nothing is known. (This source of uncertainty is addressed below.)

In the particular studies used in this section, some more particular observations may be made regarding uncertainties. For example, the preliminary performance assessment in the repository environmental assessment (DOE 1986b) used the most credible site-specific data. However, their scopes were limited to the evaluation of the expected case. The evaluation of lowprobability, disruptive, or intrusive event consequences for a specific site, to be credible, must be based on site-specific data. Since relatively little site-specific data was currently available, scenario consequence analyses were not deemed appropriate at this time.

The work done in support of the NRC by Pepping et a1. (1983a,b,c), by Siegel and Chu (1983), and by EPA (1985b) did evaluate unexpected events and consequences because the objective of this work was to demonstrate a methodology for doing such analyses to evaluate the proposed or final regulations, or both. Although best estimates were used for probabilities where possible, and unity (certain occurrence) was assumed for the probability of more likely intrusive events, these studies were not based on sufficiently credible site-specific information to make them definitive. Their major contribution was to provide examples of how the regulatory compliance calculations may be done. Their use of generally conservative assumptions regarding intrusive events and consequences, as well as in the assumed ranges of site parameters, made it likely that their results provide conservative bounding risk estimates.

The Swedish work cited as an analog for a basalt repository (see Section 4.2.1.8) was an attempt at conservatively modeling the risk resulting 
from the expected performance of a waste disposal system in fractured rock beneath the water table. That this work was indeed conservative was supported by the work done in Switzerland (NAGRA 1985), which similarly attempted to model the risk from a system in granite. In the NAGRA assessment, however, an attempt was made to be realistic, as well as conservative, in the choices of parameter values. Conservative values were selected from ranges of realistic estimates, where available, for a given parameter. The resulting peak risk was about 4 orders of magnitude below that calculated in the Swedish analysis. NAGRA's expectation was that as site-specific data became available and even more realism was allowed in the risk assessment, risk estimates would be reduced even further.

The simplified analysis of risks from a hypothetical repository at Yucca Mountain (Thompson et a1. 1984) was also an attempt at a simple, conservative, scoping calculation of long-term repository consequences and risks. Although there was great uncertainty in every aspect of these simplified calculations, there is reason to believe that the conservative nature of the analysis makes it likely that this scoping analysis overestimated the risks.

The numbers cited above in Section 5.2.1 are highly uncertain. The expectation is that these estimates will be found to be conservative as sitespecific data becomes available, and the data ranges used in system risk analyses are adjusted. The use of the generic conversion of EPA release limits to health-effects in Section 5.2.1 contributes uncertainty and conservatism in every case except, perhaps, the tuff case. The tuff location is an arid site where only a groundwater pathway is plausible. Therefore, postulating a generic river pathway, as in the EPA analysis, introduced an inappropriate dilution factor. On the other hand, the population that could be exposed through the groundwater pathway is much smaller than that assumed in the generic EPA model, which may compensate for the nonconservative assumed river pathway. The numbers recommended as interim risk values above may all be considered conservative bounding estimates. 


\subsection{MRS FACILITY RISKS}

The risks of construction, operation, and decommissioning of the potential MRS facility are estimated in this section. The review of documents to provide the basis for these estimates was presented in Section 4.3. This section discusses the adjustments made to the risk values in the ifterature to normalize them to the system parameters assumed for this study. To the extent possible, the values in the literature were normalized to a 3,000 MTU/yr throughput rate, and a 15,000 MTU maximum storage capacity. Nonradiological risk estimates are also presented in this section. Uncertainties are discussed in Section 5.3.2.

\subsubsection{MRS Facility Risk Values}

This section describes the calculations that were performed to normalize or adjust the risk values found in the literature to a common basis. In general, the risk values were normalized in terms of facility throughput rate and capacity to address the system configuration described in Chapter 3.0 . Separate subsections aie presented for radiological and nonradiological risk categories. Some wastes will likely be shipped directly to the repository after being consolidated and packaged at the MRS facility. Decisions about the amount of waste that would be handled in this way have not yet been made. For conservatism, the risk estimates developed here assume that all waste received at the MRS facility is stored for several years before being shipped to the repository for disposal.

\subsubsection{Radiological Health Risks}

Public and occupational radiological risks were estimated for operation and decommissioning of the MRS facility. Radiological risks during construction were neglected because there were no radioactive materials onsite during construction and excavation operations were not expected to release significant quantities of radionuclides (DOE 1985g).

Occupational radiation doses were generally calculated by task and were the product of the dose rates at specific locations within the facility where 
a specific task was performed and the amount of time the worker was exposed to this specific radlation field. Unless otherwise noted, the results are expressed as collective doses.

Routine occupational radiation doses were estimated for radiation workers at the MRS factlity by Harty and Stoetze1 (1986), Schneider et al. (1986), and in the MRS facility environmental assessment (DOE 1985g). These values were used here because they were directiy applicable to the MRS fact1ity design. Minor adjustments were made to reflect differences in throughput rate assumptions. It should be noted that these estimates were based on maximum permisstble dose rates in occupied areas. Actual dose rates in these areas wil1 be lower.

Preliminary estimates for the task doses associated with spent fuel receipt, storage, and shipment were given in Table 4.49 (Harty and Stoetzel 1986). The collective occupational dose estimate was 318.7 person-rem/year for a 3,600 MTU/yr facility. The occupational dose estimates presented in the MRS facility environmental assessment (DOE 1985g) amounted to 95 personrem/1,000 MTU. Schneider et a1. (1986) estimated total occupational doses for shipping cask receiving and handling and spent fuel consolidation functions at 63 person-rem/1,000 MTU, after adjustments were made to reflect a $30 \%$ truck $/ 70 \%$ rafl shipping split. After adding the occupational doses given in DOE (1985g) for handling consolidated fuel rods, maintenance/monitoring, and emplacement/ retrieval functions (31 person-rem/1,000 MTU), the doses estimated by Schneider et a1. (1986) amounted to 94 person-rem/1,000 MTU. Assuming occupational exposures are approximately linear with respect to throughput rate, these estimates become about 266, 285, and 258 person-rem/yr for a 3,000 MTU/yr facility. A risk value of 285 person-rem/yr (6E-2 LHE/yr) was used in this study.

Radiological doses to the public from routine operation of the MRS facility were dominated by airborne effluents. At the MRS facility, this was primarily from the venting and unloading of incoming transportation casks and from spent fuel disassembly and consolidation operations. DOE (1985g) estimated 50-year dose commitments to the surrounding population from annual emissions for four specific organs. These organ-specific doses were 
converted to equivalent whole body doses using weighting factors recommended by the International Cominission on Radiological Protection (Waite et al. 1986) and then converted to untts of LHE/yr using the health effects converston factor (2.0E-4 LHE/person-rem). The annual population risk estimate shown in Table 5.5 is 5.1E-3 LHE/yr, integrated over an area within a 50-mile radius. Bechtel (1979) reported estimates ranging from 6.7 person-rem/year (1.3E-3 LHE/yr) total body dose for a single processing/ericapsulation ( $P / E)$ factlity to 36 person-rem/year (7.2E-3 LHE/yr) for an away-from-reactor (AFR) storage facility with a capacity of 5,000 MTU. Both of these estimates assumed 1-year-old incoming fuel, and wet cask unloading facilities and procedures. After adjusting these estimates to reflect a 3,000 MTU/year throughput rate, the resulting risk estimates ranged from 13.4 personrem/year (2.7E-3 LHE/year) to 194 person-rem/year (3.9E-2 LHE/year) for the $P / E$ and AFR facilities, respectively. No adjustments were made to reflect the differences in risk due to fuel age and dry cask handing factilties and procedures at the MRS facility. Therefore, a representative range of population risk estimates was established of 3E-3 to 4E-2 LHE/yr (Bechte1 1979). The estimates developed for the MRS factitty environmental assessment fell about in the middle of the range. This value was used for this risk category. TABLE 5.5. Annual Radiological Rjsk from Routine Emissions
from the MRS Facility a)

\begin{tabular}{|c|c|c|c|}
\hline Organ & $\begin{array}{l}\text { 50-Year Dose } \\
\text { Commitment } \\
\text { (person/rem) }\end{array}$ & $\begin{array}{l}\text { Equivalent Whole- } \\
\text { Body Dose } \\
\text { Converston Factor (c) }\end{array}$ & $\begin{array}{c}\text { Equivalent Whole- } \\
\text { Body Dose } \\
\text { (person-rem/yr) }\end{array}$ \\
\hline Total Body & $2 E+1$ & 1.0 & $2.0 E+1$ \\
\hline Bone & $1 E-1$ & 0.12 & $1.2 E-2$ \\
\hline Lungs & $2 E+1$ & 0.12 & $2.4 \mathrm{E} 00$ \\
\hline Thyroid & $1 E+2$ & 0.03 & $3.0 E 00$ \\
\hline Total & & & $\begin{array}{l}2.5 E+1 \\
(5 E-3 \text { L.HE/yr) (d) }\end{array}$ \\
\hline
\end{tabular}

(a) Source: $\operatorname{DOE}(1985 \mathrm{~g})$.

(b) Doses to surrounding population within 80 kilometers (50 miles).

(c) Source: Waite et a1. (1986).

(d) Health effects conversion factor of $2 E-4$ LHE/person-rem was used. 
Occupational radiological exposures resulting from accidents at the MRS factlity are taken from Jackson et a1. (1984). The Jackson study estimated accident consequence for repository surface facilities. No evaluation of MRS or spent fuel storage facllity occupational accidents was found in the 1tt. erature. Results from the fuel assembly drop in the hot cell at the repost tory were considered comparable to results expected at the MRS facility and were used here.

Jackson et a1. (1984) estimated a first year total body dose commitment of 8.1E-3 rem for reposttory personnel from a fuel assembly drop accident in a hot ce11. In the case of the repository, it was assumed that all surface and subsurface personnel were equally exposed as a consequence of the accident. Assuming an MRS facility operations staff of 852 (Parsons 1985) and a frequency of 0.1 fuel assembly drop accidents per year releasing radioactive material from the fuel rods (Jackson et a1. 1984), a conservative occupational dose estimate of 0.69 person-rem/yr $(1.4 \mathrm{E}-4 \mathrm{LHE} / \mathrm{yr})$ due to the accident was calculated.

Public radiological exposures that would result from releases associated with MRS facility operational accidents were evaluated in DOE (1985g), the GEIS (DOE 1980), Ligon et a1. (1983), and Orvis (1984). Population dose estimates for three hypothetical accidents were developed in the MRS facility environmental assessment (DOE $1985 \mathrm{~g}$; see Table 4.43 of this report). No probabilistic bases for these accidents were developed. To estimate the risks of these accidents, it was assumed that the frequency of a spent fuel assembly drop was $0.1 /$ yr (Jackson et a1. 1984), and the frequenctes associated with the shipping cask drop and the storage cask drop were a factor of 10 or less. The organ-specific doses given in the MRS facility environmental assessment were converted to an equivalent whole-body dose value, as discussed previously (see Waite et a1. 1986). The effective public risk estimate was approximately $8.3 \mathrm{E}-7 \mathrm{LHE} / \mathrm{yr}$.

Ligon et al. (1983) developed estimates of accident risks for a drywe11 storage facility operating at a throughput rate of about $900 \mathrm{MTU} / \mathrm{yr}$. A more comprehensive set of accident scenarios was analyzed by Ligon et al. than were analyzed in the MRS facility environmental assessment. The sum of the 
risk values for these accidents was 1.7E-3 LCF/yr (see Table 4.46). Ligon used a health effects converston factor of $1.35 \mathrm{E}-4 \mathrm{LCF} /$ person-rem. The risk value estimated by Ligon was adjusted to reflect the different health effects conversion factor used in this study (2.0E-4 LHE/person-rem) and the different facility throughput rate $(3,000 \mathrm{MTU} / \mathrm{yr})$. Therefore, the adjusted accident risk value based on the analyses presented by Ligon et al. (1983) was $8.4 \mathrm{E}-3 \mathrm{LHE} / \mathrm{yr}$.

Orvis (1984) also evaluated a more comprehensive set of accident scenartos than was evaluated in the MRS factitty environmental assessment. The risk value for cask storage estimated by Orvis was 2.6E-4 LCF/yr. These values were based on an annual throughput rate equal to 1 year's reactor discharge of spent fuel (60 PWR assemblies/yr or about $30 \mathrm{MTU} / \mathrm{yr}$ ). The health effects conversion factor used was 1.0E-4 LHE/person-rem. The risk value was 4.6E-2 LHE/yr after adjusting the health effects conversion factor and normalizing to a $3,000 \mathrm{MTU} / \mathrm{yr}$ throughput rate.

The final document in which accident risks were estimated was the GEIS (DOE 1980). Only two accidents were evaluated, as shown in Table 4.51. Population doses were estimated only for the package fatlure accident. To estimate the population doses for the fuel assembly drop accident, the dose from the package-fatlure-accident was multiplied by the ratio of maximum individual exposures that were given for both accidents. This ratio was about 10 , so the population dose estimate for the fuel assembly drop accident was $3.2 E-2$ person-rem/event. The sum of the risk values for the two accidents was estimated at 3.5E-3 person-rem/yr or 7.0E-7 LHE/yr.

The range of the MRS facility accident risk estimates developed in the 1 iterature was about 7.0E-7 to $4.6 \mathrm{E}-2 \mathrm{LHE} / \mathrm{yr}$. The more comprehensive studies fell near the top of the range and the studies in which only 2 or 3 accidents were analyzed were near the bottom of the range.

The risk value to be used in Section 5.6 to estimate total system risks was estimated as follows. First, it was noted that the population dose estimates developed in the most comprehensive studies (Orvis 1984; Ligon et al. 1983) were based on "worst-case" meteorological and population assumptions. This was not the case for the repository accident dose analyses 
presented by Jackson et a1. (1984) and Waite et a1. (1986) and the dose ana1yses for MRS faciltty accidents (DOE 1986g). To make the MRS facilitiy accident risk values more consistent with the repository accident risk values, the MRS factlity accident frequencles from Orvis et a1. (1984) were combined with the results of the population dose analyses presented in DOE (1985g) to calculate annual MRS facility risks. The resulting annual accident risk value for the MRS facility was 8.3-7 LHE/yr. This value is more comparabie to the repository preclosure accident risk values estimated in Section 5.1.

Decommissioning of the MRS facility has associated radiological risks for decommissioning personne1. Estimated occupational radiation doses accrued during various decommissioning alternatives were estimated by Ludwick and Moore (1984). The reference cask Independent Spent Fuel Storage Installation (ISFSI) configuration was chosen as most representative of the sealed cask MRS factilty. The immediate decommissioning operations applied to the fuel storage area for the cask ISFSI resulted ill an estimated dose of 12.5 person-rem. This figure was based on a maximum capacity of 2,000 MTU of LWR fue 1 and 46 man-months for immediate decommissioning. Assuming that the dose increases with increased fuel storage capacity for a 15,000 MTU storage facility, the estimated exposure associated with decommissioning may increase to 94 person-rem. A hot cell was not associated with the reference cask ISFSI. However, this major facility was included as a component of the reference vault, drywe11, and s110 ISFSIs. Immediate decommissioning of the hot cel1 was estimated to require 34 man-months of labor and result in a total occupational dose of 111.8 person-rem. If the hot cell decommissioning requirements for the MRS facility remained the same, the total exposure was approximately 205 person-rem. Ralph M. Parsons Company (Parsons 1985) estimated a 9-year decommissioning effort at the MRS factlity that resulted in an occupational radiological exposure estimate of 23 person-rem/yr (4.6E-3 LHE/yr). Bechtel (1979) estimated a 23 person-rem/yr (4.6E-3 LHE/yr) exposure estimate prorated over the lifetime of the operating years for decommissioning the surface facilities at a repository, which is the same as the value based on data in Ludwick and Moore (1984). As a result, 4.6E-3 LHE/yr was used to estimate total system risks. 
The occupational accident risks associated with decommissioning an MRS facility have not been extensively analyzed. However, Bechtel (1979) estimated risks from abnormal conditions associated with decommissioning a repository. These data were generated by comparing repository handling with handling and process operations at a modern reprocessing facility and estimating prcbable doses by adjusting the amounts of waste handled, the number of personnel associated with decommissioning tasks, and the length of time required for the tasks. Estimates in this study were based on the assumption that decommissioning of surface hot cell and fuel handling facilities would produce the most significant occupational doses and that these facilities would be similar when comparing the repository and the MRS facility. When considering the decommissioning of the additional surface storage facilities at the MRS facility, estimates given here may tend to be lower-bound figures. The estimated occupational dose associated with abnormal decommissioning occurrences, prorated over the operating years, was approximately 16 person$\mathrm{rem} / \mathrm{yr}(3.2 \mathrm{E}-3 \mathrm{~L}$.HE/yr).

Decommissioning of the MRS facility is expected to produce a small routine dose to the public, primarily due to airborne effluents released during decommissioning operations. The transportation of radioactive wastes generated during decommissioning to a disposal facility has not been addressed at this time. The public radiation dose for routine releases during immediate decommissioning was estimated to be $5.6 \mathrm{E}-7$ person-rem at a reference ISFSI (Ludwick and Moore 1984). This value represented a 50-year dose commitment equivalent to the lung for a total population within a 50 -mile radius of the site. The estimated lung dose was con ated to an equivalent whole body dose using the method described by waite et al. (1986, see Table 5.5). The resulting whole body dose equivalent was $6.7 E-8$ personrem. Immediate decommissioning of the reference ISFSI was estimated by Ludwick and Moore (1984) to require an average of 0.8 years of active decommissioning following shutdown. This yielded a public radiation dose estimate of 8.4E-8 person-rem/year (2E-11 LHE/yr).

Public dose estimates for releases resulting from accidents during decommissioning of the MRS facility are anticipated to be extremely small. No quantitative estimates were found in the literature.

\subsection{7}


The normalized radiological health risks estimated in this section are summarized in Table 5.6 .

\subsubsection{Nonradiological Health Risks}

This section develops the nonradiological health risks for the reference MRS facility. Occupational accident risks associated with facility construction, operation, and decommissioning will provide the greatest nonradiological risk. Other nonradiological risks to onsite personnel due to routine operations and risks to the public during routine and accident events were considered to be negligible.

Nonradiological accident risks for the MRS facility, 1isted in Table 5.7, were calculated using the same methods that were used to estinate repository accident risks. The fatality rate for the above-surface workers at a repository (see Section 5.1.1) were used to develop these estimates. The annual work force estimates were based on a construction phase of 4.25 years, an operational phase of 27 years, and a 9 -year decommissioning phase (DOE 1986g). All work-force estimates were taken from the MRS facility conceptual design report (Parsons 1985).

Construction and operation of the MRS facility will generate additional traffic-related fatalities from workers traveling to and from the site. As was done for the repository, these risks were included for the MRS facility. The annual traffic-related fatalities for the MRS facility were estimated

TABLE 5.6. Estimated Annual Radiological Rjsks from the MRS Facility, LHE/yr(a)

Operating Phase/Medium

Construction

Operations

Decommissioning

$$
\begin{aligned}
& \text { Publi } \\
& 5 E-3
\end{aligned}
$$

$2 E-11$

\section{Routine} No Radioactive Materials on Site

(a) LHE includes latent cancer fatalities plus first and second generations genetic effects. 
TABLE 5.7. Annual Nonradiological Accident Risks

for the MRS Facility by Phase

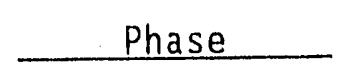

Construction

Operations

Decommissioning
Annual Nonradiological Risk (fatalities/year)

Site Related (a

0.18

1.4

1.6

0.29

1.6

1.9

0.04

0.1

0.14

(a) Based on annual labor force requirements given in Parsons (1985) of 543 construction workers, 852 workers during the operations period, and 18 workers during decommissioning. Fatality rate of 0.17 fatalities $/ 10^{6}$ man-hrs was used (DOE 1986f).

(b) Includes worker as well as potential public fatalities.

using information published by DOE (1988) for the repository. These risks are a function of the number of workers that will be traveling to and from the site, the average distance they travel, and the traffic fatality rate on the roads they will be traveling. Assuming the latter two parameters are approximately the same for the MRS facility and the repository, the trafficrelated MRS facility risks can be estimated by multiplying the repository traffic-related fatalities given in DOE (1988) and the ratio of MRS facility labor requirements to those of the potential repository. The resulting annual fatality estimates were given in Table 5.7 as well as the total site plus traffic-generated annual fatalities. As shown, the traffic-generated fatalities are significantly jurger than the fatalities generated at the MRS facility site.

The greatest nonradiological health risk impact to the public is expected to occur during construction from temporary degradation of air quality. Estimates of fugitive dust during the peak periods of construction incluciad emissions levels above 50 tons per year. This exceeds the EPA's regulatory significant level for total suspended particulate (TSP). Table 5.8 gives annual emission estimates for TSP and combustion products from mobile sources as estimated for construction and operation at the MRS facility. EPA significant levels are included for comparison (DOE 1985g). These emissions are expected to cause negligible public health effects. 
TABLE 5.8. Estimated Emissions from Construction and Operation and EPA's "Significant" Levels for Emission [from 40 CFR 51 (ton/yr)]

\begin{tabular}{|c|c|c|c|}
\hline \multirow[b]{2}{*}{ Pollutant } & \multicolumn{2}{|c|}{ Annual Emissions (a) } & \multirow{2}{*}{$\begin{array}{c}\text { Significant } \\
\text { Level }\end{array}$} \\
\hline & Construction (b) & Operation(c) & \\
\hline TSP & $>50$ & $<5$ & 25 \\
\hline $\mathrm{NO}_{\mathrm{x}}$ & & 18 & 40 \\
\hline $\mathrm{SO}_{\mathrm{x}}$ & & 28 & 40 \\
\hline co & & 5 & 100 \\
\hline
\end{tabular}

\footnotetext{
(a) Source: DOE (1986g).

(b) Mobile sources are not included.

(c) Includes boiler emissions and TSP from adjacent cask manufacturing plant.
}

\subsubsection{Discussion of Uncertainties in the Risk Estimates}

One of the largest sources of uncertainty in the risk estimates for the MRS facility is the specific functions that will be performed at the facility. As discussed in Chapter 3.0, the MRS facility may be a spent fuel storage-only configuration, or it may also include the capability to consolidate fuel and/or prepare the repository disposal packages. For example, the public and occupational routine dose estimates for the MRS facility indicate the results are highly dependent upon whether or not fuel is consolidated. In addition, the transportation doses in the MRS systems will also depend upon whether or not fuel consolidation is performed because it has major impacts on the number of shipments transported from the MRS facility to the repository. Because the risk estimates for the MRS facility were developed assuming that fuel consolidation would be performed, the results presented in this section would tend to overstate the risks of a storage-only MRS facility and may understate the risks of a MRS facility that includes storage, fuel consolidation, and repository disposal packaging capabilities. The reader is therefore cautioned to note these uncertainties when using the results presented in this section. 
As with repository preclosure accident assessments, a comprehensive identification and evaluation of all possible MRS facility accident sequences has not been performed. Thus, there is no assurance that the risk-dominant accident sequence(s) have been analyzed. As discussed in Section 5.3.1, the accident risk estimates in the literature ranged from $7.0 \mathrm{E}-7$ to

\subsection{E-2 LHE/yr.}

Occupational routine radiation dose estimates from three studies (Harty and Stoetzel 1986; Schneider et a1. 1986; DOE 1986g) were relatively close to each other at about 300 person-rem/yr. This was judged to be accurate within $\pm 50 \%$, given thai they were based on detailed time-and-motion studies of conceptual MRS facility operations. These estimates were based on "hands-on" cask handling operations, which dominated the occupational doses. Improvements to this dose value could be obtained by designing the cask R\&H facilities to include robotics and/or more remote operations.

The uncertainty in the public routine doses given in the MRS facility environmental assessment is also probably relatively small. The methods and data used were relatively detailed and comprehensive. The largest source of uncertainty is the estimated routine emissions, which are believed to be conservative. As a result, it is judged that the routine population doses estimated in the MRS facility environmental assessment are conservative and tend to overestimate the actual doses.

A1: of the decommissioning risk estimates presented here have large uncertainties. Detailed plans and procedures for decommissioning the MRS facility have not yet been developed.

The occupational and public dose estimates presented here are subject to change pending finaliation of the MRS facility conceptual design. Doses are impacted by design features that increase shielding or distance from radiation sources. Automation and remote handling facilities provide examples of such features. In addition, changes in throughput rates, storage capacities, fuel age, or burnup may affect the dose estimates. Although there has been an attempt here to normalize dose estimates, uncertainties develop when referenced assumptions were not clearly stated. Additional sources of uncertainty are described below. 
- Task descriptions, staffing levels, exposure times, and distances from radioactive sources are subject to much uncertainty when estimating occupational exposures.

- Accident frequencies are often estimated from experience at other fixed nuclear facilities and accident severities are generally based on conservative assumptions when empirical data are not available.

- Dose rates normally based on maximum peitmitsible radiation levels in occupied areas. They are considerch be conservative and are not consistently applied.

- Although the MRS facility is currently designed for a throughput of 3,600 MTU/year, it is likely that the actual receipt and shipment rates will be less (Harty and Stoetzel 1986).

- When estimating the release of radionuclides from fuel assembiy drops and ruptures, the fraction of fission gas available for release must be known. Estimates are generaliy conservative (DOE 1986g).

- The release of radionuclides in postulated accidents is generally based on fuel having the highest activity at the MRS facility.

- Pessimistic assumptions are typically used for the efficiency of filtered ventilation systems. Realistic decontamination factors based on experimental data should be developed.

- Population distributions do not always reflect regional population densities and dispersion models often reflect probabilistic-based generic national-average weather distributions. Most of these uncertainties generally lead to conservative results (i.e., they tend to overestimate the risks). This conservatism can be quickly compounded in a single dose estimate when several uncertainties are incorporated together. However, until more accurate estimates are made or empirical data are available, the degree of conservatism is not known.

- A consistent set of nonradiological fatality rates for specific construction and operations activities should be developed and applied.

\subsection{TRANSPORTATION SYSTEM RISKS}

This section presents the assessment of transportation risks and impacts for system configurations with and without an MRS facility. These two system configurations and the components that comprise them were described in Chapter 3.0. As discussed in Chapter 2.0, this section focuses on the risks 
associated with operation of the transportation system, primarily because the risks of construction and decommissioning are negligible in comparison with other risk.s. Section 5.4 .1 presents the transportation risk estimates. Separate subsections are provided for radiological and nonradiological risks. Uncertainties are discussed in Section 5.4.2.

\subsubsection{Transportation Risk Values}

The adjustments made to the risk values presented by Cashwell et al. (1986) and DOE (1986 b,c,d) to normalize them to a common basis are discussed in this section. In general, the referenced documents provided estimates of the total transportation impacts over the operating period of the repositories. Levelized annual risks are calculated in this section by dividing the total impacts given in the repository environmental assessments by the assumed 26 years of repository operations. The major inputs to the estimated total transportation system impacts were discussed in Section 4.4.

\subsubsection{Radiological Health Risks}

Table 5.9 presents the annual transportation radiological risks for the waste management systems with and without an MRS facility. The annual risk estimates were calculated assuming that $30 \%$ of the spent fuel shipped from reactors goes by truck and $70 \%$ goes by rai1. The destination of these shipments would be the repository or the MRS facility, depending upon the system configuration being addressed. Shipments from the MRS facility to the repositories were assumed to be $100 \%$ by rail. Shipments of Hi.W in both system configurations were assumed to all go by rail. As shown, the projected impacts are only fractions of an LHE/yr. Since the exposed population numbers into the millions, these impacts are only a small fraction of the total latent health effects produced annually in this population by external background radiation.

\subsubsection{Nonradiological Health Risks}

Table 5.10 presents estimates of the annual transportation nonradiological risks for both system configurations. The same assumptions regarding the truck/rail modal splits that were used to estimate radiological risks were also used to develop the estimates of nonradiological risks. It can be 
TABLE 5.9. Annual Radiological Transportation Risks

\section{System Configuration/Risk Category Annual Risk LHE/Year}

System Without an MRS Facility(a)

Public Accidents

$1.1 \mathrm{E}-3$

Public Routine

$9.3 \mathrm{E}-2$

Occupational Routine

$2.1 \mathrm{E}-2$

System With an MRS Facility(b)

Public Accidents

$1.5 \mathrm{E}-3$

Public Routine

$3.0 \mathrm{E}-2$

Occupational Routine

$7.5 \mathrm{E}-3$

(a) Estimated annual risks for shipping spent fuel from reactors (30\% by truck and $70 \%$ by rail) and a 11 HLW from their sources $(100 \%$ rail).

(b) Estimated annual risks for shipping spent fuel from reactors (30\% by truck and $70 \%$ by rai1) to the MRS facility, a11 HLW from their sources to the repository $(100 \%$ rail) and spent fue 1 and sfizondary wastes (100\% raii) from the MRS to the repositories.

TABLE 5.10. Annual Nonradiological Transportation Risks

System Configuration/Risk Category

Annual Risk Fatalities/Year

System Without an MRS Facility(a)

Public Accidents

$3.3 \mathrm{E}-1$

Public Routine

$1.2 \mathrm{E}-2$

occupational Accidents

$7.9 \mathrm{E}-2$

System With an MRS Facility(b)

Public Accidents

Public Routine

$3.8 \mathrm{E}-1$

Occupational Accidents

$8.0 \mathrm{E}-3$

$3.9 \mathrm{E}-2$

(a) Estimated annual risks for shipping spent fuel from reactors $(30 \%$ by truck and $70 \%$ by rail) and all from their sources (100\% rail).

(b) Estimated annual risks for shipping spent fuel from reactors $130 \%$ by truck and $70 \%$ by rail) to the MRS facility, all HLW from their sources to the repository $(100 \%$ rail) and spent fuel and secondary wastes ( $100 \%$ rail) from the MRS to the repositories. 
seen by comparing the annual health effects in Tables "j.9 and 5.10 that nonradiological risk values are higher than those for radiological risks. However, the nonradiological risk estimates, as well as radiological risk estimates, are small values.

\subsubsection{Discussion of Uncertainties}

This section discusses the primary sources of uncertainty in the transportation risk values. The risk estimates presented in Section 5.4 .2 are recommended by DOE $(1986 b, c, d)$ to be used only for comparison purposes because of the uncertainties in the analysis. However, it was also indicated that the values should be considered to be representative.

Figure 5.2 presents a summary comparison of the spent fuel transportation risk estimates discussed in Section 4.4.1. These estimates were normalized to a common basis of person-rem $/ \mathrm{km}$ of travel. This was done by dividing the annual risk values by the total distance traveled in 1 year, as indicated in the documents. Separate "unit risk values" are shown for truck and rafl shipments and for routine exposures and accident risks. Adjustments were also made to the values given by Cashwell et a1. (1986) to develop a composite unit risk factor for travel in rural, suburban, and urban population zones. This was done using weighting factors that represent the average truck travel fractions each population zone. These fractions were 0.01 , 0.20 , and 0.79 for truck travel in urban, suburban, and rural zones, respectively, and the rail travel fractions were $0.01,0.18$, and 0.81 , respectively. The unit risk values were calculated based on the average fractions of travel in each zone from representative reactors to the three potential first repository sites (DOE 1986b,c,d). The unit risk value for truck shipments in Finley et al. (1980) were representative of urban areas, only. Elder et al. $(1978,1981)$ only addressed accident risks.

The figure indicates there was a general agreement between the accident risk values estimated by Elder et a1. (1978, 1981) and Cashwell et al. (1986). The principal difference between these studies was in the approach used to estimate shipping cask and spent fuel response t, accident environments. Elder et al. performed a more conprehensive evaluation of release 


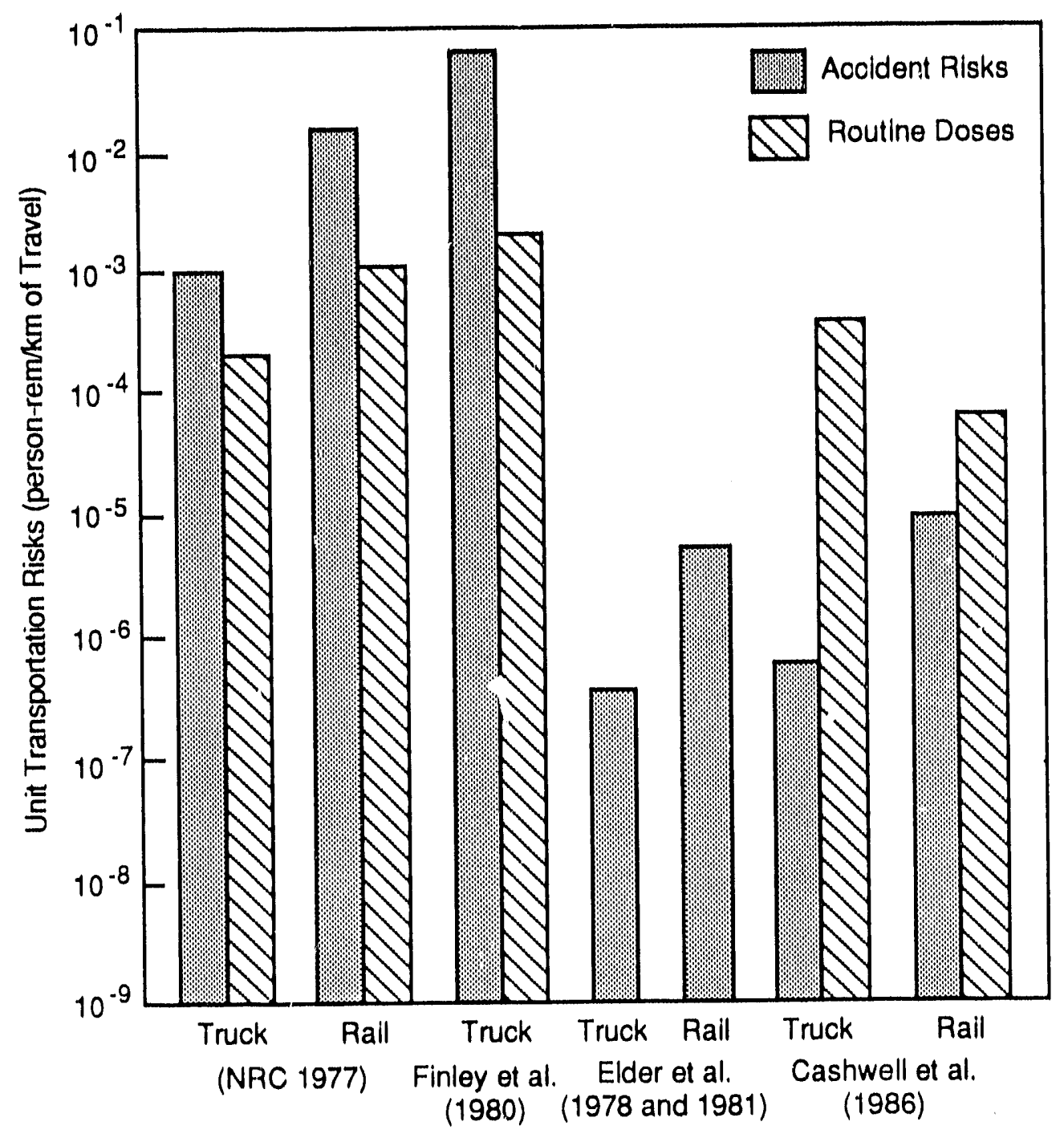

FIGURE 5.2. Comparison of Spent-Fuel Transportation Risk Estimates

scenarios and even though the fuel characteristics were significantly different (180-day cooled in Elder et al. and 5-year cooled in Cashwell et a1.), the results were approximately the same. This indicates that the data used by Cashwell et al. to describe the release source terms, including release fractions, dispersability, and respirability, were more conservative than those derived by Elder et al. The uncertainty bounds in the transportation risk estimates were judged to be about a factor of 2 to 3 higher and 1 to 2 orders of magnitude lower than the risk values provided in Section 5.4.1. This is because a comprehensive evaluation of possible accidents has been 
performed for transportation and the results were reasonably consistent with the current analyses in the environmental assessments.

Thus, this source of uncertainty, which would tend to underestimate the actual risks, does not exist for transportation. However, there is some uncertainty associated with accident release fractions, local route-specific conditions, and other transportation data that could produce risk estimates perhaps a factor of 2 to 3 higher.

Other sources of uncertainty in the transportation risk estimates include the following:

- Population distributions are based on aggregated nation-wide population data and do not accurately reflect conditions on a location- or route-specific basis.

- Meteorological conditions are based on probabilistic-based generic national-average weather distributions.

- Accident severities are based on conservative assumptions where valid data are not available. The principal parameters used to describe accident severities include package release fractions, the fraction of released material that becomes airborne, and the fraction of airborne material that is in the form of respirable particles. The values assigned to these parameters are generally pessimistic (or conservative), which tends to overestimate the risks.

- For routine radiation exposures, no credit is taken for the shielding provided by buildings, rounding terrain, or the truck cab. This results in conservative estimates of these exposures.

- It is assumed that the radiation dose rate emanating from the shipping casks is the maximum allowable under current regulations a) though the actual lose rate may be somewhat lower. Thus, this parameter, which is very important to calculating routine exposures, is assigned the most conservative foreseeable value.

- The method used to calculate groundshine exposures in most analyses assumes an infinite plane source model that does not take credit for shielding provided by irregularities or roughness of an actual surface. Consideration of surface effects would tend to decrease the risks, but is highly dependent on conditions near an accident site and thus would be difficult to model for transportation accidents. 
- Shipping cask descriptions are conceptual and the capacities of future casks are not known at this time. Clearly, however, the capacities of future spent fuel shipping casks will be larger than those in use today because of the reduced thermal load and radiation doses associated with fuel that is at least 5 years out of the reactor (current casks are designed to transport fuel that is only 120 days out of the reactor). The as sumed cask capacities are based on the best avatlable information.

\subsection{ECONOMIC RISKS}

The economic risks considered in this study are associated only with potential accidents involving releases of radioactive material to the environment. These risks are different than health risks because the consequences of the accident are measured in terms of dollars, rather than health effects. Economic risks are analogous to health risks and can be calculated by estimating the cleanup costs for a spectrum of accident and then the summing product of the accident frequencies and their economic effects. However, an economic risk analysis has not been performed for pntential waste management facility accidents, and thus the information in this document is incomplete in this area.

Estimating the economic effects of accidents at waste management facilities requires determining the effects on businesses, individuals, governments, and the environment for a potentially long time following an accident. The cleanup costs for accidents include basic emergency response costs, costs for cleanup and recovery of materials released during the accident, costs to restore the contaminated areas to normal use, costs for evacuation and relocation of individuals and businesses (including loss of salaries), and costs for denial of land use (including actual property losses due to radioactive contamination). Indirect effects include consumers' fear of buying products produced in the affected region and the impacts on travel and tourism. These costs depend strongly on the type and amount of released materials, land-use patterns in the contaminated areas, population density, geography, and the required cleanup level.

Studies of the economic consequences of reactor accidents (Tawil et al. 1985) indicate that the cleanup costs are dominated by the costs for cleanup and recovery of the released materials and costs for denial of land use. 
Atmospheric transport models are used to estimate the extent of the contaminated area and the levels of contamination. A series of calculations are then performed to estimate the costs and time required to decontaminate the affected area to permissible levels. Typically, a series of maximum residual contamination levels are assumed to bound the levels that might actually be required by federal and state agenctes. The atmospheric dispersion model also determines the number of people that must be evacuated and relocated, based on the downwind concentrations of the released material in the air and on the ground. These data help determine the extent of evacuation and relocation of individuals following an accident. Cost factors have been developed to estimate evacuation costs on this basis. Other cost factors have been developed and programed into a computer model (Tawil et a1. 1985) to convert the dispersion data into estimated costs for loss of property use, reductions in property values, and other cost categories. However, to the authors' knowledge, this model has not been exercised on waste management facility accidents.

A comprehensive analysis of economic risks of waste transportation accidents also has not been performed. A limited analysis was performed by Finley et a1. (1980) for accidents in urban areas, but none have been performed for a nation-wide transportation system. The method used to estimate the economic consequences of transportation accidents is similar to that used for preclosure economic risks. The RADTRAN III code (Taylor and Daniel 1982, Madsen et a1. 1983, Madsen et a1. 1986) generates economic unit factors (dollars/unit distance versus health risks/unit distance for unit risk factors) based on this approach. The economic unit factors are multiplied by the distance traveled in 1 year to obtain an estimate of annual economic risks. This approach is completely analogous to public risks. To illustrate this approach on a single accident, the economic risks of an extremely severe rail accident will be estimated. This accident, which involves severe impact followed by a fire as described by Sandquist et al. (1985), would result in economic consequences amounting to $\$ 620$ million. The conditional probability of this accident was indicated by Sandquist et al. to be approximateiy 2 occurrences per million transportation accidents. To convert this value to an annual frequency, it was multiplied by rail accident 
rates, converted to units of accidents per unit distance which were published DOT (1985) and estimated annual average transportation distances from the repository environmental assessments (DOE 1986b,c,d). The resulting frequency of this accident was estimated at $1.8 \mathrm{E}-6 / \mathrm{yr}$. The economic risk of this particular accident was then $1.8 \mathrm{E}-6$ accidents/yr times $\$ 6.2 \mathrm{E} 8 /$ accident or approximately $\$ 1100 / y r$. Luna (1986) used this approach on a range of potential accidents to develop a preliminary estimate of economic risks. The preliminary results indicate a value of $\$ 50,000 / \mathrm{yr}$.

Large uncertainties also exist for estimates of economic risks of the postclosure phases of the repositories. Because the consequences occur at significantly long times in the future, current economic models may not be adequate. There appears to be no satisfactory way at this time to predict future economic systems that will be in place and to develop estimates of the costs associated with the postclosure releases. It may be necessary to use current economic models with pessimistic assumptions to bound the economic risks from postclosure. This will lend some perspective lu the potential significance of these risks but will produce results with relatively large uncertainties.

\subsection{AGGREGATED RISKS OF THE WASTE MANAGEMENT SYSTEM}

This section develops estimates of the annual risks and total life-cycle risks for the various operating phases of the waste management system. Radiological risks for a single year during the operations phase of each system element are aggregated to provide an estimate of the annual risks of a fully functioning waste management system. Nonradiological occupational risks during operations are also aggregated. This provides an estimate of the number of fatalities that can be expected annually from operating the facilities in the system. Life-cycle risks were estimated by multiplying the annual risk values by the duration of each operating phase. It should be noted that the risk values presented in this section are the authors' judgment of the most representative estimates based on information available in the literature. As such, the uncertainty in the values is relatively high, perhaps plus or minus several orders of magnitude. Consequently, any comparisons made using the data are also subject to the same uncertainty. However, the 
risk values have been normalized as much as possible to a common basis and are believed to be representative approximations.

Occupational and public risk values are not added together. Since these are two entirely different population groups, separate risk values are presented for public and occupational risks. Preclosure and postclosure risks are also not added together because of the different time periods over which the health effects from these two phases might be produced. In addition, postclosure risk assessment is an evolving field, both in terms of methods and data, with much controversy surrounding the assignment of probabilities to future disruptive events. As a result, the emphasis in the past on postclosure risk (or performance) assessment has been to attempt to demonstrate the capability to achieve regulatory objectives, and not to estimate risks.

There is significant uncertainty in the risk estimates presented in the following sections. For this reason, the reader is cautioned not to make comparisons of the risk estimates. The uncertainty in the individual facility risk estimates, as well as the aggregated system risk estimates, is larger than the differences in risk between the two system configurations. In addition, the reader should consider the avoided risk at reactors and other commercial sites. Because the MRS facility is scheduled to operate sooner than the potential repository, there may be some reactors that can avoid implementing additional spent fuel storage capabilities at their sites by shipping spent fuel to the MRS facility. The avoided risks at reactors for reduced spent fuel handling and, in some cases, reduced interim storage of spent fuel, was not evaluated in this study.

\subsubsection{Aggregated Annual Risks for the System Without an MRS Facility}

The risk values for each element in the waste management system that were derived in Sections 5.1 to 5.4 are presented in Table 5.11. Public risk estimates are presented in Table 5.11, and occupational risk estimates are presented in Table 5.12. The aggregated values at the bottom of the tables represent the total annual risks of the operating the waste mallagement system elements (i.e., repository and transportation). The risk values for the other phases (i.e., construction and decommissioning) are not aggregated; 
TABLE 5.11. Aggregated Public Risks for the Preclosure Phases of the System Without an MRS Facility (a)

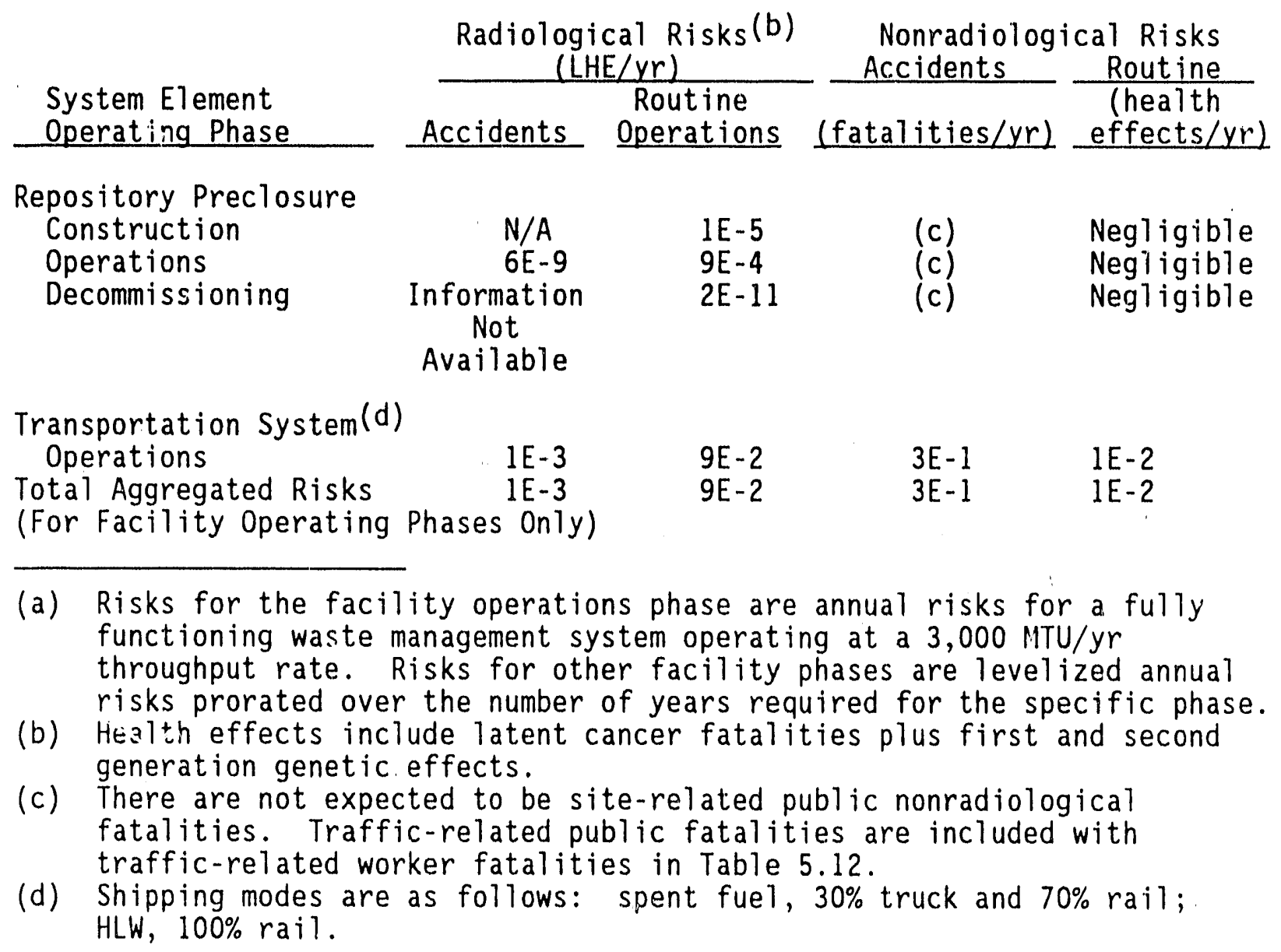

they represent levelized annual risks for these particular phases. The risks of waste handling and storage operations at reactors and other commercial sites are not included in the tables.

Postclosure risk va? ues for the potential repository in tuff were estimated in Section 5.2. Upper limit interim risk estimates of $1 E \cdot 3$ health effects per year were estimated. This risk value is given here for order-ofmagnitude comparisons with the preclosure risk estimates. The postclosure risk estimates are believed to be very conservative. They are based on population doses over the time period when the maximum doses are expected, and have large uncertainties associated with them. 
TABLE 5.12. Aggregated Occupational Risks for the Preclosure Phases of the System Without an MRS Facility(a)

\section{System Element Operating Phase \\ Repository Preclosure Construction}

Operations

Decommissioning

Transportation System (c) Operations

Total Aggregated Risks

(For Facility pperating Phases Only) (c)

\begin{tabular}{|c|c|}
\hline $\begin{array}{l}\text { Radiological Risks(b) } \\
\text { (LHE/yr) }\end{array}$ & $\begin{array}{l}\text { Nonradiological Risks } \\
\text { Accidents Operations }\end{array}$ \\
\hline $\begin{array}{c}\text { Routine } \\
\text { idents } \\
\text { Operations }\end{array}$ & $\begin{array}{l}\text { (health } \\
\text { effects/yr) }\end{array}$ \\
\hline
\end{tabular}

$N / A$

$1 E-1$

$2 E+0$

No

Significant Impact

$6 \mathrm{E}-5$

$2 \mathrm{E}-2$

$3 E+0$

No

Significant Impact

$3 E-2$

$8 E-1$

No

Significant Impact Available

$2 E-2$

$8 E-2$

Information Not With Public Risks Available

$6 E-5$

$4 E-2$

$3 E+0$

Information Not Available

(a) Risks for the facility operations phase are annual risks for a fully functioning waste management system operating at a 3,000 MTU/yr throughput rate. Risks for other facility phases are levelized annual risks prorated over the number of years required for the specific phase.

(b) Health effects include latent cancer fatalities plus first and second generation genetic effects.

(c) Shipping modes are as follows: spent fuel, $30 \%$ truck and $70 \%$ rail; HLW, $100 \%$ rail.

Aggregated system occupational risks are presented in Table 5.12 . Information was not available on the risks of routine exposure to nonradiological pollutants in the facilities. However, these risks are not expected to be significant.

\subsubsection{Aggregated Annual Risks of the System With an MRS Facility}

Tables 5.13 and 5.14 present the annual risk estimates for each operating phase of all elements in the system with an MRS facility. The aggregated 
TABLE 5.13. Aggregated Public Risks for the Preclosure Phases of the System With an MRS Facilityla)

\begin{tabular}{|c|c|c|c|c|}
\hline \multirow[b]{2}{*}{$\begin{array}{l}\text { System Element } \\
\text { Operating Phase }\end{array}$} & \multicolumn{2}{|c|}{$\begin{array}{c}\text { Radiological Risks(b) } \\
(\text { LHE/yr) }\end{array}$} & \multicolumn{2}{|c|}{$\begin{array}{l}\text { Nonradiological Risks } \\
\text { Accidents }\end{array}$} \\
\hline & Accidents & $\begin{array}{c}\text { Routine } \\
\text { Operations }\end{array}$ & (fatalities/yr) & $\begin{array}{l}\text { (health } \\
\text { effects/yr) }\end{array}$ \\
\hline $\begin{array}{l}\text { Repository Preclosure } \\
\text { Construction }\end{array}$ & $N / A$ & $1 E-5$ & (c) & Negligible \\
\hline Operations & $6 \mathrm{E}-9$ & $8 E-7$ & (c) & Negligible \\
\hline Decommissioning & $\begin{array}{l}\text { Information } \\
\text { Not } \\
\text { Available }\end{array}$ & $2 E-11$ & (c) & Negligible \\
\hline $\begin{array}{l}\text { MRS Facility } \\
\text { Construction }\end{array}$ & Radioactive $N$ & Materials Onsite & (c) & $\begin{array}{c}\text { No } \\
\text { Sianificant }\end{array}$ \\
\hline Operations & $8 \mathrm{E}-7$ & $5 E-3$ & & Impacts \\
\hline Decommissioning & $\begin{array}{c}\text { Not } \\
\text { Evaluated }\end{array}$ & $2 E-11$ & & \\
\hline $\begin{array}{l}\text { Transportation System } \\
\text { Operations }\end{array}$ & $2 E-3$ & $3 E-2$ & $4 E-1$ & $8 E-3$ \\
\hline $\begin{array}{l}\text { Total Aggregated Risks } \\
\text { (For Facility } \text { Operati } \\
\text { Phases Only) }(\mathrm{c})\end{array}$ & ing & $4 \mathrm{E}-2$ & $4 E-1$ & $8 E-3$ \\
\hline
\end{tabular}

(a) Risks for the facility operations phase are annual risks for a fully functioning waste management system operating at a 3,000 MTU/yr throughput rate. Risks for other facility phases are levelized annual risks prorated over the number of years required for the specific phase.

(b) Health effects include latent cancer fatalities plus first and second generation genetic effects.

(c) There are not expected to be site-related public nonradiological fatalities. Traffic-related public fatalities are included with traffic-related worker fatalities in Table 5.14.

(d) Shipping modes are as follows: spent fuel from reactors to MRS, $30 \%$ truck and $70 \%$ rail; HLW, $100 \%$ rail; all wastes from MRS facility to repository, $100 \%$ rail. 

TABLE 5.14. Aggregated Occupational Risks for the Preclopsure
Phases of the System With an MRS Facility

\begin{tabular}{|c|c|c|c|c|}
\hline \multirow[b]{2}{*}{$\begin{array}{l}\text { System Element } \\
\text { Operating Phase }\end{array}$} & \multicolumn{2}{|c|}{$\begin{array}{c}\text { Radiological Risks(b) } \\
\text { (LHE/yr) }\end{array}$} & \multicolumn{2}{|c|}{ Nonradiological Risks } \\
\hline & Accidents 0 & $\begin{array}{l}\text { Routine } \\
\text { Operations }\end{array}$ & $\frac{\text { Accidents }}{\text { (fatalities/yr) }}$ & $\begin{array}{l}\frac{\text { Routine }}{\text { (health }} \\
\text { effects/yr) }\end{array}$ \\
\hline $\begin{array}{l}\text { Repository Preclosure } \\
\text { Construction }\end{array}$ & $N / A$ & $1 E-1$ & $2 E+0$ & $\begin{array}{l}\text { No } \\
\text { Significant } \\
\text { Impacts }\end{array}$ \\
\hline Operations & $5 E-5$ & $2 E-2$ & $2 E+0$ & $\begin{array}{c}\text { No } \\
\text { Significant } \\
\text { Impacts }\end{array}$ \\
\hline Decommissioning & $\begin{array}{l}\text { Information } \\
\text { Not } \\
\text { Available }\end{array}$ & $3 E-2$ & $7 E-1$ & $\begin{array}{l}\text { No } \\
\text { Significant } \\
\text { Impacts }\end{array}$ \\
\hline $\begin{array}{l}\text { MRS Facility } \\
\text { Construction }\end{array}$ & Radioactive Mate & erials Onsite & $2 E+0$ & $\begin{array}{l}\text { No } \\
\text { Significant } \\
\text { Impacts }\end{array}$ \\
\hline Operations & $1 E-4$ & $6 E-2$ & $2 E+0$ & $\begin{array}{l}\text { No } \\
\text { Significant } \\
\text { Impacts }\end{array}$ \\
\hline Decommissioning & $3 E-3$ & $5 E-3$ & $1 \mathrm{E}-1$ & $\begin{array}{l}\text { No } \\
\text { Significant } \\
\text { Impacts }\end{array}$ \\
\hline Transportation System (c & $\begin{array}{l}\text { Included } \\
\text { With Public } \\
\text { Risks }\end{array}$ & $8 E-3$ & $4 E-2$ & $\begin{array}{l}\text { Information } \\
\text { Not } \\
\text { Available }\end{array}$ \\
\hline $\begin{array}{l}\text { Total Aggregated Risks } \\
\text { (For Facility Operatir } \\
\text { Phases Only) (c) }\end{array}$ & $\mathrm{ng}$ & $9 E-2$ & $4 E+0$ & $\begin{array}{l}\text { Information } \\
\text { Not } \\
\text { Available }\end{array}$ \\
\hline
\end{tabular}

\footnotetext{
(a) Risks for the facility operations phase are annual risks for a fully functioning waste management system operating at a 3,000 MTU/yr throughput rate. Risks for other facility phases are levelized annual risks prorated over the number of years required for the specific phase.

(b) Health effects include latent cancer fatalities plus first and second generation genetic effects.

(c) Shipping modes are as follows: spent fuel from reactors to MRS, $30 \%$ truck and $70 \%$ rail; HLW, $100 \%$ rail; all wastes from the MRS to the repository, $100 \%$ rail.
} 
annual risks of the operating phases of each element are also presented in the tables. As with Tables 5.11 and 5.12, the risks of the construction and decommissioning phases are not aggregated and the risks of waste handling and storage operations at reactors and other commercial sites are not included.

\subsubsection{Total System Life-Cycle Risks}

The final step in this study was to estimate the total system life-cycle risks, which provided a preliminary estimate of the total risks of constructing, operating, and decommissioning the facilities in the waste management system. Transportation risks were also included in the estimates. Potential repository retrieval operations were not included because of the lack of relevant data and because retrieval may not be needed, whereas the other operating phases will occur. It should be emphasized that there is a relatively large uncertainty associated with the life-cycle risk values, perhaps 2 to 3 orders of magnitude. Consequently, the reader is cautioned to use these values only as representative approximations. They should be used only as representative approximations because of the large uncertainty, the lack of site-specific data, and the conceptual nature of the repository designs. Postciosure risks are also not included in the life-cycle risk values because of the site-specific data needs and the different time period over which the risks are manifested.

Total life-cycle risks are presented here because erroneous conclusions can be derived from the annual risk values presented previously. This is because mission times and durations of phases are different for the different facilities. The life-cycle risk values were estimated by multiplying the annual risk values given in Tables 5.11 to 5.14 by the duration of each phase of facility operation. The construction phases for the repository and MRS facility are assumed to occur over a 5-year period. Repository operations last 26 years and the MRS facility operates for 34 years. Afiter the total risks for each operating phase are calculated, they are added together to estimate total system life-cycle risk values. An average value with respect to both potential system configurations was calculated because of the uncertainty about which configuration will be implemented and because the risk 
differences are small relative to the uncertainty in the life-cycle risk estimates. The results of these calculations are presented in Table 5.15.

Figure 5.3 illustrates the total public and occupational life-cycle risks, respectively. These bar graphs include the risks of all phases of the waste management system, including facility construction, operation, and decommissioning. Repository retrieval and postclosure risk estimates are not included in the figures. Radiological risks from accidents, radiological risks from routine operations, and nonradiological risks from both accidents and routine operations are each presented in the figure. Radiological risks.... are expressed in units of LHEs, and nonradiological risks are expressed as fatalities. This bargraph reflects the data in Table 5.15. Transportation risks were estimated assuming a truck/rail modal split of $30 / 70 \%$, respectively, for shipments from reactors to the repositories or MRS facility and $100 \%$ rail from the MRS facility to the repositories. All HLW was assumed to be shipped by rail.

To put the total system risk values in perspective with other common risks, a comparison was developed with the projected health effects from natural background radiation at each site. To be valid, this comparison must consider the same population groups in both cases. Natural background radiation levels at the tuff site and the MRS facility site were obtained from their respective environmental assessments (DOE 1986b; DOE 1986g). The affected populations, represented by the total number of persons residing TABLE 5.15. Total Preclosure Life-Cyc]e Risk(a) Estimates for the
Waste Management System $(b)$

\begin{tabular}{|c|c|c|c|}
\hline Population Group & $\begin{array}{l}\text { Radiolog } \\
\text { Accident }\end{array}$ & $\begin{array}{r}\text { Risks (LHE) } \\
\text { Routine }\end{array}$ & $\begin{array}{l}\text { Nonradiolog }(c a l \\
\text { Fatalities }(c)\end{array}$ \\
\hline Public Risks & 0.04 & 2 & 10 \\
\hline Occupational Risks & 0.004 & 3 & 100 \\
\hline
\end{tabular}

(a) Sum of risks during construction, operation, and decommissioning phases of the waste management system.

(b) Average life-cycle risks with respect to system configurations with and without an MRS facility.

(c) Sum of nonradiological accident and routine risks. 


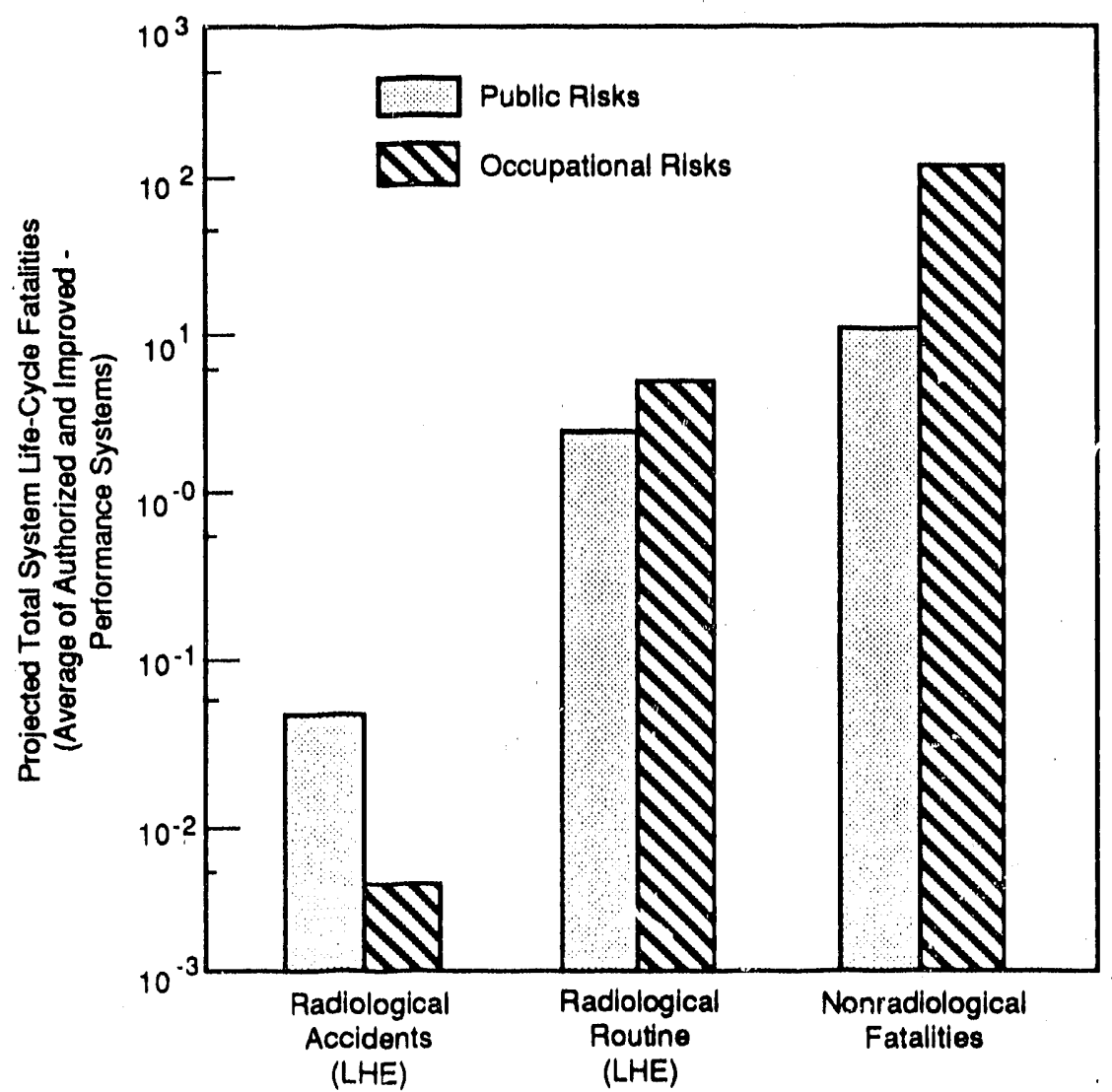

FIGURE 5.3. Illustration of the Total Life-Cycle Risks for Construction, Operation, and Decommissioning of the Waste Management System

within 80 kilometers ( 50 miles) of the facility sites, were also taken from the environmental assessments. The population group affected by the transportation system was calculated using a different approach. It was assumed that the population affected by transportation consists of persons residing within 0.5 kilometers on eitier side of an interstate highway. It is further assumed that $10 \%$ of the total interstate highway system would be used by at least one shipment of spent fuel per year. The population densities along the interstate highways are those used in the transportation analyses in the environmental assessments. These population densities are as follows: rura1, 6 persons $/ \mathrm{km}^{2}$; suburban, 791 persons $/ \mathrm{km}^{2}$; and urban, 3,861 persons/ $\mathrm{km}^{2}$. The fractions of travel in rural, suburban, and urban areas were also taken from the environmental assessments and are based on the average fractions of travel between representative reactors and the potential salt repository (see Appendix A of the repository environmental assessments). The 
total affected population is thus the sum over all three population zones of the products of the affected interstate highway distance; fractions of trave? in rural, suburban, and urban zones; and the population densities in each population zone. The results of the natural background comparisons are presented in Table 5.16.

TABLE 5.16. Projected Health Effects from Natural Background Radiation

System Element

Repository

MRS Facility

Transportation
Radiological Health Effects

Natural Background Radiation

2

900

1,000 


\subsection{CONCLUSIONS AND RECOMMENDATIONS}

This chapter presents conclusions based on the work described in this document and describes recommendations for work that the authors feel is needed to develop definitive estimates of the risks in the nuclear waste management system. The conclusions and recommendations have been developed to assist OCRWM in planning the future work in this area. These conclusions and recommendations are based on the current understanding of the needs of OCRWM for risk information. These needs are still being defined in some cases, so it is expected that OCRWM will consider and act on these recommendations as part of their ongoing planning process. The conclusions are based on the technical judgment of the authors that assessed the available safetyrelated information. Recommendations are made to suggest ways to resolve uncertainties in the existing information base. The need and priority for resolving some of these uncertainties and information gaps will be determined by OCRWM in their planning process.

\subsection{CONCLUSIONS}

Two broad categories of conclusions aire addressed in this section: 1) conclusions about the work that has been done and its adequacy or applicability to OCRWM's needs, and 2) conclusions that can be drawn about the magnitude of the risks in the system based on the available information. The waste management system for HLW is still in the conceptual stages of development. Major siting, system configuration, and facility design decisions will not be made for several years. Previous work has been done that addresses mary of the important risk categories in the system. This work is not sufficient for developing definitive estimates of the risks in the waste management system, although it is adequate for developing general insights into the magnitude of the risks in the system. All of the risks in the waste management system appear to be quite small based on the results available at this time. 


\subsubsection{Risk Literature}

Table 6.1 is a summary by risk category of the literature reviewed in this study. The number of reports that provide information on each of the risk categories is listed in the table. This table summarizes the information presented in the literature summary tables in Section 4.0. The information in Table 6.1 indicates the areas in which previous work has been concentrated. Most of the previous work addressed radiological risks to the public from routine emissions, radiological risks to the public from accidents during operations, and risks to workers from routine radiation exposure during operations. Most of the other risk categories that have been addressed have been analyzed only in a preliminary way in environmental assessments. The focus of the previous work has been on risk categories that need to be addressed to develop information needed for environmental impact statements and licensing documents that will be required to eventually site and license

TABLE 6.1. Summary of Literature by Risk Category(a)

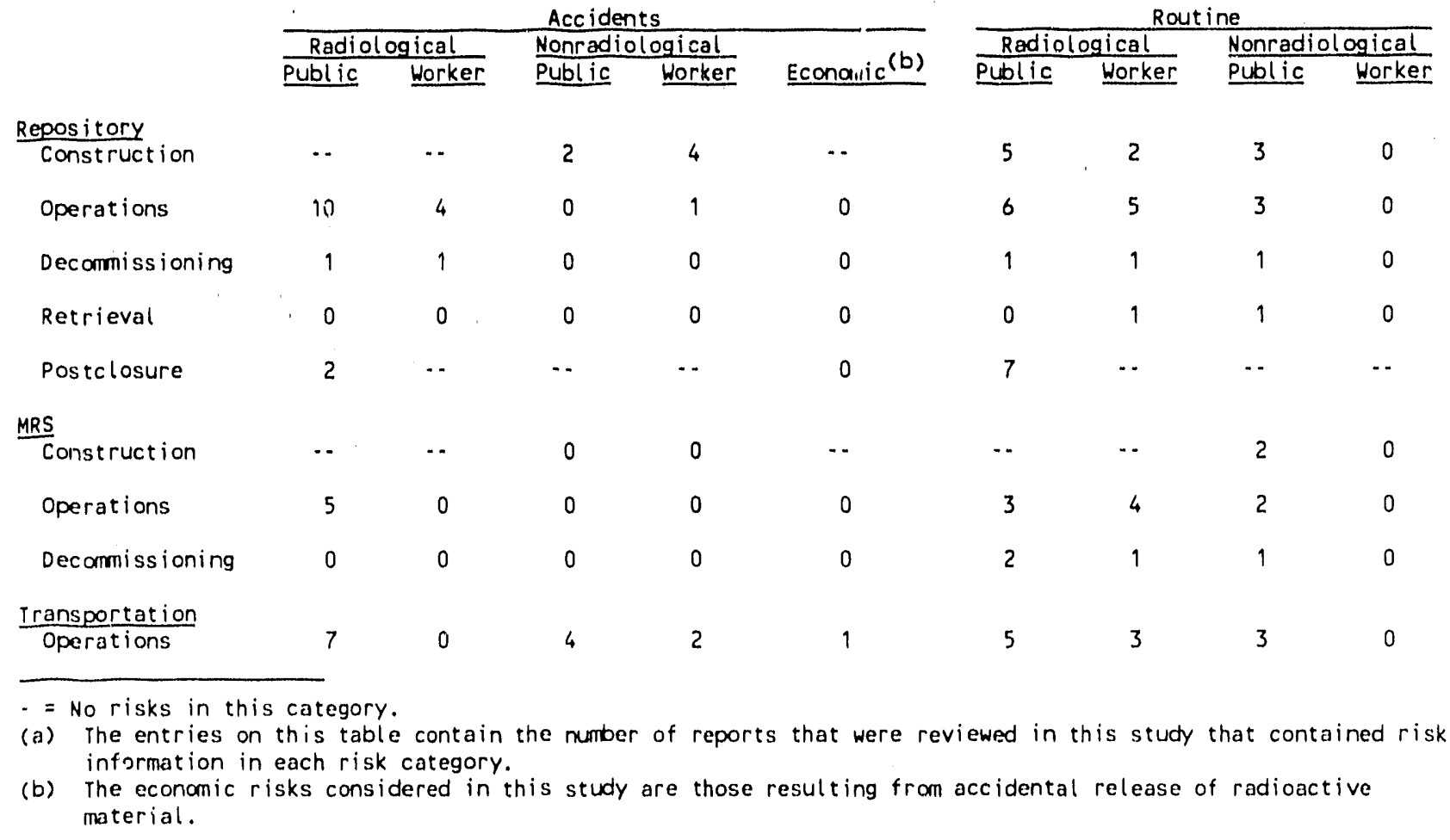


the facilities in the waste management system. There has been limited need to date for assessments of the broad range of risk categories included in this study.

The number of documents that address each of the risk categories provides a preliminary indication of the areas in which previous work has focused, but does not indicate the usefulness of this information to the current UCRWM waste management system. The available studies have been performed for many purposes and for a variety of facility designs and system configurations. The potential applicability of the information in each of the reference documents was discussed in the literature reviews presented in Section 4.0. An overall evaluation of the applicability of the information available in each risk category is presented in Table 6.2. The evaluation is qualitative and represents a consensus of the authors contributing to this

\section{TABLE 6.2. Qualitative Evaluation of Literature by Risk Category}

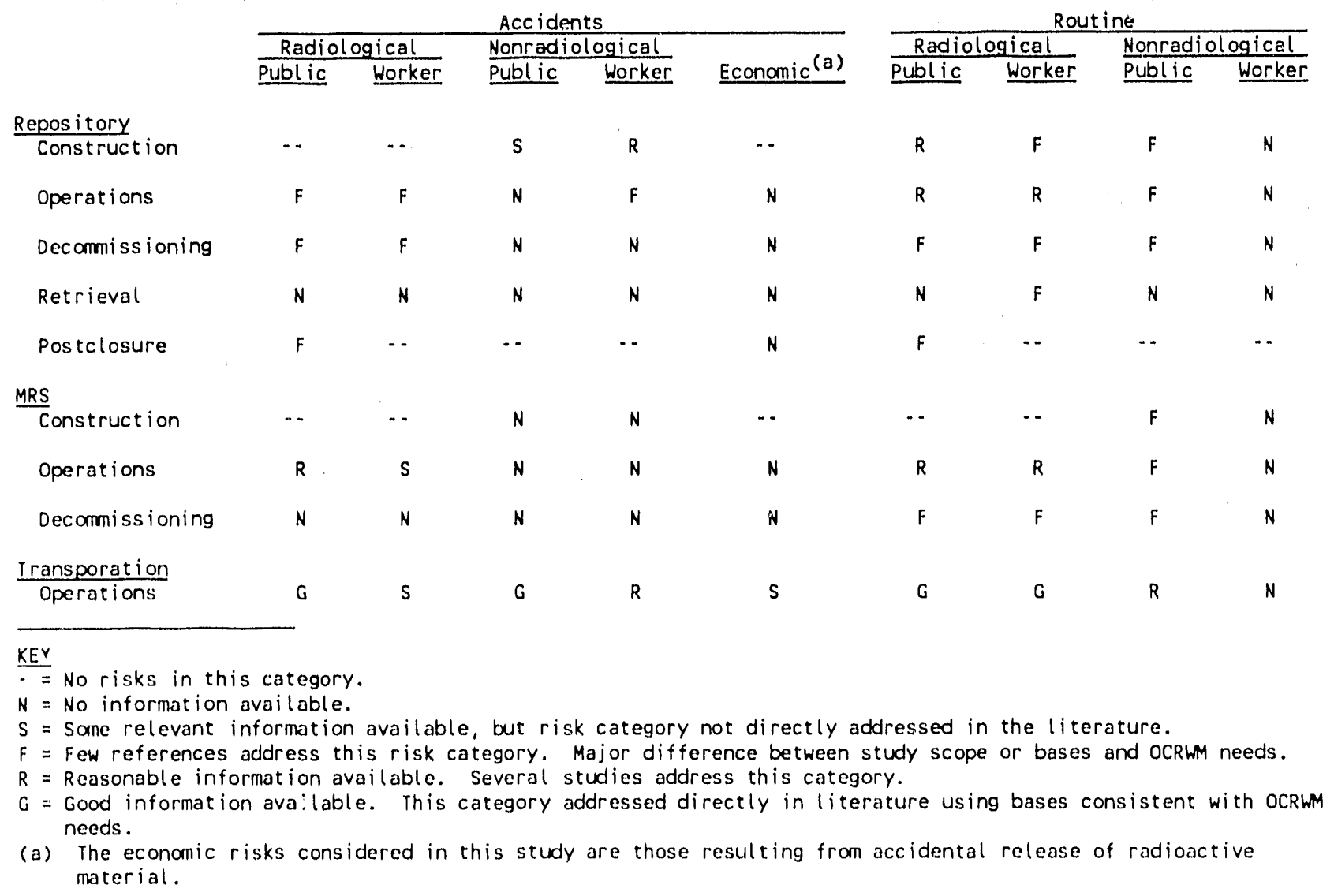


document. It was developed by examining the documents in each of the risk categories as a group and assigning them to one of the following evaluation categories:

- "N" - No relevant information was found in the literature for this risk category.

- "S" - Some relevant information was found in this risk category. The risks are not addressed directly in the literature, but enough relevant information was found to develop a crude risk estimate for use in Section 5.0. Significant uncertainty surrounds the value presented.

- "F" - A few references were found that address this risk category, but there are major differences between the scope or bases for the study and the scope or bases that would be needed for the information to be directly applicable to OCRWM. The available information has been used in Section 5.0 by applying some correction factors, but it only provides a preliminary estimate.

- "R" - Reasonable information is available in the literature to develop estimates of the risks in this category. Typically there are several references that are in general agreement with one another. Differences in the scope and bases for the studies are not as major as the studies in the " $F "$ category.

- "G" - Good information is available in this risk category. At least one reference is available that uses credible methods to develop risk estimates that are direct $1:$ applicable to OCRWM. Other literature is available that is consistent with the results of the major reference.

A number of conclusions can be drawn from the overall evaluation of the literature presented in Table 6.2. The available literature provides a reasonable technical basis for estimating the risks from the transportation system. There are, however, significant uncertainties in some of the data used in these analyses, particularly in the cask failure probability and sourceterm areas. Some work is needed to update the existing studies to incorporate the new cask designs currently being developed by DOE. Additional work will be required to collect data and adapt existing methods to perform routespecific risk studies. Many of the existing transportation risk studies are based on the computer model RADTRAN (Madsen et al. 1986). This model was developed primarily to perform the calculations needed for environmental impact assessments. It is well suited to these types of calculations, but 
the accident release model contained in the code may not be adequate for risk estimates performed for other purposes. Detailed risk studies have been performed for spent fuel transportation cperations. These studies should establish the basis for developing more comprehensive estimates of tie risks from transportation operations using the new casks that DOE is developing.

There is also reasonable information available on the risks to the public from routine radiological emissions from waste management facilities. These risks may need to be analyzed in more detail as the facility sites are chosen, site-specific data is collected, and the designs are finalized. The available information does provide credible estimates for the current state of system development. Occupational radiation exposure from routine operations of waste management facilities has also been reasonably well characterized in the existing literature. A useful addition to the existing information would be to validate the time-motion-dose models used to estimate occupational doses against measured doses in existing facilities such as the West Valley Reprocessing Plant in New York or the General Electric Spent Fuel Storage facility in Illinois. Again, more detailed estimates will be made when more definitive design information is available, but the available information provides a sound basis for estimating these risks for many of the purposes for which OCRWM is likely to need this information.

Several potentially important risk categories have not been addressed in the existing literature. There is almost no information available on the risks from potential repository retrieval operations. These operations have not been characterized sufficiently to provide a sound basis for risk estimates. These risks can be analyzed using methods similar to those applied to repository operations, but the retrieval operations and the condision of the wastes must be characterized before these assessments can be made.

There is essentially no information available on the economic risks associated with the waste management system. Economic risks associated with accidents in the waste management system have been addressed only for one very severe, low-probability transportation accident scenario. Miethods and data are available from studies done on reactors and hazardous material 
transportation systems to make reasonable estimates of these costs for repository preclosure, MRS, and waste transportation accidents. Work may be needed to apply these methods to the waste management system.

Thera has also been very little previous work that assesses the radiological risks to workers from accidents in waste management facilities. Historical data from nuclear facilities can probably be used to develop estimates of risks from small incidents. More extensive work may be needed to analyze the risks from severe accidents. Accidents that produce significant releases inside the facility, but do not breach the barriers in the facility that prevent offsite release, have not been analyzed extensively in previous studies. Additional work may be required to identify these types of accident scenarios and estimate the consequences and probabilities. This could be an important risk category, because the frequency of this type of accident may be higher than the frequency of accidents that produce offsite colisequences.

Repository and MRS decommissioning operations have not been characterizod in sufficient detail to permit other than ver. preiminary risk estimates to be made at this time. Studies have been performed that estimated the risks from decommissioning other types of nuclear facilities. These studies indicate that the risks from decommissioning waste management facilities will be very small, but further work may be needed to confirm this. Transportation risks associated with removing the decommissioning wastes from the sites have not been addressed.

There has also been essentially no previous work that analyzes the routine risks to workers from nonradiological hazards. It is expected that these risks will be very small because there will be few hazardous chemicals used or stored in waste management facilities. Some analysis may be required to confirm this, but the analys is should be straightforward. Nonradiological risks to the public from acciuents at the MRS facility and the repository have also not been addressed. Again, these risks are probably small because of the small inventories of nonradioactive hazardous materials in the facilities. 
Although there has been a significant amount of previous work that assessed repository postclosure risks, radiological risks to the public from accidents at the repository and the MRS facility, and nonradiological risks to workers from accidents at the repository, significant uncertainty is still associated with the estimates in these categories.

Major methods and data development efforts must be completed before definitive estimates of repository postclosure risks can be made. The DOE has substantial efforts ongoing in postclosure performance assessment. Hork is needed to develop comprehensive lists of release scenarios, estimate probabilities for these scenarios, and perform site-specific consequence analyses. Major uncertainties in dose assessment approaches also must be addressed. Because releases may occur thousands of years into the future, it is very difficult to determine the population distributions, 1and and groundwater use patterns, and other parameters that are needed to estimate doses from the releases. This will always be an area of major uncertainty in the analysis.

Considerable previous work was identified that analyzes the radiological risks to the public from accidents during operations at waste management facilities. This work is sufficient to develop a general idea of the magnitude of these risks, but large uncertainties are associated with these estimates. Most of the available studies either only analyze a few selected accident scenarios or they analyze facility designs that are very different from those currently planned. A comprehensive treatment of these risks will need to include development of a detailed list of accident scenarios for the current facility designs and estimation of the frequencies and consequences of these scenarios.

Reasonable historical data seems to be available to estimate noriradiological risks to workers during construction of waste management facilities. Mining accident data applicable to the underground construction and operations in the repository also seems to be available. Most available work has used this data directly. There will be significant differences between the 
mining operations covered by the data and the underground activities in the repository. Work may be needed to identify these differences, extract the portions of the mining data that best fit the waste management activities, and make adjustments to this data as needed to develop better estimates of the nonradiological risks to workers from accidents in the underground portions of the repository.

\subsubsection{Risk Estimates}

The risk estimates presented in this document have been taken from a wide variety of sources. Each of the reference studies has been done for different purposes, and they do not use common system descriptions, analysis methods, data, and major assumptions. For these reasons, there are many cases in which the results from one study are not directly comparable with the results from another study. These incomparabilities are discussed at various places in the text, but the aggregated risk estimates presented in Section 5.6 basically ignore the problems of incomparability. Great care needs to be exercised in drawing conclusions based on the aggregated results presented in this document. Conclusions that the authors judge to be valid based on the information available are described below.

Because detailed design and siting information are not yet available for major waste management facilities, many of the studies that have been done to date use straightforward methods to make "bounding" calculations of the potentiai risks in the system. This results in pessimistic risk estimates (i.e., conservative overestimates). The judgment of the contributors to this document is that most of the available risk estimates tend to overstate the magnitude of the potential consequences as well as the probabilities of occurrence. It is expected that as more definitive studies are done, they will result in lower estimates of system risks. More definitive studies will also substantially reduce the level of uncertainty associated with the results from current studies.

A11 of the radiological risks in the waste management system appear to be quite small based on the results available at this time. In general, nonradiological risks in the waste management system are a factor of 10 to 
100 larger than radiological risks. Risks from routine operations are typically a factor of 10 or more higher than risks from accidents. This indicates that radiological risks from accidents at waste management facilities will prubably not be a major contributor to the total system risks, although more definitive studies examining a wide range of accident scenarios will be needed to confirm this conclusion. This probably results because the facilities are designed to prevent major accidents and mitigate their consequences, should one occur, and because spent fuel is not readily dispersible in the accident conditions that would be encountered in waste management facilities.

No definitive studies have been performed to date to estimate repository postclosure risks. Substantial efforts are underway to develop the methods and the site-specific data needed to perform these assessments. Available studies only deal with a few of the potential release scenarios. These studies tend to use very conservative assumptions to estimate consequences from the scenarios that are analyzed. The results from these conservative studies indicate that postclosure risks are small. It appears from these studies that radiation doses to the average individual will be comparable with or smaller than the dose that an individual representative of the population receives from other sources, such as natural background radiation.

\subsection{RECOMMENDATIONS}

This section presents recommendations for future work to assess risks in the waste management system. These recommendations are based on the literature review and evaluation presented in this document and the broad range of potential OCRWM uses for risk assessment information discussed previously. Additional risk assessment work is planned at later stages in the waste management program as better data become available and more detailed designs are developed. As part of ongoing planning activities, OCRWM will identify the scope and timing of risk assessment efforts. The recommendations presented here will provide input to the planning process. They focus on activities 
that would be logical next steps from the work that has been done or activities that should be started soon to develop information or methods that will support planned future work.

The principal recommendations from this study include the following:

- Develop a consistent set of estimates for all of the risk categories for the planned waste management system.

- Develop the technical data needed to make more realistic estimates of the amount and characteristics of the materials released from spent fuel in accident conditions.

- Continue development of data and methods that will allow more definitive postclosure risk assessments to be done.

Each of these recommendations is described in more detail below.

\subsubsection{Waste Management Risk Study}

The study clocumented in this report identified a number of sources of estimates of risks from waste management facilities and operations. The available estimates were performed for a variety of purposes using a variety of methods, data, and system designs. Many risk categories are not covered in the existing literature. Categories that are covered are not treated consistently because of differences in bases, methods, and assumptions. This results in major incomparabilities among the risk estimates derived from different sources. A major conclusion of this study was that definitive, technically-consistent risk estimates are not currently available for all of the risk categories.

OCRWM is planning a number of risk and safety studies during the design, development, and licensing process for the waste management system. Many of these studies will be based on the detailed information being developed for the MRS facility and in the site characterization activities being conducted at the potential repository site. Several years may be required to develop this information and perform these studies. Preliminary risk illformation would be helpful in the near term to guide programmatic and design decisions that must be made before the detailed risk studies are completed. Methods 
and data are available now to develop new and consistent estimates for all of the risk categories. It is recommended that a study be initiated to perform this preliminary analysis.

\subsubsection{Spent Fuel Source Terms}

Review of previous risk studies indicated that there are substantial uncertiainties associated with the estimates that have been made of the amount of material that could be released from spent fuel assemblies in accident conditions. Many of the available studies relied on source term estimates made in the GEIS. The estimates in the GEIS are based on conservative assumpitions, but the technical basis for these assumptions was not presented. other studies made different conservative assumptions. Only a few studies attempted to review the available experimental data and develop independent estimates. Very little data has been found to be available that applies to the thermal and mechanical conditions to which spent fuel assemblies are likely to be exposed in accidents. Extrapolations from data developed in other conditions are very uncertain. A study is recommended to collect the data needed to develop realistic and technically defensible estimates of the amounts and the physical and chemical characteristics of the material released from spent fuel assemblies in accident conditions. A range of accident conditions, consisting of combinations of thermal and mechanical environments, would need to be specified and then the release fractions determined experimentally, analytically, or both for each combination of conditions.

\subsubsection{Postclosure Risk Assessment}

The literature review performed in this study concluded that substantial development work was needed before the site-specific models and data would be available to perform technically defensible risk estimates for the postclosure phase of the geologic repository. Much of this data collection and model development work will be carried out as part of the performance aisessment activities that will accompany the site characterization program. Some risk assessment work will also be required, since some of the regulatory requirements for the repository are written in risk terms. It is recommended that this planned work be extended to include risk assessments of the

\subsection{1}


repository site. Risk assessment provides a mechanism to analyze the residual risk in the system. It is anticipated that this type of information will be useful in the interactions among the states, other affected parties, and the Congress, and that it may be required to obtain final approval to construct the repository.

The postclosure risk assessment would include assessment of the dose to the public from the expected performance of the repository as well as from the effects of disruptive and intrusive events. The analys is would include development of a comprehensive set of intrusive and disruptive scenarios, estimation of the frequency of the scenarios and analysis of the doses, if any, that result from these scenarios. Work is also needed to develop methods to deal with the uncertainties surrounding the future population distributions at the site. Methods to deal with the effects of the timing of the disruptive or intrusive events are also needed, since consequences are dependent on the time at which the event occurs. Effective methods to present the results of postclosure risk studies are also needed. 


\subsection{REFERENCES}

Andersson, K., N. A. Kjellbert, and B. Forsberg. 1984. Radionuclide Migration Calculations with Respect to the KBS-3-Concept. Technical Report SKI 84:1. Swedish Nuclear Power Inspectorate (SKI), Stockholm, Sweden.

Bechtel National, Inc. 1979. An Assessment of LWR Spent Fuel Disposal Options. ONWI-39, prepared for the Office of Nuclear Waste Isolation, Columbus, Ohio.

Brotzen, 0. 1983. On the Environmental Impact of a Repository for Spent Nuclear Fuel. SKBF-KBS-TR-83-29. Svensk Kaernbraenslefoersoerjning $A B$, Stockholm, Sweden.

Burkholder, H. C., M. O. Cloninger, D. A. Baker, and G. Jansen. 1976. "Incentives for Partitioning High-Level Waste." Nuclear Technology, Vol. 31, p. 202.

Burkholder, H. C. 1982. Engineered Components for Radioactive waste Isolation Systems - Are They Technically Just ified? ONWI-286, Office of Nuclear Waste Isolation, Battelle Memorial Institute, Columbus, Ohio.

Cashwe11, 1. W. et a1. 1986. Transportation Impacts of the Commercial Radioactive Waste Management Program. SAND85-2715, Sandia National Laboratories, Albuquerque, New Mexico.

Cheung, H., L. Edwards, T. Harvey, and M. Revelli. 1982. Post-Closure Risks of Alternative SRP Nuclear Waste Forms in Geologic Repositories. UASG-8203, Draft Report, Lawrence Livermore National Laboratory, University of Cal iforria, Livermore, Cal iforria.

Claiborne, H. C and F. Gera. 1974. Potential Containment Failure Mechanisms and The ir Consequences at a Radioactive Waste Repository in Bedded Salt in New Mexico. ORNL-TM-4639, Oak Ridge National Laboratory, Oak Ridge, Tennessee.

Cloninger, M. 0. and C. R. Cole. 1981. A Reference Analysis on the Use of Engineered Barriers for Isolation of Spent Nuclear Fuel in Granite and Basalt. PNL-3530, Pacific Northwest Laboratory, Battelle Memorial Institute, Richland, Washington.

Cranwe11, R. M., R. V. Guzowski, J. E. Campbe11, and N. R. Ortiz. 1982a. Risk Methodology for Geologic Disposal of Radioactive Waste: Scenario Selection Procedure. NUREG/CR-1667, Sandia National Laboratories, Albuquerque, New Mexico.

Cranwe 11, R. M., J. E. Campbe11, J. C. Helton, R. L. Iman, D. E. Longsine, N. R. Ortiz, G. E. Runkle, and M. J. Shortencarier. 1982b. Risk Methodology for Geologic Disposal of Radioactive Waste: Final Report. NUREG/CR-2452, Sandia National Laboratories, Albuquerque, New Mexico. 
Dennis, A. W. et al. 1978. Severities of Transportation Accidents Involving Large Packages. SAND77-001, Sandia National Laboratories, Albuquerque, New Mexico.

Dennis, A. W. et a1. 1984. NNWSI Repository Worker Radiation Exposure, Vol. I, Spent Fuel and High-Level Waste Operations in a Geologic Repository in Tuff. SNAD83-7436/1, Sandia National Laboratories, Albuquerque, New Mexico.

Ducharme, A. R. et a1. 1978. Transport of Radionuclides in Urban Environs: Working Draft Assessment. SAND77-1927, Sandia National Laboratories, Albuquerque, New Mexico.

Duncan, D. S. 1979. "Safety Considerations of the WIPP Design." presented at the 87 th Meeting of the American Institute of Chemical Engineers, August 18-22, 1979, Boston, Massachusetts.

Elder, H. K. et a1. 1978. An Assessment of the Risk of Transporting Spent Nuclear Fuel by Truck. PNL-2588, Pacific Northwest Laboratory, Richland, Washington.

Elder, H. K. et a1. 1981. An Analysis of the Risk of Transporting Spent Nuclear Fuel By Train. PNL-2682, Pacific Northwest Laboratory, Richland, Washington.

Erdmann, R. C. et a1. 1979. Status Report on the EPRI Fuel Cycle Accident Risk Assessment. EPRI/NP-1128, Science Applications Inc., Palo Alto, California.

Exxon Nuclear Co. (Exxon). 1977. Nuclear Fuel Recovery and Recycling Center Preliminary Safety Analysis Report. Docket No. 50-264, Richland, Washington.

Finley, N. C. et à1. 1980. The Transportation of Radionuclides in Urban Environs. NUREG/CR-0743, SAND79-0369, Sandia National Laboratories, Albuquerque, New Mexico.

Ganley, J. 1982. Comparison of Cask and Drywell Concepts for a Stand-Alone Monitored Retrievable Storage/Interim Storaqe System. GA-A16839, General Atomic Co., San Diego, California.

Harris, P. A. et a1. 1985. High-Level Waste Preclosure Systems Safety Analys is Phase I Final Report. GA-A17670, G.A. Technologies, Inc., San Diego, California.

Harty, R. and G. A. Stoetze1. 1986. Occupational Dose Estimates for a Monitored Retrievable Storage Facility. PNI. 5744, Pacific Northwest Laboratory, Richland, Washington. 
Hi11, M. D. and P. H. Grimwood. 1978. Preliminary Assessment of the Radiological Protection Aspects of Disposal of High-Level Waste in Geologic Formations. NRPB-R69, National Radiological Protection Board, Harwell, United Kingdom.

Hunter, R. L., C. J. Mann, and R. M. Cranwe11. 1985. Determining Probabt1ities of Geologic Events and Processes. SAND85-0024C, Sandia National Laboratories, Albuquerque, New Mexico.

ICRP. 1979. Limits for Intakes of Radionuclides by Workers. Publication 30, Volume 1 and Supplement, International Commission on Radiological Protection. Pergamon, New York.

ICRP. 1980. Limits for Intakes of Radionuclides by Workers. Publication 30, Volume 2, International Commission on Radiological Protection, Pergamon, New York.

INTERA Environmental Consultants, Inc. 1983. PABLM: A Computer Code to Compute Accumulated Radiation Doses From Radionuclides Transported to Aquatic and Terrestrial Pathways in the Biosphere. ONWI-446, prepared for the office of Nuclear Waste Icolation, Battelle Memorial Institute, Columbus, Ohio.

INTERA Environmental Consultants, Inc. 1985. Preliminary Analyses of Scenarios for Potential Human Interference for Repositories in Three Salt Formations. BMI/Üivil-553, INTERA Technologies, Inc. Prepared for Office of Nuclear Waste Isolation, Battelle Memorial Institute, Columbus, Ohio.

Isakari, H. H. et al. 1980. Occupational Exposure Estimate for Spent Fuel Geologic Storage Operation. IAEA-SM-242/32, Kaiser Engineers, Inc., Oakland, California.

Jackson, J. L. et a1. 1984. Preliminary Safety Assessment Study for the Conceptual Design of a Repository in Tuff. SAND83-1504, Sandia National Laboratory, Albuquerque, New Mexico.

Jardine, L. J., C. W. Ma, D. J. Hartman, R. C. Sit, and S. J. Zavoshy. 1988. "Preliminary Preclosure Radiological Safety Analysis for Normal Operations of a Prospective Yucca Mountain Repository," in Proceedings of the International Topical Meeting on Nuclear and Hazardous Waste Management: Spectrum ' 88. American Nuclear Society, La Grange Park, Illinois.

Johnston, P. 1986. "The Link Between General Performance Objectives and Performance Assessments of Disposal Facilities for Radioactive Waste. "In: Proceedings of the NEA Workshop on System Performance Assessments for Radioactive Waste Disposal. Paris, 22-24 0ctober 1985. pp.43-59. Nuclear Energy Agency, Organization for Economic Cooperation and Development, Paris, France.

Kocher, D. C., E. D. Smith, G. D. O'Kelley, and A. L. Sjoreen. 1985. "A Perspective on Demonstrating Compliance With Standards for Disposal of HighLevel Radioactive Wastes." Radioactive Waste Management and the Nuclear Fuel Cycle. Vol.6, pp.1-18. 
Kcndo, S., T. Tokushita, M. J. Hwang, and T. Murano. 1980. "Risk Analysis of High-Level Radioactive Waste Disposal Into Granite Formation." pp.199-213. In: Proceedings of the NEA Workshop on System Performance Assessments for Radioactive Waste Disposal. Paris, 22-24 October 1985. Nuclear Energy Agency, Organisation for Economic Cooperation and Development, Paris, France.

Ligun, D. A. et a1. 1983. The Safety Evaiuation of Tunnel Rack and Dry Well Monitored Retrievable Storage Concepts. GA-A16955. GA Technologies, Inc. San Diego, California.

Ludwick, J. D. and E. B. Moore. 1984. Technology, Safety, and Costs of Decommissioning Reference Independent Spent Fuel Storage Installations. NUREG/CR-2210, Pacific Northwest Laboratory, Richland, Washington.

Madsen, M. M. et al. 1983. RADTRAN II User Guide. SAND82-2681, Sandia National Laboratories, Albuquerque, New Mexico.

Madsen, M. M. et a1. 1986. RADTRAN II User Guide. SAND84-0036, Sandia National Laboratories, Albuquerque, New Mexico.

MacDougal1, H. R., L.W. Scully, and J. R. Tillerson. 1987. Site Characterization Plan: Conceptual Design Report. SAND84-2641. Sandia National Laboratories, Albuquerque, New Mexico.

Moore, R. E. et a1. 1979. AIRDOS-EPA: A Computerized Methodology For Estimating Environmental Concentrations and Dose To Man From Airborne Releases of Radionuclides. ORNL-5523, Oak Ridge National Laboratory, Oak Ridge, Tennessee.

NAGRA. 1985. Project Gewahr 1985. Nuclear Waste Management in Switzerland: Feasibility Studies and Safety Analyses. Project Report NGB 85-09 (English Condensed Version of Project Reports 85-01 thru 85-08). NAGRA, National Cooperative for the Storage of Radioactive Waste, Baden, Switzerland.

Napier, B. A., W. E. Kennedy, Jr., and J.K. Soldat. 1980. PABLM - A Computer Program to Calculate Accumulated Radiation Doses from Radionuclides in the Environment. PNL-3209, Pacific Northwest Laboratory, Richland, Washington.

National Academy of Sciences-National Research Council (NAS-NRC). 1972. The Effects on Populations of Exposures to Low Levels of Ionizing Radiation. Committee on the Biological Effects of Ionizing Radiation (BEIR), Washington, D.C.

National Academy of Sciences. 1980. The Effects on Populations of Exposures to Low Levels of Ionizing Radiation. Committee on the Biological Effects of Ionizing Radiation (BEIR), Washington, D.C. 
NEA. 1981. Proceedings of the Workshop on Radionuclide Release Scenarios for Geologic Repositories, Paris, 8-12 September, 1980. Nuclear F.nerg.y Agency, Organisation for Economic Cooperation and Development, Paris, France.

NEA. 1986. Proceedings of the NEA Workshop on System Performance Assessments for Radioactive Waste Disposal. Paris, 22-24 October 1985. Nuclear Energy Agency, Organisation for Economic Cooperation and Development, Paris, France.

Neuhauser, K. S. et a1. 1984. A Preliminary Cost and Risk Analysis for Transporting Spent Fuel and High-Level Wastes to Candidate Repository Sites. SAND84-1795, Sandia National Laboratories, Albuquerque, New Mexico.

Ortiz, N. R., K. K. Wahi, M. S. Y. Chu and M.D. Siege1. 1984. "Review and Evaluation of the Draft EPA Standard (40 CFR 191)." In: R. G. Post and M. E. Wacks, (eds.), Waste Management '84, Proceedings of the Symposium on Waste Management at Tucson, Arizona, March 11-15, 1984. Vol. 1, pp.401-410. The University of Arizona, Tucson, Arizona.

Orvis, D. D. 1984. Review of Proposed Dry Storage Concepts Using Probabilistic Risk Assessment. EPRI/NP-3365, NUS Corporation, San Diego, California.

Parker, F. L., R. E. Broshears, and J. Pasztor. 1984. The Disposal of HighLevel Radioactive Waste. NAK 11 , Volumes 1 and 2. Published for Namden for Hantering av Anvant Karnbransle (NAK) by The Royal Swedish Academy of Sciences, The Beijer Institute, Stockholm, Sweden.

Parsons (Ralph M. Parsons Company). 1985. Conceptual Design Report: Inteqral Monitored Retrievable Storage (MRS) Facility. Report No. MRS 11 Vol. 1 Book 2, Bol. 5 Book 1, Pasadena, California.

Peltonen, E. K. 1984. "Use of Safety Analysis to Site Confirmation Procedure in Case of Hard Rock Repository." In: Seminar on the Site Investigation Techniques and Assessment Methods for Underground Disposal of Radioactive Wastes. Sofia, Bulgaria, 6-10 Feb., 1984. IAEA-SR-104/6. International Atomic Energy Agency, Vienna, Austria.

Pepping, R. E. 1981. Risk Analys is Methodology For Spent Fuel Repositories in Bedded Salt: Reference Repository Definition and Contribution From Waste Handling Activities. NUREG/CR-1931. Prepared for the NRC by Sandia National Laboratories, Albuquerque, New Mexico.

Pepping, R. E., M. S. Y. Chu, and M. D. Siegel. 1983a. Technical Assistance For Regulatory Development: Review and Evaluation of the Draft EPA Standard 40 CFR 191 for Disposal of High-Level Waste. Vol.2. A Simplified Analys is of a Hypothetical Repository in a Basalt Formation. NUREG/CR-3235, Sandia National Laboratories, Albuquerque, New Mexico. 
Pepping, R. E., M. S. Y. Chu, and M. D. Siegel. 1983b. Technical Assistance For Requlatory Development: Review and Evaluation of the Draft EPA Standard 40 CFR 191 for Disposal of High-Level Waste. Vol. 4. A Simplified Analys is of a Hypothetical Repository in a Salt Formation. NUREG/CR-3235, Sandia National Laboratories, Albuquerque, New Mexico.

Pepping, R. E., M. S. Y. Chu, K. K. Wahi, and N. R. Ortiz. 1983C. RiskAnalys is Metilodolngy for Spent-Fuel Repositories in Bedded Salt. NUREG/CR-2402, Salidia National Laboratories, Albuquerque, New Mexico.

PSE. 1985a. Summarized Final Report. Chapter 4: Development of a Safety Assessment Methodology for the Geological Repository for Radioactive Waste in a Salt Dome. Projekt Sicherheitsstudien Entsorgung, Berlin, West FRG.

PSE. 1985b. Summarized Final Report. Chapter 1: Introduction and Results. Projekt Sicherheitsstudien Entsorgung, Berlin, FRG.

Rao, R. R. et al. 1982. Nonradiological Impact of Transporting Radioartive Materials. SAND81-1703, Sandia National Laboratories, Albuquerque, New Mexico.

RHO. 1984. Preliminary Survey of Applicable Regulations and Repository Operations as a Basis for a Nuclear Waste Repository Safety Analys is. SD-BWI-TA-009 Rev.0., Rockwell Hanford Operations, Richland, Washington.

Roddy, J. W. et a1. 1986. Physical and Decay Characteristics of Commercial LWR Spent Fuel. ORNL/TM-951/VI and R2, Oak Ridge National Laboratory, Oak. Ridge, Tennessee.

Sagendorff, J. F. and J. T. Gol1. 1977. XOQDOQ Program for the Meteorological Evaluation of Routine Effluent Releases at Nuclear Power Stations.

NUREG-03?4, U.S. Nuclear Regulatory Commission, Washington D.C.

Sandoval, R. P. et a1. 1983. An Assessment of the Safety of Spent Fuel Transportation in Urban Environs. SAND82-2365, Sandia National Laboratories, Albuquerque, New Mexico.

Sandquist, G. M. et al. 1985. Exposures and Health Effects from Spent Fuel Transportation. RAE08339/12-1, Rogers and Associates Engineering Corp., Salt Lake City, Utah.

Schneider, K. J. et al. 1986. Preliminary Assessment of Radiological Doses in Alternative Waste Management Systems Without an MRS Facility. PNL-5872, Pacific Northwest Laboratory, Richland, Washington.

Schneider, K. J., Ross, W. A., Smith, R. I., Daling, P. M., Grinde, R. B., Hostick, C. J., Peterson, R. W., Stiles, D. L., Weakley, S. A., and J. R. Young. 1987. Analyses of Radiation Doses from Operation of Postulated Commercial Spent Fuel Transportation Systems. DOE/CH-TPO-01, Prepared by the Pacific Northwest Laboratory for the U.S. Department of Energy - Chicago Operations Office, Argonne, Illinois. 
Siegel, M. D. and M. S. Y. Chu. 1983. Technical Assistance For Regulatory Development: Review and Evaluation of the Draft EPA Standard 40 CFR 191 for Disposal of High-Level Waste. Vol. 3. A Simpl ified Analys is of a Hypothetical Repository in a Tuff Formation. NUREG/CR-3235, Sandia National Laboratories, Albuquerque, New Mexico.

SKBF. 1983. Final Storage of Spent Nuclear Fuel - KBS-3. Volume IV: Safety. Division KBS (Karnbranslesakerhet), Swedish Nuclear.Fuel Supply Company, Stockholm, Sweden.

Slade, D. H. et al. 1968. Meteorology and Atomic Energy - 1968. U.S. Atomic Energy Commission, Division of Technical Information Extension, Oak Ridge National Laboratory, Oak Ridge, Tennessee.

Smith, C. B. et a1. 1982a. Population Risks From Disposal of High-Level Radioactive Wastes in Geologic Repositories. EPA 520/3-80-006 Draft Report, U.S. Environmental Protection Agency, Washington, D.C.

Smith, J. M., T. W. Fowler, and A. S. Goldin. 1982b. Environmental Pathway Models for Estimating Population Risks From Disposal of High-Level Radioactive Wastes in Geologic Repositories. EPA 520/5-80-002 Drafi Report, U.S. Environmental Protection Agency, Washington, D.C.

Strenge, D. L. et al. 1975. SUBDOSA - A Computer Program for Calculating External Doses From Accidental. Atmospheric Releases of Radionuclides.

BNWL-B-351, Pacific Northwest Laboratory, Richland, Washington.

Strenge, D. L. et al. 1980. ALLDOS-A Computer Program For Calculation of Radiation Doses From Airborne and Waterborne Releases. PNL-3524, Pacific Northwest Laboratory, Richland, Washington.

Tawi1, J. J. et al. 1985. Off-site Consequences of Radiological Accidents: Methods, Costs, and Schedules for Decontamination. NUREG/CR-3413, PNL-4790, Pacific Northwest Laboratory, Richland, Washington.

Taylor, J. M. and S. L. Daniel. 1982. RADTRAN II: Revised Computer Code to Analyze Transportation of Radioactive Materials. SAND80-1943, Sandia National Laboratories, Albuquerque, New Mexico.

Thompson, F. L., F. H. Dove, and K. M. Krupka. 1984. Preliminary UpperBound Consequence Analys is for a Waste Repository at Yucca Mountain. Nevada. Contractor Report SAND83-7475. Prepared by Pacific Northwes: Laboratory for Sandia National Laboratories, Albuquerque, New Mexico.

U.S. Congress. 1983. Nuclear Waste Policy Act of 1982. Public Law 97-425. 42 USC 10101 through 10226, January 7, 1983.

U.S. Department of Energy (DOE). 1979a. Technology for Commercial Radioactive Waste Management. DOE/ET-0028, Assistant Secretary for Nuclear Energy, Washington, D.C. 
U.S. Department of Energy (DOE). 1979b. Environmental Aspects of Commercial Radioactive Waste Management. DOE/ET-0029, Assistant Secretary for Nuclear Energy, Washington, D.C.

U.S. Department of Energy (DOE). 1980. Generic Environmental Impact Statement. Management of Commercially Generated Radioactive Waste. DOE/EIS$0046 \mathrm{~F}, \mathrm{~V} 01.1$ of 3 , Office of Nuclear Waste Management, Washington, D.C.

U.S. Department of Energy (DOE). 1984. U.S. Department of Energy, 10 CFR Part 960. Nuclear Waste Policy Act of 1982; General Guidelines for the Recommendation of Sites for the Nuclear Waste Repositories. Final Siting Guideline. Fed. Reg., Vol. 49, pp. 47714-47770 (December 6, 1984), Washington, D.C.

U.S. Department of Energy (DOE). 1985. Mission Plan for the Civilian Radioactive Waste Management Program. DOE/RW-0005, Office of Civilian Radioactive Waste Management, Washington, D.C.

U.S. Department of Energy (DOE). 1986a. Waste Management Systems Requirements and Descriptions (SRD). DOE/RW-0063, Office of Civilian Radioactive Waste Management, Washington, D.C.

U.S. Department of Energy (DOE). 1986b. Environmental Assessment Yucca Mountain Site, Nevada Research and Development Area, Nevada. DOE./RW-0073, Office of Civilian Radioactive Waste Management, Washington, D.C.

U.S. Department of Energy (DOE). 1986c. Environmental Assessment Reference Repository Location, Hanford, Washington. DOE/RW-0070, Office of Civilian Radioactive Waste Management, Washington, D.C.

U.S. Department of Energy (DOE). 1986d. Environmental Assessment Deaf Smith County Site, Texas. D0E/RW-0069, Office of Civilian Radioactive Waste Management, Washington, D.C.

U.S. Department of Energy (DOE). 1986e. Report of the Task Force on the MRS/Repository Interface. DOE/RW-0044, Office of Civilian Radioactive Waste Management, Washington, D.C.

U.S. Department of Energy (DOE). 1986f. A Multiattribute Utility Analysis of Sites Nominated for Characterization for the First Radioactive-Waste Repository - A Decision-Aiding Methodology. DOE/RW-0074. Office of CiviTian Radioactive Waste Management, Washington, D.C.

U.S. Department of Energy (DOE). 1986g. Monitored Retrievable Storage Submission tc Congress. DOE/RW-0035, Office of Civilian Radioactive Waste Management, Washington, D.C.

U.S. Department of Energy (DOE). 1988. Section 175 Report: Secretary of Energy's Report to Congress Pursuant to Section 175 of the Nuclear Warte Policy Act, As Amended. DOE/RW-0205. Office of Civilian Radioactive Waste Management, Washington, D.C. 
U.S. Department of Transportation (DOT'). 1985. National Transportation Statistics, 1985 Annual Report. DOT-TSC-RSPA-85-5, Washington, D.C.

U.S. Environmental Protection Agency (EPA). 1985a. Envirunmental Protection Agency, 40 CFR Part 191, Environmental Standards for the Management and Disposal of Spent Nuclear Fuel High-Level and Transuranic Radioactive Wastes. Fed. Reg., Vol. 50, pp.38066-38089 (September 19, 1985), Final Rule, Washington, D.C.

U.S. Environmental Protection Agency (EPA). 1985b. High-Level and Transuranic Radioactive Wastes. Background Information Document for Final Rule. EPA 520/1-85-023, Washington, D.C.

U.S. Nuclear Regulatory Commission (NRC). 1975. Reactor Safety Study: An Assessment of Accident Risks in U.S. Commercial Nuclear Power Plants. WASH1400 (NUREG/75-014), Washington, D.C.

U.S. Nuclear Regulatory Commission (NRC). 1977. Final Environmental Assessment on the Transportation ofRadioactive Material by Air and Other Modes. NUREG-0170, Washington D.C.

U.S. Nuclear Regulatory Commission (NRC). 1983a. U.S. Nuclear Regulatory Commission, 10 CFR Part 60, Disposalof High-Level Radioactive Waste in Geologic Repositories - - Technical Criteria. Fed. Reg., Vol. 48, pp. 28194 28229 (June 20, 1983), Washington, D.C.

U.S. Nuclear Regulatory Commission (NRC). 1983b. PRA Procedures Guide. NUREG/CR-2300, Washington. D.C.

U.S. Nuclear Regulatory Commission (NRC). 1986. U.S. NuClear Regulatory Commission, 10 CFR Part 60, Disposal of High-Level Radioactive Waste in Geologic Repositories; Conforming Amendments. (Proposed Rule). Fed. Reg., Vol. 51, Fp. 22288-22301 (June 19, 1986), Washington, D.C.

Van Luik, A. E., N. A. Eisenberg, and D. H. Alexander. 1986. "A Prescriptive Approach - The Link Between the Performance Assessments of the U.S. DOE Projects and the Regulatory Requirements of NRC and EPA." In: Proceedings of the NEA Workshop on System Performance Assessments for Radioactive Waste Disposal. Paris, 22-24 October 1985." pp.61-77. Nuclear Energy Agency. Organization for Economir. Cooperation and Development, Paris, France.

Virginia Power Company. 1984. Safety Analysis Report: Surry Power Station Dry Cask Independent Spent Fuel Storage Installation, Virginia Electric and Power Co.

Waite, D. A. et al. 1986. Preclosure Radiological Calculations to Support Salt Site Evaluations. BMI/ONWI-54l RI, Office of Nuclear Waste Isolation, Columbus, Ohio.

Wa11, I. B. et a1. 1977. Overview of the Reactor Safety Consequence Model. NUREG-0340. U.S. Nuclear Regulatory Commission, Washington D.C. 
Weston, R. F. and Associates. 1986. Analys is of the Total System Life-Cycle Cost for the Civilian Radioactive Waste Management Program. DOE/RM-0047, Prepared for the Office of Civilian Radioactive Waste Management, Washington D.C.

Williams, W. A. 1980. Population Risks From Uranium Ore Bodies. EPA 520/3-80-009, Office of Radiation Programs, U.S. Environmental Protection Agency, Washington, D.C.

Wilmot, E. L. et a1. 1981. Report on a Workshop on Transportation Accident Scenarios Involving Spent Fuel. SAND80-2012, Sandia National Laboratories, Albuquerque, New Mexico.

Wilmot, E. L. et a1. 1983. A Preliminary Analysis of the Costs and Risks of Transporting Nuclear Waste to Potential Candidate Repository Sites.

SAND83-0867. Sandia National Laboratories, Albuquerque, New Mexico.

WISP. 1983. A Study of the I solation System for Geologic Disposal of Radioactive Waste. Waste Isolation Systems Pane1, (WISP): T. H. Pigford, Chairman, with: J. 0. Blomeke, T. L. Brekke, G. A. Cowan, W. E. Falconer, N. J. Grant, J. R. Johnson, J. M. Matuszek, R. R. Parizek, R. L. Pigford, and D. E. White. National Academy of Sciences, National Academy Press, Washington, D.C.

Wuschke, D. M., P. A. Gillespie, K. K. Mehta, W. F. Heinrich, D. M. LeNeveu, V. M. Gluvanesen, G. R. Sherman, D. C. Donahue, B. W. Goodwin, T. H. Andres, and R. B. Lyon. 1985. Second Interim Assessment of the Canadian Concept for Nuclear Fuel Waste Disposal Volume 4: Post-Closure Assessment. AECL-8373-4, Atomic. Energy of Canada, Ltd., Whiteshell Nuclear Research Establishment, Pinawa, Manitoba.

Yook, H. R. et a1. 1984. Repository Preclosure Accident Scenarios. BMI/ONWI-551. Prepared by Science Applications Inc. for the Office of Nuclear Waste Isolation, Battelle Memorial Institute, Columbus, Ohio. 


\section{DISTRIBUTION}

No. of

Copies

\section{OFFSITE}

J. Roberts

$\mathrm{RW}-30$

Office of Civilian Radioactive Waste Management

U.S. Department of Energy 1000 Independence Ave, SW Washington, DC 20585

S. J. Brocoum

RW- 22

Office of Civilian Radioactive Waste Management

U.S. Department of Energy 1000 Independence Avenue, SW Washington, DC 20585

C. K. Quan

$\mathrm{RW}-322$

Office of Civilian Radioactive Waste Management

U.S. Department of Energy

1000 Independence Ave, SW

Washington, DC 20585

V.W. Trebules

RW- 42

Office of Civilian Radioactive Waste Management

U.S. Department of Energy

1000 Independence Ave, SW

Washington, DC 20585

J. H. Carlson

$\mathrm{RW}-43$

Office of Civilian Radioactive Waste Management

U.S. Department of Energy

1000 Independence Ave, SW

Washington, DC 20585
No. of

Copies

N. Eisenberg

Office of Nuclear

Material Safety and Safeguards

U.S. Nuclear Regulatory

Commission

Washington, DC 20555

R. Palabrica

Roy $F$. Weston, Inc.

955 L' Enfant Plaza, SW

Eight Floor

Washington, DC 20024

M. D. Rowe

Brookhaven National Laboratory

Building 130, Upton

Long Is I and, NY 11973

E. Bonano

Sandia National Laboratory

P.0. Box 5800

Albuquerque, NM 87185

J. W. Roddy

Oak Ridge National Laboratory

P.0. Box 2008

Oak Ridge, TN 37831

D. C. Dobson

U.S. Department of Energy MS 523

P.0. Box 98518

Las Vegas, NV 89193-8518

D. E. Livingston

U.S. Departinent of Energy

MS 523

P.0. Box 98518

Las Vegas, NV 89193.8518 
PNL-6099

UC $-8,810$

No. of

No. of

Copies

Copies

OFFSITE

ONSITE

E. H. Petrie

U.S. De, lartment of Energy

MS 523

P.0. Box 98518

Las Vegas, NV 89193-8518

A. E. Van Luik

TRW/Intera

101 Convention Center Drive

Suite P 110

Las Vegas, NV 89109

K. Kirsch

SAIC

101 Convention Center Drive

Las Vegas, NV 89109

2 DOE Richland Field Office

D. C. Langstaff

J. J. Sutey

30 Pacific Northwest Laboratory

P. M. Daling (10)

B. A. Fecht

M. R. Kreiter

P. J. Pelto (10)

R. E. Rhoads

D. A. Seaver

Publishing Coordination

Technical Report Files (5)

12 DOE/Office of Scientific and Technical Information 

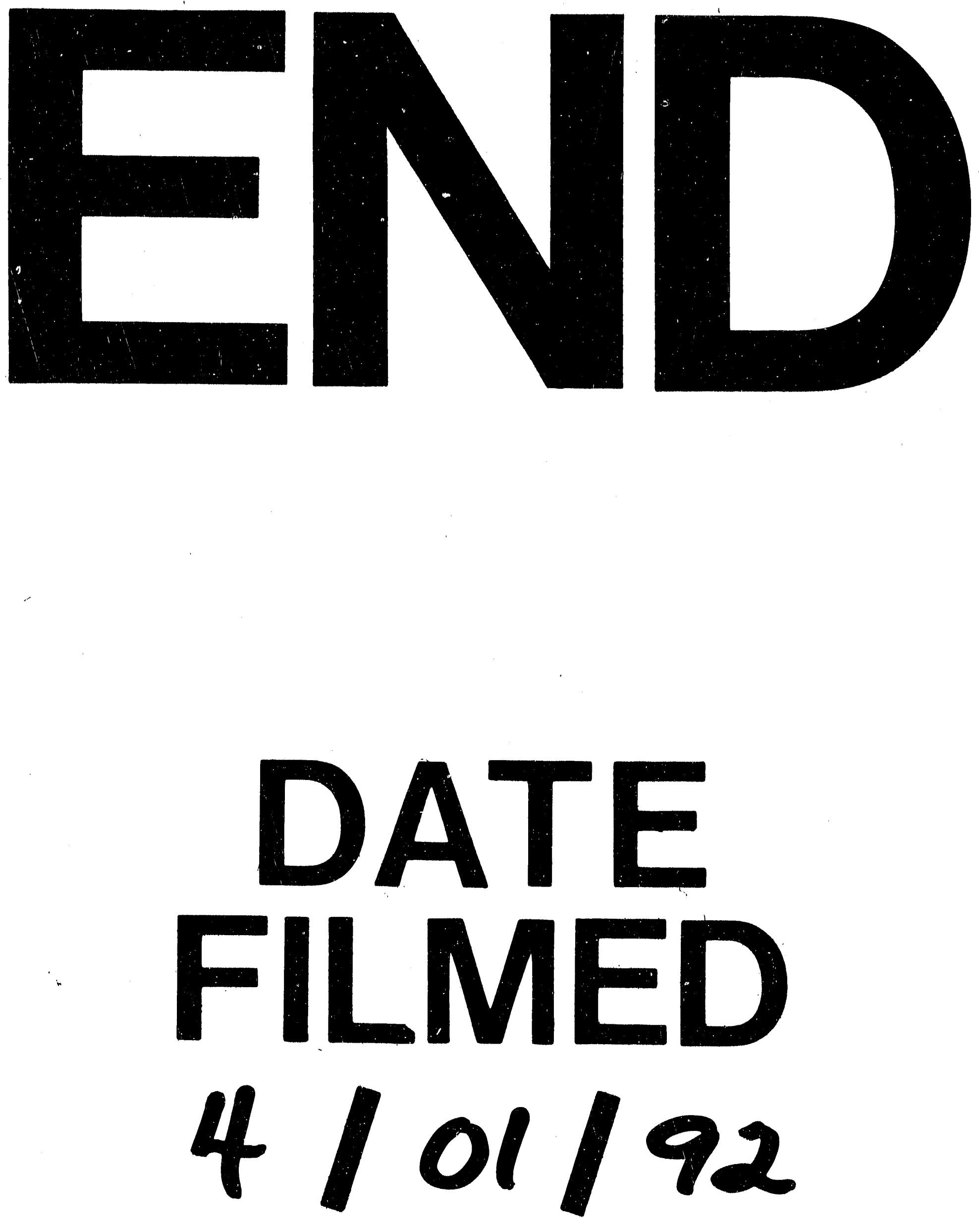
I

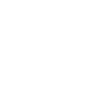

-

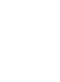

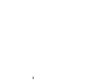

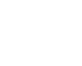

$\cdot$

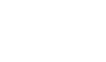

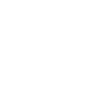

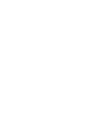

.

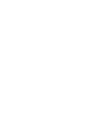

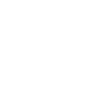

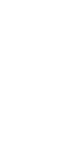

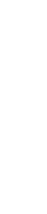
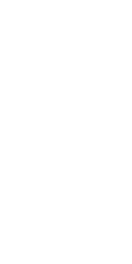
(2) 